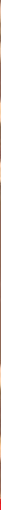

\title{
IntechOpen
}

\section{An Ethnography of Global Landscapes and Corridors}

Edited by Loshini Naidoo

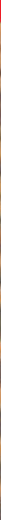





\section{AN ETHNOGRAPHY OF GLOBAL LANDSCAPES AND CORRIDORS}

Edited by Loshini Naidoo 
An Ethnography of Global Landscapes and Corridors

http://dx.doi.org/10.5772/586

Edited by Loshini Naidoo

\section{Contributors}

Massimo Canevacci, Mary Beth Privitera, Andrew Ringer, Todd Abruzzo, Keith Bletzer, Javier Rosique Gracia, Aida Galvez A., Maria Teresa Restrepo, Luz Mariela Manjarres, Erika Valencia C., Michitaka Kosaka, Maria Luisa Silva, Cynthia Hunter, Adam Scheinberg, Jakob Demant, Gunnar Haaland, Dominique Vinck, Nancy Taber, Jukka Kortti, Paivi Eriksson, Elina Henttonen, Susan Merilainen, Loshini Naidoo

\section{(c) The Editor(s) and the Author(s) 2012}

The moral rights of the and the author(s) have been asserted. All rights to the book as a whole are reserved by INTECH. The book as a whole (compilation) cannot be reproduced, distributed or used for commercial or non-commercial purposes without INTECH's written permission. Enquiries concerning the use of the book should be directed to INTECH rights and permissions department (permissions@intechopen.com).

Violations are liable to prosecution under the governing Copyright Law.

\section{(cc) BY}

Individual chapters of this publication are distributed under the terms of the Creative Commons Attribution 3.0 Unported License which permits commercial use, distribution and reproduction of the individual chapters, provided the original author(s) and source publication are appropriately acknowledged. If so indicated, certain images may not be included under the Creative Commons license. In such cases users will need to obtain permission from the license holder to reproduce the material. More details and guidelines concerning content reuse and adaptation can be foundat http://www.intechopen.com/copyright-policy.html.

\section{Notice}

Statements and opinions expressed in the chapters are these of the individual contributors and not necessarily those of the editors or publisher. No responsibility is accepted for the accuracy of information contained in the published chapters. The publisher assumes no responsibility for any damage or injury to persons or property arising out of the use of any materials, instructions, methods or ideas contained in the book.

First published in Croatia, 2012 by INTECH d.o.o.

eBook (PDF) Published by IN TECH d.o.o.

Place and year of publication of eBook (PDF): Rijeka, 2019.

IntechOpen is the global imprint of IN TECH d.o.o.

Printed in Croatia

Legal deposit, Croatia: National and University Library in Zagreb

Additional hard and PDF copies can be obtained from orders@intechopen.com

An Ethnography of Global Landscapes and Corridors Edited by Loshini Naidoo

p. cm.

ISBN 978-953-51-0254-0

eBook (PDF) ISBN 978-953-51-5094-7 


\section{We are IntechOpen, \\ the world's leading publisher of Open Access books}

Built by scientists, for scientists

\section{$4,100+$}

Open access books available

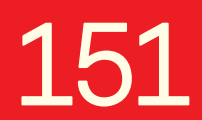

Countries delivered to
$116,000+$

International authors and editors
$120 \mathrm{M}+$

Downloads

Our authors are among the

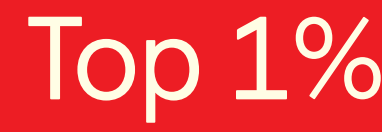

most cited scientists

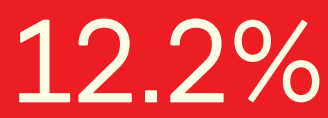

Contributors from top 500 universities

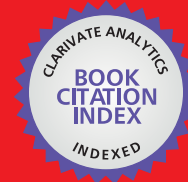

WEB OF SCIENCE ${ }^{\mathrm{TM}}$

Selection of our books indexed in the Book Citation Index in Web of Science ${ }^{\mathrm{TM}}$ Core Collection (BKCI)

Interested in publishing with us?

Contact book.department@intechopen.com

Numbers displayed above are based on latest data collected.

For more information visit www.intechopen.com

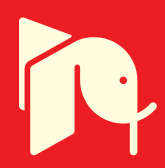





\section{Meet the editor}

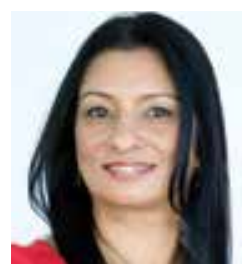

Dr Loshini Naidoo is a senior lecturer in sociology in the School of Education at the University of Western Sydney, Australia. Her academic areas of interest include social justice education, cultural diversity and difference and transnationalism. Her current research is related to internationalization of higher education, refugee and indigenous issues particularly literacy amongst newly arrived refugees in Greater Western Sydney secondary schools and literacy needs of Aboriginal students in Tennant Creek High, Northern Territory. She was a recipient of the Vice Chancellor's Award for Excellence in Community Engagement. She also received a citation from the Australian Teaching Learning Council for her outstanding contribution to student learning (2009); an ALTC team winner for a program that enhances learning (2010) and an ALTC Teaching Excellence award in 2011. 



\section{Contents}

\section{Preface XI}

Chapter 1 Ethnography:

An Introduction to Definition and Method 1

Loshini Naidoo

Chapter 2 Ethnographic Field Notes and Reflexivity 9

Päivi Eriksson, Elina Henttonen and Susan Meriläinen

Chapter 3 Event Focused Fieldwork and

Comparative Methodology: Exploring

Ethnic Boundaries and Cultural Variation 23

Gunnar Haaland

Chapter 4 Natural Interactions in Artificial Situations:

Focus Groups as an Active Social Experiment 57

Jakob Demant

Chapter 5 Beginning with the Self to Critique the

Social: Critical Researchers as Whole Beings 73

Nancy Taber

Chapter 6 Accessing Material Culture by

Following Intermediary Objects 89

Dominique Vinck

Chapter 7 A Service Value Creation Model

and the Role of Ethnography 109

Michitaka Kosaka

Chapter 8 Food and Nutrition in Embera Indigenous People 131

Javier Rosique, Aída Gálvez, María Teresa Restrepo,

Luz Mariela Manjarrés and Erika Valencia

Chapter 9 From Gambits to Case Data 157

Keith V. Bletzer 
Chapter 10 Syntax Development:

The Relevance of Realistic Methods 189

Maria Luisa Silva

Chapter 11 Informal Learning Amongst

Pediatric Rehabilitation Teams -

An Ethnography of Tea-Room Talk 209

Cynthia Hunter and Adam Scheinberg

Chapter 12 Visual Mapping of Clinical Procedures Using

Ethnographic Techniques in Medical Device Design 223

Mary Beth Privitera, Todd Abruzzo and Andrew Ringer

Chapter 13 Written Reminiscences and Media

Ethnography: Television Creating Worldview 233

Jukka Kortti

Chapter 14 Digital Auratic Reproducibility: Ubiquitous

Ethnographies and Communicational Metropolis 253

Massimo Canevacci 


\section{Preface}

The chapters presented in this book draw on ethnography as a methodology in a variety of disciplines, including education, management, design, marketing, ecology and scientific contexts, illustrating the value of a qualitative approach in research. They describe the use of traditional ethnographic methods, such as immersion, observation and interview, but many of them look at new ways of doing ethnography, as a digital culture challenges notions of identity, field and traditional culture.

In Chapter One which is a general introduction to ethnography, Naidoo explores the definition of ethnography locating the definition within the earlier debates around qualitative and quantitative research. The latter is described as etic, rather than emic or as Geertz (cited in Denzin and Lincoln, 2011), puts it, the difference between a wink and a blink. The functional significance of an action was ignored, the 'raw facts' simply described 'objectively'. She discusses further the move of the social sciences away from the physical sciences to more qualitative data gathered through data collection methods such as interviews, observations and text so that the researcher/ethnographer became the data collection instrument. In her brief historical overview, she illustrates the various data collection methods used by ethnographers today to increase the validity of their claims thereby producing insightful knowledge and meanings to social settings.

In Chapter Two, Eriksson, Henttonen and Merilainen consider reflexivity as the way in which meaning is constructed and how they, as researchers, place or position themselves within the research. In order to do this, the author analyses the research field notes in terms of selection and representation. They demonstrate reflexivity by considering how participants are selected, what determines their relevance or irrelevance for selection, and how participants are subsequently represented in the researchers' field notes. The author argues that examining their own research practice is a critical step in the process of understanding and evaluating ethnographic research methodology, particularly the ways participants or subjects are represented and why they are represented in these ways. This interpretive and reflexive process is characteristic of ethnography and is another approach to creating meaning and constructing reality.

Chapter Three discusses the problems inherent in any study of human beings, as all cultures are bound by codes and values. For Haarland, this means finding ways to 
interpret these codes and value systems. The author seeks to take the field experiences of the researcher to analyse ethnic boundaries and how they are formed and maintained. To do this a number of groups with very different cultural values and practices are studied, and compared in terms of identity and political expediency. Sometimes identity is determined by governmental policy, at other times, economic factors overcome cultural boundaries, and at other times identity is determined symbolically, leading to the conclusion that cultural identity is not longer as clearly bounded as it once was.

Chapter Four examines the value of focus groups as a way of investigating social process, and is done in the context of a study of youth and alcohol. By using focus groups, Demant believes it is possible to observe power relations that permeate a group, rather than those that exist between individual and interviewer. Whilst there are questions of validity in terms of a positivist approach, this chapter seeks to demonstrate that these can be addressed by using the focus group as a social experiment, which incorporates the artificial situation with the natural interactions that occur in the group. The advantage of this approach is that it can produce new meanings and the capacity to change problems.

In Chapter Five, Taber posits that using auto ethnography allows the researcher to examine the way in which the research becomes a lived experience, rather than an academic exercise. She looks at auto ethnography with a view to probing dominant social relations. Looking at the work of people like bell hooks, the Taber explores the notion of explicitly linking their bodies to their research to see how this is affected, and how such an examination can become an entry point into a social critique, though not an end in itself. The study should then become a challenge to structures of domination and oppression, an exploration of how some people (or non-human animals and the material world) are exploited and others are privileged.

In Chapter Six, Vinck investigates a method for tracking material culture in an effort to demonstrate how social and material relations are interwoven. The method arises from an investigation involving scientific co-operation networks and followed both actors and objects used by them. By doing this it was found just how much time and energy was used by the actors to develop such 'objects', and the interaction between them showed how networks were created and the strength of the links between them. By studying these aspects, it is possible to apply the strategy to other practices and to identify the key features, and in doing so shows it to be an important methodology for ethnography.

In Chapter Seven, Kosaka tracks the use of ethnography to identify the role of human behaviour in the development of a service value creation model. This was based on a new concept of service field in service systems, and the recognition that when considering a service the context of that service use has to be carefully evaluated. Ethnography was effective in gaining an understanding of the relationship between the service field and the people involved in providing the service and those receiving it. The 
use of ethnographic methods such as word of mouth data, brain activity measurement and observation, to identify the field, consisting of humans, time, situations and other factors, was indispensible to the outcome of the development of the model.

Chapter Eight evaluates a case study of food and nutrition as pertaining to the habits of an Indigenous people in Colombia. Rosique, Valencia, Manjarres, Restrepo and Galvez contrast two Embera communities, one inhabiting rain-forest, with a diet consisting of maize and banana, and complemented with fishing and hunting, whilst the other community lives on the urban fringe, their diet comprised mainly of rice. The crisis in diet arises because of the loss of available land for hunting and gathering, and the lack of sufficient nutritional food. The chapter discusses the methods used in the ethnographic study, such as field notes (observation), interviews with the women who are largely responsible for food preparation, and with others, to ascertain eating habits. Some quantitative data collection was also done with surveys, data collection sheets and questionnaires. The author makes the point that an interdisciplinary approach using both quantitative as well as qualitative methods provided a more comprehensive final report, which highlighted the plight of the Embera people, who are disadvantaged by poverty, lack of opportunity for education and health, lack of infrastructure and of the means to find their food by traditional methods.

During field research on farm workers who used drugs, Bletzer in Chapter Nine, makes the distinction between 'intensified' and 'sparse' sampling for ethnographic interpretation. The former is to study a particular aspect of a population sample, where the data produced will be thematic. In the case of 'sparse' sampling, the researcher produces information that will cast light on some aspect of a population group, which is not intended to be negatively representative of the whole group, or to suggest that it is typical of that group's behaviour. In this author's case study intensified samples were derived from agricultural workers who use drugs, and for 'sparse' sampling, the author uses portions of the ethnographic material where the intent was not to study the use of drugs amongst farmers, but which was considered of interest to others. Field data is examined to give an indication of the methods used, and references to literature on the subject highlight how the subject has been represented by other writers.

In Chapter Ten, Silva examines the development of language, with a particular reference to grammar in a group of Spanish speaking children aged between 3 and 7 . Ethnographic methods were used to conduct and analyse the study in the form of semi-structured interviews between adult and children, and then a careful mapping of the use of relative and conditional clauses. These forms are considered to occur in children at different stages, but this study challenges that position as they appeared in the study at the same ages. The writer believes that the use of semi-structured interviews gave a far more accurate result, because the children were relaxed and spontaneous. By avoiding an experimental context which makes children feel selfconscious, the researchers gained more speech examples from the children, giving a broader sample to analyse. 
Hunter and Scheinberg in Chapter Eleven undertake an ethnographic study of the use of a tea-room by clinicians at a hospital. It was a twelve-month, participant observation study, using field notes, varying length interviews, and an ethnographic program to analyse themes and topics. The thick description that ethnography provides meant that the multi-faceted use of the tea-room was explored over time and in detail. The study revealed the importance of this space in the working life of clinicians, promoting inter-disciplinary team-work, work-place learning, planning and organisation, reflexivity, and emotional debriefing. The work place learning that takes place is of particular significance, since much of adult learning occurs at work, and it was clear from the data that amongst the clinicians, this interaction took place regularly and included issues of patient safety and quality of care even whilst it was done in a fairly informal manner and context.

In Chapter Twelve, Privitera, Abruzzo and Ringer utilise ethnographic methods to find the most appropriate design for a surgical instrument. In any complex surgical procedure there problems inevitable arise in the process, whether haptic, visual or environmental. The use of ethnographic enquiry gives a greater understanding of the users' behaviour, which has clear implications about design choices. In this case study, the methodology included documentation of cases, careful note-taking, photography and video, and interviews. These are all discussed in terms of what they added to the process. The results are interpreted so that they provide a full and careful guide to the new users of the device.

In Chapter Thirteen, Kortti uses written narrative reminiscences of Finnish people, as ethnographic research data, by way of contributing to media ethnography. It looks at the way in which everyday life in Finland was portrayed in television during the period mid-1950s to early $21^{\text {st }}$ Century. The author suggests that the modernisation that occurred post WW2 happened rapidly in Finland, and television had a major impact on how people made sense of the world. The article discusses the advantages and disadvantages of using media ethnography as an approach and includes recognition of context as a significant impacting element in social and cultural studies of this nature. In this case the author extends the context beyond the individual Finn, and considers the institutional, political and economic context. The main sources of data are the written individual reminiscences of Finns, and other sources used include narrative folk lore, oral history, legends, memoirs and gossip.

Finally, in Chapter Fourteen, Canevacci provides a snapshot at changes in ethnography over time, and particularly focuses on the concept of self-representation in a digital society, and how studies of digital and 'glocal' cultures will challenge the way ethnography is done. The author examines the concept of ubiquity, and the loosening of the boundaries of identity, individuality and culture as perceived by anthropologists in the past. The concepts of simultaneity and ubiquity are compared in the context of urban performance within the paradigm of a digital society. Ethnography has to be able to encompass this multi-dimensional field, where individuals become multividual, the boundaries between observer/observed, 
researcher/researched are collapsed. There is a political dimension to this, too, in terms of Marx's 'division of labour', where again; the concepts of worker and labour have been changed by and within the communication paradigm.

Loshini Naidoo wishes to acknowledge the assistance provided by her research assistant, Kay Powell, in the editing of this book.

Dr Loshini Naidoo University of Western Sydney, Sydney, NSW

Australia 



\title{
Ethnography: An Introduction to Definition and Method
}

\author{
Loshini Naidoo \\ University of Western Sydney, Sydney, NSW \\ Australia
}

\section{Introduction}

Ethnography, emerging from anthropology, and adopted by sociologists, is a qualitative methodology that lends itself to the study of the beliefs, social interactions, and behaviours of small societies, involving participation and observation over a period of time, and the interpretation of the data collected (Denzin and Lincoln, 2011; Reeves, Kuper and Hodges, 2008; Berry, 1991). In its early stages, there was a desire by researchers to make ethnography appear scientific, and with this in mind a manual was produced for people in the field, with a set of instructions as to how ethnography should be 'done' (Denzin and Lincoln, 2011). As such it was seen to be more accurate than the descriptions of travellers, although not in the sense that scientific experiment or quantitative measurement is deemed accurate. A feature of positivism, the scientific approach, is that results can be tested, and the researcher is separate from the research. This was seen by ethnographers as failing to capture aspects of the way humans behave, the setting being artificial (Atkinson and Hammersley, 1994). On the other hand a naturalist approach is more interpretive, cannot be verified by tests, and the researcher 's own interpretation is part of the process (Mackenzie, 1994). The goal of ethnography then was to give an analytical description of other cultures (Barbour, 2007), an exploration of a particular phenomenon, rather than the testing of an hypothesis (Atkinson and Hammersley, 1994). The data consisted of unstructured accounts and the analysis, which provided interpretation of meaning, was done by the researcher, using observation, description and explanation (Reeves, Kuper \& Hodges, 2008).

Ethnography developed as the tool of social science, and involved the social scientific observer, the observed, the research report as text, and the audience to which the text is presented (Denzin \& Lincoln, 2011). It was hoped that the social sciences would gain the sort of credibility of physical science, and the initial approach was like physical science in that it was assumed that the researcher had the right to study any phenomenon provided it led to new knowledge (Denzin and Lincoln, 2011), and the only point of view was that of the researcher. There was a tendency to ignore the subject or to be critical of their claims (Katz and Csordas, 2003; Denzin and Lincoln, 2011), they were, rather, seen as passive participants in the research, with no impact on the content of the study. The line between the researcher and the researched was clearly defined, and this was also true of the text produced and the audience for which it was produced. Only the researcher had input into the final report, and this product in turn, became for the most part the property of the scholarly community (Denzin and Lincoln, 2011). 
As already mentioned, there was no attempt in the nineteenth century to represent the point of view of the people being observed, ethnography was conducted by outsiders providing a view of the actions of the people under study (Reeves, Kuper and Hodges, 2008; Denzin and Lincoln, 2011). It was etic, rather than emic - or as Geertz (cited in Denzin and Lincoln, 2011), puts it, the difference between a wink and a blink. The functional significance of an action was ignored, the 'raw facts' simply described 'objectively'. Malinowski is credited with creating a shift in ethnography, when he sought to introduce into his accounts the point of view of those being studied, and the cultural significance of the actions described (Denzin and Lincoln, 2011), going so far as to say that the researcher must immerse himself in the culture so that 'they' becomes 'we' (Elliott and Jankel-Elliott, 2003, p.216). AbuLughod (2000, p. 263) applauded, in ethnographic research, "the use of the poignant pronoun: we", seeing it as symbolic of the importance of location. Rather than represent cultures as alien, by creating hierarchical discourses that excluded the familiar, accentuating differences and distance, it is important to identify with those being studied rather than turning them into objects (Abu-Lughod, 2000). Hence, immersion within a culture means being able to discern the significance of the blink in that culture, and becomes the 'thick' description of ethnography (Rosen, 1991).

The idea of a method that had shifted away from the scientific, and was thorough and broad, and topic oriented, lent itself to a broader application and has appeared in other research areas such as nursing, education, social work, planning, and marketing (Devault, 2006). The advantage of using such a method to investigate work practices is that some organisations recognise some work and not other work, whereas ethnography tracks all that is done whether it is recognised or not, and by analysing the social relationships, the relevance of experiences can be highlighted. Texts and discourses in organisations can be a means of maintaining control, and researchers can track the way this occurs, through seemingly neutral documentation such as funding proposals, planning documents and accounts (Devault, 2006).

The researcher as participant observer has the advantage of being immersed in the culture over an extended period and therefore in a position to discover what was 'hidden', but it became clear that the subjectivity of the researcher also has to be taken into account. Ethnography is linked to the lived experience of the ethnographer (Berry, 2011). Rosen (1991) comments that there is no absolute truth of interpretation, but rather the value of the account lies in whether it is a plausible explanation for the data collected. The aim is to provide meaning for the culture under study, and the strength of ethnography lies in the use of more than one method (Reeves, Kuper and Hodges, 2008), this flexibility allowing for change as the research continues over time. The process involves the collection of data via field notes, journals, audio visual material and cultural artefacts, and the analysis of this data using codes and references. This is then strengthened by triangulation and analysis, using such techniques as interviews - both individual and group, and informal dialogue. The epistemological framework of ethnography encompasses meaning and behaviour in any situation, and how these are linked; the awareness of changes in behaviour that occur when understanding others; the many perspectives existing in situations; the need to understand behaviour and beliefs in the context of the culture or organisation and the need to study the group or culture 'as it is' (Mackenzie, 1994).

When people within a group or culture are studied, they are invariably being 'represented', and this raises the moral and ethical issue of the purpose of ethnography. Whilst it was 
perceived that there was some value in doing ethnography to add to the sum of knowledge, ethnography came under criticism for being an academic exercise with little constructive value (Atkinson \& Hammersley, 1994). There is a shift to a critical ethnography (Denzin and Lincoln, 2011; Atkinson and Hammersley, 1994) and a move to provide practical solutions to problems that emerge from the study. As Madison puts it (cited in Chari and Donner, 2010, p.76) critical ethnography ... begins with an ethical responsibility to address processes of unfairness or injustice within a particular lived domain. By 'ethical responsibility' I mean a compelling sense of duty and commitment based on moral principles of human freedom and well-being, and hence a compassion for the suffering of living being. The conditions for existence within a particular context are not as they could be for specific subjects; as a result, the researcher feels a moral obligation to make a contribution towards changing those conditions toward greater freedom and equity...the critical ethnographer resists domestication and moves from 'what is' to 'what could be'.

This goes beyond reflexive ethnography, which gives a critical analysis of the power relations and injustice that may exist in a culture, rather it involves writing against injustice and denouncing it (Bourgois, in Chari \& Donner, 2010). Barbour (2007) in the context of training people for school leadership, also says there is a need for ethnographers to study the uses and abuses of power in any organisation, and goes on to evaluate the use of ethnographic narrative in order to understand the issues involved in observing a cultural group, and in aligning with the members of the group.

Barab, et al (2004) describes the process of empowering people in the context of implementing a programme to facilitate learning at a local Boys and Girls club. Whilst the authors' focus was to train people to use the programme, it required the tools of ethnography for them to understand and respond to the culture of the clubs. They immersed themselves in the clubs, building relationships with the children as well as the staff. They sought to respond to the people's needs and to empower them by developing their knowledge and critical awareness, but with this came a responsibility to understand the social context and give voice to the people concerned (Barab et al, 2004).

Market research has generally been characterised and dominated by a positivist approach. The tendency to ignore qualitative in favour of quantitative research methodology was primarily due to market researchers' lack of understanding (Chong, 2010; Milliken, 2001). This inclination was borne out of the perception that the "volume" of data, the "complexity of the analysis" required, "classification" details, and the "velocity and flexibility of analysis" (Milliken, 2001, p.74) made it too cumbersome and expensive for a qualitative approach to market research. However, the growing awareness of the subjectivity, and the constructed nature of market research, demands a more socially oriented approach. An interpretive paradigm has emerged with ethnography playing an essential role in studying the habits of consumers (Chong, 2010). Elliott and Jankel-Elliott (2003) advocate an interpretive approach and suggest that people are not necessarily the best predictors of their own behaviour. Therefore, it is important to study people in situ, to see the consumer as a social being, to study them in their natural setting and for the researcher to experience the life of the consumer. Market strategies can then be improved by targeting, product and service positioning, and brand managing (Chong, 2010). It should be said, however, that it is not always possible to adhere to these strategies, and in some circumstances the researcher assumes the role of a non-participant observer where the situation is not conducive to the 
researcher being a participant observer. For example, Elliott and Jankel-Elliott (2003) describe the researcher posing as a shopper. As they observe they make field notes and assess what they see of other shoppers and their consumer behaviour. Marketing management decisions are made based on the observations and conclusions of the market researcher. Chong (2010) discusses a similar phenomenon, describing the notions of research done in real time. This is similar to an etic approach and an emic approach, as discussed earlier. She suggests that the advantages of employing ethnography to market research include recording human activity in a natural setting, a structured and more comprehensive approach to collecting data, and a more authentic representation of consumer behaviour. In addition to this, Chong advocates that thick description allows a more thorough understanding of consumer meaning. This in turn allows the marketer to modify strategies or reposition the product or service in accordance with that meaning. Because they have become immersed in the consumer culture they maintain an understanding of it over time (Chong, 2010).

Any discussion surrounding market research would not be complete without considering the immense impact of information and communication technologies, in particular, the internet. Maclaren and Catterall (2002) suggest that new strategies need to be adopted by market researchers in order to capitalise on the potential that the internet offers. For example, the internet has created the means of communicating 'many to many' in "global virtual meeting places" (p.319) rather than the 'one to one' of traditional market research. In this way, researchers can access the views of many different consumers in many different locations. What is particularly significant is that each of these online communities has a unique culture, set of values, belief systems, and sense of identity. These elements form the basis of ethnography, and ethnographic techniques provide the means to discover the essence of these communities. In a very real sense, the discussions which occur in online communities (discussion boards, chat rooms, social networks) have partly replaced the use of focus groups, and the use of symbols replaces the 'reading' of body language and facial expressions (Maclaren and Catterall, 2002). However, it is important to note that the market researcher will still use focus groups to gather research data that cannot otherwise be obtained via the online or virtual world, when it is felt that a more real setting is going to produce a clearer result. Whilst online research is essential for the market researcher, it is potentially fraught with issues relating to multiple identities of participants, authenticity of data, and less control of interviews, but Maclaren and Catterall (2002) argue that rather than ignore its vast potential, it is a question of adapting to a set of different cues and finding new ways of researching.

Much of the work of auto ethnography has investigated the ways in which dominant historical accounts maintain structures of power. Auto ethnography seeks to demonstrate that when personal experiences clash with such histories it challenges previous meanings and understandings (Denzin, 2006). It is defined by a reflexive writing as in a narrative of experiences with other cultures or experiences of other social contexts, whereby the physical, personal presence of the researcher is political (Spry, 2011). Spry (2011) uses performative auto ethnography to chronicle her traumatic experience of the death of her son at birth. She goes on to say that in itself this is not what auto ethnography is about until it is aligned with a greater social context. It must be connected to other people and the struggle to deconstruct power relations. In her particular experience Spry makes reference to the dominant discourse of grief, and yet her experience was not consistent with this. In this 
context auto ethnography was used to challenge hegemonic discourses and therefore, validates the experiences of others whatever these may be. Auto ethnography is a "small performance that asks how our personal account counts" (Jones, date, as cited by Spry, 2011, p.500).

Auto ethnography seeks to communicate the mechanisms of the "inner world" (Holt, 2003, p.5) of an individual from the perspective of the researcher. It is important to recognise that auto ethnography not only places the researcher within the experience of an individual or group, but it sees the researcher reflecting upon their own, personal experience of the experience being researched. The process involves writing the 'self' into the history and projecting it into the present, by using various writing and communication techniques and forms (Denzin, 2006; Holt, 2003). It is a study of the 'self' as 'other' and when linked with culture, involves a negotiation between the ethnographer stories (us) and their relevance to culture. It exposes the hidden ' $I$ ' in the accounts, to allow for a more authentic process (Berry, 2011). The aim of auto ethnography is always to challenge the norms of methodological practices in order to achieve a more egalitarian and just society, making clear where power, privilege and biases lie (Denzin, 2006; Berry, 2011), in the process of studying those who have been hidden or represented as "abject, abnormal, exotic, and uncivilised", and to critique the master narratives of western white history writers (Spry, 2011, p.500).

Performance ethnography links sociology, anthropology, community studies, performative arts and cultural studies, and is gaining impetus, as a useful tool for bringing new knowledge and understanding to an audience, as well as revealing power structures. From there, depending on the response of the audience, which can be varied depending on gender, ethnicity or social class, it can lead to action (Smith and Gallo, 2007; Hamera, in Denzin and Lincoln, 2011). Warren (2006) argues it has the potential to change ourselves and others, and by disrupting the 'taken-for-granted' aspect of a practice, it can make that practice more meaningful. It creates the ability to see how lives are constructed, 'real people in real places', describing lived experiences, so that what seems stable can be probed and possibly transformed (Warren, 2006, p. 318; Smith and Gallo, 2006).

The material that informs performance ethnography can range from research results, stories, field notes, journal entries and memories, and is described as a performance text that is written and read by one or more people for an audience, with a view to critique social structures of power, justice, gender and race (Smith and Gallo, 2007). It is a way of bridging the gap between the practitioner and the artist, and to bring theory and practice together, in such a way that everyone involved, subjects, audience, and performers, all gain from the experience. Presented as real, subjects gain by having their histories and their voices heard so that they no longer feel isolated. Performers have the satisfaction of communicating to an audience, who in turn are moved to act. They have travelled to the world of the subject and met there (Smith and Gallo, 2007).

The performance ethnographer's poems, plays, readings, conversations, and journals are a way of presenting the results of research, in such a way that when heard by the audience moves them to act (Smith and Gallo, 2007). The object of performance ethnography becomes the performance, and the relationship between the researcher and subject has become one of co-performance, and as stated earlier, both are transformed by this (Pollock, 2006). Where traditional ethnography's writing was about the culture, that writing is placed into a 
performance framework able to be used again and again, and has the capacity to reveal power structures, therefore requiring action on behalf of those involved (Pollock, 2006). The hidden ' $\mathrm{I}$ ' of the researcher is now immersed in the co-subject, entangled with, even ravished by the cocreative process such that the subjectivity of the researcher is diffused within, even to the point of disappearing into, the field's body. Accordingly, we no longer see the scholar ' $\mathrm{I}$ ' at work but we certainly feel her passion, his grace (Pollock, 2006, p.326).

In areas where performance ethnography has been used little, nursing and medicine, Smith and Gallo (2007) describe the potency of the voices, spoken out loud, of parents of children who have a genetic condition, and to this they add the feelings of the researcher experiencing the interviews. The information garnered from the stories was significant in that it revealed how the condition was disclosed to the parents, how the parents passed this information on to the child, and other information relating to the parents and children, and certainly gave a deep understanding of the lived experience of the families involved with children with genetic conditions (Smith and Gallo, 2007). Pollock (2006, p.327) describes this as "going in to a social field at risk of going under", and being transformed by it in profound ways.

The ubiquity of image in today's society challenges the ethnographer to consider the place of photography in qualitative research (Prosser in Denzin, 2011). In the past it has been seen as a means of portraying truth. Where images have been used to capture aspects of a culture, it was seen as an unproblematic piece of information, and was often used to portray something that was difficult to describe with words, and was considered as part of the process of observation (Harper, 2006). It was popular, as it seemed to reflect scientific realism, and was used extensively in sociology, science, geography and history. However, this view has been contested, as Prosser (In Denzin, 2011) points out, even photographs are an interpretation, they are not the thing itself. In using visual material, there is still a need for reflexivity and an understanding of the subjectivity of the photographer. Whilst this can be expressed in text, in photography, the viewer is not aware of why they are confronted with one image and not another, whether the image reflects something that is true, or simply an isolated incident. The 'gaze' of the camera leads the viewer to see the image or film from the photographer's point of view, so that they end up with the same viewpoint (Pink, 2006, p. 2).

Prosser (In Denzin and Lincoln, 2011) argues that whilst the use of images has increased, visual literacy has not kept pace with this, and most research is still focused very much on the written text. Whilst tables, charts, graphs, and pie charts are useful for quantitative research, they are limiting when using qualitative methodologies, as they lack the flexibility to represent the sort of data produced. He stresses the need to train researchers in methods of visual representation as there are definite advantages in the use of imaged based methods. For those who are less articulate, it allows them to communicate in other, creative ways, "Art can describe, reflect, and evoke emotion, which dry facts or figures and cool logic rarely do" (Prosser, in Denzin and Lincoln, 2011; p. 488). He goes on to say that the use of such methods can give a much better idea of what it is like to live that life. He sees it as a tool for thinking, when words cannot convey the meaning, images are able to grab the attention in ways that words on paper do not (Prosser, in Denzin and Lincoln, 2011). He goes on to describe how people with disability are excluded from any form of research because they are not able to articulate their ideas in interviews, but when given the opportunity to express themselves visually, showed remarkable insights into their lives. 
The challenge to ethnography from globalisation lies in the concept of 'field', and the need to provide the 'hard' data that characterises positivist research (Gille, 2001). Some researchers have always questioned the concepts of field or homework, rural or urban, community or corporation, arguing that such dichotomies create boundaries that are in fact non-existent, and are products of discriminatory white western discourses, whereby no alternative way of looking at 'other' is presented. Globalisation, however, seems to have made such concepts redundant, since the whole notion of location appears to have lost its meaning. Gille (2001) argues that such challenges need to be put into the context of global social relations. The epistemological basis of ethnography involves the study of people who are in or affected by certain situations, and sometimes locale is difficult to define, even with Marcus' attempt to put this in the context of multi-sited ethnography, allowing for the fact that many localities are no longer isolated, but linked to the world in often complex ways (Marcus in Gille, 2001; Abu-Lughod, 2000). There is what Marcus calls a 'logic of association', the ethnographer's task is to find what connects to what, and to construct subjects in changing contexts as they act and are acted upon. In taking such a stance, the ethnography becomes an ethnography of the system, too, and the global, "...an emergent dimension of arguing about the connection among sites in a multi-sited ethnography" (Marcus, 1995; p.99). In choosing, and in following the links, the ethnographer constructs reality (Gille, 2001), but Marcus (1995) argues, what is not lost by multi-sited ethnography is the translation from one culture to another, rather it loses the 'us and them' dualism, and simply becomes more complex. In contrast to the 'one site of reality' of traditional ethnography, what is being studied is social relationships that develop amongst sites and evade boundaries (Gille, 2001; p323). Gille (2001) lists Massey's four elements to the notion of place in the light of globalisation, the first being that place is not static, nor does it have the boundaries that mark it from the outside. Thirdly, place has no single identity, even though, fourthly, it is unique, this uniqueness borne of a mixture of local and wider social relations (Massey, 1994 in Gille, 2001).

\section{References}

Atkinson, P. and M. Hammersley, (1994). Ethnography and Participant Observation. Handbook of Qualitative Research. Retrieved from: http:/ / hevra.haifa.ac.il/ soc/lecturers/sgooldin/files/6461181041799.pdf

Barab, S.A., Thomas, M.K., Dodge, T., Squire, K., and Newell, M. (2004). Critical Design Ethnography: Designing for Change. Anthropology and Education Quarterly, 35(2), 254-268. DOI: 10.1525 /aeq.2004.35.2.254

Barbour, (2007). Leader Paradoxes and Critical Ethnographies. Academic Exchange Quarterly. 11(2), 117-121.

Berry, K. (2011). The Ethnographer's Choice: Why Ethnographers do ethnography. Cultural Studies - Critical Methodologies, 11(2). 165-177.

DOI: $10.1177 / 1532708611401335$

Chari, S. and Donner, H. (2010). Ethnographies of Activism: A Critical Introduction. Cultural Dynamics. 22(2), 75-85. DOI: 10.1177/0921374010380887

Chong, J. L. L. (2010). Evaluating the impact of Arnould and Wallendorf's (1994) marketoriented ethnography. Journal of Market Research, 63, 1295-1300. DOI: 10.1016/j.jbusres.2009.08.001 
Denzin, N.K. (2006). Analytical Autoethnography, or Déjà Vu all Over Again. Journal of Contemporary Ethnography. 35, 4, pp 419-428.

Denzin and Lincoln (2011). The Sage Handbook of Qualitative Research. Sage Publications: USA.

Devault, M. (2006). Introduction: What is Institutional Ethnography? Social Problems. 53, 3, pp.294-298.

Elliott, R. and Jankel-Elliott, N. (2003). Using ethnography in strategic consumer research. Qualitative Market Research: An International Journal, 6(4), 215-223. DOI: $10.1108 / 13522750310495300$

Gille, Z. (2001). Critical Ethnography in the Time of Globalization: Toward a New Concept of Site. Cultural Studies<> Critical Methodologies. 1. 319-344. DOI10.1177/153270860100100302

Holt, N. L. (2003). Representation, legitimation and autoethnography: An autoethnographic writing story. International Journal of Qualitative Methods, 2(1), 1-10.

Katz, J. and Csordas, T. (2003). Phenomenological Ethnography in Sociology and Anthropology. Ethnography, 4. 275-288.

Mackenzie, (1994). Evaluating ethnography: considerations for analysis. Journal of Advanced Nursing. 19. 774-781. DOI:10.1177/146613810343001

Maclaren, P. and Catterall, M. (2002). Researching the social Web: Marketing information from virtual communities. Marketing Intelligence and Planning, 20(6), 319-326. DOI: $10.1108 / 02634500210445374$

Milliken, J. (2001). Qualitative research and marketing management. Management Decision, 39(1), 71-77.

Pollock, D. (2006). Marking New Directions in Performance Ethnography. Text and Performance Quarterly. 26, 4, pp.325-329. DOI:10.1080/10462930600828733

Reeves, Kuper and Hodges. (2008). Qualitative research methodologies: ethnography. British Medical Journal. 337:a1020. DOI:10.1136/bmj.a1020

Rosen, M. (1991). Coming to terms with the field: Understanding and doing organizational ethnography. Journal of Management Studies, 28

Smith, C.A.M. (2007). Applications of Performance Ethnography in Nursing. Qualitative Health Research. 17.4, pp. 521-528.

DOI:10.1177/1049732306298755

Warren, J.T. (2006). Introduction: Performance Ethnography: A TPQ Symposium. Text and Performance Quarterly. 26. 4. Pp.317-319. DOI:10.1080/10462930600828667 


\title{
Ethnographic Field Notes and Reflexivity
}

\author{
Päivi Eriksson ${ }^{1}$, Elina Henttonen ${ }^{2}$ and Susan Meriläinen ${ }^{3}$ \\ 1 University of Eastern Finland \\ ${ }^{2}$ Aalto University School of Economics \\ 3 University of Lapland \\ Finland
}

\section{Introduction}

Ethnographers have devoted a great deal of attention on the issues of writing the final product of ethnographic research, the ethnographic research report. The issues related to the process of writing ethnographic field notes, however, have received much less attention in methodological discussions. Emerson et al. (1995) point out that even after the discovery of 'writing' as a central practice of ethnographic research (Clifford \& Marcus 1986, Van Maanen 1988), field notes remained as 'invisible work' in ethnographic literature. They argue that while many ethnographers are uneasy with the messy, unfinished, and personal character of their field notes, these have mostly remained private documents. Remaining private documents, the impact of field notes on research findings and results has also left unexplored.

Why should we pay more attention to field notes? Although there is no consensus concerning how ethnographic field notes should be written and what is their value in ethnographic research, most ethnographers (and many other qualitative researchers) produce some kind of field notes, particularly when doing observations. When planning and producing field notes in situ or after wards ethnographers continuously make choices about what to write down and how. Because it is impossible to collect data on everything and record all the things that are going on in the field, the researcher needs, by necessity, be selective in her writing. Furthermore, the researcher writes down her notes drawing from her sense making of the people, events and the situation and her interpretation can be different, or at least have different details and nuances, compared to another researchers' field notes from the same situation. Field notes are important because they involve the critical acts of sense making and interpretation, which inevitably have some kind of bearing on the research findings and results. To be able to understand what kind of bearing the field notes can have on your research, it is necessary to practice reflexivity in respect to one's own field notes and their analysis.

In this chapter, we will answer to the request of taking written field notes and their analysis more seriously in ethnographic research. Our main objective is to open up and analyse the process of writing and analysing ethnographic field notes. We will perform this through the investigation of our joint research project, which focused on business, technology and gender in the context of the Finnish ICT-sector (for an overview of the project, see 
Henttonen 2010). In our investigation, we will practice reflexivity in terms of exploring the relationship between the researcher and the field, questioning the knowledge that is produced in field notes and in their analysis. More specifically, we will focus attention on how the social identities of the researchers affect how knowledge about the research subjects is produced and with kind of consequences.

Our analysis elaborates two different modes of writing the field notes - selection and sensemaking activities and textual practices of representation - and their implications on our research. In our analysis, we will pay close attention to the processes of exclusion, which take place through othering and marginalizing certain groups of actors involved in our research. With regards to selection and sense-making activities, we will ask what and who do we decide as 'important' and 'relevant' enough to be included into our field notes. We will also investigate why we considered some actors and events to be 'not-so-relevant' in relation to the goals of our project and how we justified these choices in our field notes. Through the analysis of our textual practices, we will further illustrate how and with what kinds of implications the 'relevant' and 'not-so-relevant' actors and encounters were crafted in our notes.

\section{Collective reflexivity and social identity}

In general, reflexivity can be understood as an essential human capacity to make sense of our social existence, i.e. something that we are all engaged with on everyday basis. In scholarly contexts, it is useful to make a distinction between the concepts of 'reflection' and 'reflexivity'. 'Reflection' refers to a methodological principle whereby the researcher aims to make sure that her own experiences, biases and interpretations do not influence the analysis, findings and conclusions. Therefore, the concept of reflection is often connected to objectivity in research (Etherington 2006, 28). In this sense, reflection is part of the more traditional ethnographic research, which has been called 'naturalistic' and 'positivistic' ethnography.

A general goal of the main stream ethnographic research is to describe a culture or subculture in as much detail as possible, including language, customs, and values (Eriksson \& Kovalainen 2008). This typically involves becoming a participant observer and socialising oneself into the culture under study. The actual process of ethnography means that the researcher is immersed in a social setting for a certain period of time, in which they make regular observations of the behaviour of the group under study. Just as any other researchers, however, ethnographers inevitably put their own slant into the research because they are the ones making the decisions on what to observe and what to note down. Furthermore, even though the ethnographer uses several methods of recording their findings, it is highly unlikely that they capture all of the relevant aspects of the social processes, as there is simply too much going on at one time to focus on everything. Therefore, text books advice researchers to take stock of the information she has collected. In this context, reflection entails that the ethnographer writes about the potential biases or influences, so that the reader can be aware of them when reading and interpreting the data.

Along with the emergence of postmodernism and the linguistic turn in social science research, and the development of various constructionist research approaches (Alvesson \& Söldberg 2000), there has emerged an increasing interest in 'new' or 'postmodern' reflexivity 
(Etherington 2006, Lynch 2000). In this context, reflexivity refers broadly to the relationship between the researcher and the empirical field, questioning the notions of the realities we study, ways we generate knowledge, and ways we theorize (Cunliffe 2003). The basic argument in the recent discussions of reflexivity is that the authors should explicitly position themselves in relation to the research objects of the study to enable the audience to assess their knowledge claims in terms of the situated aspects of their social selves, values and assumptions (Maton 2003, 54). This development has led to different forms and uses of reflexivity (Davies 2008; Etherington 2006, Pillow 2003), to the extent that Lynch (2000) writes about 'reflexivities'.

One way to classify the forms of reflexivity is to make a distinction between 'individualistic' and 'collective' reflexivities. Individualistic reflexivity is typically used to produce confessional tales from the field (Van Maanen 1988) whereas collective reflexivity analyses how research communities and members within these communities produce collective meaning (Hardy et al. 2001, Maton 2003). Individualistic reflexivity has faced some critique according to which there is a thin line between epistemologically productive reflection, e.g. finding a suitable way to acknowledge one's position in one's texts (Rhodes 2000), and the forms of reflexivity that have been called as self-indulgence, navel-gazing, or warped narcissism (Coffey 1999).

Social identity theory (see e.g. Ellemers et al. 1999, Haslam 2001) provides a useful framework for elaborating on collective reflexivity, which revolves around the question of how shared collective understandings affect the world views and interpretations of people. While being different from personal identity, which is based on personal characteristics and individual relationships, social identity theory deals with 'the social nature of self as constituted by society' (Hogg et al. 1995, 255). In this way, social identity is a concept that connects individuals and society. The basic idea of the social identity theory is based on the issue that all of us belong to different types of groups (e.g. business school researchers, ethnographers, female entrepreneurs) and derive at least part of our identities from these groups. Identity formation in relation to groups takes place in three stages: social categorization, social identification and comparison. When developing the social identity of the group, the members construct an in-group (we) and various out-groups (others) and go through a mixture of inclusion and exclusion processes, which can have both negative and positive consequences (Haslam 2001). While social identity theory is sensitive to the contextual dimension of identity formation, it provides an understanding of identities as multiple and changing and residing in circumscribed practices such as norms and roles (Hogg et al. 1995, 255).

Common processes with negative consequences for the members of the out-groups are 'othering' and 'marginalization' (Barter-Godfrey \& Taket 2009). In the process of othering, an out-group is constructed as strange, un-familiar and different in contrast to the in-group,

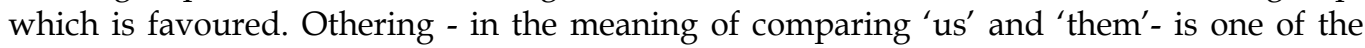
main mechanisms of collective identity construction. Therefore, collective reflexivity almost inevitably includes some type of analysis of it. Another, perhaps more extreme way of excluding the out-group is 'marginalization', which refers to a social process in which an out-group is assigned a position in the fringe of the society, or some other relevant entity (e.g. economy, business world). The processes of inclusion and exclusion are not necessarily goal-oriented or conscious and they are also pursued by people who are not even sure about 
their full membership within the in-group. These processes typically take place in strange or surprising situations when our self-esteem, or subjective uncertainty, is low. As we know, field work is often invaded by these types of situations, and this was the case in our field work also.

Carl Rhodes $(2000,522)$ suggests that researchers can acknowledge their position in their texts and account for their social roles in (re)presenting others while still not succumbing to excessive description about themselves as individuals. In this way they can take responsibility for their own textual practices through which they construct the world and lives of others. This is what we aim at in this chapter. We acknowledge our social identities as business school researchers and members of respective cultural and scientific communities. At the same time, however, we wish to move away from 'navel-gazing' into showing how collective cultural understandings which are alive in our research communities but also the sense making processes of our own small research group shape our research practice.

\section{The process of our field work}

The three of us (co-authors) have received their master's degrees and doctorates from Finnish business schools and have since then worked within the same context. The starting point for the fieldwork illustrated in this paper was our joint research project that examined women owner-managers of small Finnish ICT-companies - a project conducted within a national research programme for technology and innovation policy. Within the research programme, the goal of our project was to produce information on women's business activities in the Finnish ICT-sector, analyse how these companies were managed, and examine how women's business initiatives in technology-intensive industries were (or could be) supported. In our research project, we first collected policy texts and media texts on women-controlled companies in these types of businesses. Thereafter, we made interviews with the female CEOs of 17 small technology intensive companies, mostly within the ICTsector (for an overview, see Henttonen 2010). Thereafter, we negotiated access to four small software service companies for the purpose of doing ethnographic fieldwork with four women owner-managers (for details, see Eriksson et al. 2005, 2008a, 2008b). Before we started the ethnographic field work, we studied a number of ethnographic text books as carefully as we could.

The methodological literature (e.g. Atkinson et al. 2001, Coffey 1999, Emerson et al. 1995, Eriksson \& Kovalainen 2008) provides plenty of guidelines concerning how to collect and report observational data for ethnographic research. First of all, the literature advices ethnographers to plan their field work in a detailed manner. In terms of what to observe in the field, researchers are advised to pay attention to people (and other actors); to observe how they talk, behave, interact, move and talk. Also physical environment and the use of material artefacts should be recorded. Advice is also given on reporting one's own reactions, emotions and thoughts concerning the fieldwork.

What comes to documenting observation data, researchers are advised to write their observations down as soon as possible (depending on the situation this might be in situ, immediately afterwards, or at the end of the day). According to Emerson et al. (1995) field notes include both description portraying the physical environment, people and their 
actions, and dialogue representing the interaction. According to guidebooks, both should be documented as exact and detailed as possible, aiming to capture the language and expressions of the people in the field instead of researcher's own concepts and understandings. In terms of drawing conclusions based on the observations, some suggest that explicit analysis should be avoided during the fieldwork, while others argue that acts of observing and writing field notes are analysis per se. Despite this dissent, it is common to recommend that the researcher writes a separate personal diary of the researcher's experiences, thoughts and reflections to account how these might influence the fieldwork and interpretations it produces.

Informed by the guidelines, we started doing fieldwork with the women owner-managers of four small software service companies located in different parts of Finland. In our field work, the three of us researchers (and authors of this chapter) 'shadowed' (Bruni et al. 2004a) the owner-managers in their daily work. We followed each of them step by step observing their work and made notes of what happened. The first company of our fieldwork, Firemot Ltd. operates in a fast extending area of software business offering specialized services to large software companies. The second field work company, Kollabs helps other companies to automate their business processes through machine-to-machine communication. The third field work company, TRICT Ltd., is an ICT-training centre, which specializes in the development and use of ICT applications, system management, and data security. The fourth field work company, Content Ltd., is a tiny cross media and e-business company involved in customizing various types of software solutions for its customers.

In the first three companies, we made observations in the company offices (although occasionally we did also follow the owner-managers running their errands elsewhere). The fourth observation week was different because we followed the owner-manager travelling to work. We used, however, the same methods of making field notes at all four sites: we observed the owner-managers and their employees in their work, attended the meetings they had with partners, customers, and job applicants, manually recorded our field notes with pens and notebooks, switched between observing the same events together and taking turns in observation, assumed the role of non-participant observers by keeping quiet and stationary (when possible), adapted our observer roles according to the situation and context when our presence aroused curiosity and questions, participated actively when it seemed necessary (e.g. having meals together, carrying office shelves), and had both formal and informal discussions with various people about who we were and what we were doing. At the end of each day we (the researchers) shared and discussed our experiences with each other.

\section{Doing field work with Tiina}

\subsection{Focus of analysis}

In our analysis of the field work, we focus on the field notes written by Elina and Susan during one week's period of travelling and participating in the life and business operations of Tiina, the owner-manager of Content Ltd. The parts of the text marked with cursive are exact quotations from our field notes. To provide anonymity, the names of all people and companies are pseudonyms. 
This is what Elina wrote in her field notes in the beginning of the week:

'We spend this week observing the work of Tiina, an owner-manager of a small software service company Content Ltd. The office is located in Central Finland, but as Tiina had allocated this week for business trip, we decide to travel with her in one of the eastern counties of Finland. After all, we want to observe her work as an owner-manager of small business, whatever that work might be. Since we are travelling, we spend our time together around the clock. We stay in a house that we rented together, have our meals together, and spend our free time together.'

During the week, Elina and Susan observed how Tiina tracked down the use of electronic business among local care sector entrepreneurs, which was an assignment commissioned to her company by regional administration. We chose these particular field notes for the analysis because of their ability to illustrate selection and sense-making activities and textual practices that represent actors and encounters in the field. The analysis that follows emphasises one particular aspect of our ethnographic fieldwork, the construction of field notes, and focuses on two questions: what and who do we decide as relevant and worth writing down in the first place, and how we textually represent (or fail to represent) these research subjects and objects.

Tiina's company offers expert services in and around electronic business. To us, she characterized her path to entrepreneurship as 'traditional': graduating from a commercial institute, building a career in banking, getting married and staying home with kids, after which having further education in polytechnic. However, as Tiina describes, 'All the time the idea of entrepreneurship and independency haunted me, always cropping up in different situations'. Therefore, when Tiina was asked to participate in establishing a local business centre, she felt it was time to set up her own company in the process as well.

Tiina tells us that at first her work consisted of information technology training. Later on, she employed a few people and the company started to design home pages, portals and internet solutions for small and middle-sized companies, as well as consult them in cross media issues. Soon she realized that the company couldn't develop on its own, and decided to look for business partners. After some critical incidents, Tiina chose to concentrate on expert work instead of managing the business. Travelling is now an essential part of her work: 'I' $m$ where the customers are: consulting, training, networking and negotiating all around Finland.' According to her, 'We are a business of less than ten employees, but if you think about our close networks - the amount of people we actively buy from and co-operate weekly, with whom we have the same customers - we are no small business anymore.'

The reason for this ongoing business trip is an assignment commissioned to Tiina's company by regional administration: her job is to track down the use of electronic business in local small and medium sized companies. Therefore, Tiina (and us, the observing researchers) meet plenty of local entrepreneurs during the week. Most of them operate in the care sector, which is Tiina's first focus of the assignment. Tiina labels her role as 'the gray eminence, bridge builder or an agent' whose subtle overall plan is to link different actors doing developmental work in this field, 'spin a net', to create business for her own company through web services targeted at care entrepreneurs.

\subsection{Selective sense-making (the What's and Who's)}

The first remark we made when the three of us started to read and discuss our field notes collectively was that, in contrast to the earlier field notes from the first three software service 
companies, we had been even more selective in our observations and, particularly, in what we wrote down during the week with Tiina. In the first three field work companies, we took part in all meetings that we possibly could and were allowed to attend. This meant that we observed, among others, internal company meetings, informal lunch or coffee appointments, meetings with business partners, sales encounters, and recruitment interviews. In these situations we did our best to capture every conversation with every business partner in our notes, in detail.

A major difference in our fieldwork with Tiina was that, this time, we were not doing observations in the company premises within office hours. Elina commented in her notes that 'Fieldwork is hard work, and in the previous fieldwork companies I often waited the days to end to go home and rest. Here the time doesn't really matter, because the only free time is sleep time.' Another difference was that the people we met with Tiina were not, as in the previous companies, other ICT-sector entrepreneurs, managers, or experts. The business people that we met with Tiina were care sector entrepreneurs whose small-scale, grass-roots entrepreneurial ventures and caring world views seemed very different from the technobusiness orientations and behaviours that we had observed in the first three companies of our field work. Elina describes her first impression as 'Here it feels that we are really 'in the field'. It's a hands-on feeling compared to sterile techno-offices.'

When shadowing Tiina, we managed to follow the ideal of writing down as much as possible in a detailed manner, but only occasionally. What was striking to notice after wards was that we had excluded large parts of the interaction between Tiina and the care sector entrepreneurs. The fact that we had left considerable amount of this interaction unreported was justified by us in our field notes by appealing to the lack of time to write everything down, or by explaining that the care entrepreneurs were beyond the focus of our study. Their businesses seemed to have very little to do with techno-business issues as we understood them.

When we met Pirkko, a founder of a co-operative day care center, Susan wrote down a few facts about the center, but soon marked in her notes that 'I suppose Elina will write down this conversation, so I can concentrate on recasting what happened during this morning.' As time seemed to pass slowly, Susan began to describe the interior of the room. A telephone call for Pirkko interrupted her thoughts and when Tiina asked how much the members of the cooperative used information technology in their work, Susan momentarily concentrated again on listening the discussion between the parties involved. Soon, however, her thoughts wondered somewhere else, once again. Susan started to ponder 'Why is it that I am not writing down this conversation? Am I depreciating this conversation? In our previous fieldwork companies I wrote everything down word by word - but then again, it was so important, strategic discussion.'

Elina, in turn, listened to the discussion but did not report it in detail. Instead, she commented in her notes that 'This discussion is not 'technical'. It's more about practical issues such as communications, payment of wages, and daily activities. And the children play in the next room.' Later on she further noted that 'It might be quite interesting to analyse how these people interpret technology, and how they position themselves and others in care sector and their business. It feels, though, that is not relevant considering our focus. We're here to study Tiina and her business, not everyone else.' Similarly, in another meeting with two care entrepreneurs who had established a high quality home for the elderly Susan wrote: 'These women talk about intrinsic 
entrepreneurship. They are telling their story (it is a great story), but I am not going to write it down, because it's beyond the focus of our study.'

It is worth consideration why did we report Tiina's meetings with the care entrepreneurs rather superficially while in the previous three ICT-companies we had reported every conversation with every business partner in a detailed manner. With Tiina we justified our choices of not reporting these conversations by appealing to our research focus: we were studying Tiina and not 'anyone else' (as Elina writes), and because we did not have time to write everything down, we needed to focus on issues that were 'relevant'. But how come, in the other three field work companies, 'anyone else' seemed of interest (and 'relevant') and ended up on the pages of our notebooks, but not here? How come we characterized the previous discussions with various kinds of people as 'important' and 'strategic' business discussions, while we then neglected the conversations Tiina had with her potential business partners, the care entrepreneurs?

Although we had planned to follow the female owner-managers in all activities that they had during the observation week, and managed to do this in the first three companies of our field work, we did not manage to do this with Tiina. Why was it so? What happened? When we analyzed the situation afterwards, we came to the conclusion that we had strong pre-assumptions concerning what a proper technology intensive, ICT and software service business should be about, as well as which activities and partners would be central to this business and which ones would not be so central. When making observations and writing down field notes, we had categorized issues that we perceived closely related to technology business and ICTs as important, relevant and worth writing about. At the same time, we had categorized care work and care entrepreneurs as less relevant and non-important, even though they were Tiina's potential business partners. Where did our conceptions concerning 'what is important in business in general' and 'what is important in technology businesses in particular' come from, and how come we did not recognize them when being in the field?

At least part of the answer lies in our social identities as business school scholars. Within the business school context, we have developed an understanding of 'proper business' as something large-scale, strategic, or technological, which is far from the small scale microentrepreneurship represented by Tiina and the care entrepreneurs whom she met. Our preunderstanding coming from the business school context was not contradicted in the first three companies where we did fieldwork. Those companies were, in our minds, proper technology intensive business companies, and this is what we expected from the last company, too. When Tiina's company did not meet our expectations, we felt surprised, reluctant, and uncomfortable, but were unable to tackle these feelings and the reasons behind them while being in the field, only afterwards when reading and analyzing the field notes.

\subsection{Textual practices of representing the field (the How's)}

When we made the decision of not observing Tiinas' interaction with the care entrepreneurs, we constructed the care entrepreneurs as non-significant actors in contrast to the other actors that we connected more closely to the ICT-sector. This is not, however, the only problematic difference that we constructed in our field notes. Also Tiina, in the focus of our 
observation, gets her part of othering when evaluate her against the norms of business professionals. As a result, we characterized her behaviour as dubious in our field notes. In this process we as researchers become immersed in emotional contradictions that frame these characterizations, not being able neither to restrict the expression of emotions in a separate research diary, nor reflect in situ the powerful forces of frustration, irritation and guilt that we experienced in our fieldwork.

In the previous three fieldwork companies we followed the owner-managers and their daily work from a distance while our communication centred around work-related issues: we talked hardly nothing about our personal lives in the first three companies. For example, in our field notes we describe Jaana and Kaisa, owner-managers of two of the other software service companies we observed as follows: 'When communicating with us, Jaana is very straightforward and focused, and keeps her distance.' Or: 'Kaisa wants to define the level of our participation in her work. Basically, we are allowed to go everywhere in the office, but still she manages to keep her distance (...) She is the only person in this open plan office with her own (big!) room. If we want to talk to her, we have to knock on the door.' We respected their professional authority and personal distance even to the extent that we were hesitant (and a bit timid) to go and knock on their doors. Following this, they were able to adjust our presence - having a cigarette alone, closing office doors, going home at the end of the day - when they wanted (and so were we).

With Tiina, the situation was different. Since we were observing a business trip, we spent time together round-the-clock. Due to this closeness and Tiina's openness to share personal issues with us, the communication with her was very different from what we had experienced in the other field work companies. In a meeting with the entrepreneurs who had established a home for the elderly, Tiina takes an active role in the conversation by telling about her company and how she has managed to combine work and family life. She thanks her family for being so flexible, and keeps on telling about her children and the indispensable help she has received from her parents. Also in a meeting with Silja, one of the care entrepreneurs, the discussion turns to children when Silja weighs her chances as a single mother to participate in a seminar Tiina plans to arrange. Tiina shares stories about her four children, and appears empathetic towards Silja's childcare concerns. At some point the discussion turns to care work, and Silja mentions her mother's terminal care. Tiina starts immediately to share her own experiences of her parents-in-law, and the discussion revolves around very personal and sensitive topics. Susan comments in her field notes that 'I feel we should be invisible because they talk so personal matters'. Elina wonders later on 'how I should relate to all this 'private' stuff as a researcher'.

It is not only the topics of conversation that we feel confused about, but also Tiina's excessive talkativeness, towards which we express frustration in our field notes. In a situation where we wait for Silja in the old premises of a local association building, Elina writes: 'Tiina loves to talk, and tells one thing after another. The speech bounces from entrepreneurship and management to kid's illnesses and reverse sides of marriage. It's a flood of words that is hard to listen.' Later on, when Silja has already arrived and the discussion is well underway, Elina continues to comment: 'She definitely likes talking. It is such an informationflow that I struggle with what I can and find reasonable to catch in these notes'. During the week this information flow starts to irritate us more and more, and there are several remarks in both of our field notes about how Tiina speaks continuously about her personal matters, 
even to total strangers, and how confusing it is for us to keep up with the different spheres of her life (family, work, entrepreneurship). We do not know whether we are ascribed the role of researchers, friends, or confidantes, and where all this leads us in terms of our research.

As a result, we started to get feelings of guilt. After becoming very irritated by Tiina's behavior, Elina writes in her notes 'I feel I'm not able to listen to her anymore, but still I have to appear as interested. I'm not sure if this is a very fruitful attitude from me, but what can I do.' Susan, as well, questions the practice of field work in her notes: 'It's like social pornography: we intrude in someone's life and use it as research material. What worries me most is my own attitude towards Tiina. We analyse her life almost as if we would know better.' Elina continues to discuss the same topic in her post-field reflection notes: 'I'm struck by a bad conscience. I have wanted access in her life, and she has granted me this access, even though I'm a total stranger. Then I can't handle the situation and as a result, start to criticize her in my mind (and notes). Afterwards, it doesn't feel right. If she has been open enough to let me in her life, how can I, as a researcher, judge her?'

It is obvious that we recognize the problematic nature of fieldwork ethics, but fail to reflect in-situ why Tiina's behaviour caused such contradictory feelings for us. Down et al. (2006) note that interpersonal dynamics in the field can generate uncomfortable emotions. They also argue that these emotions inevitably influence the collection and interpretation of data, even though they hardly ever make their way to the published research report. In our case, these 'emotional dissonances' (Down et al. 2006) made us face the fact that, what we were frustrated and irritated about, was not so much Tiina herself or her behaviour (after all, we also talk much and share personal issues with those close to us), but our own pre-assumptions of how a business professional should or could behave in 'public' encounters.

The three other owner-managers we had observed earlier had enacted distance, focus and authority, i.e. qualities that are in line with the cultural image of a heroic business person, who is a tough, self-reliant, and combative man who works long hours, prioritizes business results over family and human relationships, controls his emotions, and never shows weaknesses (Binns 2008, 601, see also Bruni et al. 2004b). Accordingly, the dominant business discourse, strengthened and reproduced by media, educational practices and research, attributes business and work to the public domain of life; and home, family and kids to the private life (Ahl 2002). What Tiina did, however, was that she thoroughly mixed up the (assumedly separate) spheres of business and family, as well as rationality and emotions. Thus, her behaviour challenged the norm of business as serious work, which is performed as separate from home and family. She also confronted the assumption of business professionalism as enacting rationality, authority and distance. These social situations where our pre-assumptions about business professionalism were challenged caused us strong reactions of frustration and irritation. This also illustrates how our preunderstanding about business professionalism had directed us to textually represent Tiina in marginalizing ways compared to the female owner-managers of the other three companies, which had a better match with our expectations.

The narrow conception of business professionalism we had came up also in our notes regarding the care sector entrepreneurs and their expertise. An episode in which Susan describes the business activities of 'two middle-aged women' who run a home for the elderly is 
illustrative. Firstly, she notes that 'These women are truly professional entrepreneurs.' Later she continues to comment 'I'm once again impressed by the professional skills of these women.' Highlighting the professional skills of these women and making visible the unexpected nature of such observations reveals an underlying assumption about the unprofessional nature of their field of business, the care work. This becomes especially obvious in relation to information technology, utilization of which is one of the main topics in the meeting Tiina has arranged with these entrepreneurs.

According to our field notes we were also surprised of content of the conversation about information technology. That is, we did not expect the middle-aged female care entrepreneurs to be able to discuss technological issues on a professional basis with an expert. Subtly, but still strikingly, we reproduced the cultural hypothesis according to which technology, associated with expertise and skill, is more professional than care work, assumed to embody the 'feminine calling' (Henttonen et al., forthcoming).

\section{Discussion}

In ethnographic fieldwork we observe, make and give sense, and document social reality. Our field notes are textual representations of the observations and interpretations we have made, and as such, they are illustrative examples of the ways in which shared cultural understandings and our more local pre-assumptions have a bearing on what knowledge we produce and how. Our field descriptions of Tiina's work give evidence on what kind of issues we as business school researchers, and as researchers who had been in the 'same' (or so we thought) field before, found significant and worth writing and not writing down in our field notes. Our field notes illustrate what kind of meanings we attached to women owner-managers, business professionals and different fields of business (technology business and care business).

Recently, various types of constructionist and cultural approaches have become popular in small business studies (e.g. Bruni, Gherardi \& Poggio 2004a, 2004b, Down 2006). Being familiar with and also inspired by this literature, we considered ourselves open to various perspectives on women's small businesses when we started our research project and entered the field. Against this background it was interesting to notice that, despite our best intentions, we reproduced strong hierarchical relationships between the more professional and the less professional business activities and behaviours. In these processes of othering, a marginalized group became constructed against a norm, i.e. the care sector entrepreneurs became compared against the norm of more 'serious' businesses represented by technology intensive ICT-companies, which we considered that the first three companies of our field work represented well enough. At the same time, we compared Tiina's business activities and behaviours against our pre-assumptions concerning 'proper' business professionals, and pondered on the boundaries between public and private activities (an illustration of which is also the guilt we felt for expressing our emotions in the context of observation).

These processes of othering, illustrated in the previous sections of our paper, are closely related to the construction of gender in our research. The activities and meanings that became marginalized in our field notes, i.e. care, private, and emotionality, are those that are culturally associated with the feminine; while the valued standard norms of business, i.e. strategic orientation, rationality and authority, are attached to masculinity (Bruni et al. 
2004b, Eriksson, Henttonen \& Meriläinen 2008). Accordingly, women (and men) in feminized fields such as care are often marginalized in terms of professional status, authority and reward (Daiski \& Richards 2007), further reproducing the public-private divide and the dominant business professionalism discourse.

When analysing our field notes, it becomes evident how our social identities and the respective language and concepts that we use, the theories we draw from, and the academic practices we engage in construct (and enable) our understanding of the world. Furthermore, our research process was also shaped by our taken-for granted use of theoretical concepts and definitions, and the descriptions that we make about the subjects and events that we study. The purpose of reflexivity, then, is to unpack this in the way that the social and power relations of research are configured (Walby 2007, 1010). By practicing 'reflexivity of discomfort' (Pillow 2003), that is continuously questioning of the research process and the representations it produces, the processes of othering and marginalization become visible and accountable. This accountability refers to recognizing that the knowledge we produce is actively constructed by particular decisions and actions taken -- ones that we should take responsibility for (Rhodes 2009).

\section{Conclusion}

In this chapter we have explored the in situ construction and interpretation of the researchers' own ethnographic field notes. We have suggested that field notes can be illustrative examples of the ways in which social identities of the researchers and respective understandings and pre-assumptions have a bearing on what knowledge is produced and how. In particular, we have focused on the implications of two practices in constructing our own field notes: the selection and sense-making activities, and the textual practices of representation. Our study has shown that as the members of social groups such as business school researchers, we carry out fieldwork relying on the viable and acceptable ways of thinking, feeling, and doing in the contexts in which we operate.

Most importantly, however, we have illustrated how our earlier experiences from the field also produced more local and contextual pre-assumptions, which guided our expectations about what should happen when we continue with our field work. We have also illustrated how pre-assumptions leading social inclusion and exclusion with rather negative implications easily become reproduced on a continuous basis when we observe, take notes on, describe and analyse our research subjects - unless we practice reflexivity. Finally, because of the on-going nature of sense making and interpretation, we argue that ethnographers would benefit of practicing reflexivity throughout their research process, not only at certain points of it.

\section{References}

Ahl, H. (2002). The Making of the Female Entrepreneur. A Discourse Analysis of Research Texts on Women's Entrepreneurship. JIBS Dissertation Series No. 015, Jönköping.

Alvesson, M. \& Sköldberg, K. (2000). Reflexive Methodology: New Vistas for Qualitative Research. Sage, London.

Ashmore, M. (1989). The Reflexive Thesis. Writing Sociology of Scientific Knowledge. Chicago: The University of Chicago Press. 
Atkinson, P., Coffey, A., Delamont, S., Lofland, John \& Lofland, Lyn (2001). (eds.) Handbook of Ethnography. London: Sage.

Barter-Godfrey, S. \& Taket (2009) Othering, marginalisation and pathways to exclusion in health. In: Taket, A., Crisp, B., Nevill, A., Lamaro, G. Graham, M. \& Barter-Godfrey, S. (eds), Theorising social exclusion, pp. 166-172. Abingdon: Routledge.

Binns, J. (2008). The Ethics of Relational Leading: Gender Matters. Gender, Work and Organization, 15 (6), 600-620.

Bruni, A. \& Gherardi, S. \& Poggio, B. (2004a). Doing Gender, Doing Entrepreneurship: An Ethnographic Account of Intertwined Practices. Gender, Work and Organization, Vol. 11, No. 4, 406-429.

Bruni, A. \& Gherardi, S. \& Poggio, B. (2004b). Entrepreneur-mentality, gender and the study of women entrepreneurs. Journal of Organizational Change Management, 17 (3), 256-268.

Clifford, J. \& Marcus, G. (Eds.) (1986). Writing culture: The poetics and politics of ethnography. Berkeley, CA: University of California Press.

Coffey, A. (1999). The Ethnographic Self. Fieldwork and the Representation of Identity. London: Sage.

Daiski, I. \& Richards, E. (2007). Professional on the Sidelines: the Working Lives of Bedside Nurses and Elementary Core French Teachers. Gender, Work and Organization, 14 (3), 210-231.

Davies, C. (2008). Reflexive Ethnography. London: Routledge.

Down, S. (2006). Narratives of Enterprise: Crafting Entrepreneurial Self-Identity in a Small Firm. Cheltenham UK: Edward Elgar.

Down, S., Garrety, K. \& Badham, R. (2006). Fear and Loathing in the Field: Emotional Dissonance and Identity Work in Ethnographic Research. M@n@gement, 9 (3), 86107.

Emerson R., Fretz R. \& Shaw L. (1995). Writing Ethnographic Fieldnotes. Chicago: University of Chicago Press.

Ellemers, N., Spears, R. \& Doosje, B. (1999). Social identity: Context, content and commitment. Oxford: Blackwell.

Eriksson, P. \& Henttonen, E. \& Meriläinen, S. (2008a). Managerial work and gender Ethnography of cooperative relationships in small software companies. Scandinavian Journal of Management, Vol. 24, No. 4, 354-363.

Eriksson, P. \& Henttonen, E. \& Meriläinen, S. (2008b). Growth Strategies of Women Controlled SMEs: A Case Study of Finnish Software Companies, International Journal of Business Excellence, Vol. 1, No 4: 434-447.

Eriksson, P., Hearn, J., Henttonen, E., Hiillos M., Jyrkinen M., Katila S., Meriläinen S., Moisander, J., Niemi, H., Rolin, K., Tallberg, T. \& Vanhala, S. (eds.) (2005). Gender and Organizations in Flux? Hanken, Helsinki. Swedish School of Economics and Business Administration, Department of Management and Organisation, Management and Organisation. Research Reports 60.

Eriksson, P. \& Kovalainen, A. (2008). Qualitative Methods in Business Research. Los Angeles, London, New Delhi \& Singapore: Sage.

Etherington, K. (2006). Becoming a Reflexive Researcher. London and Philadelphia, Jessica Kingsley Publishers. 
Hardy, C. \& Phillips, N. \& Clegg, S. (2001). Reflexivity in organization and management theory: A study of the production of the research 'subject'. Human Relations. Vol. 54(5), 531-560.

Haslam, A. (2001). Psychology in Organizations - The Social Identity Approach. London, Sage Publications.

Henttonen, E. (2010). An Ethnographic Study on Women's Small ICT Businesses in Finland. Acta Universitatis Oeconomicae Helsingiensis, Series No A-371.

Henttonen, E., LaPointe, K., Pesonen, S. \& Vanhala, S. (forthcoming). A Stain on the White Uniform - Discursive Construction of Nurses' Industrial Action in the Media.

Hogg, M., Terry, D., \& White, K. (1995). A Tale of Two Theories: A Critical Comparison of Identity Theory with Social Identity Theory. Social Psychology Quarterly, 58, 255269.

Lynch, M. (2000). Against Reflexivity as an Academic Virtue and Source of Priviledged Knowledge. Theory, Culture \& Society. Vol. 17(3): 26-54.

Maton, K. (2003). Reflexivity, Relationism \& Research: Pierre Bordieu and the Epistemic Conditions of Social Scientific Knowledge. Space \& Culture, 6 (1), 52-65.

Pillow, W. (2003). Confession, catharsis, or cure? Rethinking the uses of reflexivity as methodological power in qualitative research. International Journal of Qualitative Studies in Education, 16 (2), 174-196.

Rhodes, C. (2009). After Reflexivity: Ethics, Freedom and the Writing of Organization Studies. Essai. Organization Studies, 30 (6), 653-672.

Rosaldo, R. (1993). Culture \& Truth: The Remaking of Social Analysis. Boston: Beacon.

Van Maanen, J. (1988). Tales of the Field: On Writing Ethnography. Chicago: University of Chicago Press.

Walby, K. (2007). On the Social Relations of Research: A Critical Assessment of Institutional Ethnography. Qualitative Inquiry, 13 (7), 1008-1030.

Woolgar, S. (1988). Reflexivity is the Ethnographer of the Text. In: Woolgar, S. (ed.) Knowledge and Reflexivity: New Frontiers in the Sociology of Knowledge. London, Sage, 14-34.

Wolcott, H. (1999). Ethnography: A Way of Seeing. Walnut Creek, CA: AltaMira Press. 


\section{Event Focused Fieldwork and Comparative Methodology: Exploring Ethnic Boundaries and Cultural Variation}

Gunnar Haaland

University of Bergen

Norway

"-more of our attention should be given to the contexts of the particulars, their embeddedness and linkages. That means learning from Bateson to "follow the loops" that links events together and that will give us leads in our search for connections and systems.---It puts pressure on us to adopt new categories as we go along, particularly from those we are living among, but also from our own accumulated experience" (Barth 1994: 352)

\section{Introduction}

The present paper deals with methodological problems involved in establishing the interconnection between the particular events of our field observations and their general significance in terms of causality and in terms of meanings. I shall discuss some aspects of this problem with reference to my own attempts to explore an important and hotly debated anthropological problem field, namely ethnicity. The main reference for the paper is material from my own fieldworks in different parts of the world (Darfur, Bangladesh, South East Asia and China). My argument starts with some general reflections on advantages and limitations of participant observation; on theoretical orientations as constituting a horizon of expectation (Popper, 1972: 346) influencing what we look for in the "world" we are exposed to, and what we "see" in the events of this "world"; on the way we can develop our horizon of expectations by the use of comparative ethnographic material; on variations in the factors that in particular social settings are salient in production of ethnic categorization; on looking at ethnicity not in terms of enduring holistic units, but in terms of something that happens among people; and on the importance of being sensitive to events that do not fit our preconceived horizon of expectations, of ideas, of theories, models, etc.

I see anthropological research as an unending quest directed towards development of more adequate understanding of our object of study that I understand to be interacting people. I shall make a short presentation of the state of the art in anthropology when I started my quest in the field of ethnicity. This is followed by analysis of my empirical cases from different ethnographic contexts, and concludes with the importance of comparative material as a source for reflecting back on my previous analyses. I have used my own field experiences in order to show how engagement with people in different 
interethnic situations has served as a source for my attempt to develop a generalized perspective on ethnicity. Although development of my perspectives on ethnicity has been influenced by my exposure to conceptual developments that have taken place in social science since the 1960ies, I will strongly emphasize that the main inspiration for my rethinking came from being exposed to events that did not fit the horizon of expectation I had come to entertain from the way I had managed to 'make sense' of ethnic processes in previous fieldworks.

The perspective I over time have developed is of course a provisional one, and the intention is that my representation of the analytical steps I make on my observations from different ethnographic contexts is sufficiently clear to be challenged with reference to comparative material from other ethnographic situations as well as with reference to theoretical coherence.

Fieldwork constitutes an essential part in the anthropological tradition of knowledge. Since the time of Malinowski anthropologists have emphasized the importance of participant observation. That one can learn a lot about a people's "culture" by living with people in their daily activity seems obvious, but what does one actually do in addition to hanging around and drinking local beer, occasionally taking a hoe and weeding a field, or being present at ceremonies? Furthermore what has one learnt about a people's "culture" and how does one represent this? To claim that immersion in village life is somehow like an osmotic process where the ethnographer acquires the "culture" of the people s/he studies like a child learns to understand and behave is part of anthropological mythology. It is naïve to imagine that participation is the key that opens the door into the world of values, knowledge, tacit meanings etc in terms of which members (old and young, men and women, occupational specialists etc) interact and shape the community the ethnographer is studying. As Obeyesekere has expressed it: "There is no way the anthropologist can, in any significant sense, participate in another culture. I doubt he can even when he is studying a segment of his own culture. --- Only naïve ethnographers identify with their subjects; but subjects rarely identify with the ethnographers, unless it is a key informant or interpreter locked in a personal relationship with the investigator. You are always the other, the alien; and even the most well-meaning investigator is a CIA agent for some" (Obeyesekere. 1990: 228).

We cannot pretend that our participation is not influenced by limitations imposed on us by members in the community we study, as well as by our preconceived horizon of expectation. Instead of despair of these limitations on total access to the cultural 'world' of the people studied, we should admit them, and rather search the opportunities participant observation offer for making unexpected and significant discoveries. The task we confront in our search for such conceptual filters is aptly expressed in Clifford Geertz' formulation "Believing with Max Weber, that man is an animal suspended in webs of significance he himself has spun" and that we take "culture to be those webs, and the analysis of it to be therefore not an experimental science in search of law but an interpretative in search of meaning" (Geertz, 1973: 5). Individual human beings can only act in the world if they have been able to spin webs of significance that provide them with workable mental "maps" of their social and natural environments, and workable instructions ("driving rules") for acting in these environments. Through participation in daily life one may be able learn fragments of the webs of significance people continuously are spinning. Grasping important aspects of 
the spinning process thus largely depend on our ability to follow 'loops' that connect events to meanings - 'loops' that lead us into the "world" of symbolic imagery current in the population.

However, people don't live only in a world of "meaning", they primarily live in a "world" where they depend on the impact of concrete objects (food, tools including technologies of communication, weapons etc) in terms of which they relate to each other. A major task in fieldwork is therefore also to discover the 'loops' of material causality (e.g. material flows mediated by the market, by political power, by eco-system dynamics) that connect events (whether known or unknown to the people engaged in them) in the "world". What happens among people thus has to be understood in contexts of cause-effect relations as well as in the contexts of meaning. Discovery of such 'loops' of meaning and causality is the main objective of our fieldwork, but how do we while participating in community life go about making observations that lead us into productive hypotheses about significant 'loops'? We do not possess any manual of accepted field methods that by application will lead us into them; we have to rely on our ability to make creative use of interests and orientations that we have acquired in our professional training. Long time back Karl Popper at a public lecture asked the audience to participate in a simple experiment: "My experiment consists of asking you to observe, here and now. ---However, I hope some of you, instead of observing, will feel a strong urge to ask: 'What to observe?' ---For what I am trying to illustrate is that in order to observe, we must have in mind a definite question which we might be able to decide by observation." (Popper, 1972: 259). The problem is that our professional training may serve to focus our observations on things and events that already are generally known. Thomas Kuhn has argued that normal science can be characterized as kind of puzzle solving where theoretical frameworks (paradigms) serve to formulate definite research questions that can be answered by accepted observational techniques: "The man who is striving to solve a problem defined by existing knowledge and technique is not just looking around. He knows what he wants to achieve, and he designs his instruments and directs his thoughts accordingly" (Kuhn, 1976: 96). In other words, puzzle-solving research does not aim at discovery of the unexpected, but rather document what the theoretical framework leads one to expect will be the case. Recently Peter Berger has lamented the disease of methodological fetishism that sociology (including much of anthropology) is suffering from: "There is nothing wrong with quantitative methods in themselves, and they can be useful, but because of the interests of those willing to fund the expensive budgets of survey research, the result is often increasingly sophisticated methods to explore increasingly trivial topics" (Berger, 2011: 8)

The practice of good ethnography in many ways differs from Kuhn's view of normal science, and Berger's methodological fetishism. Before going to the field most anthropologists have worked out a broad perspective on an empirical problem field they have reasons to believe is big enough to be worth investigating, accompanied by some sketchy reflections on the methods they are planning to use in order to provide answers to their research questions. However, the important thing is that it is not preconceived methods that should decide the problem to be investigated, but rather the problems that arise our curiosity in the field that should decide the methods we adopt to explore them. In contrast to normal science it is most anthropologists' ambition to discover something that is unexpected; not only documentation of features that was unknown in the anthropological community, but most importantly something that challenges pre-conceived "theoretical" 
perspectives on our understanding of general properties of the socio-cultural "reality", something that changes our horizon of expectations. Here I have drawn inspiration from Walter and Vayda's argument for curiosity driven research where "Models and theories learned beforehand should be seen as potential aids for drawing alternative working hypotheses to interpret findings of interest. In this array of theoretical tools at one's disposal, the better, but researchers in the field should strive to be open and willing to adapt to findings that are surprising or contrary to expectations and they should resist the temptation to jump uncritically to conclusions when observations appear initially to conform to such expectation (Walters \& Vayda, 2009: 544)

By exploring the particulars we have an opportunity to discover something new of general significance. Barth has advocated that we in our exploration "take a cue from Darwin. His strategy was to focus, in the tradition of the wondering naturalist, on small parts of the picture, closely observed and revealingly interpreted. He did not reach directly for the overall pattern in a myriad of forms, or the general shape and direction of phylogenies. Whether in the courting display of golden pheasants (Darwin 1871: 728) or the relations of beak form, environment, and feeding habits of Galapagos finches (Darwin 1843: 373) he looked for the generalizable features in the particular situation which might be give cumulative direction to small increments of change. In other words, he sought to extract generalizable mechanisms and processes from his particulars." (Barth, 1987: 24).

My fascination with cultural variation and the way this was related to ethnic categorization involved me in an unending tagging between immersion in the particulars of peoples' daily life, and theorizing about generalizable mechanisms underlying observed variations in time and space. Experiences from fieldwork in diverse ethnographic contexts alerted me to the importance of reflecting back on observations I had made in one community in light of comparative material from other communities.

By stepwise presenting analyses of ethnic processes from various parts of the world, I shall try to show how comparison may serve to broaden our perspective on ethnicity.

\section{Anthropological perspectives on ethnic groups and cultural variation in the 1960ies}

"Science never starts from scratch; it can never be described as free from assumptions; for at every instant it pre-supposes a horizon of expectations - yesterday's horizon of expectations as it were. Today's science is built upon yesterday's science --; and yesterday's science, in turn, is based on the science of the day before. And the oldest scientific theories are built on pre-scientific myths, and these in turn on still older expectations." (Popper 1972 pp 346-347).

When I started my anthropological career in the early 1960ies the relationship between 'culture' and 'society' was among most anthropologists generally seen as unproblematic. In the structural-functional tradition of Durkheim this relationship was not considered problematic. In Radcliffe-Brown's words: “I wish only to deal with one part of Durkheim's work, namely his theory that religious ritual is an expression of the unity of society and that its function is to 're-create' the society or the social order by reaffirming and strengthening the sentiments on which the social solidarity and therefore the social order itself depends" (Radcliffe-Brown, 1961: 165). Society was assumed to be analogous to biological organisms, and research was oriented towards the way various socio-cultural 
components contributed to maintenance of the 'social solidarity'. "Continuity and change in the forms of social life being the subjects of investigation of comparative sociology, the continuity of cultural traditions and changes in those traditions are amongst the things to be taken into account" (Radliffe-Brown, 1961: 5). The focus of research was on relations 'within' groups (e.g. 'tribes'), not on the way cultural and social forms were shaped by relations between groups. In USA Everett Hughes in 1948 formulated an important perspective that drew attention to the importance of seeing different groups in relation to each other: "An ethnic group is not one because of the degree of measurable or observable difference from other groups: it is an ethnic group, on the contrary, because both the ins and the outs talk, feel, and act as if it were a separate group. This is possible only if there are ways of telling who belongs to the group and who does not, and if a person learns early, deeply, and usually irrevocably to what group he belongs" (Hughes,/1948/1994/: 91) Stimulated by Pitirim Sorokin and Talcott Parsons, Geertz distinguished between culture and social system with reference to the different kind of integration that characterize each of them: Culture is characterized by "logico-meaningful integration", i.e. "the sort of integration one finds in a Bach fugue, in Catholic dogma, or in the general theory of relativity; it is in integration of style, of logical implication, of meaning and value. By causal-functional integration, characteristic of the social system is meant the kind of integration one finds in an organism, where all the parts are united in a single causal web; each part is an element in a reverberating causal ring which "keeps the system going. And because these two types of integration are not identical, because the particular form one of them takes does not directly imply the form the other will take there is an inherent incongruity and tension between the two-." (Geertz, /1959/ 1973:145). Geertz' perspective implies a somewhat more dynamic view on the relation between 'culture' and 'society', but it hardly takes up the processes involved in this dynamic relationship. With the growing interests in the so-called new states, anthropologists started to pay more attention to the problem of integration of culturally different groups within states. "A more exact phrasing of the nature of the problem involved here is that, considered as societies, the new states are abnormally susceptible to serious disaffection based on primordial attachments. By a primordial attachment is meant one that stems from the "givens" - or more precisely, as culture is inevitably involved in such matters, the assumed "givens" - of social existence: immediate contiguity and kin connection mainly, but beyond them the givenness that stems from being borne into a particular religious community, speaking a particular language, or even a dialect of a language, and following particular practices." (Geertz, 1963: 109). These are important comments that draw attention to the possible conflicts between citizens' primary identification with the state and their attachment to smaller culturally different groups within the state. However the processes by which peoples' embracement of cultural features were made relevant in political contexts were left largely unexplored.

Meanwhile, interesting developments were taking place in various departments in England. The Manchester school headed by Max Gluckman produced a range of publications that showed the importance of studying local communities in their relation to wider political and economic environments (Gluckman 1956, Gluckman 1958, Gluckman 1963, Epstein1958). One of the most important contributions to the study of processes affecting cultural hybridization under colonial rule was a small pamphlet by Clyde Mitchell called the 'Kalela Dance': "-the set of relationships among a group of tribesmen in their rural home is 
something very different from the set of relationships among the same group when they are transposed to an urban area. In the rural area the relationships of the members form part of a complete tribal system.--- In the towns the pattern of the social system is determined largely by the industrial system which forms the basis of their existence, and by the laws which the Government has enacted to regulate the life of the town dwellers. As cities have developed on the basis of industrial production the pecuniary nexus which implies the purchasability of services and things has displaced personal relations as the basis of associations. Individuality under these circumstances must be replaced by categories" (Mitchell, 1956:44).

Some of the most important challenges to received wisdom on ethnicity were stimulated by South east Asian ethnography. Moerman working among the Lue of Thailand could not identify any set of criteria by which he could define who was a Lue: "Since language, culture, political organization, etc., do not correlate completely, the units delimited by one criterion do not coincide with the units delimited by another" (Moerman, 1965: 1215). He concluded that a person was a Lue "by virtue of believing and calling himself Lue and of acting in ways that validate his Lueness" (Moerman, 1965: 1219). Probably the most influential publication that came out of South east Asian ethnography and which articulated a dynamic perspective on the relationship between group organization and identification on the one hand and cultural content on the other was Edmund Leach's book 'Political Systems of Highland Burma'. Writing about relationships between different groups associated with different cultural traditions (e.g. the Shan speaking dialects of Thai language, practicing wet rice cultivation, embracing Buddhism, and being organized in state-like political units, while the Kachins were speaking Tibeto-Burmese languages and being organized in fluctuating political units ranging from those based on the gumsa ideology of hierarchical ranking and those based on the gumlao ideology of anarchic equality) Leach claims "that Kachins themselves tend to think of the difference between gumsa and gumlao and Shan as being differences of the same general kind. Further they recognize that these differences are not absolute - individuals may change from one category into another ---Kachins think of the difference between Shan and gumsa Kachin as being a difference of ideal, and not, as the ethnologist would have us believe, a difference of ethnic, cultural or racial type." (Leach, 1954: 285 -286).

Contributions like this were intensely discussed in the Department of Social Anthropology in Bergen when I prepared for my first fieldwork in the early 1960ies. Fredrik Barth who brought inspirations from his studies in Chicago and Cambridge had founded this department. He was more influenced by the Weberian tradition than by the Durkheiman tradition that had dominated anthropological departments in England. The way Barth developed his analytical conceptualization of ethnic boundaries is in many ways similar to Weber's perspective: "We shall call "ethnic groups" those human groups that entertain a subjective belief in their common descent because of similarities of physical type or customs or both, or because of memories of colonization and migration; this belief must be important for the propagation of group formation; conversely, it does not matter whether or not an objective blood relationship exists. Ethnic membership (Gemeinsamkeit) differs from the kinship group precisely by being a presumed identity, not a group with concrete social action, like the latter. In our sense, ethnic membership does not constitute a group; it only facilitate group formation of any kind, particularly in 
in the political sphere" (Weber, 1978: 389) Barth had already made several important contributions to the study of ethnic processes (Barth 1956, 1963 and Barth 1964). In these studies Barth elaborated on the way ethnic group structures were related to intergroup relations of competition, cooperation and symbiosis, as well as like Leach had done, showing that ethnic groups might persist despite a substantial mobility of personnel between them.

Although I participated in discussion on ethnicity when I prepared for fieldwork, my primary interest at that time was more oriented towards the economic dimension of social life. I had in 1965 been accepted as field assistant for Fredrik Barth in a FAO regional development project in Darfur. Barth had just circulated a draft of his article "Economic spheres in Darfur" and this was a stimulating introduction to Fur economy (Barth, 1967). Although my main task was to follow up Barth's earlier research on economic anthropology, I was encouraged to pursue a conventional type of ethnographic fieldwork participating in daily activities, and documenting various dimensions of the world I was exposed to in Darfur. Instead of letting 'methods' decide the problems I took up, it should be the problems I discovered that should decide the kind of methods I applied. Barth's position was in many ways similar to what Wright-Mills had expressed: "We should be as accurate as we are able to be in our work upon problems that concern us. But no method, as such, should be used to delimit the problems we take up, if for no other reason that the most interesting and difficult issues of method usually begin where established techniques do not apply" (Wright Mills, 1973: 83).

\section{Exposure to unexpected events and discovering 'loops' structuring ethnic processes in Darfur}

"The truth of the matter is this: both sociological historians and social anthropologists are fully aware that any event has the characters of uniqueness and generality, and that in an interpretation of it both have to be given consideration" (Evans-Pritchard 1972: 175).

When I arrived in Sudan in 1965 my main task was to collect data on the social and cultural features relevant for formulation of a regional development plan in western Darfur. Barth had done his fieldwork in the culturally homogeneous Fur area in the Jebel Marra mountain, while I worked in the environmentally different areas of the western lowlands towards the Chadian border. This work involved studies of the two main groups that used the area - the Fur farmers and the Baggara Arab pastoralists who migrated into the project area in the dry season after the Fur had harvested their fields. A most visible feature characterizing the two groups was housing and settlement pattern; the Fur living in straw huts in compact villages, while the Baggara were living in straw-matted tents in migratory camps. The two groups were associated with contrasting cultural traditions; e.g. in terms of language (the Fur speaking a language of the Nilo Saharan language family while the Baggara speaking Arabic); in principles of household organization (the Fur spouses generally operating as individual management units, while the Baggara operating as family based management units); in values and symbolic expressions (both Fur and Baggara were Muslims but the Fur practiced a range of rituals not connected with Arab cultural traditions). From my earlier reading of Herskovits (Herskovits, 1926) I assumed that we here had an example of a contrast between pastoralists with a so-called cattle complex (strong emphasis of cattle rearing and the lifestyle associated with it) and cultivators with a cultural emphasis on village life. 
One day when I went to interview people in a "Baggara camp" I was greatly surprised when I heard them speak Fur instead of Arabic. My first reaction to the observed events was to explore whether this was a unique case or whether it represented more widespread phenomenon. From a simple survey of a sample of villages I found that every year about $1 \%$ of sedentary Fur cultivators left the village and established themselves in migratory camps living like the Baggara and in many respects behaving like them. Furthermore many of them actually migrated to Baggara areas in the rainy season and some even lived in mixed camps with Baggara Arabs.

This puzzled me. My initial hypothesis was that maybe the Fur also had strong cultural preference (cattle complex) for a pastoral style of life, but that economic and ecological circumstances forced them to live as farmers. However I did not find any evidence for this, neither in inteviews nor in any symbolic expressions like rituals and songs. On the contrary it was a sedentary life-style that was culturally emphasized. This negative evidence for cultural determinants behind the observed events of Fur nomadization, took me back to what was supposed to be the focus of my research namely economic processes. No matter what the cultural importance of cattle was, they represented a form of value that was accumulated through inheritance, bridewealth and most importantly through investments. That led me to the investment 'loop' and the question of why the Fur invested in cattle. The reason seemed simple; land in the Fur lowlands was communal and investment opportunities in shifting agriculture were therefore limited, while cattle on the other hand was private and provided an investment opportunity with growth potential (animals breed animals). The next question was why did so many Fur establish themselves in camps instead of keeping the cattle in the village. This led into exploring the ecological 'loop'. On the clay soils of the western lowlands there was a high risk of cattle diseases during the rainy season. The chances of success were increased if the cattle could be brought out of the cultivating areas and into less disease prone areas. That some Fur changed from successful sedentary cultivators to nomadic herdsmen I thus 'explained' as a consequence of structural features of Fur economy and of ecological variations in the larger Darfur region. But why did the nomadized Fur start behaving like the Baggara? While pondering on that I discovered that both Fur and Baggara took migratory cattle husbandry as a marker of Baggara identity and sanctioned those who practiced it according to cultural standards of evaluation current among the Baggara. This was of course particularly important for the really successful Fur cattle herders who sought access to the environmentally most favourable Baggara tribal areas in Southern Darfur. To a large extent such access was a matter of political assimilation in a Baggara camp community.

In 1967 I presented my Darfur material in a symposium Barth organized in Bergen on ethnic processes. The anthropological position at the time with regard to the study of ethnicity was roughly as follows: Ethnic groups were carriers of its own integrated culture. How social groups maintained themselves over time in contact with other groups had not been paid much attention to, neither was the question of the impact of circulation of cultural ideas and of personnel between different groups. My observations made it necessary to pay attention to these issues. In the introduction to the symposium Barth emphasized that the exploration of ethnic groups should focus on "--self-ascription and ascription by others. A categorical ascription is an ethnic ascription when it classifies a person in terms of his basic, most general identity, presumptively determined by his origin and background" (Barth, 1969: 13). 
Presumptions of common origin and background are associated with the idea that similarity is based on the assumption of sharing important cultural features making "my" group different from other "they" groups. The point is not that ethnic groups were different because they were "carriers" of different integrated "wholes" of cultural inventory. From this perspective the important dimension of ethnicity is not the total inventory of cultural features current in particular groups, but only those that are made relevant for interaction between members of dichotomized groups. Such features are basically of two orders: "(i) overt signals or signs - the diacritical features that people look for and exhibit to show identity, often such features as dress, language, house-form, or general style of life, and (ii) basic value orientations: the standards of morality and excellence by which performance is judged. Since belonging to an ethnic category implies being a certain kind of person, having that basic identity, it also implies a claim to be judged, and to judge oneself, by those standards that are relevant to that identity" (Barth, 1969: 14). Which cultural features people in particular inter-ethnic contexts emphasize and make relevant for interaction has to be discovered. In some cases they may regulate interaction in many sectors of activities, in others in just a few sectors. Maintenance of dichotomized ethnic groups depended on maintenance of interactions boundaries. As long as such ethnic interaction boundaries restrict interaction in certain sectors of activity (e.g. family and marriage, ritual, occupation) cultural differences may be maintained in these sectors, while interaction in other sectors not structured by ethnic dichotomization of activity leads to diffusion of cultural inventory between groups.

The different case material presented by participants in the symposium clearly indicated that ethnic groups might persist as distinct social units a) despite close contact and exchange of goods and services between them; b) despite a certain amount of cultural diffusion; and c) a substantial amount of flow of personnel between them. My material of nomadized Fur constituted a puzzle. On the one hand their interaction in the first camps I observed was to a large extent structured by Fur cultural ideas, while on the other hand they were judged and sanctioned both by other Fur and Baggara according to standards of evaluation according to which Baggaras were judged. Admittedly Baggaras as well as Fur villagers considered their performance according to these criteria rather mediocre. The important thing, however, is that social sanctions expressed in such evaluations stimulated them to learn Baggara culture and act like Baggaras. I thus argued that change to migratory cattle husbandry implied a change of ethnic identity, despite the fact that initially those Fur who made that change in terms of cultural features shared more with their sedentary Fur relatives. The longer a Fur managed to operate as a migratory cattle herder and the closer he had been assimilated in Baggara tribal units, the more competent he became in acting as a Baggara. In local Fur village genealogies such successful Fur nomads are manifested in disappearing lines.

My material of nomadized Fur raised further questions. Why did the Baggara tribes apparently so easily admit Fur nomads to their rainy season pasture areas? An important basis for this is personal inter-ethnic relationships that have been forged during the dry season when Fur farmers allow Baggara nomads to let their cattle graze on the sorghum stubble and eat the nutritious pods of the Acasia Albida trees growing on the Fur farmers fields. Frequently these relationships also involved herding contracts where the Baggara took the Fur farmer's cattle to the Baggara rainy season area. Such individual relations were important, but if the number of pastoralists exploiting the Baggara dry season grazing areas 
were increased by assimilation of nomadized Fur, one would expect that this would increase pressure on pasture and possible overgrazing in these areas. This led me on to an interesting macro-level demographic/ecological 'loop' - nomadization of Fur farmers reduced pressure on agricultural land in the Fur area while it potentially might increase competition for pasture in the Baggara areas. By consulting demographic surveys and medical reports on the Baggara it seemed that the Baggara were hardly able to reproduce themselves and that this was probably related to the prevalence of venereal diseases (El Hadi al Nagar \& Taha Bashar, 1962; Rushdi Henin, 1969), in other words nomadization of Fur farmers served to replenish the Baggara as an ethnic group.

The book we published, "Ethnic Groups and Boundaries" (Barth, 1969) has been widely read by anthropologists as well as sociologists, political scientists, archaeologists and historians, and for several years it ended up on the top 100 on the social science citation index. It has played a major role in the scholarly debate about ethnicity, a debate that has developed our perspectives further. One point in the debate has focused on the rather muddled issue of instrumental management versus primordial attachments.

Is ethnicity to be understood as something primordial with long historical roots that nurture deep-lying cultural values fostering identification with a specific ethnic group or as something related to opportunistic instrumentality? Those who emphasize primordiality frequently refer to Geertz' and his arguments that "congruities of blood, speech, custom, and so on, are seen as to have an ineffable, and at times overpowering, coerciveness in and of themselves" (Geertz, 1963: 109) In my field observations I was not struck by the importance of such features in the ethnic processes I observed. I must admit that I during my first fieldwork in Darfur in 1965 became biased towards an instrumental position because the reasons why Fur farmers started to behave like Baggara Arabs seemed to be dominated by economic benefits following from accumulation of cattle, by the ecological advantages of migration, and by the political importance of behaving like Baggara because it facilitated political inclusion in a Baggara group.

Looking back at those who criticize Barth's position as instrumental I think that many of them are overlooking a phrase in Geertz' formulation, namely "assumed givens" of social existence. The question is who assumes and why. Primordial attachments are social constructions, and in order to understand their relation to specific identities, we have to explore the metaphoric imagery that makes ethnic ties convincing and compelling. e.g. imagery of "birth", "blood", “earth".

Maybe because of my instrumental bias I did not see the relevance of observations I already had made in the field of symbolism and ritual and its relevance for understanding why so little seemed to be at stake in Fur identity change. It was only after I had been exposed to field experiences in different ethnographic contexts that the relevance of this material became more clear to me, not only with reference to its importance for commitment to Fur identity, but also with reference to a range of other conditions that were relevant for understanding ethnic processes in Darfur. Some are quantitative causal relations and can be counted; others (e.g. values and juridical rules) are qualitative and have to be interpreted. The problem is that there are neither methods that lead us to 'correct' interpretations of meanings, nor methods that automatically tell us what to measure. The 'loops' that connect actions to qualitative meanings as well as to quantitative cause-effect connections have be discovered. I have argued that this requires 
creative imaginative thinking, but not arbitrary intuition, but intuition stimulated by theoretical insights from a variety of approaches, as well as from familiarity with comparative material (through reading or from own fieldwork) of comparative ethnographic material. In the model I constructed of ethnic processes in Darfur I tried to identify different 'loops' and how they linked up to produce patterns in individual identity change and in aggregate demographic balances between groups. An essential part in the development of my model was to search for comparative cases that could challenge the conditional hypothesis of my model.

\section{Comparison of variations as discovery procedure}

"Science is a procedure for testing and rejecting hypotheses, not a compendium of certain knowledge" (Gould: 1972: 111)

The hypothesis I developed from my fieldwork among Fur in a particular part of Darfur (the western lowlands) I tried to test by doing fieldwork among Fur living under different conditions. I searched for cases where investment opportunities were different. I found such areas in the western foothills of Jebel Marra where there were perennial streams allowing for permanent irrigated cultivation of cash crops. Irrigated land is codified as private land and can be transacted for cash. In villages with irrigated agriculture I did not find a single case of nomadization, on the contrary I found that former Fur migratory herdsmen had sold cattle in order to invest in irrigated land. This corroborated my provisional hypothesis. Secondly, I searched for Fur communities in environments that allowed for a combination of cultivation and cattle rearing. This I found in the drier areas of Jebel Si in the northern part of the Fur area. The economic structure was essentially similar to what I had observed in other Fur communities and I also here found that cattle was a preferred investment object, but here Fur villagers kept their cattle close to villages in the rainy season and only engaged in short migrations in search of water during the dry season. Here the cattle owning Fur encounter the Zaghawa, a different ethnic group in an overlapping niche, which implies a certain amount of competition between the two. Competition thus restricts Fur cattle herders' movements and assimilation as Zaghawa. This synchronic comparison of ethnic processes in space corroborated the hypothesis I developed on the basis of material from the western lowland and showed that variations in ethnic processes within the Fur area could be understood as variations in a few underlying factors, i.e. investment opportunities, natural environment and the politics of interethnic relations (Haaland, 1972).

Diachronic comparison of case material I collected during fieldworks in the 1970ies and 1980ies showed dramatic changes in ethnic processes in Darfur. My search for factors behind these changes led me to changes of flows in 'loops' I discovered in my earlier work, primarily demographic processes and ecological balances; as well as into new 'loops' connected with the national and international market for livestock products and politicoadministrative power structure, etc. In 1973 the importance of several of these macro-level conditions became blatantly clear when I did fieldwork in Southern Darfur. This region is mainly a Baggara controlled area. Survey data showed that better health and veterinary services had led to growth in human and animal populations. These changes increased competition for pasture, primarily among different Baggara tribes. This was manifested in higher frequencies of raiding events, and most importantly in increasing construction of 
village enclosures reserving pastures for dry season grazing. Ecologically this had the advantage of establishing a primitive regime of rotational grazing, but it had the possible disadvantage of blocking migratory routes for nomads practicing long distance migrations. (Haaland, 1982).

In 1986 the symbiotic relationship that traditionally had existed between the Baggara Arabs and the Fur farmers had changed. With increasing pressure on pasture, the Baggara herders had become less interested in assimilating Fur livestock owners and tried to prevent migrations of nomadized Fur into the Baggara areas in the rainy season. The Fur reacted by preventing Baggaras moving into their areas in dry season. The Kalashnikovs started to speak. Today the border area between the Beni Helba (a Baggara tribe that used to have close symbiotic relations with the Fur) and Fur is one of the most contested areas.

Since 2003 this conflict has lead to atrocities that are among the worst in Africa. The events that had unfolded since my first visit in 1965 opened my eyes to the importance of globalizing 'loops' in understanding the position of the Baggara pastoralists in Darfur. I had in my early research mainly focused on local level 'loops' and had overlooked the importance of the fact that the Baggara for centuries had participated in ideological and political interaction systems of global scale, interaction systems that had changed over time but always served as a factor in the way the local pastoral "game" was played.

As 'players' in the Darfur 'game' the Baggara are not only positioned with reference to livestock ownership and access to pasture and water resources, but also with reference to sources of support based on their participation in the nationwide Muslim Ansar movement and its affiliated party, the Umma. In this complex 'game' the present Muslim Brotherhood supported by the Government of Omar el Bashir has played the dangerous "card" of arming local militias recruited from Arab nomadic groups (including the Baggara). This move has to be understood in the context of the newly discovered oil resources and the international support the Sudan Government gets from China as a counter-prestation for Chinas privileged access to the oil (Haaland, 2006).

The diachronic comparison showed that the ethnic boundary between Fur and Baggara over a 20 years period had changed dramatically with far-reaching consequences for individual change of ethnic identity. Furthermore, people that identified themselves as Fur were not only cultivators, an increasing number of them had for a certain period of their life been labour migrants to the irrigated schemes along the Nile and industrial factories in Khartoum. There they harvested experiences of ethnic interaction boundaries very different from those in Darfur. Assimilation into the dominant Arab groups along the Nile was hardly a realistic option and the ethnic stratification between Arabs and Fur was a dominant experience in Fur migrants' everyday life. The emergence of Fur "clubs" where Fur migrants established a forum for discourse on their position in the larger Sudan society and in particular to the Arab elite.

Another important factor was the increase of Fur with secondary school and university education. One would expect that their command Arab 'culture' would stimulate them to identify with the dominant Central Sudanese Arab elite. Many of them also made that choice, even to the extent of speaking Arabic instead of Fur to their children. Others however chose to articulate and cultivate Fur identity in ways that surprised me on the 
background of my early village fieldwork. My interpretation is that this was partly related to the importance of mobilizing Fur support in the national political game, and partly of frustrations experienced in attempts to being assimilated in the commercial and administrative Arab elite in Darfur (Haaland, 1978).

By systematically searching for diversity and variation in cases of ethnic relations, I tried to discover causal and symbolic loops that connected events with significant consequences for the organization of ethnic boundaries and for the distribution of cultural content. As I have tried to show these boundaries varied in space and time, and with that the cultural features distributed among differently positioned people who identify themselves as Fur.

Comparison of variations in Darfur cases led to modifications and elaborations of my understanding of ethnic processes in the region. Apparently, my analysis of the specific Darfur material brought out some general mechanisms that anthropologists working in different ethnographic contexts have found useful. However, over the years after I had done fieldwork in different parts of the world, I have become aware of dimensions of ethnic processes that I had overlooked in my Darfur work because they were not salient there. I shall try to develop this point by discussing how my exposure to comparative cases have affected not only my understanding of ethnic processes generally, but also how it has stimulated me to look back on my Darfur material in new ways. I shall not deal with comparison in a strict sense of comparing 'societies' analogous to anatomists' comparison of organisms, but comparison as source for discovery of different dimensions of the general problem field I am concerned with here, namely the relationship between ethnic identity and distribution of cultural features. Although I here shall focus on the way my comparative reflections were influenced by questions that arose from the different empirical 'worlds' I was confronted with, I was of course also alerted to points that had been articulated in the 'flood' of works on ethnicity that followed the publication of "Ethnic Groups and Boundaries".

\section{The Santals of the Indian sub-continent and primordial constructions}

Primordialism is the affective counterpart of the inherent birth associated nature of axiomatic identities. --- Moreover, primordialism is not a unique feature of translocal identities either; what is unique to them is the difficulty of creating and maintaining such ideas and feelings." (Obeyesekere 1995:232)

My instrumental bias was challenged when I 1979 did fieldwork in a very different multiethnic setting, primarily in Dinajpur of northern Bangladesh, but also with shorter work in Bihar and Orissa in India. This was very different from Darfur; in Dinajpur, Bengali Muslims constituted the overwhelming majority (75\%), with a minority of Bengali Hindus (24\%) and a small minority called Santal, speaking a language of the Austro-asiatic language family. Given my Darfur experience ethnic relations came to fascinate me, particularly the position of the Santals; they spoke a language unrelated to Bengali; they had their own religious practices, different consumption patterns (including pork); they were recognizable in their dress as well as in their ways of comporting themselves in public space; and they were clearly stigmatized in the larger society by Muslims as well as by Hindus. With my previous experiences from Sudan I started by searching for cases of Santals who had 
changed their identity because I thought this would be instrumentally rewarding, but what I found was rather insignificant.

Then I looked for their economic position to explore limitations in access to resources. Yes, they were to a large extent landless wage labourers, sharecroppers or very small landowners, but so were many Muslims and Hindus and these groups avoided the public stigmatization the Santals were exposed to. In fact the Santals did not seem to hide cultural idioms that clearly showed their identity in a social environment where this exposed them to prejudices and certainly was a handicap in court cases, particularly cases involving land transfers.

Since my search for material instrumentality was negative I searched in a different direction, namely symbolic expressions that might foster commitment to Santal identity. This led me into a rich symbolism found in seasonal and life cycle rites; in folk songs, proverbs, stories; in ideas of sacralization of features of the house and the natural landscape; and in origin myths expressing important rules of organizing relations among humans as well as the expressing the Santal vision of the good life. This vision is summed up in their concept raska (pleasure); which they experience in festivals, in mixed dancing, and in consumption of rice beer (handi). This view contrasts sharply with what is found in Islam as well as in Hinduism.

Conditions (droughts, floods, political harassment, diseases, economic losses) that deprive the Santals of enjoying raska lead to $d u k h$ (suffering). Whatever the objective causes are, the Santals place their experience of suffering in a cosmological framework of bonga (spirit) interference. In this cosmology, experiences of daily life are seen as being caused by or having consequences in their supernatural world of bonga spirits (Haaland, 1991). A rich corpus of traditions (hapramko ak dustur) recited on many ceremonial occasions expresses and indoctrinates the connections between bonga spirits and Santal personal identity. The bonga cosmology mirrors, in many respects, the social world of the Santals, serving to mark off important social boundaries, as well as to express dilemmas in Santal interpersonal relations. Santal acts that defile (bhond) the bongas are particularly important because they may pollute social units of different scale from household to kinship groups and local communities. The Santal observations alerted me to how processes internal to Santal communities played an important role fostering individuals' commitment to the kind of personhood implied in Santal identity in the multi-ethnic world Santals inhabit.

The strength of these symbolic expressions is manifested in the fact that today there are probably around $6-8$ million Santals living in small pockets among different majority people scattered over an enormous area covering Bihar, Orissa and West Bengal in India, several districts in Northern Bangladesh and the eastern lowlands of Nepal. There is no Santal wide organization uniting all the small pockets of Santal households, although networks of kinship and marriage serve as a channel of communication between them.

In order to further grasp the varying ways Santal identities are maintained in these scattered localities, processes internal to Santal communities must also be placed in the context of rules regulating interaction with other ethnic groups. In India caste ideology is the most important factor regulating the Santals interaction with different Hindu castes (jati) and from an organizational point of view the Santals fit into the encompassing Hindu society as 
a particular jati, although their cultural construction of personhood is based on bonga cosmology, not Hindu religious ideas. The pressures, particularly from the Arya Samaj movement on the Santals to adopt Hindu ideology and ritual practices are strong, and have in some Santal communities had an impact.

In the Muslim environment of Bangladesh the conversion to Islam was a realistic possibility and in the encompassing Muslim society a convert is definitely a different person from a non-converted Santal. In contrast to the Hindu ideological emphasis on ritual hierarchy, Islam strongly emphasises equality among the believers. Despite this I got the impression that Santals expressed closer affinity with Hindus. Given the politico-economic costs incurred by maintaining Santal identity it was puzzling for me that I found so few Santals who had converted to Islam (one woman had married a Muslim, and one man had embraced Islam and had become a maulana after several years studies at an Islamic school). Maintenance of Santal identity in the Bangladeshi Muslim environment indicates that reproduction of ethnic boundaries cannot be satisfactory explained only by focusing on the encompassing society's restrictions on assimilation, it also have to take into consideration the way cultural features fostering active embracement of Santal identity were expressed in sectors of activity (family and ritual) excluding non-Santals.

However the bonga ideology and the ritual/ceremonial institutions that played such an important role in fostering commitment to Santal identity is affected by processes of different kinds. With the Santals comparatively weak development of skills and organizational frameworks relevant in competition with other groups in larger national economic and political contexts they definitely has a handicap, particularly in competition for land. With demographic growth an increasing number of Santals are seeking urban employment (e.g. in the Tata steel mills in Jamshedpur in India) or attach themselves as landless labourers to Hindu or Muslim landowners. As Santals are increasingly drawn into the national society, the strategies of the educated Santal elites are of crucial importance for maintenance of ethnic boundaries as well as distribution of cultural features. Various Christian Missions have dominated education among the Santals and have succeeded in converting a substantial number. M. Orans has argued that one of the reasons for acceptance of Christianity among the Santals elite is related to their search for an alternative high tradition comparable to Hinduism and Islam (Orans, 1965). The consequence of the spread of Christianity is that important premises (bonga cosmology) in Santal culture is discontinued and replaced by a dramatically different worldview. This cultural change does however not imply that ethnic boundaries between Santals and other ethnic groups are discontinued, although it leads to dramatic differences in cultural traditions (bonga cosmology versus Chistianity), a difference that potentially may lead to ethnic differentiation within the Santals. In Bangladesh there is however some evidence for attempts to organise a campaign directed towards reconversion of Christian Santals to bonga cosmology.

The salient points that my fieldwork among the Santals brought out was a) primordial attachments don't exist by themselves, but are reproduced in continuous acts of institutionalized ritual communication; b) the institutions of ritual communication changes with changes in the politico-economic context of the interethnic situation; c) politicoeconomic changes may create a space for articulating alternative 'cultural messages' (e.g. Christianity) that may make cultural premises expressed in so-called primordial attachments less convincing. 


\section{The Nepalese of South East Asia and symbolic entrepreneurship}

"--metaphor conceived as a pervasive mode of understanding by which we project patterns from one domain of experience in order to structure another domain of a different kind. -- Through metaphor we make use of patterns that obtain in our physical experience to organize our more abstract understanding" (Johnson, 1987: xiv-xv)

My Santal experience had drawn my attention not only to the fact that so-called primordial attachments were reproduced and changed in daily events of cultural constructions. However, I had hardly any observations on the 'cultural constructors' who were most active in such construction processes, and on their search for metaphoric imageries that expressed and fostered ideas of belonging to a particular group. During fieldwork among garment traders in tourist resorts in Southern Thailand I was surprised when I discovered that most of them were Nepalese.

This triggered my curiosity: Why had so many Nepalese ended up as garment traders in a tourist resort in Thailand. To explore this I followed Vayda's advice on progressive contextualization (Vayda 1983) and tried to search for linkages that connected the Nepalese garment traders to other events - outwards in space and backwards in time (Haaland, 2008). From a small survey I found that most of them had not come from Nepal but from the Shan state of Northern Myanmar, and I decided to explore the Myanmar connection and went to Myitchina district. From interviews there I found that the earliest group were Gurkha soldiers from the British Army that had been sent to pacify the Shans and Kachins from the early eighteen eighties and into the twentieth century. Their fighting skills had reduced the local population significantly, but thereby also reduced the land tax revenue to the colonial power.

In order to stimulate economic activities the British actively encouraged settlements of Gurkhas in the Shan State. The Burma District Gazetteer expresses explicitly this concern as it was perceived in the beginning of the twentieth century: "A very large influx of cultivators is still needed in the plains in order to bring the fertile area, now lying uncultivated, under the plough" (Hertz, 1960: 77).

Most of the Nepalese garment traders in Thailand were descendants of Nepalese settlers in Shan State. I wondered about how the Nepalese in Burma had maintained Nepalese identity in the multi-ethnic community of Northern Burma where they were greatly influenced by another and larger culturally closely related immigrant group - Indians. It was Hindi music and songs they listened to, and it was Hindi films they watched. In interviews with people they also explicitly stated that the Nepalese had increasingly been adopting cultural features associated with the Indians. However, about 50 years ago a particular event happened that came to reverse this process of Hindization.

A gifted Nepalese singer, Rocky Thapa, came to play an important role in giving meaning to the value of being Nepalese in the Burmese context. He was the son of a Gurkha soldier and was born in the Shan state. His primary education was at a missionary school. He was interested in music and was a member of a band who performed at various functions. However, in the 1950ies they had very little idea about Nepalese music and culture, so the music and songs were mostly learned from Hindi films and records. 
A critical event in his career occurred in 1957 when a function was organized in the Shan state for the visit of the Burmese Prime Minister, $\mathrm{U}$ Nu. Many foreign visitors attended the function. The Burma government had invited different ethnic groups of the region to present folk music and dances that would represent their 'culture and tradition'. The Nepalese were also invited and Rocky Thapa and his group presented Hindi film songs and dances as representative of Nepalese culture. After the performance one of the guests, a British major in a Gurkha regiment later spoke to Rocky Thapa and told him that he did not think that what they had performed was representative of Nepalese culture.

Rocky Thapa was shaken by this comment and started to think about what cultural expressions could possibly represent Nepalese culture in Burma. Rocky had never learned Nepalese language properly. Now he started to take classes in Nepalese language and read Nepalese literature. He came to see that his mission in life was to make the Nepalese in Myanmar "shed off" aspects of Hindi culture. His means to accomplish this mission was to write and sing Nepalese songs. In his opinion it took him about 20 years to finally get the Nepalese to accept what he called their traditional music, consisting of songs he himself had written and composed. He considered his mission successful since he found that many people had been deleting their cassettes of Hindi songs by famous Indian singers like Mohammed Rafi and Mukesh, and substituted them by copies of his own songs.

In his songs, Rocky spins webs of significance from items and symbolic patterns sufficiently familiar to the Burma Nepalese, items that he "weaves" into a symbolic pattern emphasising new ways of conceiving the Nepalese's life in Burma as a Diaspora situation. In his songs he actively tries to create a collective memory, or myth, about their place of origin as an ideal home to which he encourages them to return (Haaland, 2010).

As an example of the ethnic symbolism I shall take one of his songs performed on the occasion of a Nepalese minister visiting Burma in 1964.

Phulera Phulyo Jhaka Ra Maka

English Title: Flowers Have Blossomed, Colourful and Bright

Marigold has blossomed everywhere with

its golden hue,

How did this flower spread all over this

foreign land?

Seed is ours, how beautiful is this flower,

Let it not disappear in this foreign land.

We will paint the silver Himalayas with golden hue,

Marigold in thousands let us take them with us, keeping them in our hearts,

Let us adorn our mother's body in garlands of marigold.

We, the Nepalese, have our homeland in the lap of the Himalayas

The pure blood of Nepalese run through our body;

This day is ending and the darkness of night has reached this foreign land,

This flower is withering, oh Brother! Let us take it back to our country. 
Here Rocky draws on the powerful imagery of the marigold (in Nepalese "sayapatri" literally meaning "hundreds of petals"). The marigold with its golden petals is a flower that is closely associated with Nepalese identity in the sense that Nepalese cultivate it in their gardens for use as garlands as well as in the decoration of their houses during the important festivals of Tihar (festival of lights) and Dasain (Festival of the Goddess Durga). In his song Rocky describes it with reference to its golden hue - an attribute associated with gold, i.e. the natural element that par excellence stands for purity. The flower is clearly meant to serve as a marker of Nepalese identity. This associative linkage is developed further in the second line of the song where Rocky raises the question about how the marigold comes to be spread to a land that is foreign to the homeland of the flower. He answers the question by associating the seeds of the marigold with the seeds of the Nepalese people - the reproduction of the marigold depends on the Nepalese tending it, and the reproduction of the Nepalese depend on them being faithful to their Nepalese "culture" (marigold serving as a metonym for Nepalese "culture"). If marigold disappears, Nepalese identity will disappear. The longing for return to the home country is expressed in several metaphors: "painting the silver Himalayas with golden hue, i.e. bringing the seeds of the marigold (Nepalese in Diaspora) back to Nepal; marigold (i.e. Nepalese identity) in the hearts; mother's body (motherland) adorned with marigold (filling Nepal with Diaspora Nepalese)." By using Himalayas as a metonym for the Nepalese homeland, the ideal of being Nepalese is dressed up in a garb of sacred associations with the great civilizations of Hinduism and Buddhism; by talking of the purity of Nepali blood the importance of Nepalese endogamy in relation to other groups in Myanmar is over-communicated, while endogamy within the different Nepalese castes is under-communicated - it is not stated that "different blood" runs in the bodies of members of different Nepalese castes. In the foreign land night has reached, i.e. the restrictions imposed on Nepalese and other foreigners after Ne Win's coup in 1962 caused the marigold to wither and it is time to return to the homeland. However most Nepalese in Burma preferred to migrate to Thailand instead of Nepal. The situation in Burma changed to the worse after Rocky got involved with Aung San Suu Kyi and her "National League for Democracy" (NLD).

She had heard about his popularity among the Nepalese community and was also eager to meet him to ensure the Nepali votes in the election of 1990. Rocky Thapa agreed and mobilized the Nepalese community (300 000) to vote for her. However after Aung San Suu Kyi won a landslide victory in 1990 the Ne Win government started arresting NLD party workers, and Rocky Thapa had to go into hiding. It was after this he visited Nepal for the first time in 1988.

As the short sketch of Rocky's life-story indicates, he was originally rather marginal in the Nepalese community and his embracement of Nepalese identity only became a compelling concern after a British major blamed him for using Indian songs to represent Nepalese culture.

My fragmentary sketch of Rocky's life story is meant to draw attention to the importance of exploring ethnic entrepreneurship - the small events that may trigger consciousness about the importance of identifying with a particular identity, and cultural entrepreneurs' production of expressions fostering commitment to that identity

The small event I started with brought me not only to an individual's artistic creativity, but also to how this had consequences in systems of larger scale involving processes of global 
politics (British colonialism, Burmese national politics) and economy (growth of tourist industry in Thailand and the income earning this provided for Nepalese migrants (Haaland, 2008).

Rocky is one of the actors who through his cultural creativity served to create a particular landscape of Nepalese group identity in a particular place, namely Myanmar. This ethnoscape (Appadurai, 1991) is however not spatially bounded, although it is anchored in an imagined diasporic consciousness connecting it to a specific motherland, Nepal. A certain amount of shared cultural understandings are forged between Nepalese particularly with regard to what they have in common in contrast to their Myanmar neighbours.

In terms of Saran's characterization of the main features of Diaspora (history of dispersal, memories of the homeland, alienation in the host country, desire for return, support for the homeland, collective identity significantly based on the relationship to the homeland) the Nepalese situation in South-East Asia only share some family resemblance (Saran, 1991: 83-84). The dispersal from Nepal was voluntary and motivated by economic concerns. The memories of the homeland did not have much significance until the politico-economic situation changed in Myanmar and Rocky Thapa started his "memory work" expressed in songs where "the past is at times objectified in different cultural forms such as the land, memorials, material artefats, and bodies" (Litzinger, 1998:264) Alienation from the host-country became important in Myanmar after Ne Win's coup, while this is not so in Thailand.

Desire for eventual return to Nepal was of some importance in Myanmar after King Mahendras' visit in 1970. Support for the homeland among Nepalese in South-east Asia has however been limited. There is no doubt that collective identity defined by relationship to the homeland is of importance for Nepalese spread all over the world as manifested in the networks of Nepalese associations in many countries e.g. the Manchester based "Himalayan Yeti association" and the USA based "Nepali Diaspora and Friends of Nepal for Peace Campaign". Rocky's contribution to the construction of a Nepalese ethnoscape is of relevance for understanding how Nepalese in a particular place (Myanmar) in a particular time period (after 1962) viewed their position in the "landscape" of other ethnic groups and nations. Only there, did it create a vision of an ethnoscape that included additional diaspora features like "the desire to return" and "memories of the homeland" expressed in symbolic forms.

What it means to a member of a particular Nepalese ethnic group varies from the mountain villages of Nepal, to the farms and businesses of Northern Myanmar, to the tourist resorts in Thailand. However, fields of communication are still to a large extent maintained, and thus serve as a channel for mediating discourses about relevant identities in Nepal as well as in various Nepalese settlements in South-east Asia.

\section{Minorities in Yunnan China and the context of political economy}

"The Communist project has been the most explicit and systematic in its process of definition. It has classified the population within China's political borders into fifty-six minzu, or "nationalities," so that every citizen of the People's Republic is defined as belonging to a group that is more civilized or less so. This scaling of groups, in turn, is based on an avowedly 
scientific scale of material stages of social process (derived from Morgan and Engels, refined by Lenin and Stalin) that tells each group exactly how far it needs to go to catch up with the civilizers." (Harell, 1995 )

In my attempts to understand the events that arose my curiosity in southern Thailand I discovered 'loops' of meaning as well as causality that fundamentally connected ethnic processes to macro-level state politics. This macro-level impact became blatantly evident when I during the first decade of the $21^{\text {st }}$ century supervised Chinese and Norwegian students doing fieldwork in Yunnan, southwestern China.

How many different ethnic groups there are in Yunnan I do not know. However the Communist Government decided that non-Han Chinese people should be registered as members of specific so-called Nationalities according to Stalin's theory of Nationalities. Stalin defines a Nationality as follows: A nation is a historically evolved, stable community of people, based upon the common possession of four principle attributes, namely: a common language, a common territory, a common economic life, and a common special features of national culture (Stalin, 1950: 8).

According to orthodox Marxist theory, the economy constitutes the infra-structure of societies, while the political institutions that maintains the dominant economic class interests constitutes the structure, and the cultural ideologies that legitimate the institutions serving these interests constitute the super-structure. The driving force in social evolution is supposed to be class conflicts emerging in the economic infrastructure. Chairman Mao somewhat contrary to conventional Marxist theory tried to find a shortcut to development by taking control of the political structure and through this force the economic infrastructure to correspond to Marxist theory, a theory that through systematic indoctrination served as an ideology legitimating Communist Party rule. During this time tourism and other service industries were castigated as unproductive.

With the post-Mao reforms from 1976, Chinese reality has in many ways turned Marxism upside down. The economy assumed to be the determining basis of society is largely organized on a capitalist mode of production. The political structure that according to theory should reflect the infrastructure, is still controlled by a party that calls itself the Chinese Communist Party, while the ideological superstructure that during Mao's time claimed to follow Marx conflict theory is increasingly drawing inspiration from Confucian teachings emphasizing harmony between different ethnic groups; between different classes; between men and women; between urban and rural communities. According to Confucian theory such harmony is based on clear perceptions of the proper hierarchical relations between these social categories, e.g. the urban centre above the rural periphery, Han majority nationality above minority nationalities, men above women. The connection between capitalist economy and communist polity is not as contradictory as it seems. Members of the ruling Communist Party are closely involved in the capitalist economy both through their privileged access to privatized public assets, and in the close networks (guanxi) connecting Party bureaucrats to capitalist entrepreneurs. However despite these changes in ideological emphasis, there are still some remnants on conventional Marxism manifested in the Government's understanding of and policy towards minority groups.

This can be seen in the concept of Nationality as defined by the Chinese Government. This concept should not be confused with the anthropological concept of ethnic group. Both 
concepts relate to cultural difference, but the relation between ethnic identity and cultural traditions is far more complex than what is often assumed.

It is important to recognize that although ethnic categories take cultural differences into account, we can assume no simple one-to-one relationship between ethnic groups and cultural contents. The cultural features that are taken into account in ethnic dichotomization are not the sum of 'objective' cultural differences, but only those which the actors themselves regard as significant" (Barth, 1969: 13-14). In anthropology the concept of ethnicity thus refers to peoples self-identification while the concept of nationality in Stalinist theory refers to the Government's concern about administrating a culturally diverse population.

Stalin's program of organizing the different ethnic groups in so-called Nationalities can be seen as a strategy of reducing the possible conflicts between loyalties to the ethnic group and loyalty to the state. The state was ideally supposed to be organized as a confederacy of equal Republics each identified with a specific nationality.

However the territories in China (like most Soviet Republics) also contained smaller ethnic groups. Establishing a Chinese boxes-like hierarchy of encapsulating units solved the problem of reconciling administrative feasibility with ethnic diversity. Multi-ethnic Republics were organized in Autonomous Regions identified with its dominant ethnic group. The Regions might again be sub-divided into smaller Autonomous units such as provinces and districts associated with the ethnic groups that were dominant in these smaller units. The reality of ethnic diversity in China however was more like a mosaic where many ethnic groups were intermingled with each other and spread in often vastly separated localities. This made it impossible to administratively recognize all of them. The most important point is that it was the state that identified and recognized the nationalities. Nationality identification is thus from above. In China the application of Stalin's criteria often led to great discrepancies between peoples self-identification and the Government's definition of the Nationality they belonged to.

By allowing for expression of ethnic identity within the administrative system this solution was intended to diffuse a possible threat to the state, and it allowed for expression of cultural features (language, religion, costumes etc) associated with the recognized Nationalities. Most importantly, autonomous units on different administrative levels were supposed to be represented by their own political leaders. These however had to be approved by the Chinese Government and had as their task to carry out the central policy within their respective administrative units. This administrative system seemed to imply bottom-up channels for articulation of concerns related to ethnic identity. In reality it constituted a very strict top-down control of ethnic loyalties according to the administrative concerns of the political centre.

Furthermore the Chinese Communist government was not only concerned about defining groups that constituted Nationalities, they were also concerned about scaling the Nationalities according to their evolutionary stage. The scaling of Nationalities as being on different levels of socio-cultural evolution was based on Engels' modification of Morgan's theory of stages of human evolution (Engels, 2010). The earliest stage "Savagery" was characterized by hunting-gathering, and by promiscuous mating. Higher up on the evolutionary ladder on transition to Barbary we find an early stage of matrilineality. On 
higher levels of Barbary patrilineality emerges. On the highest level of Civilization we have writing, urbanism, advanced division of labour, and family life characterized by patriarchal monogamy.

An important aspect of this theoretical perspective is the assumption that the peripheral minority people today represent stages the civilized people were on in earlier periods. In China the lower ranked peoples are in many publications referred to as living fossils from the past, they illustrate the stages the civilized "society" was at in earlier times..

It is interesting to note that this theory of evolutionary hierarchical levels fits nicely with the Confucian philosophy of a moral hierarchy among people. In this hierarchy the Han majority represents the civilizational centre, while the minorities can be ranked according to how much Confucian civilization they have acquired.

However according to orthodox Marxist evolutionary theory, "ideas of ethnicity and nationalism were part of false consciousness of people who were still in bourgeois, presocialist stage of development. Once they understood that history was determined by class struggle, they would see things in terms of class rather than ethnicity, which would gradually fade away. In the meantime, the soviet state would have to see that its institutionalization of ethnicity was not allowed to impede progress toward the triumph of socialism when ethnic attachments would disappear because they had no further relevance" (Maybury-Lewis, 2002: 53).

It is on this background we can understand the importance the Chinese Communist Government attached to scaling of Nationalities. The Communist Party saw as its task to uplift people placed lower down on the evolutionary ladder. One way of doing this was a policy of affirmative action - allowing lower ranked minority people to have more than one child, and allow minority students applying for admission to Universities to add 25 extra points to their test results. Since a couple could choose to register their child to the nationality of any of their parents, it was a clear advantage for a Han couple to register their child as a minority nationality if one of them had a parent from a minority group. By ethnicity their child would be Han, but by nationality it would be minority nationality.

An important component in affirmative action is promotion of ethno-tourism. The way this is promoted is consistent both with Morgan/Engels evolutionary theory, but also with the Government's strategy of legitimating its rule with reference to its capacity to increase the material welfare of China's population - rural and urban, majority and minorities.

While tourist expansion is clearly shaped by the Government's manipulation of economic conditions that may serve to increase foreign currency earnings and to redistribute wealth from urban to rural minority populations, it is also significantly shaped by the tourist business symbolic manipulation of images of minority people (Tan Chee-beng et al. 2001).

To attract tourists to different groups they have to be represented in ways that evoke the tourists' desires, fantasies and interests. Various agents involved in the tourist trade play up to this by making representations that project minority people as "exotic", "authentic" "ancient", "erotic" etc.

By exploring two cases of representations of minority people in Yunnan Province I shall draw attention to their underlying ideas or fantasies. The first case is the Jinuo Ethnic Park 
and illustrates the Chinese Government's cultural policy of representing minority groups with items that fit the evolutionary scaling expressed in the Morgan/Engels theory.

The Jinuo is a small Tibeto-Burmese speaking minority group in Xishuangbanna Dai Prefecturat in Southern Yunnan. It was originally categorised by the Government as being on the first stage of human evolution, and therefore worthy special development efforts (Shieh-chung Hsieh, 1995). One of these efforts was to stimulate tourist industry by construction of an Ethnic Park.

The Park is supposed to represent the cultural evolution of the Jinuo. A central part is a longhouse that is said the Jinuo used to live in during earlier times. The long houses are almost exactly like the long houses of the matrilineal Iroqois Indians of North - East USA where Morgan made his major study and which inspired his evolutionary theory. The Jinuo are cultivators and practice patrilineal descent. Consequently they are classified as being on the evolutionary stage of Barbary. However, since longhouses are found among the matrilineal Iroquois (the proto-type of the upper sub-stage of savagery) this must from a Morgan/Engels perspective be understood as a survival from a time when the Jinuo were on the upper stage of savagery, and that they in the recent past practiced other features, e.g. matrilineality is assumed to characterize societies on that stage. To represent other stages of the evolutionary development of Jinuo, the Partk has constructed objects similar to cultural items ethnographically documented from culture-historically unrelated communities elsewhere, but according to Morgan/Engels' theory classified as being on lower stages of evolution.

Next to the longhouse is constructed an amphitheatre similar to ancient Greek theatres. This strange construction may be understood when seen in the light of Engels' reference to Bachofen's argument that the ancient Greek play-writer Aeschylos in his play Oresteia presents the dramatic conflict between declining mother right and the rising father right that lead to the victory of the latter completing the transition to Barbary in ancient Greece. Earlier stages in Jinuo evolution is represented by cultural features taken from other ethnographic cases assumed to be on lower stages. On the other side of the longhouse we find a remarkable totem pole similar to those found among the Northwest coast Indians in America. Engels mention that totems is a characteristic cultural element of people on the upper stage of Savagery, such as the Northwest coast Indians of America. This totem pillar can thus be interpreted as a reconstruction of the stage the Jinuo were on in earlier times when they presumably lived by fishing. There is no archaeological evidence for such items, but since it is assumed that all societies at specific levels of evolution share a similar bundle of cultural features characteristic of this stage, the evolution of the Jinuo is represented by items copied from cultural inventories found in culture historically unrelated ethnographic and archaeological contexts. In contrast to the "memory work" of Rocky Thapa among the Nepalese in Myanmar, the Jinuo Ethnic Park is an example of "memory work" produced by the state that present a narrative representing the position of the Jinuo within the Chinese state. This narrative is based on a generalized quasi-evolutionary theory consistent with the country's Marxist ideology and serves to repress alternative narratives of the specific historical events that have shaped that position. Litzinger has argued: "If the modernist narrative of the nation's unfolding in history forces people to forget or ignore other ways of telling, seeing, and behaving in the world, then memory is one site where power enacts its violence" (Litzinger, 2000: 70) 
The second case is the $\mathrm{Na}$ (Mosuo) and exemplifies the lack of correspondance between peoples' self-identification and the Governments administrative classification of nationalities. Most importantly in this context it illustrates the tourist business's commodification of ethnicity.

The $\mathrm{Na}$ is a small Tibeto-Burmese speaking ethnic group in Lijiang Naxi Prefecture. The $\mathrm{Na}$ who live in Yunnan province are classified as members of the Naxi Nationality, while some who live on the Sichuan side are classified as Mongols. Classification of Yunnan Na as Naxi was based on administrative convenience legitimated by Chinese scholars' assumption of culture historical common origin between the Naxi ethnic group and the Na ethnic group, despite the facts that they speak mutually unintelligible languages and practice contrasting principles of descent (The Naxi practising patrilineality and the Na matrilineality). The Naxi Nationality thus includes two ethnic groups the Naxi and the Na. Today many of the $\mathrm{Na}$ elite articulates demands for recognition as a separate nationality. The Classification of Sichuan Na as Mongols is apparently a legacy of Kublai Khan's conquest of Yunnan in 12521253. The Mongols ruled through an administrative system of local leaders (tusi) recognized by the Mongol state. With establishment of a Mongol military colony and inclusion in the administrative system of the Mongol dynasty, the Na on the Sichuan side were classified as Mongols (Harell, 1995) despite identifying themselves as Na.

Descent among the $\mathrm{Na}$ is overwhelmingly matrilineal. The basic unit of $\mathrm{Na}$ social organization is the yidu. This is a family based corporate group having an agricultural estate in the form of land and livestock. Recruitment to the yidu is through children borne to its women. Sex between male and female members of the yidu is strictly prohibited. Reproduction of the yidu thus requires that its women have sex with males of other yidus, socalled walking marriage. The male partner $(a d z u)$ of a girl in a yidu does normally not enter through the main door of the house on the ground floor, but climbs through a window in the girl's room on the first floor. The sexual encounter is not secret, but by not entering the main door the importance of the matrilineal descent relations are over-communicated, while the importance of the sexual relation is under-communicated. In the morning the $a d z u$ is supposed to leave through the window and return to his mother's yidu, where he performs the male tasks in the division of labour within his mother's household. While sexual relations are socially regulated, they neither seem to establish any social arrangement with rights and duties of a kind commonly labelled as marriage, nor do they lead to relations that can be considered as social fatherhood, although the Na do recognize men who are the genitors of the children borne to the women of the yidu. The yidu thus lacks two dyadic relations generally found in family units, namely: Husband - wife relation and father - children relation (Cai Hua, 2001, Wu Yunchuan, 2005).

This kind of male - female relations are clearly strange to most people, and the tourist business makes a lot out of it. In glossy brochures, e.g. "Eastern Girl's Kingdom" romantic pictures of loving girls and boys placed in the beautiful landscape of Lake Lugu clearly play on the contrast to the conventional more strict sexual mores of the Han. These pictures illustrate Stevan Harrell's point about differences in the way the central Han majority and the peripheral minorities are represented in China (Harrell, 1995). Peripheral people are generally (except Mongols, Yuighurs, and Tibetans) represented with pictures of women. The sexual metaphors of erotization and promiscuousness of the peripheral people are very explicit in the books on the $\mathrm{Na}$ - they have not learned the proper moral rules of the 
civilizing centre. Such representations foster an image of minority women as more "ethnic" than the men of the minority group. This contrasts with representations of the Han who are considered the civilizers and pictorially represented primarily by men.

There is here in interesting analogy between women as peripheral in relation to men, and minorities as peripheral in relation to Han. Both women and minorities are subordinate categories that have to be uplifted by the state's civilizing projects - they lend themselves to be conceptualized as being of a similar kind. Minorities are like women, therefore women represents minorities.

Harrell has argued that in terms of Han cultural frameworks both minorities and women are considered to be polluting. Menstruation is considered dirty and dangerous for males like minorities are also considered dirty and dangerous. Women and minorities are similar in the sense that they both have the power to pollute as manifested in the majority population's fear of local food and sanitation. The sexual metaphor is a metaphor for domination - it serves to indoctrinate a hegemonic legitimization for the superiority of the centre Pictures in tourists brochures from the Na clearly play on images that appeal to males' erotic fantasies as well as being consistent with Marxist evolutionary theory according to which the Na can be considered to be on the transition to Barbary since its subsistence is based on primitive cultivation while its members practice sexual relations that seems pretty close to promiscuity.

Expansion of ethno-tourism leads to increasing commodification of culture and ethnicity; "clothes become costumes, and steps become slick moves" (McKhann, 1995: 44), tools and ritual objects become curios; local dances, ceremonies and rituals become performances staged for tourists paying a fee for watching them.

While the tourists are interested in something they think is "authentic", the fact that the tourist industry arrange staged "ethnic" performances inevitably leads the members of ethnic groups participating to understand what the tourists want to see and adopt their performance accordingly. Clearly having learnt to perform for tourists has become part of minority groups' culture in the sense that they have knowledge about how to behave in tourist encounters. This need not imply that they agree on the images projected. It is quite possible to have a backstage where they can comment about and evaluate what takes place in the tourist front stage. Learning new cultural ideas may reduce cultural differences between Han majority and the peripheral minorities. However ethnic boundaries may persist despite such cultural diffusion.

Such reduction of cultural difference may however be against the interests of the tourist business, because it is the "difference" between the minorities and tourists they sell. The tourist business may thus try to make people in "ethnic villages" behave in ways that project ways of life not practiced in daily life any longer. It may seem like a paradox that playing on ethnic differences for profit purposes may run counter to the government's concern about potential political problems that follow if ethnic loyalties are mobilized to challenge loyalty to the Chinese state. In China "People are considered Chinese in perpetuity if they have ever belonged to the Chinese family of nations. ---. Those who have been brought into the orbit of Han civilization cannot leave it, for they have become part of it" (Maybury-Lewis, 2002: 110). Tibetans, Uighurs, and Hui may not entirely agree on this, because they associate themselves with alternative civilizational centres. 


\section{Reflecting on the Fur in light of comparative experiences}

"It may be that "ethnicity" is simply a convenient - though in certain respects misleading rubric under which to group phenomena that, on the one hand, are highly disparate, and, on the other have a great deal in common with phenomena that are not ordinarily subsumed under the rubric of ethnicity" (Brubaker 2004: 27)

In the comparative cases I discussed different kinds of conditions were most salient in shaping ethnic processes, and this made me pay more attention to them.

In the 1960ies it seemed that economic structure and ecological setting primarily channelled processes on the Fur - Baggara boundary, and this made me focus on instrumental aspects of identity change.

Looking back at my Fur analysis after my Santal fieldwork I became concerned about the kind of solidarities expressed in the Fur symbolic constructions that I had observed without having considered their implications for ethnic processes (Haaland, 1998). Now I was alerted to the qualities in human relations they might express; qualities like trust and solidarity; suspicion and witchcraft; rivalry and murder. Drawing on perspectives from Bateson ideas about communication of qualities in social relations (Bateson, 1975), I tried to argue that the elaborate symbolic imagery constructed around a key symbol called bora fatta (white milk - mother's milk) served to foster the quality of solidarity. Solidarity in social relations is a fundamental concern everywhere. Among the Fur this is expressed in development of a rich symbolic language focused on a relation where this quality is taken for granted, namely the mother-child relation. A very convincing metonym for this solidarity is mother's milk (bora fatta). The concrete item mother's milk (bora fatta) is metaphorically linked to another concrete item, namely millet mixed with water and also called bora fatta. The use of millet flour mixed with water on a variety of critical situations in individual and collective life e.g. at circumcision, at rain rituals, at treatment of certain diseases, expresses and foster a precarious solidarity in a wider range of social relations (May I trust your solidarity like I trust the solidarity of my mother). Furthermore bora fatta (as millet flour mixed with water) is associated with two other items kira (millet beer) and nung (millet porridge).

The two items, kira and nung, are related to each other by being produced from the same raw material (millet) by the addition of female labour. They are also related in Fur thinking; and to sell either of them would imply an activity categorized as ora (shameful act similar to prostitution). The metaphoric and metonymic associations connected with millet items are convincing when used to signify a quality of solidarity.

Solidarity is the desired state of interpersonal relations, but lingering doubts about this quality in fellow community members is an ever present concern. Such doubt is expressed in ideas and symbols standing for the opposite of solidarity, namely betrayal. This quality is expressed as witchcraft (kar). Witchcraft is assumed to work on an unconscious level and it was said that during sleep a black bird would come out from the witch's heart and suck blood from its victims causing diseases. When looking for relations where the quality of witchcraft was suspected I was told that observable manifestation of this quality was behaviour considered unsociable, e.g. not participating as expected on community occasions like beer-work parties. The sanction of being identified as witch (kar) is ostracism. 
On the conscious level there is another quality that contrasts with solidarity, namely competition, rivalry and enmity. This is expressed in the term nungi toke (hot eyes - evil eyes). In its most extreme form competition is manifested in killings. The relation between a killer and the victim's relatives is expressed by the statement that there is blood (kewa) between them. Where the kewa relation exists, food sharing should not take place. If it does, the mystical sanction is leprosy that is also called kewa. Leprosy is understood as caused by having shared porridge or beer with someone who has killed one of the lepers' relatives, but he may never know when that event took place or who the killer was.

The ideas expressed in the connected symbolism of bora fatta, kar and nungi toké do not serve to express and foster Fur solidarity in contrast to other groups. The "others" who are a threat are ones neighbours, even ones relatives - it is among them that the suspicion of witchcraft arises, and it is among them that competition is most likely to occur.

While important cultural constructs produce suspicion about solidarity among Fur neighbours, other ideas communicate close connection between the Fur and the Baggara. Most importantly they were both Muslims and different versions of genealogies served to create a symbolic linkage between Fur and Baggara since they connected Fur dynasties to a North African Hilali, Ahmad al-Ma'qur, and his importance in introducing Islam to Darfur. Such a connection is also expressed in the story that the first historical ruler of the Fur Keira dynasty, Suliman Solong was an Arab (Solong means Arab in Fur language). While there were clear cultural differences between Fur and Baggara, these differences were reproduced in fora like family life, village ceremonies (rain rituals and circumcision etc). The cultural differences were clear, but they were not a big issue in day-to-day interaction. Symbolic and ritual events did thus not serve to produce a high level of Fur-wide groupness in the 1960ies. My reflections on the Fur and the Santal material supports Brubaker's argument that we should not assume that ethnic categorization implies ethnic group solidarity: "Shifting attention from groups to groupness, and treating groupness as a variable and contingent rather than fixed and given, allows us to take account of - and potentially, to account for - phases of extraordinary cohesion and moments of intensely felt collective solidarity, without implicitly treating high levels of groupness as constant, enduring, or definitely present. It allows us to treat groupness as something that happens" (Brubaker, 2004: 12)

Later fieldworks in the 1970ies and 1980ies had drawn my attention to how Fur groupness was manifested in events caused by the dynamics of macro-level economic and ecological processes. The importance of macro-level political dynamics was blatantly clear in the China case. Macro-level politics had of course also been an important dimension in Darfur from the colonial time until today, but I had left it unexplored because the micro-level processes of identity change could be understood as an outcome of political, economic and political conditions during my fieldwork. However political changes have occurred over time, from the time of the independent Fur sultanate, to the Ottoman Empire, to British colonial administration (the Anglo-Egyptian condominium) and after independence. These political changes must have had far-reaching impacts on ethnic relations in Darfur.

In China, state policy impact on ethnic processes is blatant and very explicit since it here is based on a clearly formulated (albeit outdated) evolutionary theory. Reflecting back on our contributions in Ethnic groups and Boundaries, Barth some years ago argued "“"--we 
must start by analyzing the policies of each state by linking these policies to features of the regime, that is, the state's policy-making core. We are then able to depict the power represented by the state as a specifiable third player in the boundary construction between groups,----. Different regimes require very different conditions for their perpetuation and have quite different policies towards ethnic categories and movements in the populations they seek to control. Identity management, ethnic community formation, public laws and policies, regime interests and measures, and global processes thus fuse and form a complex field of politics and cultural processes" (Barth, 1994: 20). Like China, European colonial empires were frequently confronted with the problem of administrating culturally and organizationally very heterogeneous populations that inhabited their colonies. The common British solutions was the indirect rule policy of identifying so-called tribes they could administrate through their chiefs, i.e. formalize features of the tribal structure that the British found convenient for their administrative purposes. Hierarchies of 'tribal' rulers were in this system included in the British Empire and had their power sanctioned ultimately from London. This so-called indirect rule masked several important social dimensions: the pre-colonial 'tribal' structures were fluid and power was to some extent based on mobilization of local support. Colonial rule froze 'tribal' boundaries and made the rulers not only dependent on the colonial power, but frequently seeing their interests best served by cooperating with it. The whole problem of classification of people became particularly difficult in areas where the rulers did confront groups with weak institutionalization of leadership. The problem of organizing a sociocultural heterogeneous population on geographically contiguous areas was often similar to the situation the Chinese faced, and often 'tribal' administrative units came to include culturally rather diverse groups of people, not to mention the many cases where ethnic groups were divided by international borders. The correlation between colonial tribal classification and existing ethnic boundaries was far from perfect, but in some cases this discrepancy over time have been reduced because the people being administrated as 'a tribe' may increasingly identify with and act according to the cultural values of the dominant group within the 'tribe'. Although the British colonialists were also influenced by evolutionary theories of the 19th hundred century they did not use it for ranking purposes as systematically as the Chinese Communist Party did. Ideas of inherent inequality between the rulers and the ruled were however common and then largely based on racist ideas current in Europe at the time.

With the independence of Sudan the political game changed dramatically and with that the importance of ethno-politics on governmental distribution of goods and services, as well as of bureaucratic positions. The final source of power was not any longer in London but had to be based on forces within the country (control of the means of suppression as well as on mobilization of popular support).

The changes I described in Fur-Baggara relations on a regional level have thus to be analyzed with reference to processes on the macro level of national political economy. A major factor in this context is the contrast between the narrow strip of irrigated land and urban centres along the Nile dominated by an Arab commercial and educational elite; and the vast savannah regions like Darfur with a scattered population of animal herders and shifting cultivators the population in the Nile area has thus for centuries participated in a market economy where survival depended on skills in capital management and on the ability to exploit off-farm income-earning opportunities. The riveraine groups also 
perceived the advantages of education much earlier than did the farmers in the rainfed savannah areas. As a result, the Nile valley, mainly Arab population was much better prepared, than the Savannah groups to participate in modern developments in the economy as well as in civilian and military services. The population of nomads and shifting cultivators like the Fur of the Sahel-Savannah zone has of course been affected by the developments in the Nile valley, but have to a much lesser extent participated in occupations outside primary production or gained access to the specialized knowledge such participation required. Politically these demographic, economic and cultural contrast gave the Nile valley population a vastly greater influence on national politics and with this distribution of public goods and services. The Darfurians perceived themselves as losers in the national political game, and from the 1960ies voices articulating separation was heard. In 2003 anti-Government forces attacked the airport in El Fasher - the provinsial headquarter of Darfur. The Sudan Government responded by sending in its air force, and by directing its paramilitary units, the so-called Janjaweed and the Muraheleen to fight the insurgents. These paramilitary units were mainly recruited from Arab livestock herders (Baggara cattle herders in southern Darfur and Jumala camel herders in northern Darfur). This linked regional resource competition to national politics giving the Darfurian Arab livestock herders a critical advantage. Furthermore it stimulated formation of alliances between traditional enemies (African groups like Fur, Masalit and Zaghawa) underpinned by symbolic work under-communicating traditional stereotypes of animosity, and overcommunicating similarity in opposition to the Arab groups supporting the Government. This could lead to the emergence of a larger regionally based ethnic categorization, but so far the Sudan Government has been very clever in its divide and rule tactics, particularly by attracting local opposition leaders to positions in the Central Government.

The relevance of ethnic identity in Darfur today is therefore very different from what it was 40 years ago. With the changing economic and political conditions, I expect a growth in primordial constructions, although to make them convincing is difficult, because they will have to bridge many different visions current among the regional elites.

\section{Conclusion}

" - there are some brute facts about the world of the twentieth century that any ethnography must confront. Central among these facts is the changing social, territorial, and cultural reproduction of group identity. As groups migrate, regroup in new locations, reconstruct their histories, and reconfigure their ethnic "projects", the ethno in ethnography takes on a slippery, nonlocalized quality, to which the descriptive practices of anthropology will have to respond. The landscapes of group identity - the ethnoscapes - around the world are no longer familiar anthropological objects, insofar as groups are no longer territorialized, spatially bounded, historically unselfconscious, or culturally homogeneous." (Appadurai, 1991: 191)

By focusing on a particular problem field, namely the interconnection between cultural features and ethnic categorization I have tried to argue for the importance of curiosity driven research focused on particular events where ethnicity was "happening". My attempts to understand these "happenings" lead to a search for "loops" that connected the events in linkages of meaning and of causality. In the ethnographically bestdocumented case of Fur-Baggara relations I tried to establish a hypothesis about underlying general mechanism. In many ways I found this analysis quite satisfactory. 
However as I did fieldwork in very different ethnographic settings I was alerted to other conditions channelling ethnic processes and started to wonder whether the processes I had observed in Darfur also were affected by underlying conditions I had not questioned because their impact in the cases of ethnic "happenings" were less conspicuous. My exposure to events in different ethnographic settings led to awareness of different kinds of "loops" that affected the chain of events affecting the way ethnicity was unfolding. I have used this awareness as a source for reflecting back on my Fur material to develop a more nuanced understanding of the processes taking place there. The further development of my understanding of ethnic processes in Darfur shows the importance of accidental observations that a fieldworker in Malinowskian tradition of participant observation may accumulate. The Darwinian "watch and wonder" approach built into the over-ambitious Malinowskian idea of "learning" the culture of the people we study by unstructured observations made while hanging around, drinking beer, occasionally participating in work activities, engaging in ritual activities etc, is therefore an invaluable part of anthropological practice and may lead to observations that significantly alert us to other factors than those we have discovered in our more systematic search for "loops" that connect events that emerge in peoples interaction vis-à-vis each other and vis-à-vis components in the natural environment.

I have tried to draw on various theoretical and methodological approaches in exploration of a particular empirical problem field, namely ethnicity. I have not advanced any theory about ethnicity but rather explored a set of empirical cases that show enough family resemblances to justify being taken as examples of a the fuzzy category that anthropologists call ethnicity. My first article about Fur nomadization and change of ethnic categorization seemed counter-intuitive to our idea of identity as something deeply anchored in our personality, and not something we change like changing shirts. The importance of my argument was that it focused on the sociological dimension of categorization, and not on how the people subjectively experienced such change in categorization. That such subjective embracement could be a factor in identity change was brought home to me in my work among the Santals. In the Chinese example I discussed the management of public information in publications and other representations in ways directed towards reshaping personal memory among minority groups. This made me aware of how Sudan state level campaigns for prohibition on consumption of local beer, can be seen as a means to suppress memories attached to a fundamental symbol of construction of Fur personhood. Absence of public representation of important symbols of ethnicity should however not be taken to imply that attachment to such identity is absent. The most important context for reproduction of such attachments may in fact be the publicly unobservable fora of family life and other small-scale settings.

The lesson I draw from my attempts to make sense of various dimensions of ethnicity is that we need to improve our conceptualization of the interplay of ethnicity on different interpenetrating levels from the micro-level formation of personhood, to the median level of entrepreneurial formulation of programs for ethnic mobilization, and to the macro-level of state policies and the way governments manipulate public discourse about the rivaling identities of nationalism and ethnicity. A very important research problem today with fundamental practical implications is to study this interplay in modern complex societies like China, India, France, Brazil and USA. Multi-culturalism within the state versus 
assimilation to the culture of the dominant ethnic group of the state is a critical issue in public discourse in modern societies. I will particularly draw attention to processes that serve to produce variations in commitment to own identity - the extent to which such commitment is "hard-coded" seems to vary enormously between ethnic groups. I will particularly draw attention to the connection between ethnicity and high religious traditions e.g. Buddhism, Hinduism, Judaism, Christianity and Islam. The large-scale international migrations we are experiencing today further complicate this problem field, particularly when it leads to creation of ethnically based and religiously justified international networks of social relations crosscutting national boundaries. In exploring this complex problem field we have to be careful to avoid confusing the categories of ethno-political practice, with our categories of social analysis. The categories of ethno-political discource are part of our data in the sense that they are ethno-political entrepreneurs attempts to invoke ethnic categories in order to evoke ethnic group action. If we confuse the two levels we end up reifying groups by treating them as substantial things in the world, a fallacy that Bourdieu has referred to as "our primary inclination to think of the social world in a substantialist manner" (Bourdieu \& Wacquant 1992: 228).

\section{References}

Appadurai, A. (1991). Global Ethnoscapes: Notes and Queries for a Transnational Anthropology, In R. Fox (ed.), Recapturing Anthropology, (191 - 210) School of American Research Press, Santa Fe.

Barth, F. (1956). Ecologic relations among ethnic groups in Swat, North Pakistan. American Anthropologist, Vol 58, No 6, (1079-89)

Barth, F. (1963). Ethnic processes on the Pathan-Baluch boundary, In G. Redard (ed.), IndoIranica, (13-20) Wiesbaden

Barth, F. (1964). Competition and symbiosis in North East Baluchistan. Folk, Vol 6, no 1 (1522).

Barth, F. (1967). Economic Spheres in Darfur, In R. Firth (ed.), Themes in Economic Anthropology, (149-174) Tavistock Publications, London

Barth, F. (1969). Introduction, In F. Barth (ed.), Ethnic Groups and Boundaries, (9 - 38) George Allen and Unwin, London

Barth, F. (1987). Cosmologies in the Making. Cambridge University Press. Cambridge

Barth, F. (1994 a). A Personal View of Present Tasks and Priorities in Cultural and Social Anthropology, In R. Borofsky (ed.), Asessing Cultural Anthropology, (349 - 361) McGraw-Hill, INC. London.

Barth, F. (1994 b). Enduring and emerging issues in the analysis of ethnicity, In H. Vermeulen \& C. Govers (eds.), Beyond ethnic groups and boundaries, $(11$ - 32) Het Spinhuis. Amsterdam)

Bateson, G. (1975). Redundancy and Coding, In G. Bateson (ed.), Steps towards and Ecology of Mind, (387 - 401) Paladin, New York.

Berger, P. (2011). Adventures of an accidental sociologist. Prometheus Books, New York

Bourdieu, P. \& Loie J. D Wacquant (1992). An invitation to Reflexive Sociology. Chicago University Press, Chicago.

Brubaker, R. (2004). Ethnicity without Groups. Harward University Press, London. 
Cai Hua (2001). A society without Fathers or Husbands. Zone Books, New York.

El Hadi al Nagar \& Taha Bashar (1962). A Psycho-Medical Aspect of Nomadism in the Sudan, In The Effect of Nomadism on the Economic and Social Development of the Sudan(29 - 39). Proceedings of the Tenth Annual Conference of The Philosophical Society of the Sudan, Khartoum.

Engels, F. (2010). The Origin of the Family, Private Property and the State. Penguin Classics

Epstein, A. L. (1958). Politics in an Urban African Community, Manchester University press, Manchester.

Evans-Pritchard, E.E. (1962). Social Anthropology and Essays. The Free Press, New York.

Geertz, C. (1963). The integrative revolution, In C. Geertz (ed.), Old societies and New States.

The quest for modernity in Asia and Africa, (105 - 157) The Free Press of Glencoe, London.

Geertz, C. (1973 a). Thick Description. Towards an interpretative Theory of Culture, In C. Geertz (ed.), The Interpreation of Cultures, (3 - 32), Fontana Press, London.

Geertz, C. (/1959/ 1973 b). Ritual and Social Change: A Javanese Example, In Clifford Geertz (ed.), The Interpretation of Cultures, (142 - 169) Fontana Press, London.

Gluckman, M. (1956). Custom and Conflict in Africa. Blackwell, Oxford.

Gluckman, M. (1958). Analysis of the Social Situation in Modern Zululand, Manchester University Press, Rhodes-Livingstone Papers no 28.

Gluckman, M. (1963). Order and Rebellion in Tribal Africa, Cohen and West, London.

Gould, S. J. (1991). The Flamingo's Smile. Penguin Books, London.

Haaland, G. (1969). Economic Determinants in Ethnic Processes, In F. Barth (ed.), Ethnic Groups and Boundaries, (58 - 73) George Allen and Unwin, London.

Haaland, G. (1972). Nomadization as an Economic Career among Sedentaries in the Sudan Savanna Belt, In I. Cunnison \& W. James (eds.), Essays in Sudan Ethnography presented to Sir Evans-Pritchard (149 - 172), C Hurst \& Compan, London.

Haaland, G. (1978). Ethnic Groups and Language Use in Darfur, In R. Thelwell (ed.), Aspects of Language in the Sudan (181 - 199), Occasional Papers in Linguistics and Language Learning. No 5 The New University of Ulster.

Haaland, G. (1982). Social Organization and Ecological Pressure in the Southern Darfur, in G. Haaland (ed.), Problems of Savanna Development (55-106) Department of Social Anthropology. Occasional Paper no 18. University of Bergen, Bergen.

Haaland, G. (1991). Cultural Content and Ethnic Identity, In R. Grønhaug et al (eds.), The Ecology of Choice and Symbol (155 - 179) Alma Mater, Bergen

Haaland, G. (1998). Beer, Blood and Mother's Milk. Sudan Notes and Records, N.S. Vol 2 (53 76)

Haaland, G. 2006. The Darfur Conflict in evolving Politico-economic and socio-cultural contexts, In The international Journal of Diversity in Organizations, Communities, and Nations. Vol V.

Haaland, G. (2008). Explaining causes in evolving contexts: From Nepali hill Farmers to Business Managers in Thailand, In B.B.Walters, et al (eds.) Against the Grain. The Vayda Tradition in Human Ecology and Ecological Anthropology Alta Mira Press. Lanham. 
Haaland, G. (2010). Cultural Landscape and Migration, In Dhaulagiri Journal of Sociology and Anthropology Vol. 4, 2010 (99 - 110).

Harrel, S. (1995). Introduction, In Stevan Harrel (ed.), Cultural Encounters on China's Ethnic Frontiers (3 - 36) University of Washington Press, Seattle.

Henin, R.A. (1969). The Patterns and Causes of Fertility differences in the Sudan, In Population Studies, xxiii, 2 (171 - 198).

Herskowitz, M. (1926). The Cattle complex in East Africa, In American Anthropologist Vol 28, issue 2,1926 .

Hertz, H. F. (1960). Burma Gazetteer, Myitkyina District, Vol A. Rangoon: Superintendent, Govt. Printing and Staty, Union of Burma.

Hughes, E. (/1949/ 1994). On work, Race and the sociological imagination. The University of Chicago Press, Chicago.

Johnson, M. (1987). The Body in the Mind, Chicago University press, Chicago.

Kuhn, T. E. (1976). The Structure of Scientific Revolutions. The University of Chicago Press. Chicago.

Leach, E. R. (1954). Political Systems of Highland Burma, The Athlone Press, London.

Litzinger, R. (1998). Memory Work: Reconstituting the Ethnic in Post-Mao China. Cultural Anthropology Vol 13 No 2 (224 - 255).

Litzinger, R. (2000). Other Chinas, Duke University Press, Durham.

McKhann, C. F. (1995). The Naxi and the Nationalities Question, In S. Harrell (ed.), Cultural Encounters on China's Ethnic Frontiers, $(39$ - 62) University of Washington Press, Seattle.

Maybury-Lewis, D. (2002). Indigenous Peoples, Ethnic Groups, and the State, Allyn \& Bacon, Boston.

Mitchell, C. (1956). The Kalela Dance. Aspects of Social Relations among Urban Africans in N. Rhodesia. The Rhodes-Livingstone Papers no 27. Manchester University Press, Manchester.

Moerman, M. (1965). Ethnic Identification in a Complex Civilization: Who are the Lue, American Anthropologist Vol 65, no 5 (1215 - 1230).

Obeyesekere, G. (1990). The work of culture, The University of Chicago Press, Chicago.

Obeyesekere, G. (1995). On Buddhist Identity in Sri Lanka. In Lola Romanucci-Ross \& George A. De Vos (eds.), Ethnic Identity. Creation, Conflict and Accommodation, (222248) Alta Mira Press, Walnut Creek.

Orans, M. (1965) The Santal. Detroit, Wayne State University.

Popper, K. (1972). Objective knowledge, At the Clarendon Press, Oxford.

Radcliffe-Brown, A. R. (1961). Structure and function in primitive society. Cohen and west LTD, London.

Safran, W. (1991). Diasporas in Modern Societies: Myths of Homeland and Return, Diaspora vol. 1. No. 5 (83 - 99).

Shieh-chung Hsieh. (1995). Tai/Dai-Lue Ethnicity, In S. Harrell (ed.). Cultural Encounters on China's Ethnic Frontiers. (301 - 328). University of Washington Press, Seattle.

Stalin, J.( 1950): The National Question and Leninism. Moscow: Foreign Language Publishing House. 
Tan Chee-Beng, Sidney C.H. Cheung, Yang Hui (2001). Tourism, Anthropology and China, White Lotus Press, Bangkok.

Vayda, A. (1983). "Progressive Contextualization: methods for research in human ecology." Human Ecology Vol 11, No 3 (285 - 281).

Walters, B. B. \& A. Vayda (2009). Event Ecology, causal Historical Analysis and Human Environment Research, Annals of the Association of American Geographers Vol. 99, No $3,(534-553)$.

Weber, M. (1978). Economy and Society, University of California Press Ltd, London.

Wright Mills, C. (1973) The Sociological Imagination. Penguin Books, Hammondsworth.

Wu Yunchuan (2005). Yidu, Sexuality, and Social Relationships of the Na. Thesis submitted for the Degree of Master of Philosophy in Social Anthropology. Department of Social Anthropology, University of Bergen, Bergen. 


\title{
Natural Interactions in Artificial Situations: Focus Groups as an Active Social Experiment
}

\author{
Jakob Demant \\ Aarhus University, \\ Business and Social Sciences, \\ Centre for Alcohol and Drug Research \\ Denmark
}

\section{Introduction}

The focus group interviews can provide a unique access to interaction 'at play', and can as such serve as a method for investigating the social processes in society (Holstein \& Gubrium, 1995, Morgan \& Spanish 1984, Meyers \& Macnaghten, 1999). Power is an imminent part of the dialogue in interviews (Atkinson \& Silverman, 1997; Gubrium \& KoroLjungberg, 2005; Kvale, 2006), and in focus groups power relations are even more interwoven with participant interactions than in individual interviews, and are no longer confined to the relation between interviewer and interviewed (Hofmeyer \& Scott, 2007). As such focus group data could be framed as on one side a biased by the social setting of the group. On the other side the participant interaction could be viewed as unique data that lets the researcher follow the construction of data. In other words, the focus group interaction can be observed as it were "talk" within a ethnographic study. This dissolves the distinction between interview data and observational data (Halkier, 2010), and as I will argue, between interview-data, observational data and experimental data. More positivistic as well as constructivist approaches do however struggle with what kind of validity focus group data has. This is reflected in questions as to what degree focus group discussions reflect real life situations, and, what can be considered a finding and what is a bias.

This chapter discuss the question of how the validity of focus group data can be reframed when approaching focus groups as social experiments in a science and technology approach. By using this frame we first of all comes to perceive the focus group discussion as an artificial situation, while the interactions going on in the group can be described as natural occurring data (cf. Silverman, 2007). Thus this approach comes to terms with some of the problems addressed within both positivistic as well as constructivist uses of focus group methods. Secondly, framing focus groups as social experiments also highlights possibilities of a more active use of groups (by intervention) that resembles the interviewing situations as an active ethnomethodological breaching. It is within this framework of "stimulated or irritated" natural occurring data that focus groups will be discussed.

The use of metaphors like experiments, laboratory-like settings and artificial interactions is not new to the focus group literature (Morrison, 1998; Dimitriadis \& Weis, 2001; Lezaun, 2007). When Merton and Kendall in 1946 presented the focus group interview as a 
sociological method it was with the intention of dealing with the uncertainties of intervening effects in social experiment and thus arguing that focus groups could be a relatively controlled setting for testing out norms and values in humans (Merton and Kendall, 1946). The experimental setting of the focus group was, as Merton recalls in a late paper, used in media studies, to produce observable outcomes as much as it was an interview technique (Merton, 1987). More recently Dimitriadis and Weis' raised a central point about how the focus group should be seen as a laboratory where we as moderators actively influence the group and slip into a mixed role as teacher or mentor. Lezaun argues that the moderator's skilled facilitating of individual standpoints combined with the clinical interview rooms with one-way-mirrors becomes a "machinery" that produces individual opinions. He argues critically that the focus group, primarily in market research, makes use of this unnatural element in order to produce sincere and non-socially biased opinions.

This article argues, in opposition to Lezauns argument, that the researcher must not only put emphasis on the relations between people, actions, statements and occurrences in the group, but should creatively use group composition as well as topics and moderation (i.e. the control of the dialogue) to create interesting focus group data. The framing of the focus group study as a social experiment can be an epistemologically productive position, if the researcher acknowledges a), the plastic laboratory-like focus group setting, the social experiment can become a more active part of the methodology, and b) in the same epistemological position social interaction as occurring naturally within the setting of the experiment. It is, thus, not argued that the researcher should try to control the experiment in as many possible aspects (as is the notion in e.g. randomized controlled trials), but more be acknowledged as a way to make the focus group participants interested in the topic. The method becomes less a "testing tool" for values and moral, in the way that Merton created the focused interview, and more a tool for describing other versions of a given phenomenon. This argument is based on the assumption that if the focus group data cannot be argued to mimic a naturally occurring situation, then research can use focus groups for investigating aspects of the phenomenon that will become less visible outside the scientific setting of the focus group. The focus group is, in line with this argument, not directly a method that can solve a problem of knowledge by producing specific data (Despret, 2004; Law, 2004; Stengers, 2000). Instead, focus groups can be able to change the problem by bringing new versions of the phenomenon into light. Thus, it can be an active tool for producing more contrasts. In addition, the metaphor of the experiment draws attention to the ethical considerations involved in using the social setting for data production more actively.

This article discusses the above themes by using data from a qualitative study on youth and alcohol based on thirty-seven focus group interviews. ${ }^{1}$ The teenagers were first interviewed in the $8^{\text {th }}$ grade (aged 14), and then re-interviewed in the $9^{\text {th }}$ and $10^{\text {th }}$ grades. In this way, each individual participated in up to five focus groups over the three years, but within different settings. The social dynamics unfolding in studies with groups of teenagers is often argued to be very strong (e.g. Green \& Hart, 1998; Allen, 2005; Fingerson, 2005) and could as such be argued to by leading to more socially biased or constructed data. The large number

\footnotetext{
${ }^{1}$ The author would like to thank the Rockwool Foundation for funding the research project "Youth and Alcohol" of which this piece of research is part. The project was directed by Professor Margaretha Järvinen and Professor Peter Gundelach, Department of Sociology, University of Copenhagen. The project group consisted of Jeanette Østergaard and Jakob Demant.
} 
of different focus groups on the same topic enables this paper to investigate an active strategy of using different "social experiments" in knowledge production.

\section{From representations to observations of presentations}

What does the focus group say about actual practice? The nature of interactional processes in the focus groups can in a social constructivist or in an interactional perspective be observed as representations of reality. The focus group is a unique method in that it can account for the ongoing processes, which - through interaction - unfold before the moderator as the interview progresses. The processes, interactions, discussions and powerrelations established between the participants can become basis for the researcher's method (Tanggard, 2007). Thus, the pivotal point of using the focus group is to recognize that the statements of an individual participant in the focus group are as much a product of the processes going on in the group as they are an expression of individual experiences. The individuals' presentations (Goffman, 1959) in the group can as such be viewed as socially negotiated representations of reality. If we turn towards the suggested understanding of the focus group as a social experiment, however, we could to a lesser degree perceive epistemologically the interaction in the group as re-presentations of a negotiated outside reality, but instead as presentations in the setting of the focus group. As such the focus group can be argued to produce data of the present; we can ethnographically follow what goes on in the interview. The data observed in the group as such changes character from somehow unclear representations to become presentations when the analytical setting is moved from the outside of the group to the inside of what happens in the group. The interaction practices are not represented in the interview but actually taking place during the interview. However, the focus group setting does not exist naturally. This brings us to the central question of this paper. How can we account for the awkward combination of natural occurring data (the interactions taking place here and now) and the artificial situation (the focus group as a social experiment)?

The traditional psychological experiment had the assumption that it is possible to test human or animal behavior by narrowing down the options of possible behavior (Barkan, 1996). These assumptions are abandoned by the modern randomized experiment, where control groups and statistics account for the finding of causal effects (Kristiansen \& Mooney, 2004). In the birth of the sociological tradition, experiments were regarded as making reliable data on society (e.g. positivistic concepts of social laws) (Brearley, 1931). But since the rise of Verstehende Soziologie the significance of the experiment was reduced in sociology (Gross \& Krohn, 2005). Social laws were generally abandoned as a central epistemological approach (Dehue, 2005). It was also questioned if it was possible to actually test social phenomena because of their complexities and the lack of controlled, experimental settings (Angell, 1932; Merton \& Kendall, 1946). In addition, the ethical questions of experimenting with people's lives were also a central issue.

In Science and Technology Studies the experiment has been closely related to the laboratory as the concrete setting of knowledge production. Karin Knorr Cetina argues that "Laboratories are based upon the premise that objects are not fixed entities that have to be taken "as they are" or left by themselves" (Cetina, 1999). At first the researcher does not have to "accept" the object as it is, but can transform it (as particles in fog chambers are transformed into traces), and second, the researcher does not need to work with the object 
where it is (in its natural setting a particle will in some cases be to complex, it can e.g. be isolated) and last, the researcher does not need to study the event when it happens (e.g. when a CERN particle accelerator simulates the moment of the big-bang). These descriptions fits overall on the focus group: it is a laboratory-like setting that constitutes the framing that transforms naturally existing data into a social experiment. This is a transformation of the interaction by the use of a different setting related to time and space. The focus group is as such a range of different techniques that transform natural interactions into a form, that assembles the social experiment. This makes the focus group a specific "inscription device" (Latour and Woolgar, 1979); a device that transforms first natural interactions into a form that enables the researcher to observe interactions in a way that makes us able to stabilize results in time and space (Barry 1995). The focus groups "laboratory" makes observations of social experiments possible through its technology ${ }^{2}$ of video-taping, one-way mirrors, discussion guides, conference tables and transcripts. The laboratory process will be a transcription device that makes certain natural occurring data observable as statements and transcripts.

\section{The passive experiment}

Even though most focus group studies use the rhetoric from the controlled experimental, the technologies are seldom regarded as partaking in the transformation of data. The methodological concepts of control groups and test groups are used in order to narrow down the risk of possible misinterpretation based on social interaction during the focus groups. ${ }^{3}$ In the same way, the use of stimuli material in focus groups is referring to an understanding of a stimuli-response relation in a closed setting. These technologies in the focus group methodology does as such support an epistemological assumption of the controlled social experiment.

The use of the controlled experimental setting for focus groups can be understood by what Andrew Barry (1995) has termed a passive technique. By accepting the focus group to be passive the researcher chooses not to understand it as acting upon the phenomenon that it describes. In other words, there is a tendency among researchers, when using the most controlled form of data collection, to describe the method as the most passive. If we use the passive understanding of the focus group we in the same time perceive how data is influenced by the setting of the group to be a bias. This means that such an approach supposes that focus group data is very close to natural occurring data, that may be "disturbed" by certain biases. There is a risk that the metaphor of the "natural" presents the researcher and focus group moderator as what Haraway (1998) has ironically termed a "modest witness": a scientist who through his observations only modestly describes the world. The focus group study is anything but a modest observation of facts. Indeed, Burman (2001) argues that a focus group to the participants always feels as "entering unfamiliar

\footnotetext{
2 Javier Lezaun's (2007) discussion of the focus group as a machinery for producing individual data is a very good example of an inscription device - even though he does not refer directly to Latour and Woolgar's concept.

${ }^{3}$ The notion of control groups means that several focus groups should be sampled and constituted in the same way in order to use the similarities to have more reliability of the method and therefore more valid results. Test groups are on the other hand groups with other compositions (eg. different mix of gender and age).
} 
territory". We as researchers do often need to familiarize participants with the concept of the focus group (by introduction) and with how to engage in discussions (by moderation) (Morrison, 1998; Lezaun, 2007). It becomes a non-natural formal social space with certain expectations on group participants. This means that there is a tendency to produce rather restricted data. In particular, it is a social setting where the often non-spoken rules exclude some kind of data (c.f. Despret, 2004).

I suggest acknowledging the artificiality of the focus group situation and as such view its techniques as an inscription device that co-produces data. This framing of focus groups methods puts emphasis on the virtue of concrete descriptions of methods and process, because it allows other researchers follow how it produces knowledge. At the same time the reframing of the focus groups as social experiments allows a more actively open strategy that makes researchers produce interesting data. I will now describe this by using the concept "active experiments".

\section{The active experiment}

Harold Garfinkel (1967, p.37) asks "what can be done to make trouble?": The ethnomethodologist must, by way of a friction or intervention, make elements of a phenomenon visible which are normally hidden in natural social settings. Garfinkel terms this a process of breaching: a way of gaining insights into aspects of lives which the qualitative interview probably would not give access to. Ethnomethodology finds ways to intervene in daily life (Garfinkel, 2002) in order to produce these breaches. However, the key strategy of the focus group is not to intervene into the common practices, but to produce an artificial or experimental-like situation that can establish productive interactions with the studied (Callon, 2006). I will discuss a case well known in Science and Technology studies to open up the discussion on how focus groups as experiments can become active in producing data on the entities studied.

In a discussion of a study of sheep (sic), Vinciane Despret (2005) argues along Certina (1999), Isabelle Stengers (2000) and Bruno Latour (2000) that the construction of the experiment is decisive for the kind of empirical data that is produced. Earlier studies of sheep behavior had focused on how sheep's behavior in the flock was affected by shortage of food. In Despret's experiment, however, an extra bowl of food was given to the animals so there were more bowls of food than animals. This implied that shortages of food were no longer a dominant factor in the observations. Most studies on sheep behavior have concluded that the herd is organized according to strength because strength is central in order to get food. In supplying plenty of food, the experiment attempted to shed light on other aspects of the behavior of the sheep. The sheep no longer only behaved strategically in their fight for food, but also organized their relations according to other principles. I will not go into details with the findings; I just want to point out that this study shows that sheep have an emotional relationship and that they do care for each other by making pairs (couplings), groups etc.

Even though there is a long way from experiments with sheep to focus groups, and I have absolutely no intention of suggesting that group participants are comparable with sheep, there is a methodological finding that makes the sheep-study relevant to focus groups. By strategically making the focus group differ from natural situations, it is possible to make 
other parts of the researched phenomenon visual to the researcher. Thus, focus groups can be used as a kind of ethnomethodological breaching or experiment, drawing out aspects which would otherwise have remained hidden. Whereas ethnomethodology is a way of making a phenomenon visible in the natural setting of everyday life, conducting focus groups is rather a matter of taking the phenomenon out of its embeddedness in everyday life. What I suggest is to try to actively establish interactions with the studied that enable it to speak up (Callon, 2006 Latour, 2004; Stengers, 2000). The social experiment can be used as already argued - as a form of enacting of reality and thus to pinpoint that it is not naturally occurring. This enacting is essential in order to actively use the method to bring aspects of the studied forward (at show and on the stage) and in that way make it interesting - both to those that are being researched (participants in the focus group) as well as to the research society. It is not only essential that the phenomenon become interesting to the researcher - as when she is able to visualize logics of the phenomenon - but it is equally important to make the studied (focus group participant) participate with interest in the subject studied. As such the argument of using the experiments of the focus groups actively is used in a slightly different way compared to how it is presented in "The Active Interview" (Holstein and Gubrium, 1995). 4

In line with the discussion of experiments with sheep it is essential that the scientific setting is active in making versions of the studied, that allow the hitherto mute to speak up. By creating a situation which differs from the everyday life of the participants, we can provoke statements and reactions about topics such as drinking alcohol, that would probably remain hidden to the subject in an everyday life context. The group interactions create the opportunity to investigate other versions of the same reality. The parallel to the social experiment should be regarded as central in constructing social data even though it does not mean that the researcher is able to control the setting. However, focus groups produce an intervention or shock to the social interactions by pushing group participants into orally expressing their thoughts on the subject, their positions in relation to others, their view on other participants' habits, etc. In light of this, I argue in line with Andrew Barry that "What is true is that which can be seen or can be made visible" (Barry, 1995, p. 54). When pushing the social interactions out of their ordinary settings we are able to investigate some of the other forms they might take. These forms of the phenomena are what Despret terms versions, which become very central contrasts in order to analyze yet again other versions of the phenomena. It is exactly because of the non-natural setting of

\footnotetext{
${ }^{4}$ The active interview technique successfully developed by Holstein and Gubrium is very central to sociology in its refined approach to understanding the interactions and power relations between interviewer and participant. As such they argue that interviews should be regarded as a social construction and less as a data collection process where the professional clean questions and related crisp answers could describe practice. The perspectives developed in the constructivist Active Interview approach are indeed relevant in the suggest approach to focus groups as social experiments suggested here. And they do by all means permeate the discussion in this paper. However, I suggest that the term active also could be used as a way to highlight how we can use the experimental focus group setting as a way of making the objects studied both interested in the study and objecting to the study. This argument has a very great debt to the active interview and the numbers of other central social construction perspectives to interviews. But whereas the argument of the social construction approach emphasizes the social situation between parts in the interview, I suggest focusing on the construction of the scientific setting.
} 
the focus group that we can produce these new versions. The focus group should not only be approached as a setting for investigating what we expect, but as a tool to add further courses to an explanation of a phenomenon. By epistemologically viewing findings as versions we, as researchers, could focus less on biases and focus more on how the focus group could be a tool to investigate versions of the phenomenon that we would probably not see otherwise.

In particular, two aspects in the active use of experiments should be considered: (1) how the researcher - intentionally or accidentally - creates a specifically artificial situation through composition of groups and facilitating interaction, and (2) how this can be used productively in making interesting data. In the following I will address these two aspects separately with an empirical example.

\section{Composition of focus groups}

One of the strengths of the artificially created social setting is that it enables the researcher to actively use the different positions of the participants to influence the social situations. This requires the researcher to consider the sampling of participants and group composition thoroughly. The methodological concept of sampling is primarily used in order to be able to strengthen the validity of general results in special quantitative data. When sampling is used in relation to focus group studies it in some cases relates to a practice of screening possible participants in order to ensure a combination of group participants in the same way as when dealing with quantitative studies (cf. Flick, 2007). That way it becomes possible to argue for general findings based on a quantitative notion of validity. However, I will argue that it is essential to look at the composition of groups for another reason as well. It is argued that composition of groups is not only a matter of "sampling" persons with a certain biography "outside" the group but also in question of how these persons can be made to interact inside the group.

The group composition is crucial in order to construct a social setting which enables the participants to interact in unexpected ways. In the research project on teenagers and alcohol I used a variety of group compositions which provided a unique possibility to explore the making of different versions of the phenomenon of teenage drinking. Even though the intended strategy of the focus groups aimed to facilitate specific aspects of the phenomena, it was not always these versions that appeared in the material. Thus some might argue that the strategies did not work. However they worked out well in terms of making it possible to discover how the different compositions of the focus group actually produced unexpected knowledge of the phenomenon. Here the research design showed - as it probably will in many studies - a dual practice of on the one hand trying to actually understand how data was formed by letting the data production strategy be part of the analysis. And on the other hand letting the experiments be as open as possible in order for the researched to be able to object and react with productive interactions.

In the focus groups sampled from the school classes, we decided to conduct male, female and gender-mixed groups. ${ }^{5}$ This configuration was chosen primarily in order to make the

\footnotetext{
${ }^{5}$ Groups consisting of friends were same-gender or gender-mixed according to whom the participants considered to be their friends.
} 
girls more comfortable with talking about alcohol. We assumed that the girls would be a bit shy when interviewed in gender-mixed groups, because we supposed that males would drink more and would have a tendency to talk more enthusiastically about their binge drinking. In order to meet our strategy of making the girls more comfortable, the girls only groups were moderated by a female moderator. Surprisingly, the expected data was not produced by this sampling strategy. It soon became clear that the girls in the $8^{\text {th }}$ grade often had more experience with alcohol than the boys their age, because some of them had been partying with older boys. In the gender-mixed groups the girls did not allow this 'male dominance' to silence them. Moreover, in a few of the boys only groups very few had alcohol experience, and the expected boastful behavior around alcohol was less evident (I will return to this). Thus, the sampling strategy might be considered a failure, because the construction of groups did not produce the expected data. It was, however, only because of the sampling strategy that this was revealed and could be included as a finding. My discovery about the girls in particular implied that I changed moderation and group composition strategy so that the groups of both boys and girls were moderated by both male and female moderators and that implied a greater openness towards the possible outcomes. In consequence, I changed the composition of the groups to be more in line with Despret's reflection on experiments - as active experiments that are supposed to make interesting and surprising data, and in which both the interviewed and the researcher get themselves involved.

In the present study the same teenagers were interviewed several times over the three succeeding years $\left(8^{\text {th }}, 9^{\text {th }}\right.$ and $10^{\text {th }}$ grades). This longitudinal design offered a good opportunity for investigating how the experienced drinkers positioned themselves in relation to the less experienced drinkers in the early grades, and how the different subject positions were negotiated when the participants changed their behavior. The experimental group composition also made it possible to see how the heavy drinkers reacted when some of the non-drinkers later took up their binge-drinking lifestyle. ${ }^{6}$ By the 9 th and especially the $10^{\text {th }}$ grade interviews most of the participants were partying and binge drinking on a regular (weekend) basis. Thus that the distinctions made by the experienced drinkers were no longer considered the most important by the other participants. One might suspect that the experienced drinkers would drink even more in order to keep their positions as the more mature, but in general this was not what happened. Instead the more experienced drinkers downplayed the significance of drinking heavily and in this way tried to construct those who had just started partying and drinking in the $9^{\text {th }}$ or $10^{\text {th }}$ grade as beginners or amateurs who had not yet found the proper way to practice drinking. However, most of the late starters were not willing to accept this social identity. Instead, they related to the social understanding that the experienced drinkers were able to make powerful in the groups (e.g.

\footnotetext{
${ }^{6}$ This study used a notion of procedural informed consent (Heath et al., 2009). Even though the teenagers involved in the study were fully informed of the study before partaking in it at grade $8^{\text {th }}$, we would not have been able to actually in detail describe the process of research all to the end of the longitudinal range. As such we tried constantly to inform and to accept that some might chose not to continue their participation. In this respect it was interesting that some of the very empowered participants (girls with intense drinking experience in the grade $8^{\text {th }}$ ) seemed unwilling to partake in the grade $10^{\text {th }}$. Their objection could be seen as a central finding; they were no longer able to set the agenda and would thus rather omit to partake.
} 
by presenting e.g. vomiting at parties as childish). They tried to re-present their drinking practice as more mature (according to the more experienced drinker' perspective). Some of the late starters did accept the image of the beginner, but used it constructively to change the presentation of themselves from a person who used to be quiet and non-partying but has matured and is now outspoken and sexually active (Demant, 2009).

As we have seen, the focus group creates different results and knowledge, depending on how we choose to compose the groups. The different versions of the phenomenon can be viewed as the strength of the method. The focus groups turned out to be a kind of social experiment; the alcohol discussions formed a specific social setting that let the researcher look into the more refined aspects of how alcohol works as a symbolic marker among youths. The experiment enables the researcher to construct different analytical perspectives on the same topic - through forming of different forms of focus group settings and thereby pose unpleasant, yet productive, questions to his or her own conclusions. It could be argued that the focus group data on the early debuting teenagers as well as the late starters might be possible to observe through ethnography in school classes. However, I believe that these findings were possible only because the teenagers were put into the experiment of focus groups and confronted with questions on drinking and that we - the researchers, as well as the teenagers themselves - were able to see different versions of realities. In the groups we were able to observe how teenagers both conformed and objected to symbolic dominance as well as how some worked hard to maintain their symbolical dominance through their drinking practice. Had we instead choosen a methodology of ethnography in school class-rooms we might not have observed the power relations around alcohol. In the class-room a separation of nondrinkers and drinkers may have made it impossible to observe the practice of dominance that is related to the alcohol-party identities. Thus, the "laboratory" of the focus group setting lets researchers target and challenge some of the 'natural' or matter-of-course practices which exist in the interviews with the teenagers and in this way gives the researcher a privileged insight into to the phenomenon.

\section{Interaction and moderator}

The interview guide creates an underlying structure for the focus group interviews. Relevant statements relate to the topics of the interview guide and are in this way possible within the discourse of the interview. In the study of youth and alcohol I, as a moderator, tried to build up an ambience in which the participants did not understand the interview (themes, style etc.) as an expression of a moral condemnation of their lives. In line with this, I tried to avoid facilitating a health or risk discourse at the outset of the interview. It is, however, open for discussion whether this has in fact made the group discussions more "naturally", or if it has facilitated another discourse. I will now address how moderation and themes can play an active part in opening up the interview. In particular, I will focus on the concept of natural data and the productiveness of failed interview situations where interview participants objected to the researcher's projection of them.

Green \& Hart (1998) argue that a focus group should have a kind of natural ambience. They argue that the participants' ability to act naturally in relation to each other will make it possible to have sincere and honest discussions, especially when interviewing children and young people. In their discussion of how to interview school-age children, they argue that 
the validity of the group results should be valued in relation to the success of creating a natural setting. They consider the setting to be more natural if some kind of chaos is generated in the focus group thus resulting in a natural ambience. ${ }^{7}$ These reflections are indeed very relevant and are visible in my own moderation technique of producing a social space for discussion close to the participant's everyday lives and interactions. However, as discussed, the focus group never puts the participants in a natural setting: even though aspects of their daily lives are discussed, they would in most cases be put on display in ways that are new to the participants (Warr, 2005), and the social situation forces the participants to engage in such a discussion. To discuss this, I will focus on what happened when I used bottles (alcohol, beer, alcopops and energy drink bottles) as stimulus material in the $8^{\text {th }}$ grade groups (14 years of age). The bottles were put on the table half an hour into the interviews when the participants had discussed the leisure life in their home town. The stimuli were introduced as a way of shifting focus towards alcohol and drinking. ${ }^{8}$

In most of the groups, the following happened: when the bottles were put on the table, it caused a lot of noise and inspired the participants to point comment and cheer. ${ }^{9}$ The ambience changed radically into a form of effervesce. Sometimes the participants asked for permission to grab the bottles, at other times they just grabbed them and started telling stories about drinking or about their attitudes towards the different kinds of alcohol. The alcohol products were used as a stepping stone to defining themselves in relation to each other. The bottles with alcohol seem to slide into most of the groups with some kind of naturalness. A quote from a group of girls from a $9^{\text {th }}$ grade focus group seems to confirm this: "You sit and talk like right now [in the focus group], just with a couple of beers on the table. Well, that's how I think of a house party." This statement could be understood as if the focus group discussion were very close to the situation of a group of friends talking together - a natural situation. Due to this, it was a great surprise that particularly two focus groups with boys did not respond when the bottles were put on the table. When the moderator asked about the products, it turned out that the participants knew of them and had tried drinking them in small amounts. However, alcohol was not a central element of their leisure lifeworld. As the bottles stood there on the table, they did not relate to the participants' stories or in any way interfere with their reality. The bottles were present in the discussions but did not have any central symbolic effect. The reluctance, uneasiness and negative comments to a certain theme or in a focus group as a whole are known from other studies (Pösö et al., 2008) but are seldom reported (Michael, 2004b). On one side, it would

\footnotetext{
${ }^{7}$ John Law (2004) argues that methodology should be allowed to be messy, because of the simple fact that society is messy. This argument is somehow not far from Green \& Hart (1998) and neither from the fact that sociology also does consider controlled experiments as too simplistic to match the complexity of society. Law's argument is as such both relevant and interesting, but has a tendency to understand method as transparent and in this way as not acting upon the object of study.

${ }^{8}$ It is interesting how especially commercial use of focus groups makes use of stimulus material. The point of the stimulus material is normally to test its effects on the group and their responses to its form, substance, taste etc. This use is mostly parallel to the traditional use of the social experiment.

${ }^{9}$ The focus groups were video filmed and transcribed using both video and audio, which made it possible to include the most central body language and gestures (e.g. Rosenstein 2002). But it is not possible to transcribe the aroused ambience of the groups. Despite this, the videotapes were valid sources for analyzing the material, exactly because they documented the observational part of the interactions in the groups.
} 
have been interesting to follow what other aspects that could have been relevant to them. Efforts in order to interest the boys in the research topic with another designing of the social experiment (other stimuli and other questions) could have contributed to the study. On the other side, it is also an interesting finding in it-self that the boys silently refused to participate in the discussion. The research 'objects' objected to use Latours (2004) words. The boys used their collective power to obstruct the dominant discourse facilitated by the moderator (through choice of topics and stimuli). This was a very strong and coherent local counter discourse that was in opposition to and awkward for the moderator. At first I considered these groups as failed. In order to keep the discussion going I found myself (as a moderator) asking more and more direct questions to the singular individuals in the groups, and the focus group changed into a group interview with a structured "guide". And no discussion arose as in the other groups. The groups were, at first, not transcribed as it seemed pointless to use them in the analysis. Even though these focus groups were considered failed, these groups nevertheless made it possible for the participating boys to position themselves rather powerfully (in this particular setting) by actually objecting to the maturity discourse, which I, as a moderator, was facilitating.

Stengers (2000) and Latour (2005) discuss how humans often become docile and obedient "objects" when studied by social scientists. However, the incident of the failed focus groups proves to be successful. The method was able to produce a situation where the "objects" would not only confirm or reject a thesis, but where some of the versions of the practices were put into words. This is not only an issue of visualizing seldom discussed aspects of a phenomenon. The collective power that was produced in these specific groups - these social experiments - made the focus group a central tool in producing interesting data that were new to the researchers. The objections would probably not have existed in casual class-room interactions between pupils but were produced in the social experiment of the focus groups. Michael (2004a, 2004b) argues that a somehow failed or mistaken element of the data collection is actually rather productive. In the present focus group study I similarly found that the way the participants objected to the (unspoken) expectations of the focus group actually provided what turned out to be very different findings. The failed interviews made it clear that the use of alcohol bottles as stimuli was thus not transparent (neutral), but worked to facilitate one particular kind of group discussion; a powerful discourse which connected alcohol experience to both maturity and gender, in ways that made it very hard for those with relatively little alcohol experience to reject it. An objection to this dominant way of self-presentation would position those in opposition as both childish and not presenting a self that would be culturally understandable in the setting of the Danish teenagers intensive drinking culture (Demant, 2009; Demant, 2007; Demant \& Järvinen, 2006). Thus, in the end these "failed" interviews proved to be very central because the versions that they actually provided became central contrasts to the other (dominant) versions of the phenomenon.

As we have seen, the focus group study is anything but a modest observation of facts (Haraway, 1997). It is an active co-production of reality by way of moderation, topics and sampling (Whatmore, 2003). Any moderation technique is active in some ways. When we acknowledge this, it first and foremost makes it more valid to work directly with asking questions that counteract the discourse in the interviews or in other ways interact in the social setting of the groups. The examples presented show how these aspects of the active 
un-naturally setting would not have occurred by themselves, and how they actually contributed with central versions of teenage drinking. And secondly, the examples also point towards the fact that the experiments should not alone be acknowledged as a control of the social focus group setting, but that they might as well open the study to constructive mistakes.

\section{Conclusion}

I have argued that if researchers explore the artificiality of the focus group setting we can provide very good and specific data on social interaction. It also enables us to transcend the unproductive discussion of when focus groups are biased in relation to real life situations. The un-naturally situations of the group are exactly the inscription devices that are able to articulate some of the social relations of which the vast majority is rather mute in other materials. In comparison, ethnography enables researchers to observe social interactions and relations in a natural setting. This is unquestionably the reason why it is often in the ethnographic field work that we sense some of the interesting - and hidden - logics of the social. However, even hanging out for a very long time in a "street corner society" will unlikely provide inscriptions of social interactions at the level of focus group interviews. This is because the focus group method is a device that can both transform the interaction in the present into an easily accessible form of data for analysis, and to an even greater extent because the artificial setting actively makes silent versions of the social interactions appear. As such, considering the focus group as an experiment facilitates an inclusion of some of the social logics that often remain mute in other kinds of data.

Focus group's social experimental character tend to produce data that would not have been found or produced in natural occurring data. As such, these data are constructed in the specific setting of the focus groups. I have argued that this data could be understood as versions. Desprets concept of versions is closely related to Donna Haraway's (1988) concept of situated knowledge. Both authors focus less on the epistemological problems with relative data, but argue that the concept of situated knowledge or versions is an opportunity to integrate science production as a part visualizing the many different and conflicting aspects of the phenomenon studied. Latour argues in the same line, when he describes the fact construction of science as a process of human and non-human actors that interact with the studied and how facts become possible only in the different inscription devices that are involved in translating them. As such different facts will be possible because science makes them solid through its construction. "Construction" has different implications from those of "social construction". Results do not become less real when we accept that they are a result of a number of inscription devices like focus groups. Instead we will have to be critical towards these inscription devices and ask the question: Have we, as researchers, made productive interactions with the objects studied so that these have had the possibility to act?

Methodologies using social or psychological experiments draw attention to the question of ethics. By applying the metaphor of the social experiment and being skeptical to the notion of the natural data in the focus group I also wish to expose the method of focus groups more to an ethical discussion. The process in focus groups may expose and in some cases suppress the participants. Thus the focus group always runs a risk of being unethical. Even though these issues become the more highlighted in relation to using 
focus groups as more active experiments they are as important in more passive forms of focus groups. It is the intention that the use of the concept of experiments in describing focus groups should draw more attention to these ethical problems and help push for a development of the discussion of ethics in relation to the use of focus groups. Even though focus groups are able to provide interesting data, it is necessary to discuss in what cases it would be more ethically sensitive to use other methods, and how to deal responsibly with some of the sensitive issues when they appear in - often unexpected situations. However, it also becomes an issue to discuss how social empowerment can happen in focus groups when participants object to being objects of research in a specific framing, thus making focus groups more ethical?!

Even though researchers design focus group studies in order to actively use the social setting experimentally for producing data, we should not - and cannot - control data. This is paradoxical: On the one hand, researchers are strategically trying to produce certain versions of reality through sampling, moderating etc., and on the other hand anticipate that these experiments will not necessarily produce the kind of data we expect. However, an active use of the experimental designing makes researchers focus on the fact that we are actually producing situated data. This means that we cannot hide behind a modest veil of passive methodological designs, even if we want to. And, secondly, the use of the active experiment would make researchers focus on how to produce settings that would unveil new versions of reality. Thirdly, these experimental designs should also make researchers take interest in what happens when things go wrong: what aspects of the design actually enforced these situations and ask what are the logics of group participants objecting to the data design that the researcher made (either manifest or latently).

The reintroduction of the social experiment in relation to focus groups can make researchers more aware of how the method can be active in data production. The epistemological position of the social experiment as an active inscription device is as such not (only) a critical view on focus group methodology. It is critical towards the argument that validity is obtained through a "close to natural" situation. However, it does not abandon focus groups with a potential relativistic status as has happened within some social constructivist approaches. Instead it is argued that focus groups as social experiments situates findings within a more clear and transparent methodology. The validity of focus group methods must, within this perspective, be judged on its ability to provide (and clearly describe) active experiments that can contribute with situations for groups participants to provide other versions of the studied. These kinds of approach are not at all absent in most focus group studies. But reframing the focus group epistemological as social experiments forces us as researchers to pinpoint how the focus groups can be a productive social space for making translations that are less possible to follow in other data materials.

\section{References}

Allen, L. (2005). Managing masculinity: young men's identity work in focus groups. Qualitative Research 5(1), 35-57.

Angell, R.C. (1932). The Experimental Approach II. The Difficulties of Experimental Sociology. Social Forces 11(2):207-210.

Atkinson, P. \& Silverman, D. (1997). Kindera's Immorality: The Interview Society and the Invention of the Self. Qualitative inquiry 3: 304- 325. 
Barkan, D. (1996). The crisis in Psychology. Journal of Social Distress and the Homeless 5(4): 335-342.

Barry, A (1995). Reporting and Visualising. In C. Jenks (ed.) Visual Culture, London: Routledge.

Brearley, H.C. (1931). Experimental Sociology in the United States. Social Forces 10(2):196199.

Burman, M., Batchelor, J.S.A. \& J.A. Brown (2001). Researching Girls and Violence. Facing Dilemmas of Fieldwork. British Journal of Criminology 41(3): 443-59.

Callon, M. (2006). Can methods for analysing large numbers organize a productive dialogue with the actors they study?. European Manegement Review 3: 7-16.

Cetina, K. K.(1999). Epistemic Cultures. How the Science Make Knowledge. Cambridge: Harvard University Press.

Dehue, T. (2005). Social Experiments, History of. In K. kempf-Leonard (ed.) Encyclopedia of Social Measurement 3(P-Y):509-516.

Demant, J. \& Järvinen, M. (2006). Constructing maturity through alcohol practice - Focus group interviews with teenagers. Addiction Research and Theory 14(6): 589-602.

Demant, J. (2007). Youthful drinking with a purpose. Intersections of age and sex in teenage identity work. Nordic Studies on Alcohol and Drugs 24(2): 133-159.

Demant, J. (2009). When alcohol acts: An actor-network approach to teenagers, alcohol and parties. Body E Society, 15(1):25-46.

Despret, V (2005). Sheep Do Have Opinions. In B. Latour \& P. Weibel (eds.) Making Things Public: Atmospheres of Democracy. Massachusetts: Cambridge.

Despret, V. (2004). Our Emotional Makeup. Ethnopsychology and Selfhood. New York: Other Press

Dimitriadis, G. \& Weis, L. (2001). Imagining possibilities with and for contemporary youth: (re)writing and (re)visioning education today. Qualitative Research 1(2): 223-240.

Fingerson, L. (2005).'Year, Me too': Adolescent talk building in group interviews. Sociological Studies of Children and Youth 11: 261-87

Flick,U. (2007). Managing Quality in Qualitative Research, Los Angeles: Sage.

Garfinkel, H. (1967). Studies in Ethnomethodology. New Jersy: Prentice-Hall.

Garfinkel, H. (2002). Ethnomethodological Politics and Method. In H. Garfinkel, Ethnomethodology's Program. Working out Durkheim's Aphoris. New York: Rowman \& Littlefield Publishers.

Goffman, E. (1959). The Presentation of Self in Everyday Life. New York: Doubleday.

Gubrium, E. \& Koro-Ljungberg, M. (2005). Contending With Border Making in the Social Constructionist Interview. Qualitative Inquiry 11: 689-715.

Green, J. \& Hart, L. (1998). The impact on Context on Data. In R.S. Barbour \& B. J. Kitzinger (eds.), Focus Group Research. Politics, Theory and Pratice, pp. 21-35. London: Sage.

Greenbaum, T. (1998). The Handbook of Focus Group Research. London: Sage

Gross, M. \& Krohn, W. (2005). Society as experiment: sociological foundations for an selfexperimental society. History of the Human Sciences 18(2): 63-86.

Halkier, B. (2010). Focus groups as social enactments: integrating interaction and content in the analysis of focus group data. Qualitative Research, (10) 1: 71-89. 
Haraway, D.J. (1988). Situated Knowledges: The Science Question on Feminism and the Privilege of Partial perspectives. Feminist Studies 14(3):575-599.

Haraway, D.J. (1997).Modest_Witness@Second_Millennium.FemaleMan(c)_Meets_OncoMouse (TM). Feminism And TechnoScience. New York: Routledge.

Holstein, J. \& J. F. Gubrium (1995). The Active Interview. London: Sage.

Kristiansen, I.S. \& Mooney, G. (2004). Evidence-based medicine. Method, collaboration, movement or crusade? In I.S. Kristiansen \& G. Mooney (eds.) Evindence-Based Medicine. In its place, pp. 1-19. London: Routledge.

Kvale, S. (2006). Dominance Through Interviews and Dialogues. Qualitative Inquiry, (12) 3: 480-500.

Law, J (2004). After Method. Mess in social science research. London: Routledge.

Latour, B. (2000). A Well-Articulated Primatology: Reflections of a Fellow-Traveller. In S. C Strum and L. M. Fidigan (eds.) Primate Encounters. Models of Science, Gender, and Society. Chicago, University of Chicago Press.

Latour, B (2005). Reassembling the social. An Introduction to Actor-Network-Theory. Oxford, Oxford University Press.

Latour, B \& Woolgar, S (1979) Laboratory Life: The Social Construction of Scientific Facts. Beverly Hills: Sage.

Lezaun, J. (2007). A market of opinions: the political epistemology of focus groups. In. M. Callon, Y.Millo \& F. Muniesa (eds.). Market Devices. Oxford: Blackwell Publishing.

Meyers, G. \& Macnaghten (1999). Can focus groups be analysed as talk? In R.S. Barbour \& J. Kitzinger (eds.). Developing Focus Group Research: Politics, Theory and Pratice. London: Sage.

Merton, R.K. (1987). The Focused Interview and Focus Groups: Continuities and Discontinuities. The Public Opinion Quarterly 51 (4): 550-566.

Merton, R.K. and Kendall, P.L. (1946). The Focused Interview. The American Journal of Sociology 51 (6): 541-557.

Michael, M. (2004a). On making data social: heterogeneneity in sociological practice. Qualitative Research 4(1): 5-23.

Michael, M. (2004b). When things go wrong. In: C. Seale (ed.). Researching Society and Culture. Second edition. London: Sage.

Morgan, D. \& Spanish, M. (1984). Focus Groups: A New Tool for Qualitative Research. Qualitative Sociology, 7(3): 253-270.

Morrison, D.E. (1998). The Search for a Method: Focus Groups and the Development of Mass Communication Research. Luton: University of Luton Press.

Pösö. T., P. Honkatukia \& L. Nyqvist (2008). Focus groups and the study of violence. Qualitative Research 8(1):73-89.

Silverman, D. (2007). A very short, fairly interesting and reasonably cheap book about Qualitative Research. London: Sage.

Stengers, I. (2000). The Invention of Modern Science. Minneapolis: University of Minnesota Press.

Tanggard, L., (2007). The Research Interview as Discourses Crossing Swords. The Researcher and Apprentice on Crossing Roads. Qualitative Inquiry 13(1): 160-176. 
Warr, D.J. (2005)."It was fun. But we don't usually talk about these things": Analyzing Sociable Interaction in Focus Groups. Qualitative Inquiry, (11): 200-225.

Whatmore, S. (2003). Generating materials. In. M.Pryke, G.Rose \& S.Whatmore (eds.). Using Social Theory. Thinking Through research, pp. 89-104. London: Sage. 


\title{
Beginning with the Self to Critique the Social: Critical Researchers as Whole Beings
}

\author{
Nancy Taber \\ Brock University \\ Canada
}

\section{Introduction}

In this chapter, I argue for the importance of problematizing researcher subjectivity using an analytic autoethnographic lens in critical social research, from a feminist perspective. The aim is not to use autoethnography as a methodology per se, but to use autoethnography as a theory and a method as an (iterative) starting point to interrogate social ruling relations. In much the same way that Dorothy Smith (2005) explains that institutional ethnography is not only a methodology but is a "sociology for people" (p. 220), I view autoethnography as a lens through which researchers can connect their own everyday lives to the various contexts of their research in order to engage in a societal critique.

To do this, I begin the chapter with a brief introduction of my own positionality in relation to my argument (a brief autoethnography). This chapter is centred on my own experiences, connecting my personal life with my ongoing scholarly journey, leading me to address the question, Am I am feminist anti-militarist (Enloe, 2000, 2007; Feinman, 2000) or do I use feminist antimilitarist theories? In so doing, I explore how my research is very much connected to who I am, not only as a scholar, but in other contexts of my life. In other words, I do not simply utilize theories, but I live them.

Next, I draw on the work of bell hooks (1994) to explore academics as whole beings with bodies, emotions, and lives outside academia, not as decontextualized disembodied minds confined to research. In my argument, I also discuss researchers from various disciplines who explicitly examine how their own selves (i.e., who they are themselves as humans as well as how they appear to others) directly affect their research itself (Ellingson, 2006; Reich, 2003; Woodward, 2008).

Then, I discuss the main tenets of autoethnography (Anderson, 2006; Reed-Danahay, 1997a, $1997 b, 2002)$ leading to an exploration of how it can be used to frame other methodologies conceptually, theoretically, and empirically (i.e. as a theory and a method). I delineate how an examination of embodiment, subjectivity, and researcher positionality through autoethnographic methods can be an entry point into critical social research, but should not be the end point.

Finally, building on Smith's $(1987,1999,2005)$ work on institutional ethnography, I discuss how, in critical social research, the aim is to explore ruling relations with the purpose of 
critiquing systemic structures. Due to intersecting oppressions, while it is often not possible to delineate people categorically into the oppressed and the oppressors (as Freire, 2000 might argue), it is nonetheless important to explore how systems (as created, maintained, and altered by humans) serve to marginalize and oppress certain groups of people (as well as non-human animals and the earth itself) while privileging others. By beginning with the self, I argue, researchers can better explore their own positionality in order to critique the social.

\section{My own journey as a researcher}

I came to academia through a rather circuitous route. Indeed, having a career as a scholar had never entered my mind when I was younger. As a teenager, I wanted to have an exciting life that was nontraditional for a woman, so I decided to join the Canadian military. I went to military college for my undergraduate degree, trained as an air navigator, and deployed on Canadian destroyers and warships as a Sea King helicopter Tactical Coordinator (TACCO). I loved my life in this "masculine" role, disregarding the ways in which my being a woman often worked to my detriment. However, I gradually became further and further dissatisfied with militarized masculine ways of knowing and acting, eventually deciding to leave the military after getting married and having a child. During my last few years of service, while on a ground tour (after deploying operationally), I had also become increasingly involved with military Workplace Relations (WR), facilitating anti-harassment seminars and participating in the mediation of disagreements that fell under the parameters of WR. Knowing I would need some other form of education to help me successfully switch careers, I took my Master of Education (MEd) degree, originally intending to participate in military WR as a Reserve Officer or as a civilian.

Eventually, I came to realize that, although WR policies were intended to increase tolerance and decrease harassment, they could only do so much. My MEd helped me to see the world in different ways, as I read work by critical and feminist scholars, and I began to question my experiences in the military, starting to see them from a political perspective, not just a personal one. I became enthralled with the ability of theory to illuminate my understandings of the world (see Taber, 2005, for an exploration of how my MEd led me to consciously and critically question my place in the military). I began to acknowledge that "the importance of our everyday experiences cannot be ignored, and are a rich source of data when approached with an integration of theory and reflexivity" (Taber, 2005, p. 290). My personal story is unique to me and does not speak for others. However, "my narrative is important to reveal the complexities of being a woman in the CF [Canadian Forces], and to connect women's experiences with organizational ruling relations and societal influences. We cannot afford to separate theory and research from the daily experiences of women" (Taber, 2005, p. 299).

My article about my gendered learnings in the military has led to my understanding that, in an organization that valued heteronormative militarized masculinity, women and those designated as "other" are only likely to be tolerated, not accepted in any sense of the word. As I have more recently written in reference to my research with military mothers (Taber, 2011c), policies intended to recruit and retain women members are "a safe way for militaries 
to appear gender-equitable at the same time as they are able to protect the militarized hegemonic masculinity that characterizes their organizational cultures" (p. 345). There appears to be no intention of changing military culture, just making designated groups fit the system better. However, at the time that I left the military, my understandings of these complex dynamics were just beginning to emerge. It was in doing further reading and research that I was able to problematize the connections between my own experiences and the military organizational context.

After my MEd, I did some consulting work in the field of career development and taught a non-credit post-secondary student success course. I then began teaching courses with my MEd alma mater as a Lecturer. In so doing, I realized that I wanted a career in academia. Over the next several years, I took my $\mathrm{PhD}$ in Education, taught in a limited term appointment (LTA), and attained a tenure-track position. Originally, while working on my $\mathrm{PhD}$, I did not want to explore anything even remotely related to my military experiences. I eventually came to realize that it was precisely those military experiences that needed to be problematized, centering my dissertation (Taber, 2007; also, Taber, 2011b in book format) on them. I used autoethnography as an entry point into an institutional ethnography of the military (see Taber, 2010 for an extended discussion of my methodology, as well as below), exploring how my experiences connected to military policies and texts, as well as to books written for the children of military members.

Instead of separating from the military, as I once thought I would do, my research program extends from it. As I wrote in my dissertation:

I made a decision to ground my research from my own standpoint in the everyday as a woman, a former mother in the military, and as an academic whose work increasingly draws upon notions of social justice and care, using autoethnography and access to military information in the public domain. It is this often contradictory standpoint [as a former military member critiquing the military] (which I do not aim to resolve) that grounds my research, and is useful as it allows me to explore the military from both 'insider' and 'outsider' perspectives (Taber, 2007, pp. 50-51).

In retrospect, it was rather naïve to think that there was a before, during, and after to my military life, each neatly detached from the others, with one aspect of my life never informing another one. By embracing my own personal history instead of separating from it, I have built a research program focusing on militarism, gender, and learning, extending my military analysis from my experiences and the military institution itself to the experiences of other military mothers, everyday life, popular culture, and children's literature.

In telling my story, I aim to demonstrate that I am not an objective, unbiased researcher who is disconnected from her focus of study, nor do I want to be. My personal history, experiences, and subjectivity strengthen my research; they do not detract from it. "My understandings of military life, combined with my feminist academic background, make me unique as a researcher focusing on the organizational policies and practices of the military" (Taber, 2010, p. 12). By acknowledging that I am not disconnected from my research, I can better position myself as a whole being; various aspects of my life are not dichotomized but are interconnected. I do not simply use theory and methodology in my research, I live it. 
The question of how theory is embedded in my life came up in conversation with a colleague several years ago. I was describing how, in introducing myself in the first session of one of my courses, I had explained that I am a feminist antimilitarist. My colleague asked why I had used that specific framing of myself. Why had I not, he asked, simply stated that I used feminist antimilitarist theory? The question was an illuminating one, prompting me to think of my own positionality as a scholar. Why indeed had I employed that specific wording? Am I a feminist antimilitarist or do I use feminist antimilitarist theory?

Feminist antimilitarism critiques "armed force as a way of politics....[and engages in a] complex analysis of militarism...to destabilize notions of gendered armed forces...to account for the economic and environmental repercussions of maintaining a militarized government, and to separate martial service from first-class citizenship rights" (Feinman, 2000, p. 212). It explores how "military needs and militaristic presumptions [are seen] to be not only valuable but also normal.... [Militarism] involves cultural as well as institutional, ideological, and economic transformation" (Enloe, 2000, p. 3). In specifically addressing how gender and women are wrapped up with militarism, Enloe argues that:

Militaries rely on women, but not all women experience militarization identically. Militaries have needed, and continue to need, some women to provide commercialized sexual services to male soldiers, other women to commit themselves to marital fidelity in military families; simultaneously, they need still other women to find economic security and maybe even pride in working for defense contractors. At times governments even need some civilian women to act as feminist lobbyists promoting women's right to serve in the state's military (Enloe, 2000, p. xii).

It is this complex web of somewhat contradictory relations that has captured my personal and academic interest, bound up in my personal experiences, scholarly research, and professional identity. I believe that my research informs my life and my life informs my research. I do not so much use feminist antimilitarist theories as I live and breathe them. The ways in which I view the world, in my everyday life outside academia, are very similar to the ways in which I view it in academia. When I interact with my family and friends, with my community, with news media and popular culture, feminist antimilitarist theories inform my understandings, words, and actions. In other words, my life as a scholar is very much connected to my life as a citizen, community member, mother, partner,... I do not claim a harmonic identity without contradiction or complication (and certainly there are various understandings of feminist antimilitarism), but that I have recognized that I am a whole being who cannot separate one aspect of her life from another. Upon reflection, I realized that the wording I originally used was extremely apt. I can claim that I am a feminist antimilitarist.

\section{Subjectivity, researcher positionality, and whole beings}

How (or even if) a researcher locates her/himself in research depends on the focus of specific research projects and the various research methodologies that could be utilized. For instance, ethnographies, case studies, grounded theory, narrative, and phenomenology focus on participant cultures, experiences, stories, and understandings (Creswell, 2006). In each case, a researcher may or may not choose to explore her/his own positionality, 
although with narrative, it is common for researchers to share their own stories (Clandinin \& Connelly, 2000; Cole \& Knowles, 2001) and in autoethnography, researchers' stories themselves are the focus.

In general, much of qualitative research does entail researcher reflexivity on her/his own subjectivity and how she/he is positioned with respect to her/his research. However, although "most qualitative researchers are reflexive...they do not publish their reflections.... To many researchers, it seems safer to leave some issues unspoken and unwritten" (Possick, 2009, p. 861). Publishing reflections can leave researchers feeling vulnerable and "may lead to criticism by colleagues that the researcher is too subjective" (p. 861).

Nonetheless, many researchers are overtly reflective, acknowledging that they are not objective outsiders but are intricately connected to the contexts and participants of their research. In fact, as Woodward (2008) states:

the insider/outsider dichotomy and that between objectivity and subjectivity... are based on far too crude a polarization. The research process can never be totally 'inside' or completely 'outside', but involves an interrogation of situatedness and how 'being inside' relates to lived bodies and their practices and experiences (Woodward, 2008, p. 547).

Researchers' lived bodies come not only with minds (which are often privileged above all else in academia) but with spirits, emotions, and whole lives. hooks (1994) argues that "the task for those of us who chose this vocation [of academia] was to be holistically questing for self-actualization" (p. 16). She states that, unfortunately, "The idea of the intellectual questing for a union of mind, body, and spirit had been replaced with notions that being smart meant that one was inherently emotionally unstable and that the best in oneself emerged in one's academic work" (p. 16). This disconnection between the lived experiences of academics and their scholarship as teachers and researchers is a result of "a mind/body split, one that promotes and supports compartmentalization" (p. 160).

It is impossible to work as holistic beings when "what counts" in academia is measured solely by the scholarly work of disembodied minds. Yet it can be difficult to bring selves into research, particularly when much of academia frowns on it, even in qualitative research. hooks (1994) states that "most professors must practice being vulnerable in the classroom, being wholly present in mind, body, and spirit" (p. 21). I would argue that this is equally true for researchers. To bring in one's own story to academic work can be an uncomfortable exercise in vulnerability. Yet one's subjectivity, embodiment, and experiences always affect research, whether it is recognized or not.

An interesting example of a researcher who recognized how her embodied self was intricately connected with her work is Reich's (2003) account of the ways in which her pregnant body interacted with her research in child protection. While she at first tried to hide and then downplay her pregnancy, she eventually embraced it as a researcher.

Realizing I could no longer avoid it, I surrendered to the assigned role of pregnant person, and began to observe the expectations of that role. I was surprised to find that my own pregnancy was an important source of data, both in terms of more viscerally understanding the experience of the public gaze pregnancy and children elicit and in terms of the unique information it yielded (Reich, 2003, p. 356). 
Feminist research, although as diverse as the various forms of feminism (Ramazanoglu \& Holland, 2002), has main tenets that support researcher reflexivity. It contests the argument that "the voice of science is a masculine one" (Harding, 1986, p. 3) from a positionless objective standpoint (Smith, 1999). "Defining what is in need of scientific explanation only from the perspective of bourgeois, white men's experiences leads to partial and even perverse understandings of social life. ...feminist research...generates its problematics from the perspective of women's experiences" (Harding, 1986, p. 7). By acknowledging academics as whole beings, we can resolve the "bifurcation" that often exists between the world scholars experience in academia and in everyday life (Smith, 1986). "The only way of knowing a socially constructed world is knowing it from within. We can never stand outside it" (Smith, 1986, p. 92). Feminism not only places gendered social relations at the centre of analysis, which is an achievement in itself, but "it insists that the inquirer her/himself be placed in the same critical plane as the overt subject matter, thereby recovering the entire research process for scrutiny" (Harding, 1986, p. 9). The researcher cannot be detached from the research.

In my own research, although I have often highlighted an exploration of my own subjectivity (i.e. Taber, 2005, 2007, 2011a), I have also unconsciously sidelined it. For instance, in conducting a collaborative narrative inquiry on the experiences of adult educators, my co-researchers and I gradually came to an understanding that, in an effort to be collaboratively open-minded, we had unintentionally disregarded our own conceptual and theoretical understandings, only to have them resurface through our data analysis (Taber, Howard, \& Watson, 2010).

In our original attempts to engage in a collaborative process with each other as researchers, we consciously focused on how to work well together while unconsciously sidelining issues of our own subjectivities and analytical frameworks. When we began to consciously acknowledge our own perspectives, both individually and collectively, we were able to view the data in a different light (Taber, Howard, \& Watson, 2010, p. 41).

By collaboratively acknowledging who we were as scholars, we were better able to reflexively analyze each of our own interactions with the data and the research. We argued that, as researchers, there are "unique ways in which we bring our personal selves to our research process.... We wear lenses from our own lived experiences that inform us...we must be diligent in our practice of reflexive inquiry" (p. 45). Subjectivity "is a powerful yet too often unacknowledged and unexplored tool" (Taber, Howard, \& Watson, 2010, p.41) for understanding research, participants, and researchers themselves. We therefore explored how, "by locating our presence within the inquiry process in a more intentional manner, we were able not only to attend to our participants' stories, but to forefront how our own various perspectives informed our findings" (p. 46). In other words, we were better able to explore how who we are continually interacts with how we research.

In a separate collaborative research project that led to conducting a girl empowerment book club for struggling readers (through a sociological case study), our research stance was much more delineated from the beginning. In fact, another faculty member and I had decided to work together based on our differing interests (mine on gender and hers on learning exceptionalities). As we proceeded with our research, a graduate student also 
began to work with us, moving from her position as a research assistant to a collaborative research partner. What became interesting for us methodologically was how we began to interact with our participants, attempting to balance the tensions in our roles as researchers, observers, and facilitators for girl empowerment (Lane, Taber, \& Woloshyn, in progress), which were intricately connected to who we were professionally and personally. One aspect of our work explored how, at various stages in our careers, we have different professional concerns and personal situations, as well as varying scholarly foci, each of which affected our research.

While one of us was a full professor who was formally secure in her university position but is in an ongoing search for ways to engage in meaningful research, one of us was applying for tenure at the time of the research, with the other completing her Master's degree and applying for a PhD program. As such, we were feeling differential pressures to complete our research in order to publish it in peer-reviewed journal articles. Feminist research can be challenging as universities typically value forms of academic commitment and productivity that 'are generally defined within a masculine marketplace framework' (Gouthro, 2002, p. 8). Universities are becoming ever more corporatized (Reimer, 2004; Webber, 2008) leading to the "commercialization of all aspects of university life" (Hornosty, 2004, p. 47) wherein "the primary danger...is the subtle intrusion of a corporate ideology, which works to redefine the university's priorities" (p. 48). This corporate ideology often gives "priority to entrepreneurial-type research" (p. 54) which "undermine[s] feminist research...which would carry little weight in tenure and promotion considerations" (pp. 54,55). Although our focus on girl empowerment never wavered, we were conscious of the ways in which the academic context in which we work interacted with our research as well as with our plans for publication. Ignoring this context, and how our subjectivity as researchers and academics affected the research process, would have been to negate significant influences on our work. At the same time as we were dedicated to our participants and our research aims, we were conscious of the need to publish in order to move up the academic ranks.

I argue that, regardless of methodology used, it is always appropriate to examine researchers' subjectivities through an autoethnographic lens. I have conducted various research projects, as described above, that drew on the different methodologies of institutional ethnography (with an autoethnographical entry point), narrative inquiry, and sociological case study. In each of these examples, a critical examination of researcher subjectivity and positionality became integral to the research process. Ramazanoglu and Holland (2002) state, "if you want direct contact with research subjects, it may be useful to reflect on your own experiences and to clarify your taken for granted assumptions where these could be relevant" (p. 155). I extend this statement to encompass any research, including that which does not use human participants. The positionality of researchers is an inherent part of research, whether acknowledged or not. Although many researchers do explore their subjectivity, this exploration should be extended to allow for an appreciation and acceptance of researchers as whole beings who are central to their own research.

\section{Autoethnography: Connecting the self to the social}

Autoethnography is a research methodology that places the researcher in the research as a participant, with varying emphases on the self and the social (Reed-Danahay, 1997a). 
Ellingson's (2006) work points to the ways in which autoethnography can "(potentially) offer embodied details, celebrate the author's position, problematize the production of knowledge, and reveal the profane [i.e. the body] in the sacred processes of research" ( $p$. 304). Autoethnography makes the researcher central to the research process, refusing to view researchers as disconnected in any way from their research. However, autoethnographers disagree on the specific position that a researcher's self should take in relation to the social.

A useful definition from Reed-Danahay (1997a) describes autoethnography as "referring either to the ethnography of one's own group or to autobiographical writing that has ethnographic interest. Thus, either a self (auto) ethnography or an autobiographical (auto) ethnography can be signalled by 'autoethnography'" (1997b, p. 2). She views these two types as not discrete but connected, with autoethnographic researchers exploring self within a larger ethnographic context.

While certain scholars would argue that a research focus on the self should be privileged without an overt sociocultural critique, where making meaning is left to the reader, termed evocative autoethnographies (Ellis \& Bochner, 2000; Ellis, 2002, 2004), others argue that the self should be used as an entry point only, enabling an exploration of experiences that leads to a sociocultural analysis, termed analytic autoethnographies (Anderson, 2006; Atkinson, 2006; Atkinson \& Delamont, 2006). I subscribe to the latter argument, wherein the research aim is not to explore oneself per se, but to engage in a sociocultural critique by beginning in one's everyday experiences (Taber, 2005, 2007, 2010, 2011a), exploring how and why we as researchers come to focus on specific concepts, theories, questions, and methodologies.

Atkinson and Delamont (2006) welcome the introduction of stories into qualitative research at the same time as they bemoan the ways in which they are often accepted at face value. They contend that a critical analysis of any data, in particular that which arises from personal experience stories, is crucial. Stories should not stand on their own but should be interrogated in order to engage in a social critique.

When it comes to personal narratives, spoken performances, oral testimony and autoethnographies, we should not simply collect them as if they were untrammelled, unmediated representations of social realities. While the development and spread of qualitative social science are to be welcomed, too many of its manifestations result in slack social science, born of an adherence to the evocation of 'experience', as opposed to the systematic analysis of social action and cultural forms. It is, we suggest, a vital corrective that narrative should be viewed as a form of social action, with its indigenous, socially shared, forms of organization. Narratives should be analyzed as a social phenomenon, not as the vehicle for personal or private experience (Atkinson \& Delamont, 2006, p. 170).

When "narrative [is]...viewed as a form of social action," it can become a vital starting point for critical social research. Walford (2004) similarly argues that researchers "learn about the general from the particular" (p. 413), which necessarily means that we cannot stay with the particular alone. Personal stories should be a starting point (and iterative touchstone) that allows researchers to link the self to the social. 
More recently, Reed-Danahay herself (2009) argues for critical autoethnography, stating:

Autoethnography is not the kind of autobiography in which the author as hero or heroine is neither constrained nor assisted in life by economic, social, or cultural position; autoethnography is also not a form of writing ethnography that erases the anthropologist and his or her encounters with research participants. It is a form of writing, a method for life writing and for social analysis, which depends upon an ethnographer's capacities for observation and sensibilities of empathy, reflexivity, and critique. Autoethnography falls squarely at the intersection of insider and outsider perspectives, and thereby encourages us to explore more fully the implications and, perhaps, misguided uses of this dualism (p. 43, italics added).

It is precisely the "method for life writing and for social analysis" for which I am arguing. In all forms of research, researchers should connect who they are with what and who they research. As Reed-Danahay (1997b) states, "The notion of autoethnography foregrounds the multiple nature of selfhood and opens up new ways of writing about social life" (p. 3). When researchers connect their own lives to their research, they do not explore decontextualized phenomena to which they are disinterested, but explore meaningful issues in which they are intricately invested. Motzafi-Haller (1997), who conducted an autoethnography of her insider/outsider research as a Mizrahi (minority) Jew in Israel, describes her connection to her work as follows: "The questions I dealt with were not abstract issues of social justice but pertinent to my daily existence" (p. 202).

An autoethnographic lens should therefore start with the self in order to the critique the social. There is a "dual nature of social research: that it depends both on some connection with that being researched and on some degree of separation from it" (Davies, 1999, p. 10). Therefore, researchers should consider "how does who I am, who I have been, who I think I am, and how I feel affect data collection and analysis"? (Pillow, 2003, p. 176).Yet, this begs the questions, "how much autobiography is too much? How much is not enough? Disclosing ourselves in our research is risky, and, at the same time, frightening" (LePage \& Givens-Generett, 2003, p. 26). This risk points to the importance of "foreground[ing]" (Possick, 2009, p. 861) researcher reflections due to the ways in which "emotional experiences...aid understanding and raise significant unanticipated insights (Lankshear, 2000)" (Possick, 2009, p. 861).

Unfortunately, "certain discourses, such as disembodied, abstract theories, have a high status in our Western society; [and] others, the embodied [and emotional] ones, have less prestige and often gain less hearing" (Abma, 2002, p. 7). There is a "myth of the positionless speaker as the one who speaks the most valuable truths....'Masculinity' and 'science' gain much of their status through their claim to positionless 'truth'; that is, a truth that, no matter who one is or where one stands, would still be the same" (Davies, 1992, p. 54). Smith (1986, $1987,1999,2005)$ also argues that there is no such thing as a positionless speaker. Any claim to be thoroughly objective is false. All research and all researchers come from somewhere, with their own histories, perspectives, and understandings.

By using autoethnography as a research lens, researchers can acknowledge the ways in which they are connected to their research and use these connections as valid and validated entry points into their work, as well as touchstones throughout the research process. This approach treats researchers as holistic beings with bodies, minds, and spirits, not disembodied decontextualized positionless minds. It is important therefore to not only have 
a methodological understanding of autoethnography, but a conceptual one as well. While there may not be a place for a full autoethnography in every research project, there is certainly a place for an autoethnographic lens that explores the researcher's subjectivity and positionality as a whole being in relation to research.

\section{Critical social research: Using institutional ethnography as a sociology}

Smith's (1999) work points to the importance of starting research from the everyday lives of women, as researchers and participants. Researchers need to work from the bottom-up, beginning with the localized concrete realities of people's lives, not from grand theory that proposes an overarching generalized view of universal knowledge. She argues that:

The standpoint of women....begins one step back before the Cartesian shift that forgets the body. The body isn't forgotten; hence, the actual local site of the body isn't forgotten. Inquiry starts with the knower who is actually located; she is active; she is at work; she is connected up with particular other people in various ways; she thinks, eats, sleeps, laughs, desires, sorrows, sings, curses, loves....Activities, feelings, and experiences hook her into extended social relations, linking her activities to others and in ways beyond her knowing (Smith, 1999, pp. 4, 5).

Although Smith's focus is largely on starting with participant experiences, not researcher ones, she does discuss the need for researchers to start with a problematic that emerges from their own lives (Smith, 2005). In so doing, not only would the research be personally meaningful but would give the researcher an inside perspective from which to begin. I argue for a continuation of this line of thinking in order to allow for the problematization of the researcher's connection to the research as central to the analysis. Inquiry would start with the researcher as knower and progress to participants as knowers, leading to a critical sociocultural analysis. Researcher and participant experiences and understandings would be used to not only explore an issue/context, but to engage in social critique by exploring wider power relations. Furthermore, although researcher positionality is a beginning point and significant aspect of the research, the research inquiry must broaden out from the researcher, moving to other empirical data (whether it be texts, artifacts, interviews with participants, observations, or a combination of various possibilities) in order to gain a social perspective of the wider implications of the study. In other words, it is not enough to engage in an evocative representation of experiences and understandings; an analytic critical examination that focuses on power relations is key in order to work against systemic societal marginalization and oppression.

Additionally, there are multiple oppressions (i.e., gender, race, class, heteronormativity, ableism,...) that intersect with each other in various and complex ways. People are active agents who have the ability to change their lives, but they have differential access to systems of power, leaving some more able to influence structural ruling relations than others. It is these ruling relations that need to be problematized from the standpoint of the actuality of people's everyday lives.

Smith advanced a methodology, institutional ethnography (IE), that:

is designed to create an alternative to the objectified subject of knowledge of established social scientific discourse. The latter conforms to and is integrated with that I have come 
to call the 'ruling relations' - that extraordinary yet ordinary complex of relations that are textually mediated, that connect us across space and time and organize our everyday lives - the corporations, government bureaucracies, academic and professional discourses, mass media, and the complex of relations that interconnect them (Smith, 2005, p. 11).

IE takes a subjective stance by recognizing the importance of unique individual experiences while connecting them to societal ruling relations to which most people do not have direct access. "The movement of research is from a woman's account of her everyday experience to exploring from that perspective the generalizing and generalized relations in which each individual's everyday world is embedded" (Smith, 1987, p. 185, italics in original). IE "works from the actualities of people's everyday lives and experience to discover the social as it extends beyond the experience. A standpoint in people's everyday lives is integral" (Smith, 2005, p. 10).

Briefly, IE begins with entry level data from the actualities of people's everyday experiences, typically through interviewing participants (Campbell \& Gregor, 2002) but sometimes through observations (Diamond, 2006), textual analysis (Kinsman, 1995; Walker, 1995), or researcher's own lives (Taber, 2007, 2010). These experiences are then analyzed through thematic coding that does not reduce their experiences to codes but searches for illuminating themes that help explain their standpoints (Smith, 1987). The "analysis of entry level data leads the institutional ethnographer to second level data (Campbell \& Gregor, 2002), such as texts and policies and/or interviews with policy makers, to explore how participants' lives are socially organized" (Taber, 2010, p. 11). As DeVault and McCoy (2002) state, "the key is to ask, 'How is it that these people are saying what they are saying'... the methodology allows you to go back to a political-economic context for the answer" (p. 769).

Furthermore, IE is not just a methodology but a sociology (Smith, 2005); it is not just a way of framing research but a way of understanding the world. It is an "alternative sociology" (p. 7) that "takes the everyday world as an unfinished arena of discovery in which the lines of social relations are present to be explored beyond it" (p. 39). The methodological description above can be applied sociologically by grounding research in everyday experiences in order to engage in a critique of ruling relations. Data (whether interviews, observations, texts, or researcher experiences) is not reduced to common codes but expanded to emerging themes that connect to a societal analysis of power. In my research, I have found this line of thinking to be very helpful in critiquing the ways in which women's everyday lives are bound up in structural institutions, whether the institution is a reified abstract concept such as family or a concrete organization such as a military. By beginning with researcher and participant experiences, one can explore the ways in which societal ruling relations are implicated in their lives.

In my dissertation (Taber, 2007), I methodologically adapted IE to include autoethnography and narrative (see also Taber, 2010). Doing so fit my unique research context and situation and is not necessarily relevant to all IE's. However, what may be relevant to various forms of research is the ways in which I consciously and specifically explored my own subjective experiences and understandings. Correspondingly, I have been considering how, by combining autoethnography as a lens with institutional ethnography as a sociology, researchers can approach any methodology in a reflexive, critical way. 
If, as Smith (1987) states:

the ways in which we think about ourselves and one another and about our society - our images of how we should look, our homes, our lives, even our inner worlds - are given shape and distributed by the specialized work of people in universities and schools, in television, radio and newspapers, in advertising agencies, in book publishing and other organizations forming the 'ideological apparatuses' of the society (p. 17),

then the ways in which we think about research are equally affected. Academia is a societal institution that operates as an ideological apparatus, defining how research is understood, conducted, and disseminated. As researchers, therefore, "the ways in which we think about ourselves and one another and about our society" (Smith, 1987, p. 17) must be problematized as they are intricately connected to the research that academics conduct.

\section{Conclusion}

In keeping with my argument that researchers must explore their own subjectivity and reflexivity, this chapter has focused on my own understandings and experiences. As I review my work so far, I see an ever-present theme, which has often snuck up on me in somewhat unexpected ways, about researcher positionality. What is central in this theme is the ways in which my research is implicated in my life. For me, my research is not about "abstract issues of social justice but [it is] pertinent to my daily existence" (Motzafi-Haller, 1997, p. 202). This connection is likely what draws me to methodologies such as autoethnography and institutional ethnography, although I often use other methodologies as well, depending on my research question and context (for instance, case study, life history, and feminist discourse analysis). However, even when using other methodologies, core aspects of autoethnography and IE remain with me, highlighting how they are not only methodologies but are lenses and sociologies; they are understandings that have become underpinnings in much of my work.

Academics are whole beings, not disembodied minds (hooks, 1994; Reich, 2003; Woodward, 2008), who often care deeply about their work. There should be no "bifurcation" (Smith, 1986) between academia and everyday life. Despite the vulnerability that can arise when acknowledging the ways in which we are implicated in our own research (LePage \& GivensGenerett, 2003), it is important to be consciously and overtly reflexive (Possick, 2009), exploring how the self is connected to the social (Anderson, 2006; Reed-Danahay, 1997a, 1997b, 2002), with respect to researchers as well as participants. "Narrative should be viewed as a form of social action" (Atkinson \& Delamont, 2006, p. 170) wherein there is a recognition that knowledge is socially organized (Smith, 1987, 1999, 2005). Stories and experiences necessitate a social analysis that connects the researcher to the research, the everyday to structural ruling relations, regardless of methodology. This does not mean that researchers' stories should dominate research, but should be acknowledged as an intricate part of it. My hope is that, by telling my story, I can assist others in exploring their own.

\section{References}

Abma, T. (2002). Emerging narrative forms of knowledge representation in the health sciences: Two texts in a postmodern context. Qualitative Health Research, Vol. 12, No. 1, pp. 5-27. ISSN 10497323 
Anderson, L. (2006). Analytic autoethnography. Journal of Contemporary Ethnography, Vol. 35, No. 4, pp. 373-395. ISSN 08912416

Atkinson, P. (2006). Rescuing autoethnography. Journal of Contemporary Ethnography, Vol. 35, No. 4, pp. 400-404. ISSN 08912416

Atkinson, P., \& Delamont, S. (2006). Rescuing narrative from qualitative research. Narrative Inquiry, Vol. 16, No. 1, pp. 164-172. ISSN 13876740

Campbell, M., \& Gregor, F. (2002). Mapping social relations: A primer in doing institutional ethnography, Garamond Press, ISBN 1-44260-119-2, Aurora, Ontario

Cole, A. L., \& Knowles, J. G. (2001). Lives in context: The art of life history research, AltaMira Press, ISBN 0-7591-0144-2, Walnut Creek

Clandinin, D. J., \& Connelly, F. M. (2000). Narrative inquiry: Experience and story in qualitative research, Jossey-Bass Publishers, ISBN 0787943439, San Francisco

Creswell, J. W. (2006). Qualitative inquiry and research design: Choosing among five approaches, Sage Publications, ISBN 0761901442, Thousand Oaks

Davies, B. (1992). Women's subjectivity and feminist stories. In: Investigating subjectivity: Research on lived experience, C. Ellis \& M. Flaherty (Eds), pp. 53-76. Sage Publications, Inc., ISBN 0-8039-4496-9, Newbury Park, California

Davies, C. (1999). Reflexive ethnography: A guide to researching selves and others, Routledge, ISBN 0415409018, London

DeVault, M., \& McCoy, L. (2002). Institutional ethnography: Using interviews to investigate ruling relations. In: Handbook of interview research: Context $\mathcal{E}$ method, J. Gubrium \& J. Holstein (Eds), pp. 751-776, Sage Publications, Inc., ISBN 0-7619-1951-1, Thousand Oaks

Diamond, T. (2006). "Where did you get the fur coat, Fern?" Participant observation in institutional ethnography. In: Institutional Ethnography as Practice, D. Smith (Ed), pp. 45-63, Rowman \& Littlefield Publishers, Inc., ISBN 917-0-7425-4676-9, Lanham, Maryland

Ellingson, L. L. (2006). Embodied knowledge: Writing researchers' bodies into qualitative health research. Qualitative Health Research, Vol. 16, No.2, pp. 298-310, ISSN 10497323

Ellis, C. (2002). Being real: moving inward toward social change. International Journal of Qualitative Studies in Education, Vol. 15, No. 4, pp. 399-406, ISSN 09518398

Ellis, C. (2004). The ethnographic I: A methodological novel about autoethnography, AltaMira Press, ISBN 0-7591-0051-9, Walnut Creek, CA

Ellis, C. \& Bochner, A. (2000). Autoethnography, personal narrative, reflexivity, In Handbook of Qualitative Research (2nd ed.), N.K. Denzin \& Y.S. Lincoln (Eds.), pp. 733-768. Sage Publications, ISBN 0761915125, Thousand Oaks, CA

Enloe, C. (2000). Maneuvers: The international politics of militarizing women's lives, University of California Press, ISBN 0520220706, Berkeley

Enloe, C. (2007). Globalization and militarism: Feminists make the link, Rowman \& Littlefield Publishers, Inc., ISBN 074241126, Lanham, MD

Feinman, I. R. (2000). Citizenship rites: Feminist soldiers $\mathcal{E}$ feminist antimilitarists, New York University Press, ISBN 0814726895, New York 
Freire, P. (2000). Pedagogy of the oppressed: $30^{\text {th }}$ anniversary edition. Continuum, 0-8264-1276-9, New York

Gouthro, P. (2002). What counts? Examining academic values and women's life experiences from a critical feminist perspective. Canadian Journal for the Study of Education, Vol. 16, No. 1, pp. 1-19

Harding, S. (1986). Introduction: Is there a feminist method? In: Feminism and methodology: Social science issues, Harding, S. (Ed.), pp. 1-14, Indiana University Press, ISBN 0253204445, Bloomington

hooks, b. (1994). Teaching to transgress: Education as the practice of freedom, Routledge, ISBN 0415-90808-6, New York

Hornosty, J.M. (2004). Corporate challenges to academic freedom and gender equity. In: Inside corporate $U$ : Women in the academy speak out, M. Reimer (Ed.), pp. 43-66, Sumach Press, ISBN 1894549317, Toronto

Kinsman, G. (1995). The textual practices of sexual rule: Sexual policing and gay men. In. Knowledge, experience, and ruling relations: Studies in the social organization of knowledge, Campbell, M., \& Manicom, A. (Eds.), pp. 80-95, University of Toronto Press, ISBN 0802007201, Toronto

Lane, L., Taber, N., \& Woloshyn, V. (in progress). Negotiating tensions between researching, facilitating, and critiquing gender: Exploring institutional and feminist influences.

LePage, P. \& Givens-Generett, G. (2003). Working against the grain: Rewards and consequences of developing a personal voice in academia, In Advancing Women in Leadership, 09.08.2005, Available from

http:/ / www.advancingwomen.com/awl/winter2003/LEPAGE 1.html

Motzafi-Haller, P. (1997) Writing birthright: On native anthropologists and the politics of representation, In: Auto/ethnography: Rewriting the self and the social, D. ReedDanahay (Ed.), pp. 195-222, Berg, ISBN 9781859739754, Oxford

Pillow, W. (2003). Confession, catharsis, or cure? Rethinking the uses of reflexivity as methodological power in qualitative research, Qualitative Studies in Education, Vol. 16, No. 2, pp. 175-196, ISSN 09518398

Possick, C. (2009). Reflexive positioning in a politically sensitive situation: Dealing with the threats of researching the West Bank settler experience, Qualitative Inquiry, Vol. 15, No. 5, pp. 859-875, ISSN 10778004

Ramazanoglu, C. \& Holland, J. (2002). Feminist methodology: Challenges and choices, Sage Publications, ISBN 0761951237, Thousand Oaks

Reed-Danahay, D. (Ed.). (1997a). Auto/ethnography: Rewriting the self and the social, Berg, ISBN 9781859739754, Oxford

Reed-Danahay, D. (1997b). Introduction. In: Auto/ethnography: Rewriting the self and the social, D. Reed-Danahay (Ed.), pp. 1-17, Berg, ISBN 9781859739754, Oxford

Reed-Danahay, D. (2002). Turning points and textual strategies in ethnographic writing, International Journal of Qualitative Studies in Education, Vol. 15, No. 4, pp. 421-425, ISSN 09518398 
Reich, J. (2003). Pregnant with possibility: Reflections on embodiment, access, and inclusion in field research, Qualitative Sociology, Vol. 26, No. 3, pp. 351-367, ISSN 13207881

Reimer, M. (Ed.). (2004). Inside corporate U: Women in the academy speak out, Sumach Press, ISBN 1894549317, Toronto

Smith, D. E. (1986). Women's perspective as a radical critique of sociology. In: Feminism and methodology: Social science issues, Harding, S. (Ed.), pp. 84-96, Indiana University Press, ISBN 0253204445, Bloomington

Smith, D. E. (1987). The everyday world as problematic: A feminist sociology, Northeastern University Press, ISBN 1555530362, Boston, MA.

Smith, D. E. (1999). Writing the social: Critique, theory, and investigations, University of Toronto Press, ISBN 0802081355, Toronto.

Smith, D. E. (2005). Institutional ethnography: A sociology for people, AltaMira Press, ISBN 0759105022, Lanham, MD

Taber, N. (2005). Learning how to be a woman in the Canadian Forces/unlearning it through feminism: An autoethnography of my learning journey, Studies in Continuing Education, Vol. 27, No. 3, pp. 289-301, ISSN 0158037X

Taber, N. (2007). Ruling relations, warring, and mothering: Writing the social from the everyday life of a military mother. Unpublished PhD dissertation. Adelaide: University of South Australia.

Taber, N. (2010). Institutional ethnography, autoethnography, and narrative: An argument for incorporating multiple methodologies, Qualitative Research, Vol. 10, No. 1, pp. 525, ISSN 14687941

Taber, N. (2011a). Critiquing war in the classroom: Problematizing the normalization of gendered militarism. Proceedings (S. Carpenter, S. Dossa, \& B. Osborne) of Canadian Association for Studies in Adult Education (CASAE)/Adult Education Research Conference (AERC), 2011 Joint Conference. Toronto: Ontario Institute for the Study of Education, University of Toronto.

Taber, N. (2011b). Ruling relations, warring, and mothering: Writing the social from the everyday life of a military mother, Lambert Academic Publishing, ISBN 3838349083, Saarbrucken, Germany

Taber, N. (2011c). "You better not get pregnant while you're here": Tensions between masculinities and femininities in military communities of practice, International Journal of Lifelong Education, Vol. 30, No. 3, pp. 331-348, ISSN 02601370

Taber, N., Howard, L. \& Watson, G. C. (2010). Researcher subjectivities as a conceptual frame in collaborative research: How exploring the experiences of adult educators led to examining researcher lenses, Canadian Journal for the Study of Adult Education, Vol. 23, No. 1, pp. 39-54, ISSN 0835-4944

Walford, G. (2004). Finding the limits: Autoethnography and being an Oxford University Proctor. Qualitative Research, Vol. 4, No. 3, pp. 403-417, ISSN 14687941

Walker, G. (1995). Violence and the relations of ruling: Lessons from the battered women's movement. In: Knowledge, experience, and ruling relations: Studies in the social organization of knowledge, Campbell, M., \& Manicom, A. (Eds.), pp. 65-79, University of Toronto Press, ISBN 0802007201, Toronto 
Webber, M. (2008). Miss Congeniality meets the new managerialism: Feminism, contingent labour, and the new university. Canadian Journal of Higher Education, Vol. 38, No. 3, pp. 37-56, ISSN 03161218

Woodward, K. (2008). Hanging out and hanging about: Insider/outsider research in the sport of boxing. Ethnography, Vol. 9, No. 4, pp. 536-561, ISSN 14661381 


\title{
Accessing Material Culture by Following Intermediary Objects
}

\author{
Dominique Vinck \\ University of Lausanne \\ Switzerland
}

\section{Introduction}

In this chapter, we outline a method for describing material culture in situations where there are many interconnected places to be studied, which is the case in organisational ethnography or multi-situated ethnography (Marcus, 1995). In these kinds of setting, the aim of ethnography is to describe the linkages along the chains and paths articulating different sites. To help perform multi-situated investigations, we suggest using the concept of intermediary object as an ethnography-enriching tool. The key methodological idea is to take into account material objects and to follow them as they move from one site to another and from one person to another. Following these intermediary objects proves to be very useful in terms of data collection, as can be seen in studies of scientific cooperation networks (Vinck et al., 1993; Vinck, 1999) and engineering practices in design offices (Vinck \& Jeantet, 1995; Vinck, 2003), but also in studies of day-to-day relations within the couple (Kaufmann, 1998). This method helps to reveal activities, actors, connections, networks and processes and contributes to providing accurate accounts of localities without losing sight of their connections. Thus, it serves the purpose of studying dynamic and contingently settled activities across organisational borders. The spaces produced are made up of flows and translations of things, people and texts.

With this suggestion to follow intermediary objects, the chapter therefore contributes to social science by taking into account material culture and the materiality of things (bodies, artefacts, etc.). Indeed, when constructivism had dissolved everything that was solid into fluid, materiality made a renewed entry into social theory (Latour, 1999). Some authors (Pels et al., 2002) pointed out that it was time to grasp the force of things and rediscover how social and material relations are entangled. They emphasised the extent to which social matters are ordered and 'set' by material things. The ethnographic suggestion to follow humans and non-humans (Latour, 1987) reflected the idea that the social world could not be sustained and achieve coherence without non-humans (Latour, 1996). The same applied to the question about what moves society and what makes up society's mobility and fluidity. The "Actor-Network Theory" agnostic approach, developed by Michel Callon, Bruno Latour and John Law (Callon, 1986; Latour, 1993; Law, 1991, 1999), with the principle of methodological symmetry between humans and non-humans, the ontological idea of the hybrid character of socio-technical collectives, the description of heterogeneous engineering (Law, 1987) and the 'interobjectivity' of social order (Latour, 
1996), lead to the suppression of modernist categories separating society from technology and culture from nature.

The hypothesis that people's relationships to materiality and society are mutually dependent (Appadurai, 1986) calls for methodologies that help us to study the artefacts and technical gestures accompanying the fabrication and use of objects. Looking at intermediary objects involves focusing on artefacts and material accomplishments (acquisition of material and display of material prosperity, skill, crafts and technology). These objects are part of a culture and evolve as they interact with society. Thus Kopytoff (1986) suggests studying their biography to understand their changes in terms of status, variability and intermediary forms. Various traditions in social sciences converge towards the idea of taking into account material culture in the analysis of past and present societies. However, these traditions differ in terms of how to conceptualise the role and the meaning of artefacts. They also have very different methodological approaches to materiality: gathering the artefacts as testimony, symbols or indicators of a culture or of a stage in the evolution or dissemination of cultures; explaining their function in society; describing their interconnections and the technical system they form; following their career and biography; looking at gestures more than at the artefacts; seeing them as a coercitive force shaping the behaviour of human beings or society. We suggest using an open methodology, a methodology that allows various interpretations in order to support inductive conceptualisation.

The chapter will first trace how the concept of intermediary object emerged as part of a sociology-of-science investigation spanning more than one hundred scientific cooperation networks in the health field. We shall explore its emergence through the narrative of this investigation into scientific activity and the associated field observations. The chapter will present some of the findings and show how the concept was used.

We shall then explore how this concept can be capitalised on in the study of other practices, relations and material cultures. To do this, we shall highlight the concept's descriptive and analytical capacity when applied to a field study. This will also help us to illustrate the methodology and its importance for ethnography. We show that by describing and following intermediary objects it is possible to categorise key features of practices and relations. Among other things, we will explain how the intermediary object might be considered and theorised as a form of representation (the inscription of intentions, working habits, power relations or agreements in the very matter of an object), but also as a form of translation (uncontrolled shifts), mediation and framework.

We conclude the chapter with new developments in the concept of intermediary object and their potential application to design ethnography, as well as engineering, organisational and innovation studies. Indeed, looking at the objects being manipulated and produced, even if they are common, unspecific (e.g. a pencil) and apparently unimportant, sheds additional light on the activity under study. The hypothesis is that by following these objects and their circulation it is possible to produce another picture of human activity and organisation.

\section{Networks and activities revealed through intermediary objects}

In this section, we shall first retrace the emergence of the notion of intermediary object and then explore how it was initially used. 


\subsection{Beginnings of the notion of intermediary object}

The notion of intermediary object emerged through a sociology-of-science investigation whose aim was to describe and characterise 120 scientific cooperation networks operating in the health field (Vinck, 1992, 1999; Vinck et al, 1993). These networks brought together over three thousand five hundred teams of researchers, industrialists and clinical practitioners as part of a European programme. To characterise these networks and understand what "networking" entailed, the survey identified the actors, characterised the forms of organisation and coordination, and the agreements binding the actors together. It also strove to capture the content of activity: the objectives of each network, the desired end results and the acquired or expected intermediaries. The aim was to describe the networks of relations between actors and what the research cooperative networks produced.

At the time when the investigation was performed, the network was considered a new way to organise scientific work. Promoted within the framework of public research programmes, the constitution of networks became a purposeful and collective enterprise in the 1980's. The network was the result of a political decision to organise scientific work around projects. The European Community Commission's involvement reflected the growing popularity of these new forms of scientific work organisation. It encouraged the setting up of cooperation between research bodies, whose political managers hoped to gain much from the collaboration. However, how these networks were formed, how they changed, what their regulation mechanisms or the difficulties they encountered were, or what their impact on research directions was, remained unknown factors. Research then began to focus on what "networking" actually meant. What forms of coordination were set up through networking? To what extent did networks make it possible to switch from a local focus on scientific practices to the universalisation and relocation of research outcomes? One main question was: what is a network and what does it produce?

The investigation rapidly revealed a diverse range of situations; each network had its own individual characteristics. Many turned out to be very different from what the science policy managers had imagined, in other words forums for discussion and trading of ideas between researchers. Instead, they reflected the collective dynamics underpinning the building of research infrastructures. Table 1 lists some examples of the scientific cooperation networks studied.

The preliminary interviews with the project leaders and network members very quickly revealed that the most active members devoted a considerable amount of time to designing, negotiating, producing and disseminating all kinds of "objects": texts, computer files, biological samples, instruments, animals, phantoms and even patients (see table 2). Initially aiming to study relationships between researchers, the investigation began to focus on the objects that were exchanged and circulated between the network members, referred to then as "intermediary objects." The notion was used for descriptive purposes and did not initially carry any conceptual weight. It represented additional input for the investigation. The aim was not to judge either the nature or role of these intermediary objects as they moved "between" the actors. The notion was then extended to larger objects, such as facilities or fixed pieces of equipment around which the research teams gravitated. For example, it was applied to a colony of chimpanzees suffering from AIDS or a large database. 


\begin{tabular}{|c|c|}
\hline Network theme & Type of network \\
\hline $\begin{array}{l}\text { Medical laser } \\
\text { applications }\end{array}$ & $\begin{array}{l}\text { Theme-based forum: bringing together a community of } \\
\text { researchers with the aim of developing new projects + organising } \\
\text { mutual research team visits + setting up exchanges for training }\end{array}$ \\
\hline Artheriosclerosis & $\begin{array}{l}\text { Research infrastructure: in charge of structuring a protocol, } \\
\text { resources (database, sample banks) and logistics to bring together } \\
\text { clinical research teams working on a clinical trial. The idea was to } \\
\text { be able to reuse the infrastructure for other trials. }\end{array}$ \\
\hline $\begin{array}{l}\text { Molecular cytogenetics } \\
\text { of solid tumours }\end{array}$ & $\begin{array}{l}\text { Research infrastructure: responsible for organising } 10 \text { cell bank } \\
\text { lines, structuring logistics and harmonising access to equipment } \\
\text { by other teams. }\end{array}$ \\
\hline HIV genetic screening & $\begin{array}{l}\text { Research infrastructure: in charge of organising a sequencing } \\
\text { laboratory to be used by other research teams, and setting up an } \\
\text { experiment committee responsible for harmonising equipment } \\
\text { preparation and deciding on access to the sequencing service. }\end{array}$ \\
\hline AIDS vaccine & $\begin{array}{l}\text { Research infrastructure: involved in drawing up product } \\
\text { specifications (viruses, peptides and additives) to allow for } \\
\text { grouped orders to be placed by the entire scientific community, } \\
\text { and distributing products to research teams with validated } \\
\text { projects. }\end{array}$ \\
\hline $\begin{array}{l}\text { Biomaterials and } \\
\text { haemocompatibility }\end{array}$ & $\begin{array}{l}\text { Research infrastructure: responsible for organising a test centre } \\
\text { network, inter-comparisons and protocol standardisation. }\end{array}$ \\
\hline $\begin{array}{l}\text { Congenital } \\
\text { malformations }\end{array}$ & $\begin{array}{l}\text { Central facility: in charge of organising a network of } \\
\text { correspondents for collecting data and setting up a centralised } \\
\text { database and a team to perform analyses. }\end{array}$ \\
\hline Drug carriers & $\begin{array}{l}\text { Project team: involved mobilising teams with complementary } \\
\text { skills, each in charge of performing a specific task, and articulating } \\
\text { intermediate outcomes prior to the development of the final } \\
\text { products (carriers). }\end{array}$ \\
\hline
\end{tabular}

Table 1. Examples of scientific cooperation networks

The researchers' focus on these objects - more than on the epistemological aspects of their research project - highlights their importance. They came to study their slightest detail, exploring them especially in terms of the action undertaken (e.g. investigation or technological developement), either because they seemed to contribute something to the action, or because they extended or transformed it (introduction of a biais, cause of failure or discovery of new scientific avenues or challenges). The researchers then developed the hypothesis that the details of these intermediary objects - notably the way they were equipped, for example, with code marks (Vinck, 2011) - should also be taken into account in order to understand actions and relations, the structuring of the network and the results generated: data, publications, reference materials, best practices and health devices notably. The decision was therefore taken to follow both actors and intermediary objects and this proved to be very useful in terms of collecting data about the connections between research, clinical teams and technological teams. 


\begin{tabular}{|l|l|}
\hline \multicolumn{1}{|c|}{ Type of intermediary object } & \multicolumn{1}{c|}{ Examples } \\
\hline Text & $\begin{array}{l}\text { Mail, intermediary reports, technical documentation, } \\
\text { blank and completed forms, protocols, decision- } \\
\text { making trees for diagnosis, analysis catalogues and } \\
\text { laboratory directories, etc. }\end{array}$ \\
\hline Instrument & Detectors, filters, software, digital media, etc. \\
\hline Material and sample & $\begin{array}{l}\text { DNA probes, HIV viral strains, brain sections, } \\
\text { conjunctive tissue sections, lungs immersed in } \\
\text { formalin, pancreases, peptides, reference reagents, } \\
\text { etc. }\end{array}$ \\
\hline Phantom (human substitute) & $\begin{array}{l}\text { Trunk in hydroxyapatite, standard skull for } \\
\text { hyperthermia, etc. }\end{array}$ \\
\hline Animal & $\begin{array}{l}\text { NUDE mice carrying a cancerous human tumour, } \\
\text { transgenic rats, dogs, etc. }\end{array}$ \\
\hline $\begin{array}{l}\text { Large instrument, technological } \\
\text { platform and instrumental device }\end{array}$ & $\begin{array}{l}\text { Particle accelerators, prototype instruments, } \\
\text { laboratories operating as open facilities for research } \\
\text { teams, colonies of macaques or chimpanzees } \\
\text { suffering from AIDS whose use was supervised by } \\
\text { skilled staff, a scientific committee and an ethics } \\
\text { committee. }\end{array}$ \\
\hline
\end{tabular}

Table 2. Intermediary objects encountered in the scientific cooperation networks studied

It should be pointed out that the notion of intermediary object differs significantly from the notion of boundary object (Star and Griesemer, 1989). Both notions are part of the research tradition in sociology of science but they emerged within different research frameworks. In the notion of boundary object, the situation analysed is that of the intersections between several social worlds ${ }^{1}$ around a specific place, i.e. a museum of natural history. Furthermore, the two notions come from two leading traditions: the notion of boundary object from symbolic interactionism ${ }^{2}$ and the notion of intermediary object from the actor-network theory ${ }^{3}$. Both movements take into account the heterogeneity of the social worlds of science; they follow the actors and report on their activities and effective practices, including the development of knowledge, objects and social arrangements. In both cases, the authors behind the emergence of these notions strive to account for the materiality of things that

\footnotetext{
1 These "social worlds" are groups of activity having neither a clear border nor a formal and stable organisation. These are built up through the relation between social interactions generated by the primary activity and a suitable definition of reality. The notion stems from the symbolic interactionism movement.

2 Micro-sociology movement that refuses the idea of sociological or biological determinism, preferring instead to base its explanations on the dynamics of observable interactions between individuals. It underlines the fact that the meaning of phenomena results from actors' interpretations in a given situation. These interpretations rely on interpretive frameworks produced through interactions between actors (verbal and non-verbal symbolic interactions).

${ }^{3}$ Sociology movement that reports on sociotechnical constructions (knowledge statements, innovation, devices, actors, etc.), in terms of networks of associations between heterogeneous entities (human and non-human) obtained following a translation operation (Callon, 1986).
} 
actors produce and use in a given situation. However, the boundary object theory aims to understand how several social worlds are cognitively synchronised, not describe the networks of relations between research groups.

\subsection{The intermediary object as a revelation agent}

Using the notion of intermediary object makes it possible to identify a large number of objects and, through these, to gain better access to actors as they engage in action. It also provides a better view of the relations, activities and practices that are otherwise difficult to pinpoint in the official and spontaneous presentations of actors where the focus is on rationales, challenges and epistemological considerations. An example of this can be drawn from a cooperative network studying pancreas B cells, which was studied during the investigation. By reconstituting the set of practices surrounding the circulation of pancreases between hospital surgeons and research laboratories, it was possible to discover an actor whose role proved to be important in the network dynamics, notably through the practical and deontological rules that it imposed. This actor was the company in charge of transferring the organs. Hence, by identifying and following intermediary objects it was possible to map and qualify the relations between actors and to document their practices within this scientific knowledge production universe.

As the researchers studied the intermediary objects, asking where they came from, how they were circulated and what the network members did with them, they discovered that the actors invested in them greatly. The actors were observed to work on and negotiate their design, packaging, accompanying logistics, transfer, inventory, conservation, use and destruction. Success and failure of scientific projects seemed to depend on these objects. If a biological sample was lost or withheld by customs for too long, if a form or a probe were badly designed, if a virus was badly packaged or the chimpanzees suffering from AIDS used improperly, then this represented a threat to the scientific project as a whole: it jeopardised the meeting of objectives, the comparison of results and the widespread, rather than local, validation of the hypotheses developed. Intermediary objects were found to be involved in the structuring of individual and collective research activities, in the harmonisation of researchers' practices and in the constitution of a knowledge circulation space (for data, hypotheses, ideas to be explored, intermediary results, etc.). Their standardisation helped to stabilise both research hypotheses and new ideas for health practices. Their appearance in the scientific cooperation networks investigated varied over time and seemed to punctuate the life of both content and social configurations.

In spite of its ability to reveal things during the investigation, the notion of intermediary object was purposefully limited from a conceptual point of view. Unlike the notion of boundary object, it remained open to interpretation in terms of the mechanisms at work. Whether the objects were subject to interpretation or not, whether they were located at the intersection of several social worlds or internal to a given social world, whether they ensured a minimum identity between heterogeneous worlds or not, were all questions left open to the ethnographic researcher. At the time, there was nothing to suggest that the notion of intermediary object would lead to the development of an interpretive framework to report on the existence of such objects and what they generated in a given situation: a reflection of technical determinism or social constructivism, the materialisation of social 
relations and vectors of social forces or social neutrality, a projection screen reflecting society or social actors themselves.

\subsection{Articulating the notion of intermediary object as a form of representation}

We shall now explore how we might capitalise on this concept in the study of various kinds of practices, relations and material cultures. We shall therefore highlight the concept's descriptive and analytical capacity. This will also help us to illustrate the methodology and its importance for ethnography. We show that by describing and following intermediary objects it is possible to categorise key features of practices and relations. Among other things, we will explain how the intermediary object might be considered and theorised as a form of representation and a form of translation.

First, we can theorise intermedairy objects as a form of representation. Representation, through intermediary objects, refers to the idea of inscribing something in the very matter of an object. Part of the meaning of the object (a data sheet, a biological sample, an instrument), together with its identity and its properties, is thus drawn from what is inscribed on it or shaped by the actors. This representation process is twofold: it concerns the processes upstream of the object's making and the projections downstream of the object. Upstream, the intermediary object represents those who designed it, the researchers who defined the kind of sample and the sampling protocol, the medical doctors qualified to do the sampling, the technicians' habits in terms of storage and transport, etc. It materialises their intentions (e.g. the research question they want to answer, the scientific hypothesis they are exploring), their working or thinking habits, the identity they defend (e.g. scientific discipline, researcher or practitioner), their relations (e.g. of power) and their interactions (e.g. negotiations), their perspectives and the compromises they have set up. Sometimes, the inscription is negotiated and conventional. It is the result of many meetings and discussions about draft protocols. The intermediary object constitutes a trace and a mark of its authors and their relations. In this respect, looking at the intermediary object tells us something about its authors and the sociotechnical conditions of their activity, about the paths they follow and the contingencies that arise.

In the case of the scientific cooperation networks observed, the intermediary object also represents the "natural phenomenon" being studied (AIDS, diseases of the conjunctive tissue, a patient's tumour, etc.). It is not therefore just a straightforward social construction. Hence, a blood sample is constructed and used by actors as a reliable spokesperson of a patient's illness. A phantom in hydroxyapatite used to calibrate instruments for measuring osteoporosis is assumed to represent a "standard" woman likely to suffer from this type of biological development. In this respect, the intermediary object is required by its authors to channel fragments of a natural phenomenon as part of a knowledge-building process. Because it has been chosen and developed, the sample is attached to an operative and interpretive framework that is often the subject of long discussions between researchers. Its material nature sometimes reflects negotiated and stabilised collective knowledge, as well as acting as a vector of knowledge yet to be explained. It is therefore a sociotechnical construction that cannot be reduced to social interpretations and intentions upstream of its making.

Finally, the intermediary object also carries some of the actors' projections and expectations in terms of future scientific results: it is a promise or a hypothesis relating to potential 
scientific outcome. A sample represents a potentiel set of data, data represent a potential equation or a correlation between variables and the draft of an abstract represents a potential scientific paper.

Thus, whether intermediary objects are interpreted as traces, inscriptions, materalisations or carriers, they have much to say regarding actors, their projected identity, their relations and activities, their intentions and the world they are studying and shaping.

\subsection{The intermediary object as a form of translation}

Intermediary objects can also be theorised as a form of translation, i.e. of intentional moves and uncontrolled shifts. Translation refers to the idea that when there is a shift from intention to realisation or from one register to another (e.g. from a sample to a set of data), there is some kind of transformation involved (Latour, 1995), such as the construction of coherence or the creation of new possibilities. The intermediary object cannot be reduced to its author's intention. When it is materialised, something new is introduced. The shift, which is not necessarily desired or controlled, may even lead the investigator astray. For example, when coloured, biological tissue may react in unexpected ways or produce an interesting artefact. In other words, following translation, the resulting object may generate something different from what was originally aimed at. Similarly, objects do not simply materialise the social relations (e.g. power struggles between physicists and physicians when defining a nuclear beam for cancer treatment) presiding over their making. This is because the matter (or the formalism used) introduces something new to the action (Almklov, 2008). This sometimes creates opaqueness and, in the case of scientific cooperation networks, leads to discussions between members as to how to interpret the intermediary object they have produced. Along the same lines, while an intermediary object can represent a fragment of a natural phenomenon or a disease, it is also the place where nature is transformed and socialised (Knorr, 1995) through technical and conceptual developments within a research community. In the case of a network working on osteoporis, the researchers can be seen to enter into discussions about what the intermediary objects constructed and circulated really show. The material nature of objects (written traces, samples, technical artefacts or manipulated living beings) is seen as a source of opaqueness in the action. Such objects cannot therefore be reduced to initial intentions as these are overridden by other factors entering into the situation (Latour, 1996).

The development of the notion of intermediary object stems from work on and thinking about a series of other notions: especially the notions of inscription (Latour and Woolgar, 1979) and immutable and combinable mobiles (Latour, 1987) used in the analysis of scientific fact construction, the notion of boundary object (Star and Griesemer, 1989) and Callon's notion of intermediaries (1989). Latour and Woolgar (1979) and Latour (1987), in particular, showed that when inscriptions are followed (e.g. plots from analysis instruments, tables of figures, diagrams and texts) it is possible to analyse scientific practices differently and to deflate some of the abusive questions arising in epistemology. These inscriptions are not just pieces of information, they are also material entities, which may or may not be difficult to produce, keep and use. Similarly, our investigations into scientific and technological practices show how strongly actors invest in intermediary objects. They do this in order to control what they are doing and control the objects' meanings, partly because they know how risky the translation process can be. They also invest in the 
manipulation and interpretation of these objects. The objects are sometimes explored further in investigation work because their opaqueness is a source of new knowledge.

For the social scientist studying cooperative networks, taking a closer look at what is going on and around these intermediary objects makes it possible to uncover and characterise the exchanges and relations between actors, define the organisation and cooperation networks involved, and access investments and activities before, during and after these exchanges. Studying the processes of representation and translation as the story of an intermediary object unfolds can thus be of great benefit to the social scientist.

\subsection{The intermediary object as a mediator}

In scientific cooperation networks, researchers have many opportunities to meet up through workshops, coordination meetings and conferences, for example. During one such meeting where researchers are seated around a table discussing and exploring possible solutions, one of them finds it difficult to express his idea in words. He therefore produces a diagram and places it in front of his colleagues to explain it. However, before pursuing his explanation, he stops, surprised to discover in his diagram something he has not previously thought of. The act of drawing, and then looking at the result, produces a different effect from the one he has in mind. It is as if, during the research process, the intermediary object is able to introduce something new to the action. This "new" element partly escapes the control of the actors. In this way, it can be compared to a mediator that interacts with the actors present. In such situations, the intermediary object provides support during the discussion as it offers each person involved something to hold on to (each researcher, clinician or engineer can grasp the object from his/her usual point of view). In another working discussion, the joint completion of a table of design criteria and solutions lead the researchers to discover a new solution. This is because the table allows them to draw parallels between otherwise disassociated aspects. In others situations, like discussions between mathematicians, intermediary objects might appear when the participants do not understand each other, such as a drawing on the blackboard. These objects then disappear once a level of mutual understanding has been achieved (Lefebvre, 2003). Thus, following the activity surrounding an intermediary object helps to describe the emergence of a solution. More generally, during a meeting, researchers will produce and mobilise several objects (e.g. pictures and diagrams). Moving from one to another, they will reconstruct the objects and hence generate new ideas, interpratations, data and solutions. This demonstrates that the materiality of the movements acts as a form of mediation. During the mediation process, the movement occurs partly unbeknownst to the participants. Materiality builds and resticts the dynamics at work. Thus, following the intermediary objects produced and mobilised during interactions between actors helps to describe how these objects facilitate, foster or complicate the building of compromises and the sharing of knowledge. Depending on the details of these objects, they displace the actors' viewpoints, act as a memory support and contribute to the setting up of a work collective.

Some intermediary objects, e.g. roughs, diagrams, protocols, $\mathrm{X}$ ray pictures or data tables have a low level of codification. This sometimes facilitates the integration of knowledge and viewpoints during cooperative action. Others, on the other hand, are highly codified and use high level conventions, e.g. a formal, detailed protocol or software with a black-box algorithm. However, such objects offer medical data collectors little scope for acting on the 
research. They are closed objects, operating within a prescriptive register. Roughs, on the other hand, only actively support research action when they are developed jointly, and as long as they remain within the framework of the collective having built them. This local characteristic comes from the fact that they are not systematically attached to highly general representational conventions. By following the activities surrounding a series of roughs, we can see the relative stability of these objects as memory back-ups.

Finally, the notion of intermediary object teaches us that during research activity the materiality of objects, roughs, writings, samples or probes influences the emergence of knowledge. The gradual construction of such knowledge can be tracked through these objects and the activity surrounding them. The research process cannot be reduced to the application of methods. Something (a new idea, a shift in viewpoint, different connections, etc.) occurs in the research process through the materiality of the action. The socio-cognitive processes mediated by the objects depend on this something. Looking at these objects thus provides access to these processes.

\subsection{The intermediary object as an operator of change and a temporal marker}

Objects can act as temporal markers and operators of change. The history of scientific cooperation networks is punctuated by the production of intermediary objects: the first version of a protocol to be discussed, the final version of a protocol based on a consensus, a standard phantom that is mass-produced and distributed to network members, the standardised analysis procedures of different laboratories, etc. They mark the stages of work performed and render its evolution less reversible. Once a common research protocol has been approved by participants, the network is no longer the same. Before this stage is reached, the participants seek to set up a common denominator. Once the denominator has been found, they are ready to align their work. They go from a situation where, in spite of the wish to work on something common, each participant gives a specifc slant to their work and, to varying degrees, attempts to modify that of other participants, to a situation where the teams agree to act according to the joint protocol. In theory, they can still question this protocol, but may find themselves excluded from the network when it is aready following a certain direction and is unlikely to swerve from it.

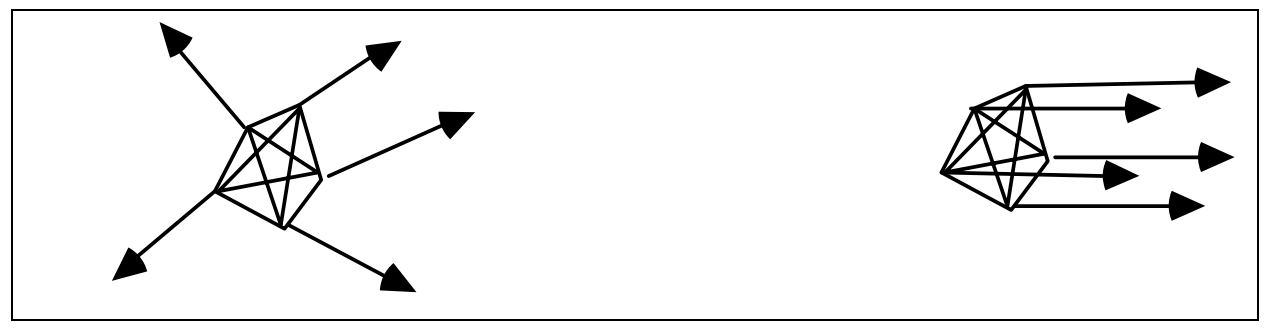

Fig. 1. The network before and after agreement regarding a common protocol has been reached. Each arrow represents a research team and the direction followed by its action. The lines represent the relations inside the network.

Intermediary objects progressively consolidate networks while at the same time they act as time arrows heralding a change in phase. They thus embody two complementary dimensions: 
- They reflect the agreement that is gradually built up between the teams having constructed them. In turn, this agreement reflects two simultaneous types of effect: the links the teams develop to obtain a result (structuring effect) and the common references they must embrace in order to be able to work together (alignment effect: languages, experimental practices, etc.).

- $\quad$ They serve as back-up to the widening of the network. A result can only exist if it is taken up and used by others. Intermediary objects are therefore operators of the network's transformation depending on the degree of involvement of the actors who are already in the network or on the enrolment of new actors. Both situations follow different action paths: in the first case, the action deepens the scientific and technical work while, in the other, it broadens its scope to the extent that what has been acquired becomes universal.

Let us take the example of a network in charge of standardising the recording and automatic analysis of electrocardiograms (ECG's). The development of this network might be described in the diagram below (figure 2). The diagram shows the structuring of a core of

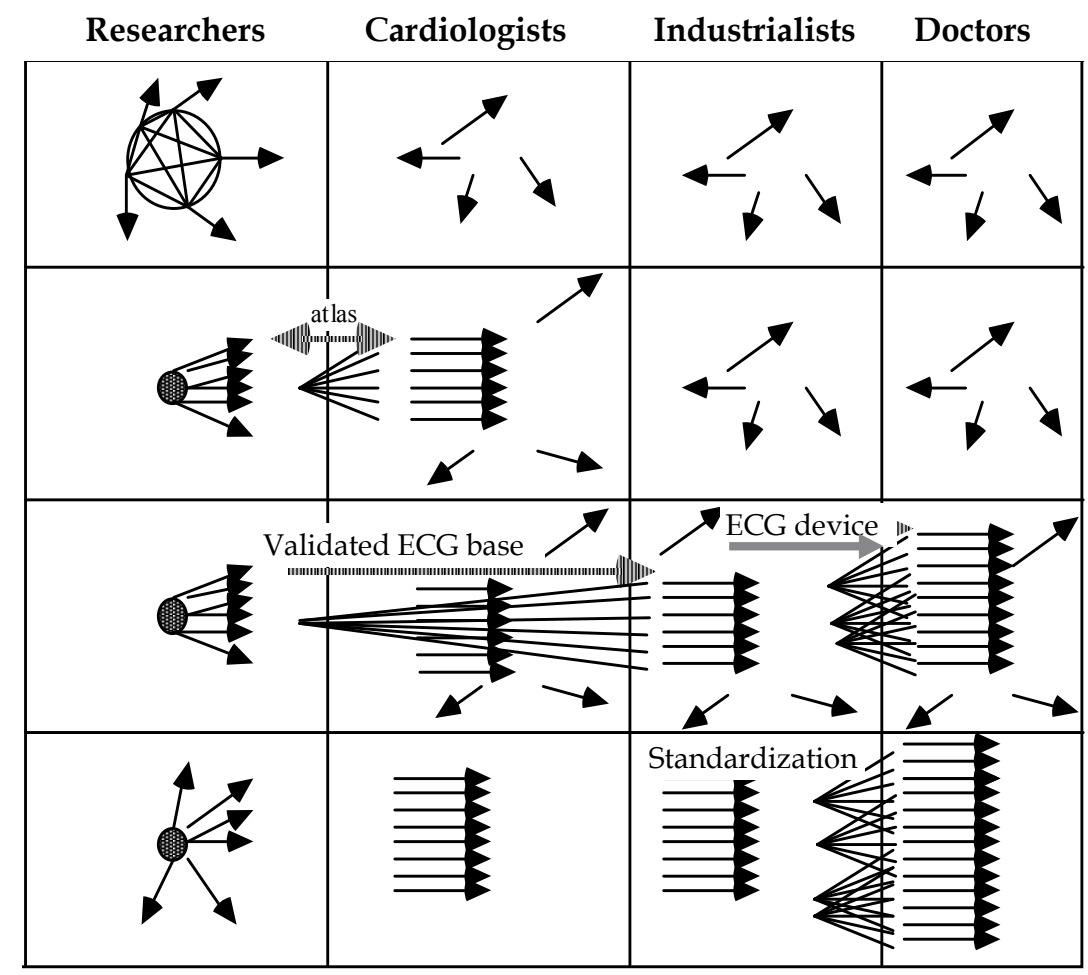

The columns represent the different categories of actors that the network progressively wishes to reach and mobilise. The lines correspond to the different action phases (structuring implemented and transfer). The boxes reflect the intermediary objects and their effects on the teams producing them and the teams then taking them up. The arrows represent the actors. The direction of the arrows reflects the alignment or the non-alignment of the actors' practices. The lines represent the exchanges. The direction and content of the exchanges is indicated by the hatched arrows (except the relations between researchers where the interactions are many and varied). The dark dot indicates that the researchers interact with each other to such an extent that they can be considered by the other actors involved as a single entity.

Fig. 2. Dynamics of the ECG network. 
teams and the progressive alignment of an increasing number of actors. The end result is the standardisation of ECG recording and automatic analysis equipment. If we go down the "researchers" column, we can see that one group of research teams regularly discusses messages, ECG measurement and analysis algorithms, working documents, data, records, etc. The exchanges between these teams are such that this network can quickly be treated as a single actor. At the same time, the research directions of the teams in this network notably come together around a few common themes. Once the work is complete, and the common objectives achieved, it is likely that the different teams will explore new research directions while maintaining close links with the others, even if these are not as close as before.

The other actors who are progressively involved are not, in theory, linked up. They are involved in a network via the central network. Relations with the cardiologists consist of exchanges of ECG traces: these are blank traces on which the cardiologists indicate segment cuts (p, q, r, s or t) (figure 3). Once the segment cuts have been marked by the cardiologists, the traces are then submitted for a second, and sometimes third, opinion. The only time the cardiologists interact is when they meet to come to a consensus about how to segment the $3 \%$ of traces for which a consensus has not been previously reached. The industrialists are aligned to the network via the validated ECG trace database that they buy from the network. They compare, test and ensure their instruments comply with this reference base. However, compliance with the reference base is not compulsory (it is based on factual standardisation), which means that some may continue to distribute and interpret the traces differently. The alignment of all the industrialists and all the doctors can only occur via the specifications imposed by, for example, a standardisation body.

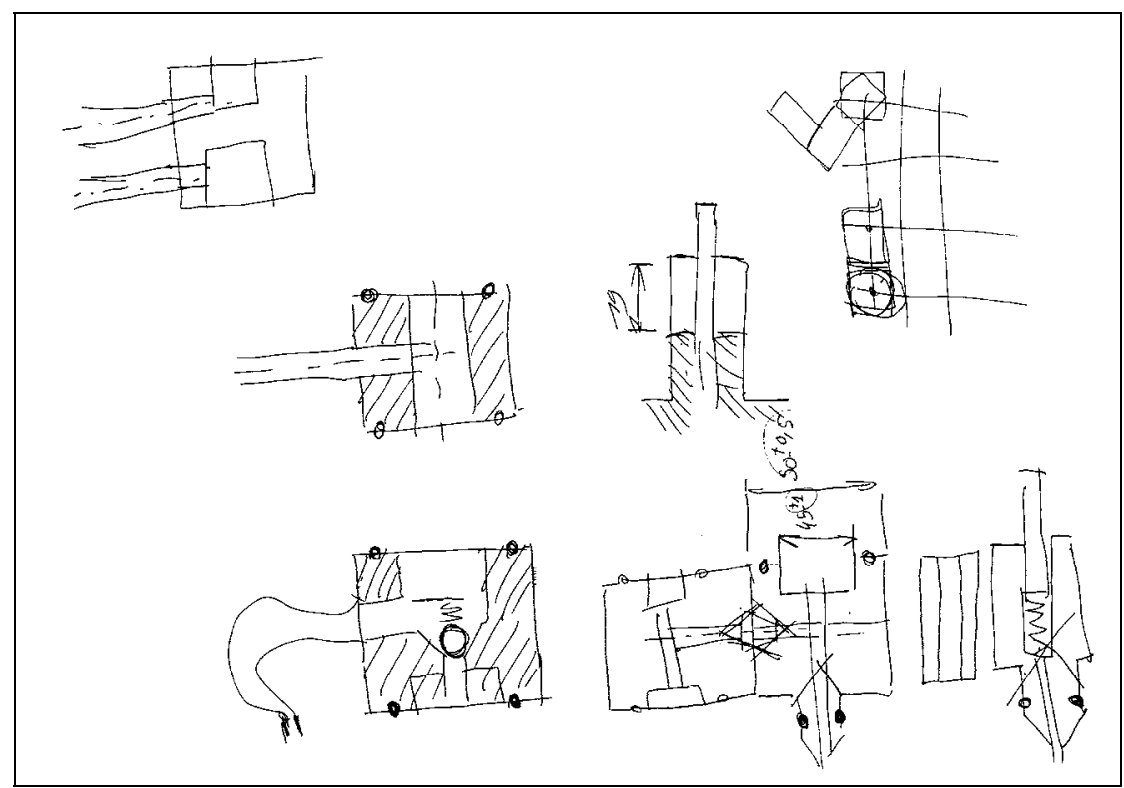

Fig. 3. Sketches of $1^{\text {st }}$ overall plan

These actors' use of intermediary objects reveals the temporal structure of the sociocognitive process: understanding of the problem, exploration of possible solutions and their evaluation, sharing of knowledge, design of a protocol, settling of agreements regarding this 
protocol, collection of data, definition of a standard, etc. These socio-cognitive activities are developed through material activity. Thus, looking at this materiality helps to grasp the cognitive process.

The intermediary objects are produced and used according to a process of succession and substitution. When one object is taken up, others sometimes disappear from the workspace.

Objects previously left to one side may make a come-back. Some of these intermediary objects also play a specific role in the temporal dynamics. They correspond to breaks or transitions between distinct phases of the activity. They define the boundary between design phases. They can be considered as phase change markers. The change of objects corresponds to a change in action. Their completion contributes to irreversibility in the process. They accompany the process and reveal the temporal organisation and changes at work.

However, it is not enough to look at these objects and their inventory alone. Indeed, they cannot be dissociated from the actions and interactions taking place. They are surrounded by diverse activities.

\section{Accessing material culture in engineering work}

Following this short account of how the notion of intermediary objects has been used in the study of scientific cooperation networks, we shall now turn our attention to some of the ways in which the notion has been further developed and its potential application to ethnography, mainly in engineering and innovation studies. Indeed, studying objects as they are handled and produced, even apparently common, unspecific (e.g. a pencil) and unimportant objects, sheds additional light on activity. As previously suggested, by following these objects and their circulation it is possible to produce another picture of human activity and organisation. This section will thus review some of the findings relating to intermediary objects in engineering design activity.

Based on the observation and monitoring of intermediary objects, ethnographic studies of design activities in the manufacturing industry have also borne their fruit. They have produced a very different picture from the one presented in engineering literature where reference is made to methods, tools and organisation, the potential benefits of these and the (best) way to work. Unlike this normative and idealistic vision of engineering activities, a description based on following actors and intermediary objects has helped to capture real practices and organisation (Vinck \& Jeantet, 1995; Vinck et al, 1996; Grégori et al, 1998; Brassac \& Grégori, 2001; Boujut \& Blanco, 2002; Godjo et al, 2003; Lécaille, 2003; Vinck, 2003; Ruffier, 2008). Their research work has led these authors to discover quantities of sketches, drawings, prototypes, listings and screen shots in the offices visited. Many of these objects are textual documents (Anomaly Sheets, Open-ended Specifications, Technical Instructions, Forecast Cost Price Documents, Detailed Methods, Operation Plans, Summary Documents, etc.) or graphic documents (Sketches, Manufacturing Plans, Block Diagrams, etc.). They are also physical objects (Prototypes, Broken Parts, Models made of Cardboard or Modelling Clay).

When the focus of a study is on these intermediary objects, each design office appears to be very different, presenting a specific type of material culture. One might be observed to have 


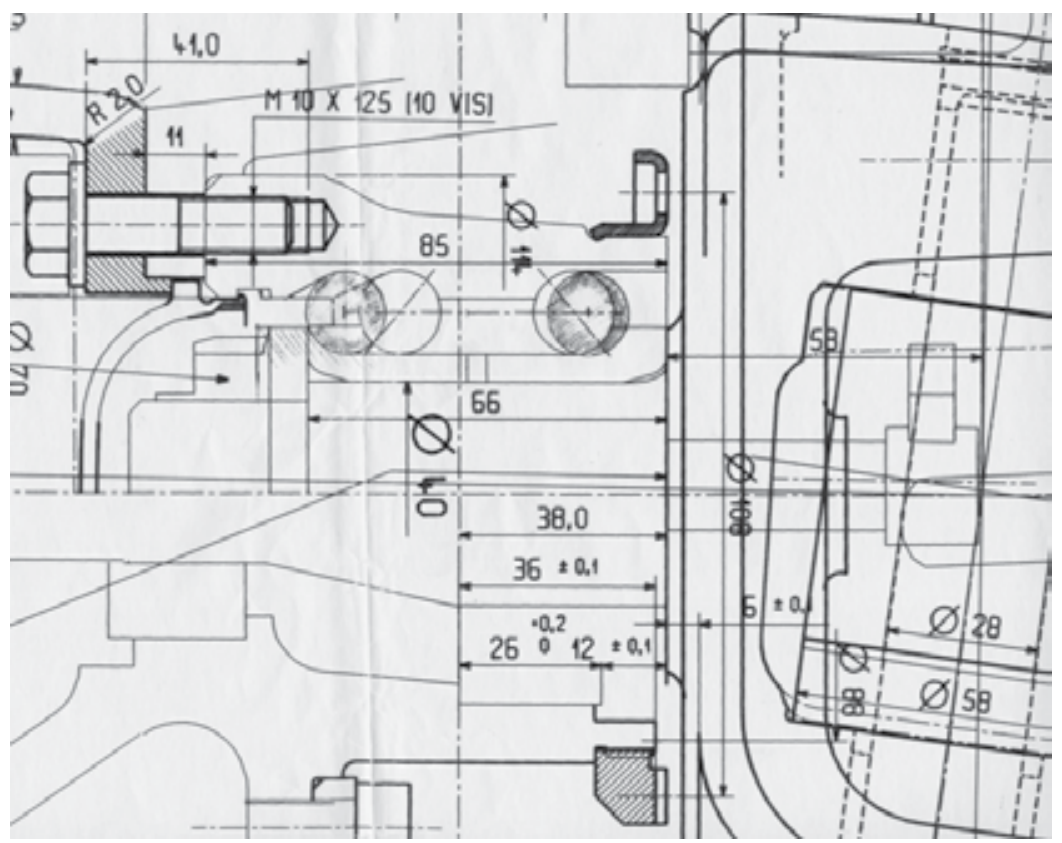

Fig. 4. A 2-D overall plan

well-ordered stacks of folded sheets, which are apparently not used very often. Another might present a disorganised mass of large sheets portraying industrial drawings and manual annotations, with people touching them and talking around them. Another design office may be full of lists of data and equations, while a fourth might display a mass of prototypes and broken parts, which people are looking at, picking up and moving from their desk to a test bench. Some objects and activities also appear to be somewhat clandestine (e.g. the use of modelling clay in a firm whose management insists on the use of digital modelling only).

By following these intermediary objects, in addition to performing interviews and observing what people do and say, it is possible to capture ethnomethods and map design processes, thereby uncovering relations between people that are not in the description of the official working process. As the ethnographer follows the activity as it unfolds, s/he also discovers a mutual cross-referencing, built by design office members, as various drawings and series of movements are pieced together. As they talk, designers point to different documents, sometimes making annotations on one drawing, explaining its relation to another drawing or using bodily gestures to show how the mechanism represented on the drawing works.

Reconstituting this activity reveals task-sharing, process sequencing and regulation points as different opinions are compared and constrasted and explanations requested. As with the description of the design office, following the moves of people and intermediary objects brings to light contrasting dynamics, cultures and socio-cognitive processes from one organisation to another, even when they perform very similar technical activities (Ravaille \& Vinck, 2003). Observing the in situ activity (as Hutchins (1995) did on planes and boats), and looking at intermediary objects, are effective ways of gaining access to collective activities. 
This method helps to shed light on cultural and cognitive aspects, social networks inside organisations and the effective practices of engineers.

\subsection{Revealing representation and translation processes in technical practices}

In design offices, it is also within the intermediary object that the representation process unfolds. The object reflects the designers' intentions (i.e. the desire, purpose and initial demand of the customer and the way designers expect to satify that demand), their working habits (e.g. technical culture reflecting the social milieu specific to various engineering fields like mechanics, hydrodynamics, electricity, aesthetics, but also organisational restrictions relating to cost, deadline and reputation), their interactions (e.g. more than 1000 technicians and engineers might be involved in the car design process), and the compromises they introduce (e.g. between designers and marketers on what to propose to the customer). Sometimes designers put their names or signatures on the intermediary objects that serve as the basis for the final future product to be sold to the customer. By following such intermediary objects (which are like various versions of both the customer's desire and the solution proposed), it is possible to trace the design journey and how the designers shape the demand. Upstream in the design process, intermediary objects represent the actors involved while, downstream, they reflect the emerging new object supposed to satisfy the initial demand. They are like pieces of society shaping the future of that society.

As in scientific cooperation networks, the design environment intermediary object is also where the translation takes place. When the intended solution is materialised, something new is introduced owing to the materiality or to the formalism used. For instance, the formalism pertaining to an industrial drawing requires the designer to define all surfaces, including unspecified features that the customer may consider to be unimportant. The designer might take it upon himself to specify theses unimportant surfaces. This may lead to a solution that is difficult and costly because the operator in charge of making the product is bound to follow the indications on the drawing. The operator does not necessarily realise that the surface is unimportant and can therefore be manufactured differently to avoid complications. Following intermediary objects thus makes it possible to describe the wanted or unwanted translation processes unfolding through the design process, and how constraints are introduced to the design. The material nature of objects and the formalism and tools used to produce intermediary objects are sources of opaqueness. The resulting objects do not simply reflect social relations and intentions; they also inherit something from the materiality, abilities and tools used to make them. This material culture cannot therefore be reduced to social interactions and inscriptions. This becomes much clearer when the ethnographer follows the intermediary objects.

\subsection{Framing the action}

In a functional sizing meeting, five designers are gathered around a square table. One of them acts as the facilitator. It is assumed he will play this role before the start of the meeting owing to his central role in the project. The intermediary object is an A1 format drawing. This is placed on the table opposite the facilitator. The other designers have a side view of the drawing. Each therefore has a different viewpoint. Although there are no rules telling the designers to stay put, nobody gets up to move around to see the drawing from a 
different viewpoint at any time. Similarly, the drawing is never moved or turned around. Throughout the observation of this scene, each thing and each person seems to have a set, immutable place. The designers seem to be enrolled within a framework defined by the configuration of the objects and which is never called into question.

This framework is set by the intermediary objects, such as the drawing on the table and other surrounding objects like the furniture. It is sometimes desired, perceived and accepted by the designers present but, in other working situations, it can be unwanted and subject to negotiation. It seems to define and delimit a space for action. It structures the space by differentiating it: the places around the table are not all equivalent. The viewpoints of the actors present are thus necessarily different. If they act as though they share the same point of view, this is either because they are building a collective illusion (they do not realise they have different viewpoints) or attempting to cognitively offset the differences introduced by their respective points of view.

The intermediary object, in the form of the drawing placed on the table, helps to set the framework for this engineering activity by focusing views in a certain way. Everything happens around the table with almost constant reference to the drawing through words, gestures, inscriptions and looks. The drawing and its physical limits also help to define and outline a space for action around the table. There is a strong differentiation between the public space (the drawing), common to the five designers, and the private spaces in which each designer is surrounded by his or her own pencils, mementos and notebooks. Some actions take place within the collective space, such as when an item is pointed out on the drawing and a collectively defined line is added to it. Others belong to the private space, such as when the objects surrounding a person are readjusted, or when somebody consults the drawing analysis grid or jots down notes in their private notebook. There are sometimes shifts between one space and another. Actions performed on personal objects might prepare the way for actions performed in the common space, such as a chair being moved before an actor speaks, a pencil being picked up before something is said, the pencil being put down again to mark the end of the designer's engagement on the collective stage or to mark their withdrawal.

The objects help to frame the action, notably by outlining, structuring and differentiating the spaces. They bring something to the action, even if their effects are not those of technical determination - insofar as the effects depend on the way in which the framework is reviewed, modified or left unchanged over the course of the ensuing action. Given that they can contribute to setting the action framework for the various actors present, intermediary objects constitute a form of implicit structure.

\subsection{Equipping intermediary objects and spaces of exchange}

Recent developments in the notion of intermediary object have extended its use in new ways. The controversies observed between design technicians and engineers regarding some of the details of intermediary objects underline the need for these objects to be equipped with marks or codes (Vinck, 2011). These details seem to be central to the actors because they appear to structure their activity and relations, as well as the social and technical world. The actors will talk about requirements, technical problems and solutions, but also about the details of drawings. They invest highly in these objects in terms of their 
preparation and realisation, but also in terms of checking who will receive them, who might explain a drawing and who should have control over the use of such objects. Many of these discussions concern the circulation of both people and drawings. One of the topics of major concern is the signatures, codes and dates appearing on drawings. A project seems to depend on these details. Improperly numbered, a drawing can even jeopardise the integration of each designer's results.

Our following of actors and intermediary objects has also revealed the importance of the place occupied by the exchange of data and information between designers. These actors are constantly searching for information (calling up other designers, looking inside shared databases or walking around a colleague's desktop). They strive to recover information associated with drawings (authors and holders, location and access, existence of new versions, etc.). Their search for information also encompasses the quality of technical data and the degree of trust they can have in them with respect to their origin, the identity of the author and the history of their construction. Their concern about whether information should be circulated highlights the importance of information exchange. Careful examination of the forms of exchange shows that what is at stake in this passing on of technical data has to do with the anthropological issue of gift exchange; the technical data given is a gift carrying with it something of the person offering it. There is a close relationship between the anthropological conditions of the information exchange and the elements equipping the objects being circulated.

\section{Conclusion}

Since the end of the 1980's, the social sciences have given increasing consideration to the materiality of things (bodies, artefacts, etc.). The Actor-Network Theory (ANT) and a number of other social sciences (sociology of consumption, anthropology of material culture, science and technology studies, and sociology of the risk society) have called attention to the importance of materiality, among other aspects in the study of science, technology, engineering and innovation. ANT has played a major role in this respect. It reports on sociotechnical constructions of knowledge, devices, actors and institutions, in terms of networks of associations between heterogeneous entities (human and non-human) obtained following a translation operation (Callon, 1986).

Providing a short overview of some of the discoveries made through the use of the notion of intermediary object, this chapter contributes to sociological considerations of materiality. The methodological approach underlying the notion reveals actors and relations, practices and activities, real organisations, and processes and networks. The chapter is based on investigations performed in the field of scientific cooperation networks and design activities. However, various authors have also used the concept in the field of organisational studies (e.g. Reverdy (2003) on quality insurance or Bazet \& de Terssac (2001) on industrial planning), political sciences focusing on public policies (e.g. Mélard (2008) on ecology), geography (e.g. Laron et al, 2001), and technology transfer (e.g. Ruffier (2008) on trucks).

The chapter provides a summary of some of the conceptual developments surrounding the notion: mainly representation, translation and mediation processes, the marking of changes and temporality and action framing. It concludes with a new development of the notion in the field of design activity ethnography. This development shows the importance of two 
things: the circulation spaces between actors and the equipping of intermediary objects. Through the process of equipping, new properties are conferred on the intermediary object and this contributes to the shaping of collective dynamics.

\section{References}

Almklov, P. (2008). Standardized Data and Singular Situations, Social Studies of Science, Vol.38, No.6, pp. 873-897.

Appadurai, A. (Ed.) (1986). The Social Life of Things. Commodities in Cultural Perspective, Cambridge University Press, Cambridge.

Bazet, I. \& de Terssac, G. (2001). Analyse sociologique du travail de planification, In: Organisation et gestion de la production, Erschler, J. (Dir.), pp. 89-129, Hermes, Paris.

Boujut, J.-F. \& Blanco, E. (2002). Intermediary Objects as a Means to Foster Co-operation in Engineering Design. Journal of computer supported collaborative, Vol.12, No.2, pp. 205219.

Brassac, C. \& Grégori, N. (2001). Situated and Distributed Design of a Computer Teaching Device. Journal of Design Sciences and Technology, Vol.8, No.2, pp. 11-31.

Callon, M. (1986). Some Elements of a Sociology of Translation: Domestication of the Scallops and the Fishermen of St Brieuc Bay, In: Power, Action and Belief: A New Sociology of Knowledge, Law, J. (Ed.), pp. 196-233, Routledge \& Kegan Paul, London.

Godjo, T.; Marouzé, C.; Boujut, J.-F.; Giroux, F. (2003). Analysis of the intermediary objects involved in the design of food processing equipment in developing countries. The case of a peanut processing plant in Benin. In CIRP Design seminar. Grenoble.

Grégori, N.; Blanco, E.; Brassac, C.; Garro, O. (1998). Analyse de la distribution en conception par la dynamique des objets intermédiaires, In: Les objets dans la conception, Trousse, B. \& Zreik, K. (Eds), pp. 135-154, Europia, Paris.

Hutchins, E. (1995). Cognition in the Wild, MIT Press, Cambridge, MA.

Kaufmann, J.-C. (1998). Dirty linen: couples and their laundry, Middlesex University Press, Londres.

Knorr, K. (1995). Laboratory Studies: The Cultural Approach to the Study of Science, In: Handbook of Science and Technology Studies, Jasanoff, S. et al, pp. 140-166, Sage Publications, London.

Kopytoff, I. (1986) The cultural biography of things: Commoditization as process, In: The Social Life of Things: Commodities in Cultural Perspective, Appadurai, A. (Ed.), pp. 6491, Cambridge University Press, Cambridge.

Lardon, S.; Maurel, P.; Piveteau, V. (2001). Représentations spatiales et développement territorial, Hermes, Paris.

Latour, B. (1987). Science in action: how to follow scientists and engineers through society, Harvard University Press, Cambridge, MA.

Latour, B. (1993). We Have Never Been Modern, Harvard University Press, New York.

Latour, B. (1995). The "Pedofil" of Boa Vista: A Photo-philosophical Montage, Common Knowledge, Vol.4, No.1, pp. 144-87.

Latour, B. (1996). On interobjectivity. Mind, Culture, and Activity. Vol.3, No.4, pp. 228-245.

Latour, B. (1999). When Things Strike Back a Possible Contribution of Science Studies to the Social Sciences, British Journal of Sociology. Vol.51, No.1, pp. 105-123.

Latour, B. \& Woolgar, S. (1979). Laboratory life: the social construction of scientific facts. Sage Publications, Beverly Hills. 
Law, J. (1987). Technology and Heterogeneous Engineering: The Case of Portuguese Expansion, In : The Social Construction of Technological Systems: New Directions in the Sociology and History of Technology, W.E. Bijker, T.P. Hughes, and T.J. Pinch (Eds.), MIT Press, Cambridge, MA.

Law, J. (Ed.) (1991). A Sociology of Monsters: Essays on Power, Technology, and Domination, Routledge, London \& New York.

Law, J. (1999). After ANT: Complexity, Naming and Topology, In : Actor Network Theory and After, Law, J. \& Hassard, J., pp. 1-14, Blackwell, Oxford.

Lécaille, P. (2003), La trace habilitée. Thèse de doctorat en génie industriel, INPG-UPMF, Grenoble.

Lefebvre, M. (2003). Pictures and boundaries work in mathematics, Questions de Communication. No.3, pp. 69-80.

Marcus, G. (1995). Ethnography in/of the world system: The emergence of the multi-sited ethnography, Annual Review in Anthropology, No.24, pp.95-117

Mélard, F. (Ed.) (2008), Ecologisation. Objets et concepts intermédiaires. Peter Lang, Bruxelles.

Pels, D.; Hetherington, K. \& Vandenberghe, F. (2002). The Status of the Object. Performances, Mediations, and Techniques. Theory, Culture \& Society, Vol.19, No.5/6, pp. 1-21.

Ravaille, N. \& Vinck, D. (2003). Contrasting Design Cultures: Designing Dies for Drawing Aluminum, In: Everyday engineering. Ethnography of design and innovation, Vinck, D. (Ed.), pp. 93)117, MIT Press, Cambridge, MA.

Reverdy, T. (2003). Writing Procedures: The Role of Quality Assurance Formats, In: Everyday engineering. Ethnography of design and innovation, Vinck, D. (Ed.), pp. 137-157, MIT Press, Cambridge, MA.

Ruffier, C. (2008). Sociologie de la carrière des objets techniques. Le cas du camion dans le transfert de techniques entre France et Chine. Thèse de doctorat en sociologie, Université de Lyon II, $678 \mathrm{p}$.

Star, S.L. \& Griesemer, J. (1989). Institutionnal ecology, 'Translations' and Boundary objects: amateurs and professionals on Berkeley's museum of vertrebate zoology. Social Studies of Science, No.19, pp. 387-420.

Vinck, D. (1992). Du laboratoire aux réseaux. Le travail scientifique en mutation, Office des Publications Officielles des Communautés Européennes, Luxembourg.

Vinck, D. (1999). Les objets intermédiaires dans les réseaux de coopération scientifique. Contribution à la prise en compte des objets dans les dynamiques sociales. Revue Française de Sociologie. Vol.XI, pp. 385-414.

Vinck, D. (ed.) (2003). Everyday engineering. An ethnography of design and innovation, MIT press, Cambridge, MA.

Vinck, D. (2011). Taking intermediary objects and equipping work into account in the study of engineering practices. Engineering Studies, Vol.3, No.1, pp. 25-44.

Vinck, D. \& Jeantet, A. (1995). Mediating and Commissioning Objects in the Sociotechnical Process of Product Design : a conceptual approach, In: Designs, Networks and Strategies, Maclean, D.; Saviotti, P. \& Vinck, D. (Eds), pp. 111-129, vol. 2, COST A3 Social Sciences, EC Directorate General Science R\&D, Bruxelles.

Vinck, D.; Jeantet, A.; Laureillard, P. (1996). Objects and Other Intermediaries in the Sociotechnical Process of Product Design : an exploratory approach, In The role of 
design in the shaping of technology, Perrin, J.\& Vinck, D. (Eds), pp. 297-320, vol. 5, COST A4 Social Sciences, EC Directorate General Science R\&D, Bruxelles.

Vinck, D.; Kahane, B.; Laredo, P. \& Meyer, J.-B. (1993). A Network Approach to Studying Research Programmes : Mobilising and coordinating public responses to HIV AIDS. Technology Analysis \& Strategic Management. Vol.5, No.1, pp. 39-54. 


\title{
A Service Value Creation Model and the Role of Ethnography
}

\author{
Michitaka Kosaka \\ Japan Advanced Institute of Science and Technology \\ Japan
}

\section{Introduction}

The importance of services has been growing in various fields in the 21st century. Service science has become a common thread in information and knowledge industries. Various service research proposals have been put forward, such as Service Dominant Logic (SDL) (Lusch \& Vargo, 2006), persona marketing (Pruitt \& Adlin, 2007), and service as a theater (Fisk et al., 2008). These new service-related concepts are based on the idea of "value in use". At issue is how the person who receives a service recognizes the value of the received service.That is, discussions on service value are important to service businesses.

The application of ethnographic knowledge to services is one such direction of research. New terminology, e.g., "business ethnography" or "ethnography for marketers", has emerged. Why is ethnography so important in service science? What is the role of ethnography in service value creation? The answers to these questions are very important if ethnographic knowledge is to be of use in service science. However, there is no theoretical foundation as yet. This chapter proposes the new theoretical framework for service value creation based on the concepts of the service field, which can explain the relationship between service value and ethnography.

In general, the value of a provided service depends on the situation (human characteristics, needs, place, time, cost, etc.). Even if an identical service is provided, its service value will still depend on the specific human characteristics involved and the particular situation. The "value in use" concept in SDL (Lusch \& Vargo, 2006), for example, depends on the situation. Also, context-aware service (Kolari et al., 2004) considers the relationship between service value and its situation. However, to the best of our knowledge, there is no previous research that offers a theoretical framework for service value creation in which the situationdependent characteristics of service value are considered.

We propose using a new concept to create a service value that depends on the situation. This concept is derived from the physical theory of the electromagnetic field, wherein the electromagnetic power is determined by the relation between the electric charge and the electromagnetic field. According to this analogy, the service value for customers is determined by the relation between the provided service and the situation where the service is provided. The identification of the service field is very important in this model, and technologies for analyzing human behavior such as ethnography, brain activity 
measurements, and word-of-mouth data analysis, are indispensable for identifying the service field. In particular, ethonography provides a new methodology by observing human behavior, and it gives a different viewpoint from those of conventional methodologies such as questionaire/interview analysis.

In this chapter, a systems engineering approach incorporating various humanities related fields of study such as ethnography is proposed for creating high service value for customers. First, the importance of service research in industry is explained. Then, the concept of the service system and the service field is explained, and it is shown that proper identification of the service field is very important for creating high service value. An ethnographic methodology is introduced as a way to identify the service field based on the findings presented in previous books on business ethnography and marketing ethnography (Mariampolski, 2006). After that, a successful example is presented to show the effectiveness of the ethnography methodology. Finally, a service innovation creation model in industry and a service management education curriculum based on the service value creation methodology are described.

\section{Importance of service research in industry}

\subsection{Importance of innovation}

There are many types of service business. They range from traditional services such as hotel, travel, maintenance, and outsourcing to new services with new business models such as those offered through the Internet. The importance of innovation in services has been discussed in various industries as a means of obtaining competitive advantages. As the name implies, services innovation fuses two methodologies. The first focuses on innovation in current service industries. It aims to give the means to improve productivity and quality in service industries such as hotel lodging, travel, and so on. The second methodology focuses on applying service concepts and individual service approaches. It emphasizes new value creation by using information technology to help customers in the 21st century. The rise of Google, mobile phone services, and IC card applications is clear indication that such an emphasis is needed. In this sense, service innovation is an important business issue in the era of the Internet and globalization.

Specifically, the targets of service innovation in 21st century are as follows:

1. Convergence of IT technology and services in the development and provision of new services

2. Servitization in the manufacturing industry

3. IT 'solution' services for various industries

4. Services in the information industry

To create such new services, service innovators should have skills in human science, social science, IT technology, and management. Their abilities range from conceptualizing a new service and being able to perform system integration to being able to empathize with service recipients and understand their needs.

There are two major reasons for stressing the importance of service innovation. One is the impact of IT technologies, and the other is the influence of product commoditization. 


\subsubsection{Impact of IT technologies}

IT technologies have become indispensable in various industries. In particular, various IT technologies, including the Internet, smart terminals, data mining, etc., are being utilized to improve service quality and enhance value. As shown in Figure 1, they are used in the front stage, networks and in the back stage of the service system.

a. Front Stage

The front stage of a service includes ubiquitous information terminals, such as car information systems, mobile phones, tablets, etc., which provide user interfaces with a network service environment. These intelligent terminals enable people to utilize information services through the Internet anytime and everywhere. Self-service functions on terminals such as ATM machines in banks also improve service productivity.

b. Back Stage

Various information technologies, such as data mining technology, are used in the back stage to analyze customer data for marketing purposes. The results of these analyses can be used raise customer satisfaction and improve quality of service.

c. Network

The most important network is the Internet. The Internet aggregates various services and provides them to the world at a very low cost. Many new business models have been created by using the Internet, and the long tail business model is one such example.

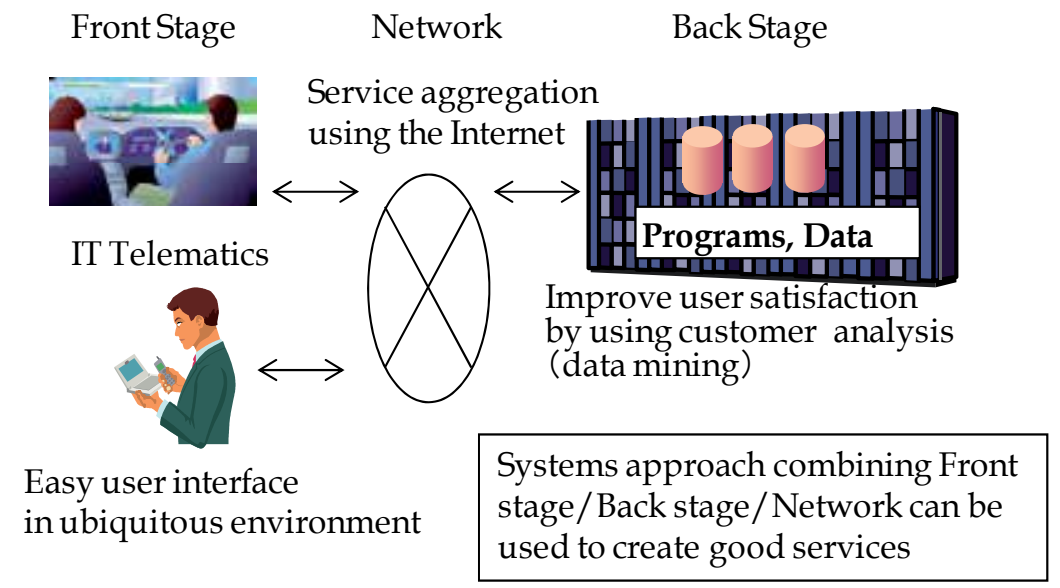

Fig. 1. ICT for service innovation

\subsubsection{Impact of product commoditization}

Figure 2 illustrates the concept of the customers' total value, as defined by Kameoka (Kameoka, 2007). The customers' total value consists of product value, service value provided by service providers, and customers' added value. Many products have become commoditized, and the value of products is in general decreasing. Consequently, services have become a larger portion of the customers' total value (Fig. 2). In particular, 


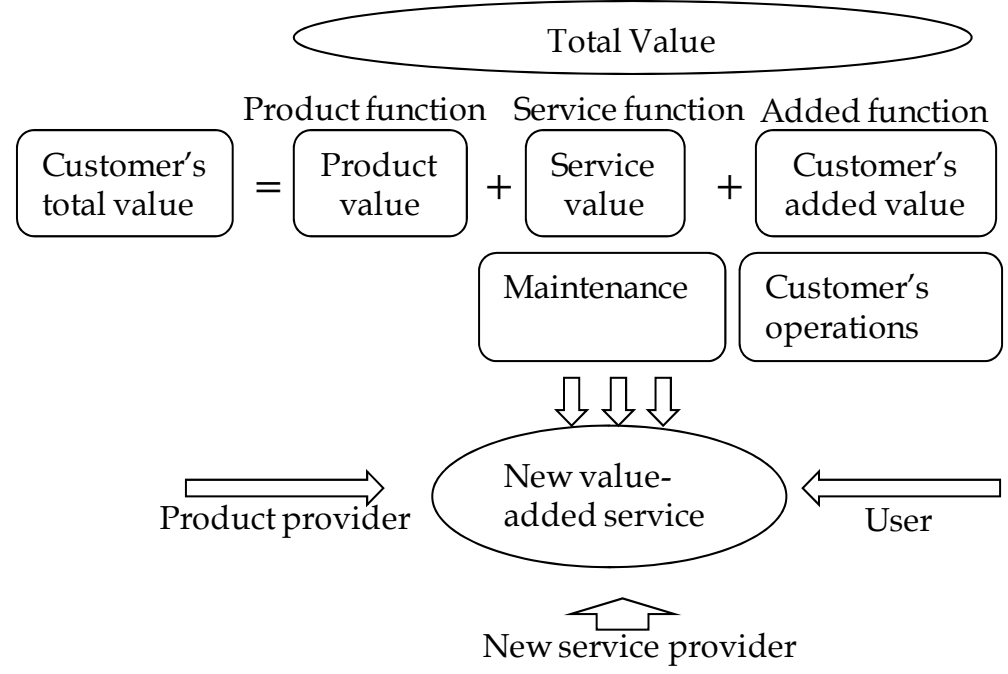

Fig. 2. Customers' total value, as defined by Kameoka

servitization in manufacturing is a key issue for obtaining a competitive advantage, and service value creation is indispensable for customers in 21st century. In knowledge science, a service can be defined as a knowledge creation process for customers' value, and knowledge creation for new service value is essential for service innovation. A value added service can be created by a product provider, new service provider, and user collaborating, and this activity leads to service innovation. The above definition of service value creation means that it is relevant not only to the traditional service industry but also to manufactuing and the information industry.

\subsection{Service dominant logic (SDL) and goods dominant logic (GDL)}

New concepts related to service science have been proposed. Vargo proposed the service dominant logic (SDL) concept and argued that our economy has shifted from a goods economy to a service economy (Lusch \& Vargo, 2006). The key point of SDL is that its determination of value is different from that of goods dominant logic (GDL). In GDL, the value is determined by the producers, whereas in SDL, the value is determined by the customer on the basis of "value in use". Figure 3 compares SDL and GDL. Many service science researchers have examined the SDL concept and are looking for ways to maximize customer or personal satisfaction by combining it with the concept of "value in use." SDL leads to a new viewpoint of service through extension of its concept to include goods. This concept is very suitable for explaining global business in the 21st century. Moreover, the concept of "value in use" is essential in the service businesses of the new era.

\section{Concept of the service system and service field}

As regards service innovation, it is important to create service value for customers. In this section, such an activity is modelled as a service system, and a new concept, that of the service field, is introduced in order to create high service value. After that, it is explained that the service field must be identified in order to create service value for customers. 


\begin{tabular}{lll}
\hline Dominant logic & \multicolumn{1}{c}{ Goods } & \multicolumn{1}{c}{ Service } \\
Role of the customer & $\begin{array}{l}\text { The customer is the } \\
\text { recipient of goods }\end{array}$ & $\begin{array}{l}\text { The customer is a co-producer } \\
\text { of the service }\end{array}$ \\
$\begin{array}{l}\text { Determination and } \\
\text { meaning of value }\end{array}$ & $\begin{array}{l}\text { Value is determined by } \\
\text { the producer }\end{array}$ & $\begin{array}{l}\text { Value is perceived and } \\
\text { determined by the consumer } \\
\text { on the basis of "value in use" }\end{array}$ \\
Interaction & $\begin{array}{l}\text { Customers are acted on } \\
\text { to create transactions } \\
\text { with resources }\end{array}$ & $\begin{array}{l}\text { Customers are active } \\
\text { participants }\end{array}$ \\
& &
\end{tabular}

Fig. 3. Comparison of SDL and GDL

\subsection{Definition of the service system}

According to Kameoka (Kameoka, 2007), service is the activity of supporting human beings or organizations to enable them to achieve their objectives or desires. Sadahiko Oda, the chairman of Kagaya, Co., a famous Japanese spa hotel and a well-known services oriented company, describes service as an activity that provides professional techniques, satisfies the customer, and results in compensation for the service provider. According to these definitions, service is the most productive of human activities, and it covers various business activities. These definitions are illustrated in Figure 4.

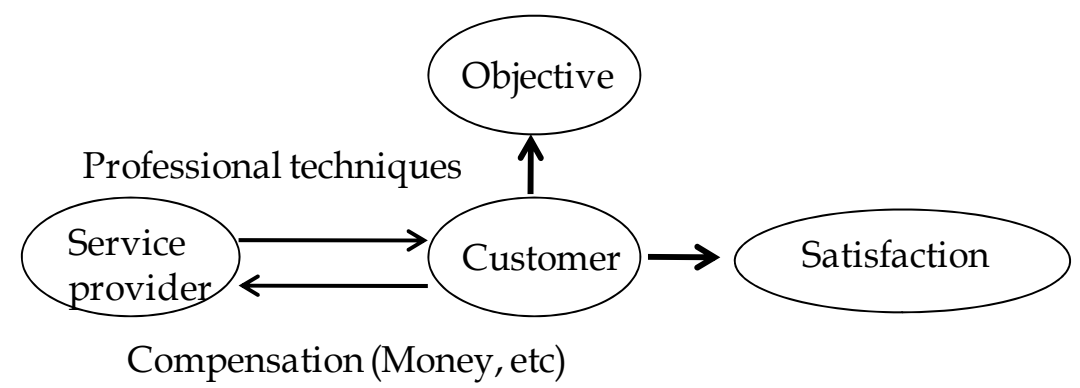

Fig. 4. Definitions of service

According to the above definitions, a service activity consists of three factors:

1. Service providers who perform professional techniques,

2. Customers who feel satisfaction from provided services, and

3. Customers who award compensate, usually in the the form of money, the provider for its services.

According to SDL, service value for customers is created through a collaboration between service providers and customers. A service can be described as a system (Fig. 5) that consists of customers, service providers, and service co-creation activities. In other words, a service system includes human beings, and its objective is to maximize the service value for customers as reagrds their objectives in order to assure their satisfaction. Various technologies related to human beings or system sciences are used to maximize the level of satisfaction. 
The relationship between customers and service providers (the providers could be people, information systems, or social infrastructures) is very important in the service system. Three types of technology or methodology are required to maximize customers satisfaction. The first is a kind of human-related transdisciplinary technology for analyzing customers. It could be persona marketing, brain science, ethnography, etc. The second is a technology or methodology for co-creation of service value, e.g., service as a theater (Fisk et al., 2008), "Ba" in knowledge management (Nonaka \& Takeuchi, 1995). The third is various system engineering technology for optimizing the service, such as service integration, simulation, optimization, and so on. Figure 5 shows that systems engineering approach seems to be an effective way of service value creation.

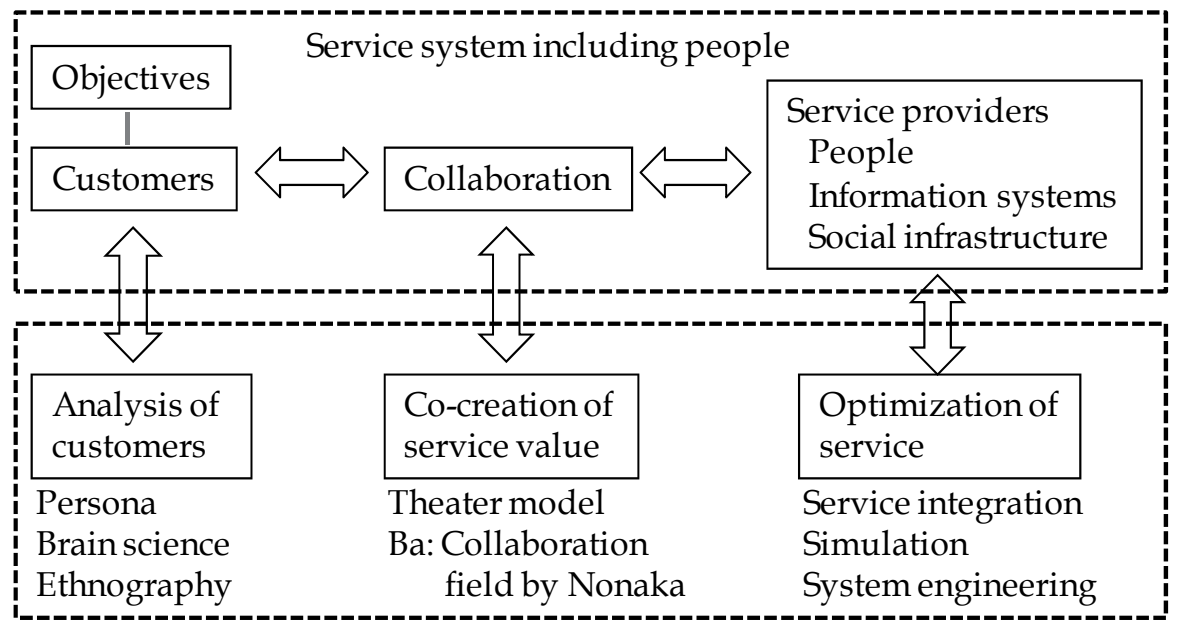

Transdisciplinary technology

Fig. 5. Service system

\subsection{The concept of the service field}

In general, the value of a provided service depends on the situation (consumer characteristics, needs, place, time, cost, etc.). Even if an identical service is provided, the service value may differ due to the consumer's characteristics or situation. The "value in use" concept in SDL (Lusch \& Vargo, 2006) greatly depends on the situation. Note that context-aware service also considers the relationship between the service value and the situation. However, there is no previous research that provides a theoretical framework for service value creation considering situation-dependent characteristics.

In this chapter, the concept of using a service field in service systems is proposed for creating service values dependent on the situation. This concept is an analogy of the electromagnetic field, where electromagnetic power is determined by the relation between the electric charge and the electromagnetic field. According to this analogy, the service value is determined based on the relation between the provided service and its situation.

In electromagnetic field theory, the electromagnetic power $\boldsymbol{F}$ is given by the equation $\boldsymbol{F}=\boldsymbol{q} \cdot(\boldsymbol{E}+\boldsymbol{v} \times \boldsymbol{B})$, where $\boldsymbol{q}$ is the electric charge, $\boldsymbol{E}$ is the electric field, $\boldsymbol{B}$ is the magnetic field, and $v$ is velocity of the electron. In theory, even if charge $q$ is large, there is no 
electromagnetic power if there is no electromagnetic field. This relationship can be used to describe the creation of service value. Even if the service quality is high, there is no service value if the service is not required by a customer; that is, if there is no service field. The service value is determined by the relationship between a service and its service field, which shows how the customer needs the service.

The service field model can be specified as (Service value) $=($ Service $) \times($ Service field $)$, where $\times$ denotes the relationship between the service and the service field. The concept of the service field is shown in Figure 6. A high service value for the customer is generated when the services are provided in accordance with high potential values in the service field. A high potential means that the requirement for the provided service is high. Otherwise, the provided services cannot obtain a high service value. To maximize the service value, a service field should first be identified, then suitable services should be provided that correspond to the customers' characteristics and/or requirements.

This new proposal to create and improve service values is based on service fields and service systems, and it can be applied to various services where providers and receivers cocreate service values. This means that the service system and the concept of service fields are applicable to modeling service value creation.

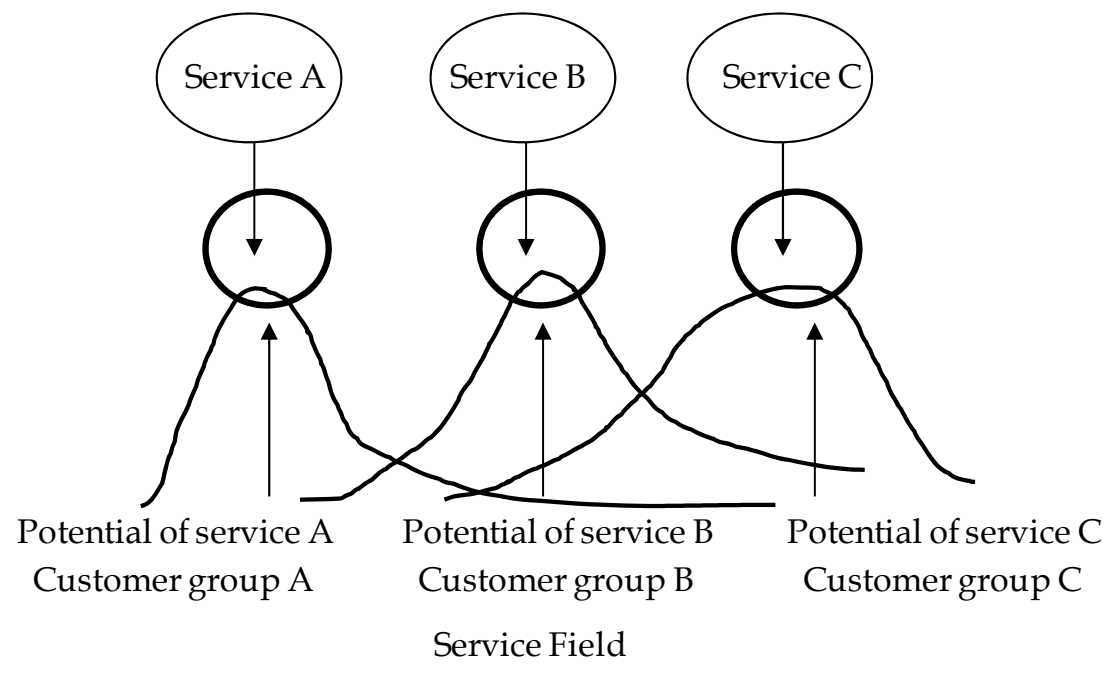

Fig. 6. Potential of a service in the service field

\subsection{Identification of service fields}

Figure 7 shows the basic idea of identifying a service field to create high service value. Once the service field is identified, it is easy to determine what kind of service is most preferable for the target customer. Once the field is identified, the most optimal service can be provided. The service field is determined by the relationship between customers and target services, and it expresses the intensity of the service requirement.

The service field should be identified to clarify what services are required by customers in various environments and situations. The procedure of such a methodology consists of three steps: 
1. Collect data related to human behavior, thoughts and opinions, and so on,

2. Analyze data using various methods or technologies, and

3. Draw conclusions from the analyses.

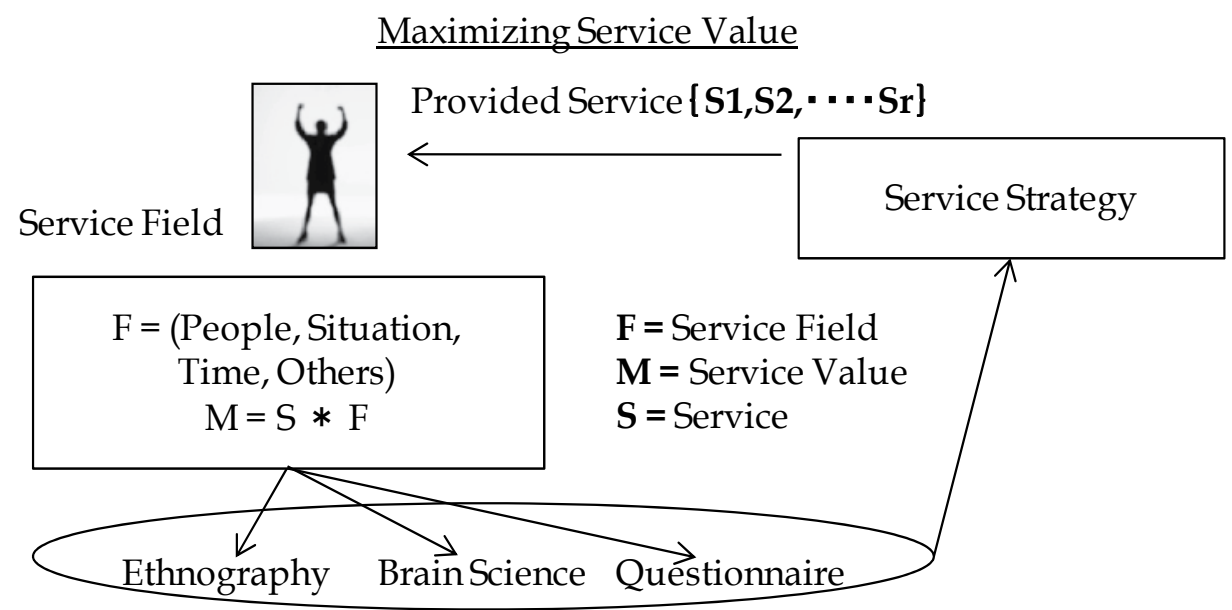

Measurement of Service Field

Fig. 7. Identification of service field

There are many conventional methodologies related to the identification of service fields, and they mainly fall into the categories of field research or questionnaire analysis in marketing. Recently, IT technology and brain science have been employed to analyze users' needs or inclinations. Ethnography has also been put to use for identifying users' needs in business or marketing through observations of human behavior. These methodologies are summarized as follows.

1. Conventional interview or questionnaire analysis

Interviews and questionnaires are popular in conventional marketing surveys. These analyses collect interviewees' thoughts about a target product or service. The unstructured interview method is used for the sake of flexibility as regards the interview situation. The collected data are subjective and are affected by the intentions or biases of the interviewees. Therefore, the results of such an analysis are sometimes different from the true or actual needs.

2. Ethnography

Ethnography, which has been employed in anthropological and sociological studies, has been introduced to business for the purposes of marketing, design, and organizational restructuring. Ethnography in business aims at clarifying customers' needs by observing the behaviors of target peoples, recording them in the form of field notes, pictures, and video data, and analyzing these data. Through field work at real sites, ethnographers obtain findings related to the customers' true needs. However, the findings derived from ethnographic observations depend on ethnographers' subjectivity and ability, and ethnography is hence a qualitative form of research. The ethnographic approach to identifying customers' needs is described in Section 4. 
3. IT technologies

IT technologies such as POS terminals or data mining technology have been utilized for identifying users' needs in the distribution industry and other service industries. The collected data in these cases are usually objective sales data or operations data. IT technologies are useful for identifying the service field. They are good for clarifying the users' true needs and enhancing the service quality. The most important form of IT is the Internet. In the Internet, there are many kinds of customer data, such as word-ofmouth data, web site access records, and so on. Service requirements and/or service satisfaction data are obtained and analyzed from word-of-mouth and questionnaire data collected from the Internet, the service field associated with the target customers is identified, a suitable service is provided, and ideally the customers are very satisfied. IT technologies are used for collecting and analyzing consumer data to identify the service field. Thus, IT is one of the most important factors in service innovation. For examples, IT has frequently been used to identify the service field during maintenance operations in manufacturing and for analyzing customer needs in Internet service businesses.

KOMTRAX (Kitatani, 2010) is a successful system of Komatsu, Ltd that collects realtime operation data about its products (construction machines) from all over the world and provides information related to the maintenance schedules and details of the target products. It is a way of identifying the service field associated with the products. The KOMTRAX system also offers a suitable service recommendation depending on the service field situation.

In most of the successful cases where IT has been utilized for service innovation, the role of IT has been to measure and identify the service field of the target customers.

4. "Human" technologies

Recently, "human" technologies, such as those used in brain science (Shirahada et al., 2010) and eye tracking equipment, have been used for the purposes of marketing, design, and so on. These technologies are very effective for identifying the service field because service value is dependent on the characteristics and thoughts and opinions of people.

For example, brain measurement technologies such as NIRS (Near Infrared Spectroscopy) can measure brain activities related to the feeling of satisfaction or decision making (Shirahada et al., 2010) and eye tracking technology can analyze eye movements in relation to the provided services. Accordingly, feelings of satisfaction can be quantitatively analyzed. A combination of brain measurements and eye tracking seems to be a promising methodology for identifying service fields from human characteristics.

\subsection{Integrated methodology for identifying service fields}

These methodologies have their own characteristics and can be categorized according to some criterion. For instance, ethnography and interviews belong to the realm of qualitative research; on the other hand, data analysis using IT or brain measurements are forms of quantitative research. Figure 8 shows a categorization of these methodologies from the viewpoint of whether they are subjective or objective about the data source and the analysis.

As explained above, there are many methodologies for identifying service fields. They have different characteristics, but their objective of identifying the service field is the same. That means these methodologies can be integrated to give a more precise identification. 


\begin{tabular}{|c|c|c|c|}
\hline & \multicolumn{2}{|c|}{ Data source } \\
\hline & & Subjective & Objective \\
\hline \multirow{2}{*}{$\begin{array}{l}\text { Data } \\
\text { analysis }\end{array}$} & Subjective & $\begin{array}{l}\text { Interview } \\
\text { analysis }\end{array}$ & Ethnography \\
\hline & Objective & $\begin{array}{l}\text { Questionnaire } \\
\text { analysis }\end{array}$ & $\begin{array}{l}\text { ICT technology } \\
\text { Brain measurements } \\
\text { Eye tracking }\end{array}$ \\
\hline
\end{tabular}

Fig. 8. Categorization of methodologies for identifying service fields

In systems engineering, the integration of many methodologies for identifying the same target will result in a more precise identification than would be possible with just one methodology. For example, in the case of multi-sensor tracking (Kosaka et al., 1987), sensor integration (different kinds of sensor data are integrated in some way) can obtain a more precise estimate of a target's situation. An analogy of multi-sensor tracking can be used to identify the service field. That is, the methodologies shown in Figure 8 can be integrated into one to identify the specific service field.

Figure 9 shows the concept of methodology integration for identifying the service field. How to integrate such methodologies will be an issue of future studies in this field.

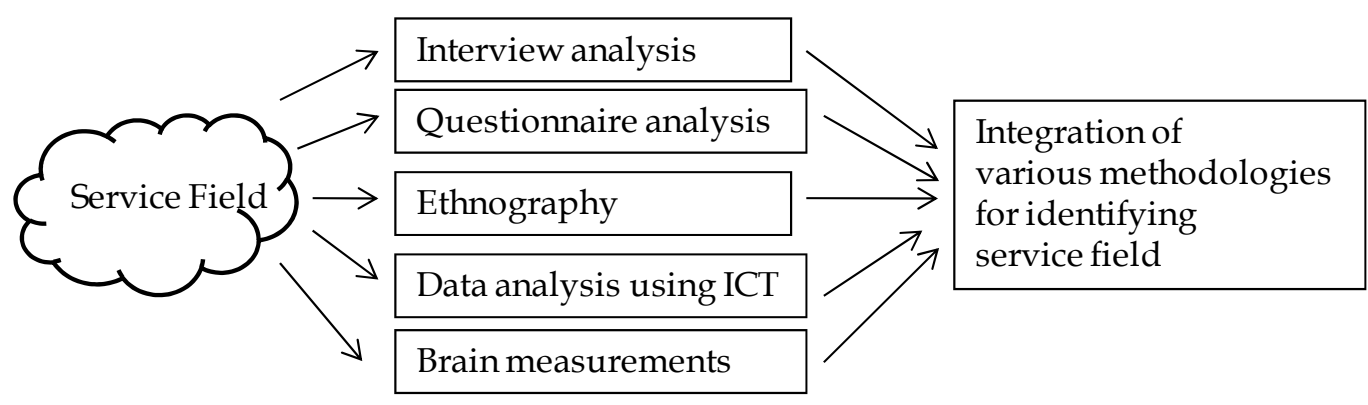

Fig. 9. Integration of various methodologies for identifying service fields

\section{Role of ethnography in service value creation}

The service field is formed from human characteristics, contexts, needs, and situations. Human factors have an especially significant impact. To identify the service field precisely, various approaches and their combination are required, as described in section 3.4. Ethnography is a qualitative form of research and provides a different viewpoint from that of conventional quantitative methodologies such as questionnaire analysis, customer data analysis using IT technology, and so on.

This section briefly summarizes the application of ethnography to business situations and demonstrates that it is useful for creating service value through an example of persona marketing. 


\subsection{Basic idea of business ethnography}

Ethnography was originally developed to study social life and institutions on a scientific basis. Anthropological and sociological studies are carried out through on-site observations, field work, and qualitative research. In classical ethnography, ethnographers may stay onsite for a long time. The characteristics of ethnography are observation without prejudice, learning from observation, context awareness, and using the ethnographer's intuition for revealing the reality or truth of their targets of study. These features of ethnography are suitable for gaining insights on consumer roles and for learning good product usage. The ethnographic methodology has been used in business for purposes of marketing, design, and organizational management. These aspects of business are deeply related to human intentions and characteristics. The characteristics of ethnography as a form of qualitative research are summarized as follows:

1. Reality: finding the truth from on-site observations

2. Collecting data only by observing targets on-site

3. Improvisation

4. Understanding in context

5. Intuition

6. Bridging from one to the other

Let's consider how ethnography is of use in product or service marketing where ethnographers observe how customers use the target product or service. This observation is done at the site where customers use products or services (reality (1)). The observed data are recorded as notes or pictures (2). Observations and collected data are forms of improvisation because how customers will deal with a product is not known in advance (3). How customers use the products or services should be understood in the context of their culture or context (4). By analyzing the recorded data, the customers' true needs can be identified and ideas for new products arise from the ethnographers' intuitions (5). This ethnographic approach is a bridging activity from the customer's daily life to the designing of products and services (6).

There are many textbooks and technical papers related to ethnography and its application to business (Kishimoto, 2009) (Mariampolski, 2006). In particular, business ethnography is aimed at applying qualitative methodology to fact finding in business situations. However, applications of ethnography to business have time and budget restrictions. Therefore, a methodology for business ethnography requires an engineering sort of procedure, i.e., a standardized procedure with supporting tools, etc., in order to shorten the project term. A combination of qualitative and quantitative research is used for reaching the objectives of business ethnography.

Let's consider the role of the ethnographer in business applications. Figure 10 shows the role of the ethnographer in identifying service fields. S/he observes human behaviors and artifacts, and listens to speech of customers that reflect the characteristics, needs, intents, and so on. These observations should be analyzed by taking into account the culture, social system, and history of the subjects. S/he interprets the customers' real needs or intents from the observations and interprets them into service requirements and product requirements. This is a bridging activity from a real situation where services are provided to the task of specifying the required services. 


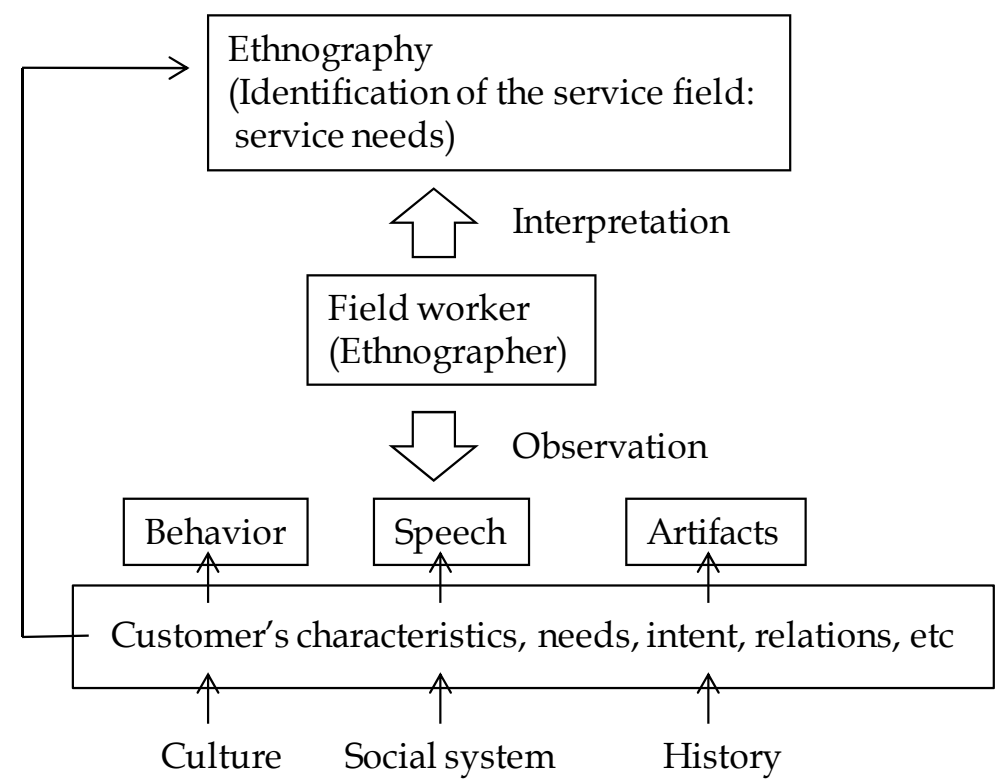

Fig. 10. Role of the ethnographer

\subsection{Design of field work and analysis of collected field data}

Ethnography as it is applied to business in the form of marketing ethnography or business ethnography must be able to find solutions within a limited period and under cost constraints. Therefore, the ethnographic fieldwork employs a engineering methodology that is formulated as follows:

\section{Step 1. Planning phase}

The objectives of ethnography are clarified first. Then, various information related to the target of ethnography is collected and analyzed. Next, the fieldwork, including determining the targets for ethnographic observation, the site, and the period, is planned.

\section{Step 2. Observation}

Ethnographers observe the target people's behaviors, speech, and situation. They record the results of objective observations by using various tools such as field notes, digital cameras, and IC recorders. The visualization of the actual behaviors of the target people is the most important task in this step. In addition, ethnographers sometimes relive the behaviors of their targets.

\section{Step 3. Team analysis}

The data collected in Step 2 is qalitatively analyzed by a team of ethnographers. Team members should create ideas and systematize these ideas into findings. The K-J method, which is a Japanese ethnology technique of analyzing data, or other idea generation support methodology is used in Step 3. The qualitative research is very important for developing an understanding the context of the collected data in field work. The quantitative research should be done by using various data collected by IT systems. A 
hybrid analysis combining the qualitative and quantitative research can derive more precise understanding of the target.

\section{Step 4. Documentation}

The ethnographic documentation based on team analysis of Step 3 is summarized.

There are two types of qualitative field work. One is hypothesis verification, and the other is hypothesis generation. The qualitative research of ethnography is of the latter type, and ethnographers should generate a hypothesis and verify it through observations. Therefore, Step 2 and Step 3 are repeated several times in order to find a hypothesis and verify it iteratively. Finding new facts in fieldwork leads one to identify the service field and clarify what services are required.

\subsection{Example: Persona marketing using ethnographic fieldwork}

This section describes persona marketing using ethnography for identifying the service field of a small convenience store in a university for the purpose of improving services within the store. Here, the service field is the customers' needs corresponding to the time (business hours) and situation. If the service field is known, the service quality of the store can be improved.

1. Persona marketing

A persona is an imaginary person that can be determined by analyzing specific data related to target customers (Pruitt \& Adlin, 2007). It can be used for effective service creation and improvement by studying its characteristics and requirements as well as its satisfaction regarding the provided services. If there are several patterns in a target group of customers, a clustering approach is used to identify customer groups and a persona is then determined for each group. The persona marketing approach is a way of identifying the target service field. That is, the target service field is categorized into groups based on various customer data by using a clustering methodology and it can thus be described by the characteristics of several personas.

Figure 11 shows the flowchart for using the persona marketing methodology. The flowchart combines ethnographic observations, interviews, questionnaires, and sales data analysis.

2. Ethnographic approach for identifying service fields

The convenience store sells commodity goods and food to customers that are made up of students, faculty, and staff. The service field is formed by the needs of the customer and their requirements for the store. The major customer group is comprised of male students, who account for $70 \%$ of sales during weekdays and $80 \%$ of sales during weekends. Female customers make up less than $15 \%$ of the customers. Therefore, the male students' behaviors and needs are the major factors influencing the service field and should be investigated.

First, ethnographic observations were performed to identify the service field. In this observation, a student who had researched persona marketing observed customers' buying behaviors from opening to closing time over a one-week period. Complete data on sales, including items, prices, time, and personae characteristics, were collected. In addition, the atmosphere of the shop and findings were recorded in the field notes. 


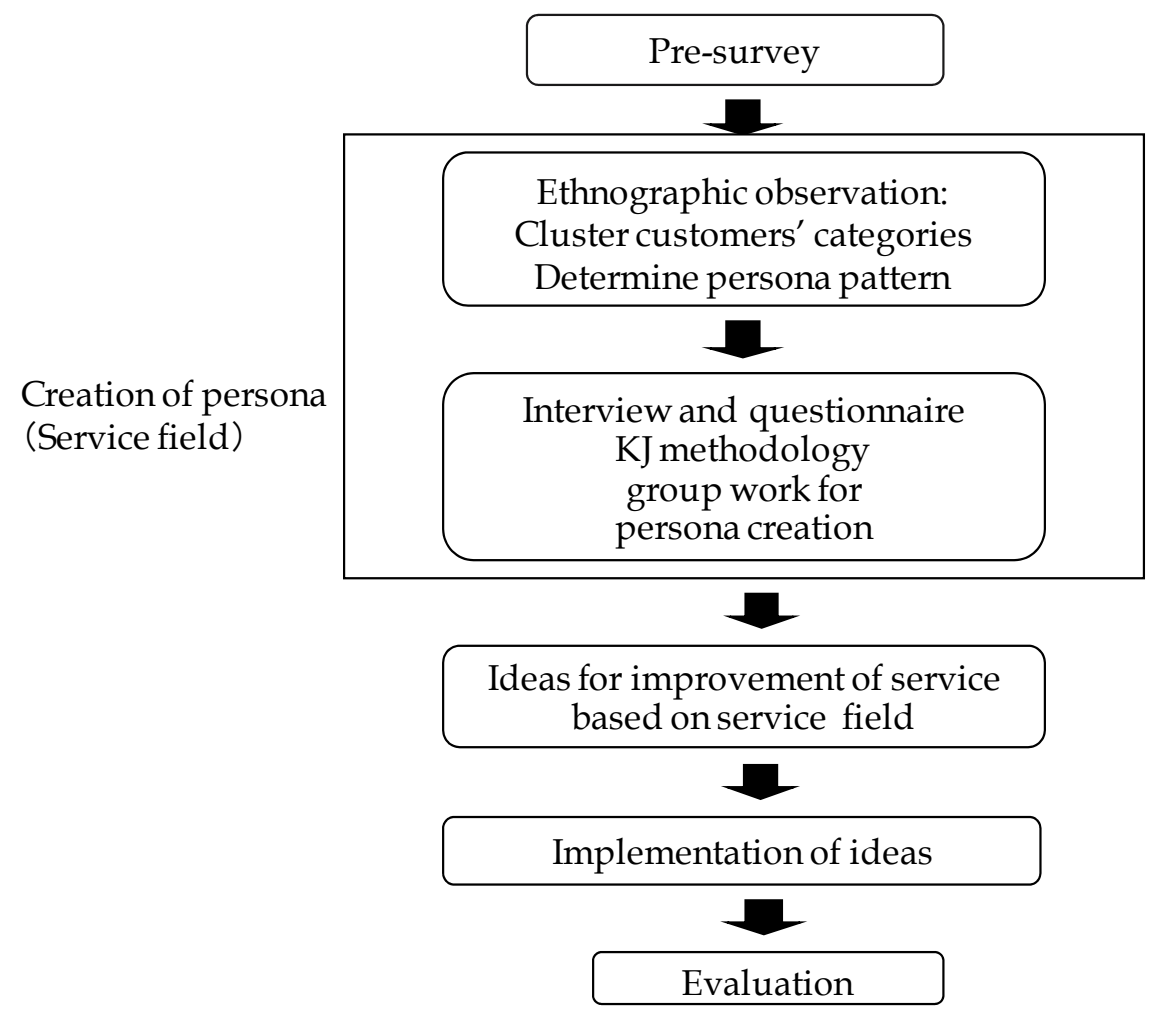

Fig. 11. Flowchart of persona marketing using ethnographic fieldwork

There were four observed sales patterns that reflected the customers' buying patterns. The male students' group was found to be categorized into two patterns: day-time customers and night-time customers. Analysis of the observations and the collected data showed that there were four customer groups: day-active male students, nightactive male students, faculty, and women. Therefore, it was considered that the service field consists of the service needs and requirements of four personae.

3. Creation of personae

Based on analysis of the ethnographic observation and clustering methodology, it was found that four personae were needed to identify the service field. The relationship between the personas' needs and services offered by the store determine the quality of service.

Interviews and questionnaires helped to clarify the characteristics and daily behavior pattern of each persona. In addition, the K-J method was used in the group work to analyze the collected data. Persona specification documents that depicted the persona's daily behavior and needs as regards the store were written for each persona.

4. Improvement and evaluation

On the basis of the persona specification documents and the results of the service field analysis, several ideas for improving services in the store were proposed. The most significant improvement was to change the opening time of the store. Before the 
analysis, the opening time on weekends was 9:00 a.m. However, the primary customers on weekends were male students who entered the store from around noon, so the opening time was changed to 10:00 a.m. Several other improvements were implemented. The variety of goods was increased in accordance with the students' requirements. Students and female customers wanted fresh vegetables, and so the amount of fresh food was increased. Various commission services were started. These improvements enhanced the quality of student life.

After improving the services of the store, questionnaires were given to the students. Eighty percent of respondents gave this project a positive evaluation. Thus, it seems that the identification of the service field by using ethnographic persona marketing seems to have been effective in enhancing service quality in the convenience store.

\section{A model of the service value creation process using the service field concept}

As described in section 3, the service value for customers is determined from the relationship between the provided service and its service field. To provide high service value for customers, the service field should be identified first; then, suitable services should be provided. In this section, a new model for service value creation using the service field concept is proposed.

\subsection{Service value creation process based on identification of the service field}

Service value depends on the relationship between a service and its situation, and a more suitable service can be provided if its service field can be identified. The following four steps are required in the service value creation process, and they involve collaboration between the service providers and receivers.

Step 1. Definition of the service system: Both collaborators in the service value co-creation process understand and share the objectives of service value co-creation and the framework of its service system, as shown in Figure 5, which consists of service providers, customers, and the environment of the service. This is a process of socializing the targeted service to place it among the participants in the service system.

Step 2. Identification of the service field: The service field is identified using various technologies and/or in collaborative work. The necessary supports for the service receivers are identified, as are the information and technical supports needed for both collaborators. This step is the identification of the service field, and it corresponds to the externalization of the customers' service requirements. Humanrelated technologies and methodologies such as those explained in section 3 and section 4 are used in this step.

Step 3. Creation of new service ideas: Knowledge is created for the required services in the service field identified in Step 2, and suitable services are designed after the service field has been elucidated. Participants gain knowledge about the service by combining various service ideas and technologies.

Step 4. Implementation of new service idea: The service idea created in Step 3 is implemented by considering the business model, price of services, and required information 
systems. Collaborators in the service value co-creation evaluate the results of knowledge creation as regards the required services and take them into account in the subsequent process for enhancing services. This process is the internalization of the new service ideas.

The required services in the service value creation process are enhanced by repeating these four steps of service value co-creation. As the knowledge creation process is repeated, collaborators come to understand the service field much more fully. The result is that the participants understand the service field more deeply.

This knowledge creation process is similar to the SECI model, which is a well-known knowledge creation process (Nonaka \& Takeuchi, 1995). The knowledge creation process is outlined in Figure 12. There are four modes in the SECI model, that correspond to Step 1 to Step 4, i.e., socialization (S), externalization (E), combination (C), and internalization (I). The SECI model is a typical knowledge creation process. So far, it has been applied to knowledge creation in organizations, and here, we have applied it to the service innovation process through service providers and receivers collaborating. The SECI model is a conceptual model of knowledge creation. However, the model for service value creation proposed in this chapter can be specified concretely in steps once the service field and its application to a suitable service are identified.

S: Socialization:

Definition of service system

(Share the objective of the service and its environment)

\section{E: Externalization:}

Identification of service field

(Collect and analyze data related to service and discover needs for services)

\section{I: Internalization:}

Implementation of new services

(Deliver the service by business

mode, pricing, IT system, etc)

Fig. 12. SECI model for service value creation

\subsection{Role of the service value creation process model}

The model for service value creation process based on the service field employs various technologies and methodologies, such as network technology, terminal devices, brain 
science, hospitality, ethnography, and human behavior. This model can cover many types of service, from traditional services and services in manufacturing to Internet services and information and knowledge services. The role of this model is shown in Figure 13. The service value creation concept (or model) is transdisciplinary and can be applied to various services. In addition, SDL can be formulated as a theoretical framework based on the service field concept proposed in this chapter.

Human-related studies such as ethnography and brain science are useful for creating high service value and seem to have great potential for innovation in various industries.

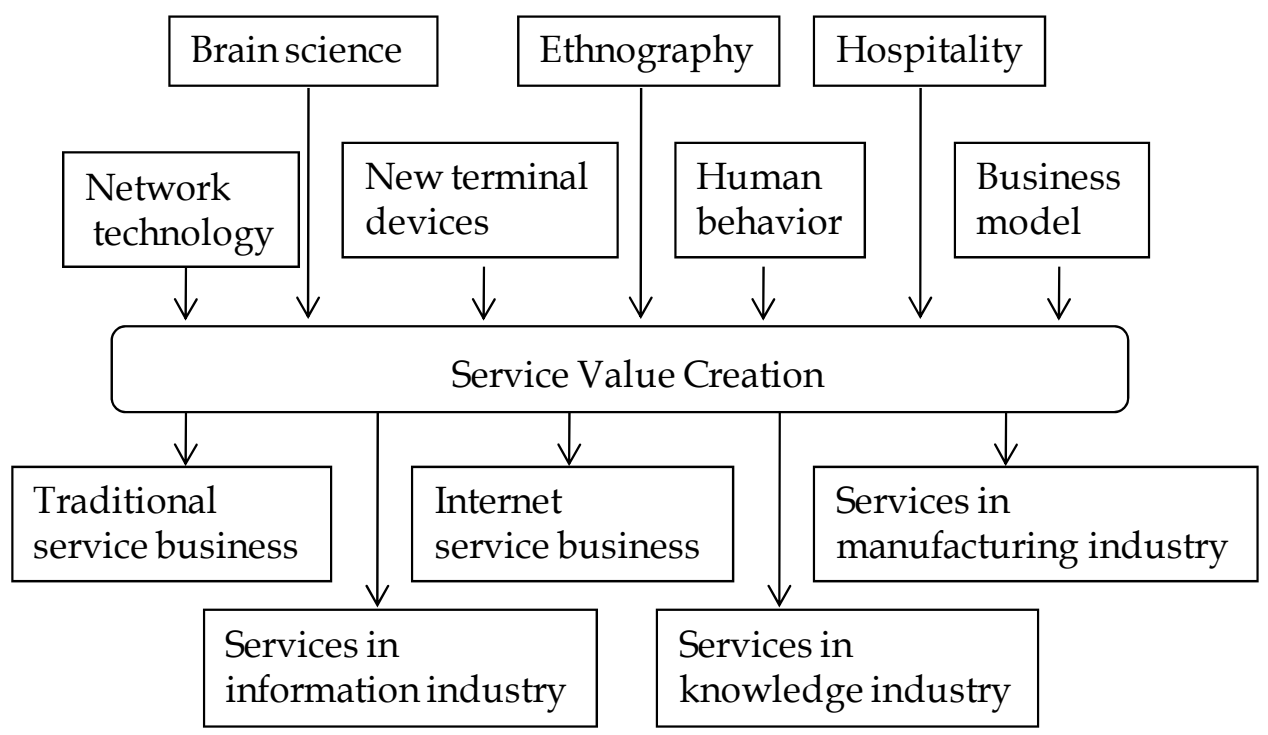

Fig. 13. Service value creation model for various services

\section{Education for service innovators based on service value creation}

With the purpose of educating managers in service value creation, a curriculum of service management education for service innovators was developed at the Japan Advanced Institute of Science and Technology (JAIST) (Kosaka, 2010). This educational course stressed the importance of knowledge science, including ethnography and design.

The importance of education, management, and science to services and services innovation has long been recognized, and subjects from these fields are taught at the MBA level. Furthermore, IT service technologies are now taught in many information science departments. Despite these encouraging developments, though, we should realize that successful innovation in the 21st century will also involve technologies and methodologies related to human behavior. We believe that knowledge sciences, such as ethnography and brain science, and information sciences studying the Internet and data management can be 
exploited to enhance the quality of services. To ensure that society benefits from the new services that will appear in the future, we have developed a new curriculum of service innovation and education from the viewpoint of service value creation. The curriculum is based on knowledge science, information science, business science, and transdisciplinary sciences and technologies.

\subsection{Basic concept of our education course for service innovation}

The topic of how to educate people in services science has been discussed all over the world. According to a survey (Kameoka, 2007), services marketing and services management are being taught at the MBA level in United States, and IT services such as Web services and SOA (service oriented architecture) are topics in the country's information science departments. Many universities are trying to integrate services education and information science into the curricula of their MBAs in order to create a new education field of services science. Moreover, the trend in Europe is the same as in the U.S. Institutions in these countries recognize the importance of practical experience in services education, and they design their higher level courses by including lectures in services engineering management and seminars involving case studies and IT technology. They also offer internships (Stauss, 2008).

JAIST's service education course is based on knowledge science and information science. This course provides education related to services innovation for business people, whereas JAIST's service education course is meant to reinforce innovators' abilities. As described in this chapter, service innovators should have skills in human science, social science, IT technology, and management. Therefore, JAIST service education course focuses on the following four disciplines that are important for services innovation from the viewpoint of service value creation.

1. Knowledge science: Customer satisfaction is the most important factor for improving service quality. Knowledge sciences such as design, ethnography, and brain science can be utilized for creating new services and for determining whether a new service will satisfy the intended recipients. Therefore, knowledge science is indespensable for identifying the service field and thereby enhance service quality.

2. Information science: Information science and information technologies provide the means for realizing new services. Internet technology, ubiquitous computing technology, data mining technology, and so on can be utilized for services innovation. Information science is also important for identifying the service field.

3. Business science: Services marketing, quality assurance, business model development, financing, and operations research methodologies are basic activities in the services business, and these subjects are taught in business schools.

4. Transdisciplinary sciences and technologies: Transdisciplinary sciences and technologies are, or will soon be understood to be, essential for creating new services. By transdisciplinary, we mean a threefold idea of the integration of various technologies, extending concepts that are valid in one domain into concepts that are valid in various domains, and applying general methods for optimization and simulations to various problems. 


\subsection{Design of curriculum for service innovation and evaluations}

To support the above four disciplines, 15 new subjects related to service innovation were developed. These can be categorized into four groups shown in figure 14 .

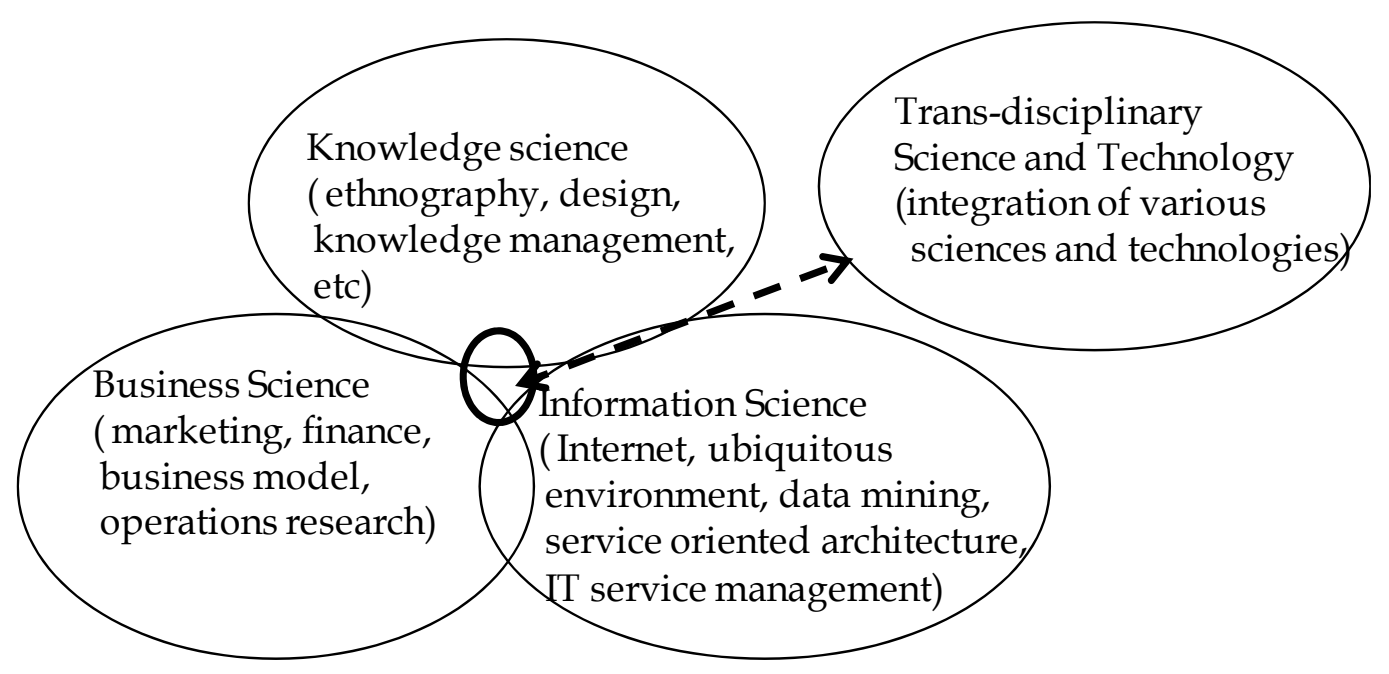

Fig. 14. Four disciplines for service innovation

[Knowledge science]

1. Service creation methodologies: methodologies based on hospitality management, service road mapping, and service value modeling.

2. Ethnography for services: applications of ethnography to service innovation.

3. Design and service innovation: design methodology and service innovation.

4. Networks and service innovation: how network technologies can foster service innovation.

[Information science]

5. Services in the IT industry: evolution of business models in the IT industry and open source resources.

6. IT service architecture: SOA, Web services, and system architectures.

7. Internet service systems: new Internet technologies, such as information retrieval technologies, and their application and new business models

8. IT service management: IT service management technologies such as ITIL and SLA and their application to outsourcing.

[Business science]

9. Introduction to service innovation: service innovation and services science trends, course orientation, outline of service marketing and IT services. 
10. Marketing innovation: the importance of marketing based on services after the commoditization of products.

11. Servitization in the manufacturing industry: examples of services in the manufacturing industry in Japan, business models, and infrastructure for services.

12. Service risk management: investment risk, financial risk, risks of $R \& D$ in the service business.

13. Business system design based on IT technology: business design and IT governance, finance, and service innovation.

[Tansdisciplinary science and technology]

14. Transdisciplinary technologies for services: significance of transdisciplinary technologies.

15. Services engineering and its applications: service engineering methodologies and good service business examples.

For the students' course evaluations, we drew up questionnaires containing 16 questions for students and 13 questions for lecturers. These questions evaluated the content of new subjects from the following viewpoints; Up-to-date knowledge such as ethnography on service innovation, Practicability in real service businesses, Basis of service technology, Suggested content for services innovation, and so on.

By analyzing the questionnaires' results, we found that this course seemed to provide up-todate and practical knowledge such as ethnography or successful service business cases for service innovators. In particular, the "Services in the manufacturing industry" and "Services in the IT industry" courses were highly evaluated as useful for business people.

\section{Conclusion}

This chapter described the concept of the service field in service systems as a new service science. This proposal is a methodology for making the service dominant logic a concept of "value in use." A theoretical framework for the determination of such a service value has been lacking. Our proposed service value creation model is based on the service field. The service value depends on the relationship between the service itself and either the situation or the customer characteristics. To raise service value for customers, the service field should be analyzed. Human-related technologies and methodologies such as ethnography as well as IT technology are keys to identifying a service field. This concept can be applied to various services, and ethnography seems to be having an important role in service businesses.

Finally, we would like to emphasize the significance of service science. The 20th century was an era of industrialization, and various industrial products such as automobiles, consumer electronics, and chemical products enriched people's lives. Universities established engineering departments based on physics or chemistry. In the late 20th century, information and communication businesses had begun to satisfy our intellectual desires and provide new information services. Universities established computer science departments based on mathematics and logic. In the 21st century, it is possible the next frontier of civilization will be services that satisfy us by combining industrial products, information 
technologies, and new service concepts. Service science based on human science such as ethnography and brain science will be indispensable.

\section{References}

Fisk, R.; Grove, S. \& John, J. (2008). Interactive Services Marketing(Third Edition), Houghton Mifflin Company, ISBN-10:0-618-64180-7, Boston, USA

Kameoka, A. (2007). Service Science, NTS, ISBN978-4-86043-144-0, Tokyo, Japan (in Japanese)

Kishimoto, K.; Tarasawa, M. \& Hirata, S. (2009). Innovation of Working Style through Ethnography for Business and Organizational Monitor, Fujitsu, Vol.60, No.6, pp.591-598, ISSN-0016-2515(in Japanese)

Kitatani, T. (2010). Global Monitoring and Support Management System for Construction Machinery using Satellite Communication, Proceedings of $7^{\text {th }}$ IEEE International Conference on Service System and Service management, ISBN 978-4-4244-6486-9, Tokyo, Japan, June 2010

Kolari, J.; Laakko T.; Hiltunen, T.; Ikonen, V.; Kulju, M.; Suihkonen, R.; Toivonen S.; \& Virtanen, T. (2004). Context-Aware Services for Mobile Users Technology and User Experiences, VTT Publications, ISBN 951-38-6396-4, Finland

Kosaka, M. (2010). A curriculum of MOS (Management of Service) course based on knowledge science and information science, Proceedings of $7^{\text {th }}$ IEEE International Conference on Service System and Service management, ISBN 978-4-4244-6486-9, Tokyo, Japan, June 2010

Kosaka, M. ; Miyamaoto, S. \& Ihara H. (1987). A Track Correlation Algorithm for MultiSensor Integration, AIAA Journal of Guidance, Control and Dynamics, Vol.10, No.2, pp.166-171, Broadway, New york

Kosaka, M. ; Shirahada, K. \& Ito, Y. (2011) . A Concept of Service Field in Service Systems for Creating Service Value, Proceedings of the 4th Japan-China Symposium on Information Systems, ISBN 978-4-88686-07-2, Nan-chang China, April 2011

Kosaka, M. \& Yabutani, T. (2009). A consideration on service business model for saving energy and reduction of $\mathrm{CO}_{2}$ emission using inverters, IEEJ Trans. On Electronics, Information and System. Vol. 129, No. 4, pp. 755-761, ISSN 0385-4221 (in Japanese)

Lovelock L. \& Wirtz J. (2007). Services Marketing (sixth Edition), Pearson Prentice Hall,

Lusch, R. F. \& Vargo, S. L. (2006). The service dominant logic of marketing, M.E. Sharpe, Inc. , ISBN 0-7656-1490-1, New York, USA

Mariampolski, H. (2006). Ethnography for Marketers: A guide to consumer immersion, Sage Publications, Inc., ISBN 0-7619-6946-2, Thousand Oaks, USA

Moeran B. (2005). The business of Ethnography, Berg, ISBN 1-84520-194-9, New York, USA

Nonaka, I. \& Takeuchi, H. (1995). The Knowledge Creating Company, Oxford University Press Inc., ISBN-13: 978-0195092691,

Pruitt, J. \& Adlin, T. (2007). Persona Strategy, Diamond-sha (transration in Japanese) , ISBN 978-4-478-00041-0, Tokyo, Japan

Shirahada K.; Imoto S.; Kosaka M. \& Katsura T. (2010). Near-Infrared Spectroscopy Approach for Web Based Service Marketing, PICMET 2010 Proceedings, Phuket Thailand, July 2010 
Stauss B.; Engelmann K.; Kremer A. \& Luhn A. (2008). Service Science, Springer, ISBN 978-3540-74487-0, New York USA 


\title{
Food and Nutrition in Embera Indigenous People
}

\author{
Javier Rosique1, Aída Gálvez¹, María Teresa Restrepo², \\ Luz Mariela Manjarrés ${ }^{3}$ and Erika Valencia ${ }^{4}$ \\ ${ }^{1}$ Group of Research: Medio Ambiente y Sociedad, \\ Department of Anthropology, \\ University of Antioquia, Medellín \\ ${ }^{2}$ School of Nutrition and Dietetics, \\ University of Antioquia, Medellin \\ ${ }^{3}$ Research Group on Food and Human Nutrition, \\ School of Nutrition and Dietetics, \\ University of Antioquia, Medellin \\ ${ }^{4}$ Group of Research: Medio Ambiente y Sociedad, \\ University of Antioquia, Medellín \\ Colombia
}

\section{Introduction}

Feeding is a critical biological function and essential for social life. As a research topic it is multidimensional, ranging from biological to cultural, from nutritional to symbolic. It also includes a dimension from the individual to the collective, social and psychological (Fischler, 1995). Since functionalist studies, in the first half of the twentieth century, the cooperation in pursuit of food was highlighted as a determinant of the nature of social groupings and of the collective activity. Feeding is considered a priority need related to a set of structural and cyclical elements, establishing the availability and access to foods that interact and are immersed in the socioeconomic and political reality. Such reality set limits and a certain space. Food is a fact that creates an interacting set of social relationships, and also acquires a central position with respect to the challenges of society as a whole and the rural world in particular (Muchnik, 2004). On the other hand, nutrition, resulting from the feeding process, is the combination of events by which living organisms receive and use food to keep their functions, and to enable their growth and development, contributing to the social productive performance (F. Correa, 1988: 21). The anthropology of food and eating (de Garine \& Harrison, 1998; Mintz \& DuBois, 2002; Contreras \& Gracia, 2005) is interested in both aspects and can support the pluralism of methods and perspectives in research.

Indigenous culture and society influence food habits in the selection of foods, the ways of combining them and of preparing them. Food is also part of the beliefs and of the identity and accompanies the indigenous development in rites to mark the human life cycle. However food contributes also to increase the opportunities for development, success in 
education and to increase the human capital of peoples. Most of the indigenous peoples conserve their traditional life but have access problems to food, with few possibilities of obtaining quality food market and with high prevalence of chronic under-nutrition, usually higher than $50 \%$ in children and often obesity in adults (Kuhnlein, 2007). Colombian indigenous lands cover the $29.8 \%$ of the Country (PNUD, 2011) however the greatest part of them are in low productive lands of Orinoco basin and Amazonia, in deserts or are in national natural parks. Indigenous continue to claim for wider their lands because the continuous state of food insecurity. Food habits research including the preferences and the nutritional status of the indigenous peoples can help to know how to approach the objectives of development in the reduction of hunger and poverty (objectives of the millennium for the 2015). The sustainability strategies of their food system need proper education for obtaining and producing traditional foods and to get market foods of better quality than those that consume at the moment. As a matter of facts, it is in the field of food security, the reduction of children under-nutrition and the increment of autochthonous food production that makes sense the research on food and nutrition in indigenous peoples.

In food security, food habits are viewed as important determinants of the food system because they are closely related not only to culture and beliefs, but also to educational level, and to economic and social aspects associated with the ability to decide on how to select, store and prepare food. Decisions on food and diets, at household level, depend not only on the availability and access (economy) to foods, but also on the health status of people. That is why anthropology and health research can gather their efforts in fieldwork. However, eating habits can be explored from various disciplines in parallel, as shown by some researches on black groups in Colombia (E. Restrepo, 1996) where agro-productive aspects, food and health are treated by independent researchers. Integrated and multifaceted approaches on food habits and food security were also present, from the late part of the 1980's, in studies on indigenous in Colombia (Alcaraz et al., 1988; Duque et al., 1997; B.N. Restrepo et al., 2006). This chapter addresses this inclusive and multifaceted perspective on health studies and anthropology of food and nutrition of indigenous communities.

Amerindian food has stimulated the literature on the symbolism of food by means of a monosite approach, the symbolic perspective, where some authors complain that the exciting indigenous worldview comes to happening in a context of food insecurity and child under-nutrition (López, 2003). On the contrary, the multisite approach has a certain tradition in Mexican studies on food (Vizcarra, 2002), and studies on vegetarianism (García, 2002) and takes into account health and nutrition. But, other pluralistic and interdisciplinary approaches are rare because they present many challenges to successfully integrate the methodologies of social sciences and health.

Embera is the third-largest demographic Amerindian native group in Colombia, and belongs to Chocó linguistic family. During 2006 and 2007, there was a strong concern of some local agents of Government and Indigenous Organization of Antioquia (OIA, Organización Indígena de Antioquia) and international cooperation agencies due to the increase in infant mortality associated with infectious diseases and under-nutrition, as well as to the recurrent problems of food insecurity and sustainability of agricultural production projects in indigenous communities. The Program for Food Security and Nutrition MANA of the Government of Antioquia requested to obtain primary information on the achievements of the Program aimed to food complementation, one of the steadier programs 
in Embera since years. The region selected was the municipality of Frontino (Figure 1) because since three years before there were some local institutions (Major Cabildo ${ }^{1}$ and Local Cabildos) and the European cooperation (from EU) interested in food security problems of Frontino thorough the project PIBP (Proyecto Integral Bosque Pacífico) managed by OIA.

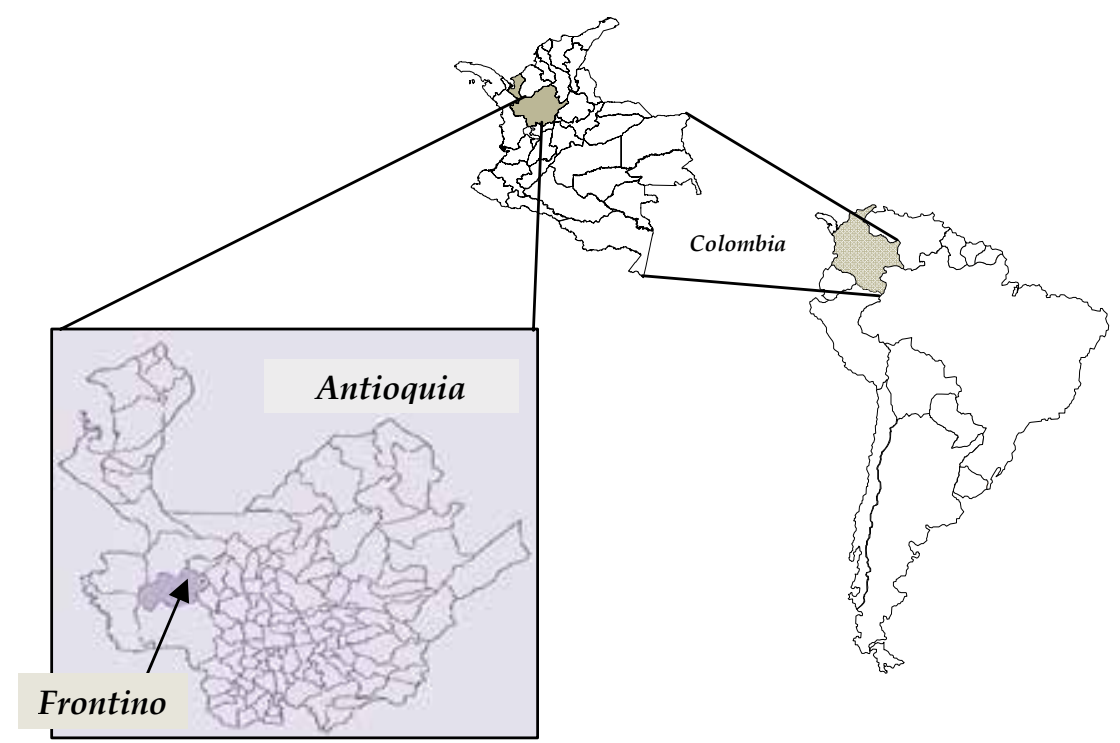

Fig. 1. Location of the municipality of Frontino in the department of Antioquia (Colombia).

The American Indians studied show specific eco-cultural models of achieving food, these distinctive features allowed a comparative study between the two Embera communities: the Oibida Embera from Atausí and the Eyabida Embera from Nusidó. The former has a dispersed settlement in the tropical rainforest, and a diet based on maize and banana with hunting, fishing and food collection in the forest and the latter lives near the town, Frontino, having a food pattern based on rice and the increasing dependence on exogenous food.

Writing food ethnographies of native indigenous people has not been a tradition in Colombian anthropology, and some aspects of Embera food habits should be traced by means of following the pages of other ethnographies, based on reproduction or on child care (Alcaraz et al., 1988; Gálvez et al., 2002) or historical perspectives (Pineda \& Gutiérrez de Pineda, 1999). It has been documented a change in the Embera food system, as traditionally relied on hunting, fishing, gathering, diversified horticulture and small animal husbandry, allocating a surplus for marketing. The bulk of food supply problems are the past and present for Embera people. In the past, the kindred groups resettled themselves in other places when the environmental supply showed some depletion, and thus guaranteeing the availability of wildlife and land recovery. But in the span of the last 20 years, researchers agree on the deterioration of the Embera food system and the loss of

${ }^{1}$ Cabildo is a traditional institution lasting until our days for legal representation of Indian communities when addressing local issues facing the Municipality and the Government. 
the ability to use space temporally, with diversified and shifting cultivation, due to the territory reorganization, the colonization pressure and the armed conflict (Arango et al., 2007). The consequences are shortage of agricultural land, reduced food availability, and the deteriorating nutritional status of population in the growth period (children and adolescents) and pregnant women.

There is a scientific literature on the effects of social stratification in Latin America on food consumption (Goloubinoff, 1996; de Suremain \& Katz, 2009) as a result of colonialism and the consequences on the difficult access to meat for indigenous and lower classes. The problems of access to meat for the Embera indigenous population have been exacerbated by environmental degradation, adding problems when the population relies on hunting and fishing. Although communal land tenure protects them from the loss of property experienced by some Colombian peasants who are unable to meet its debts (PNUD, 2011), the indigenous territories do not produce enough meat because they stay with depletion of hunting and fishing and do not hold a great number of animals by difficulties in their care.

This chapter shows a methodological perspective on how to address the integration of ethnographic information on food habits and nutrition of Embera indigenous people from Western Colombia, assuming a plural perspective based on mixed models of research. Some critical steps in the research are described in section 2, the research highlighted ethical considerations in fieldwork to ensure the process of consultation to guarantee rights of the indigenous communities (section 2.1) and address the need of practicing multiculturalism when designing survey forms and when analyzing pilot test. Section 3 deals on the use of ethnography in the study of food habits and the integration of ethnography and quantitative methods like the 24-hours recall questionnaire and the anthropometric survey. The mixed method of triangulation of quantitative and qualitative results is presented to analyze the information gathered by the food and nutrition security survey, and to take into account a wide range of determinant variables. Finally, the authors show how this kind of pluralist research is an integrated new perspective on food and nutrition permitting a useful and deeper insight addressed to improve food and nutrition security in the communities.

\section{Critical steps in the research on food and nutrition}

An interdisciplinary working group was organized by anthropologists (in the fields of ethnography of food and in biological anthropology) and nutritionists to manage the flow of information from qualitative and quantitative data. Defining common objectives in a multidisciplinary group of research was the first step because some researchers used qualitative methods, and quantitative the others. Qualitative research is often aimed to study food systems to finally understand society and people behaviour, but quantitative research focus on food and nutrition to understand health and sickness in itself. However, the theory of mixed-methods of research was able to provide a way to develop the project. Interdisciplinary researches rely on pluralism and triangulation (Olsen, 2004) or other similar mixed-methods. There are some critical steps in the design of a pluralist research on food and nutrition, mainly when biological data are collected: 1) the problem under study needs to be constructed by including the requests of the governmental agents, and indigenous representatives, 2) ethical consideration involves the consultation of the 
indigenous leaders, permission achievement and a good design of the informed consent, 3) the processes of searching for translators and indigenous helpers, 4) the process of training people and the construction of a pilot test to prove and adjust field methods, and finally 5) building an intercultural perspective in all the steps of the research mainly in the translation of the survey forms and the application of measuring instruments for fieldwork.

The multidimensionality of food requires integrating knowledge of biological and social sciences, mainly because food consumption acts on nutrition, its physiological consequences and the symbolic aspects of the society (de Garine, 1988). The perspective of human ecology in anthropology followed by the authors explores the connections between adaptation to the environment and food choices, cultural diversity, and odd-adaptation in nutrition and food ways or lifestyles. This point of view gives to culture a key role in understanding the eating habits, and in that sense, is beyond biological reductionism that has dissociated the nutrition to the cultural environment where food needs are met. Anthropological studies on the nutritional consequences of cultural patterns of consumption usually include food distribution, but should be deepened on studying intra-cultural variations and nutritional status that express food preferences, and clarify issues as: why and how changes in dietary habits?, and the reason for the contrasts in nutritional well-being (well-nourished or malnourished subjects) within populations (Messer, 1995).

\subsection{Ethical considerations}

The present study had the support of the OIA. Since 1980, it represents all ethnic groups in the region: Tule (Cuna), Embera (Chamibida, Eyabida and Dobida) and Zenú, settled within the jurisdiction of 31 municipalities in the department of Antioquia. OIA is a key social stakeholder in the recognition of the modern status of these ethnic groups (Gálvez et al., 2002). In addition, Cabildos -as they are local organization entities- were consulted directly about time, mode and duration of the entry of the research team into their land and were aware on the goals, tasks and expected results. Health researchers are often concerned only by writing a good individual informed consent, however when working with native Amerindians in Colombia, there is a prior task: obtaining the permission of the traditional authorities mainly the Cabildo. As noted by Alcaraz \& A. Correa (2006), research on indigenous peoples requires recognizing and respecting their cultural characteristics, in the consultation with local Cabildos. This enables the exercise of their autonomy to allow studies on health in their jurisdiction. Embera society has been only recently moved to reading and writing, thus informed consent it is not always the suitable method of being informed and to guarantee voluntary involvement. This is because this involvement often comes from the adherence to collective beliefs, thoughts and explanations expressed by the authorities who have the criteria to ask them, or not, on being involved in those activities concerning data collection. Identity is also expressed by means of the adherence to the project developed in their community. Before the interviews and before taking anthropometric data there is a need on explaining the objectives of the research and to remember voluntary participation. The research in Nusidó and Atausí did not implemented informed consent because in those years it was not recommended by the Cabildo. When a research in health cannot implement informed consents it is strongly recommended to follow carefully the Declaration of Helsinki promoted by the World Medical Association (http://www.wma.net/). However nowadays almost 95\% of the research with Embera is developed by signing individual informed consents. After the explanation, the 
translator reads the informed consent to the participant and makes him signing or putting the digital print (common for elderly), this is the time to answer the uncertainties, worries and fears on the research in Embera language. Then data collection will start with the participants.

In the first meetings with the authorities, some commoners, men and women were called by the Cabildo to be present and participate in the meeting to listen to academic proposals, with pauses for translation into Spanish, and proceeding to deliberate internally in their own language. Researchers collected and took in consideration concerns raised by leaders: "What will be left to the community? What would benefit the community?". These questions show how in the course of more than two decades of anthropological, social and community health researches in Colombian indigenous communities, Embera themselves have become aware of the dialogue with the academic researchers, booking a system to arrange exchanges. To deal with some exchanges, Embera often express their needs in expert support. Years ago, in our preliminary researches, they were afraid that University projects lasted a short time with no visible return because the scope of researchers is only collecting data. Nowadays, leaders are conscious that researchers should not only oversee the development of research, but they can help to overcome or improve weaknesses that have been shown by the research. Researchers could ask for council or assistants to other University departments, they can also ask for the help of graduate students that will remain in the community after data collection and after the reports point out weaknesses in food and nutrition. Our experience is on a good return of the expertise of students in communities, and this is a way of breaking into applications of their studies. Nowadays research of the University of Antioquia has a good acceptance among Embera people.

Some leaders are often called to attend meetings when a new research has to be developed with communities, but their wives are afraid the day of the meetings because they will not get the daily wage, or even worse because husbands neglect the family. The research team should take this problem into account when the leader who attends meetings depends on a daily wage. Some children of the leaders involved require more attention, because they spend less time with their parents or even may have low weight and low height for age because they grow with less care.

The Resolution 008430 of 1993 (Ministry of Health of Colombia) is the normative background that prescribes the steps to health research with people. In the classification of risks, the study was consistent with A category (no-risk), which excludes interventions on biological, physiological, psychological or social variables and individuals, and with B category (minimal risk), due to the use of surveys and anthropometric measurement. The classification of the research as A-B facilitates the acceptance by the indigenous community leaders and expedites the review of informed consent in the Ethics Committee of the University.

\subsection{Constructing a research with indigenous}

Leaders chose five indigenous, 2 women and 3 men, aged 18 to 23 years to be assistants of the researchers. At the very starting point, they were permitted to make a personal choice about the commitments to develop. However the choice was somehow determined by gender, women preferred to work with us in the food security survey and men in anthropometry as assistants. This choice tended to favor the quality of data collection in a context that uses gender division to share specific and monolingual knowledge, often among females. 
Surveys were translated into Embera language with the help of an indigenous. Translation is time consuming and in this research surveys were translated twice to the specific Oibida and Eyabida variants of the Embera language. The task goal was capturing the meaning and avoiding the literal translation when the literality was a limitation. Surveys were read and analyzed together with the translators. These were occasions to exchange views between researchers and indigenous about family organization, economics, health, and other issues. We realized on how different were Oibida and Eyabida in addressing questions on buying foods, this is because Oibida economy is scarcely linked to the money economy, due to the fact that they are more enrolled in a self-subsistence system. Thus, questions containing a monetary logic, were excluded in the surveys for Oibida, by the suggestion of the indigenous assistants. An important step in the translation was to explain questions in Spanish in different ways and, in addition, searching the redefinition of terms when necessary. This facilitated horizontal communication, which empowered the young assistants. During fieldwork, assistants discussed with researchers, as a focus group, the classification of foods and some recipes, to contrast the differential use of resources by their own ecological and cultural adaptation versus westernized adaptations.

Food is a large enabler of transactions between societies during the fieldwork in the tropical rainforest. The Oibida kitchen was perceived as an area of friction, especially among women. The women told to the indigenous assistant not to be able to cook food for us, the research team. This "failure" may be related to the lack of communicative intent of them with the others, a kind of covenant not-word (Le Breton, 2004). This hypothesis was partially confirmed by our ethnographic observations and versions of key informers with extensive knowledge of the Oibida world. It should be noted how the female assistant acted as a bridge between researchers and Oibida women, achieving on the one hand, to overcome insecurity in the culinary work, and on the other, permitting us the understanding/reading of the feminine universe of the Embera which is restricted to the private area with a limited contact with outsiders (Pineda \& Gutiérrez de Pineda, 1999).

\section{Ethnography, interdisciplinary and intercultural approaches}

Beyond building a framework for the desired ideal intake in contrast with the routine diet, ethnography was used as an input to the interdisciplinary approach because it provided an important information for the nutritional health assessments done by the nutritionists to determine the dietary intake by the method of 24-hours recall questionnaire (recalling the foods of the previous day), and also served to study the type and level of physical activity to calculate energy expenditure. Ethnography was used to capture a wide range of food preparations mainly on bananas/plantains, maize and wild food. Embera is an aggregating ethnonym it includes the word bé (maize) and it has been viewed as meaning people of maize. However, maize it is not the only axis of food habits because several types of bananas/plantains (paddara in Embera), Mussa ssp., conform main staples and are present in the verb eating (paddakode) in Embera language.

\subsection{Capturing and representing the ways of living and cooking}

Field-notes can be written during observation of daily live as meal preparation, but often it is done at night or early in the morning remembering the day before, because in the low Andean tropics, light goes away early and electricity is scarce or weak in Embera 
settlements. Field diary is such a collection of field-notes based on memorizing the events of the day, it is registered by the ethnographer systematically during a period. In ethnography, the field-notes have to serve to feed a final document (Emerson et al., 1995) useful to get and understand the true perspectives of the subjects under study; although personal feelings and experiences of the researchers are always present in field-notes, due to the introspective character of writing and the cultural impact caused by thinking on other ways of living and feeling. The researcher wrote about his difficult adaptation to long walks always accompanied by the indigenous assistant, when pained for food restriction and did not found suitable water for human consumption. In this sense, he experienced and witnessed the social suffering caused by insufficient and deficient food, but also, the strategies practiced by Embera to face food deprivation. However remembering and other bias attributed to the observer are always drawbacks for field less trained researchers. For example, writing field-notes is always a reductive method, because registering talks in social settings and events requires paying attention and choose part of the relevant information for the objectives and discard the other. These problems deserve an accurate pre-field work to train your partners with enough reliability. Designing a pilot sample of field-notes based on a reduced number of households followed by a discussion of the results in the group of ethnographers is proved to be a good step before collecting the information. Field diaries helped to follow and describe hunger in Embera children, to collect data on dietary prescriptions during menarche and puerperium and to register food and drinks consumed during meeting of relatives and neighbors for funerals. Writing the field-notes about the experiences of intense participation during cooking in households, the record of roaming consumption of wild food during walks as usually do Oibida Embera people, and participating in community meetings where food is shared were constant tasks during 2007, except on July; the only requirement was to be present and involved in the community, living as a team with the Embera people. Walking stimulates the roaming consumption of wild products by the Embera group settled in rainforest. These snacks (usually fruit) are often undetected in the surveys based on 24-hour recall questionnaire, because it is focused on more or less structured meals. As found discussed in the literature (de Garine, 1980; Murcott, 1988), there is a décalage between the views of people about their dietary habits and the answers captured by the quantitative tools of measuring food intake. Starting from the three levels of Malinowskian ethnography, analysed by Kaberry (1957), can be designed some methodological strategies to control this décalage on fieldwork, and to gather the flow of information. Studies of dietary intake in groups of rainforest, must exceed the domestic scene, as the ethnic territory is often used by residents like food store. For example, agrasia (Dolliocarpus sp.), also called "water vine", that grows in the woods, it is searched among Indians trekkers for its moisturizing properties, it is usually cut with a quick handling for pouring, in the mouth, the liquid contents.

\subsection{Talking on food and preparations}

Food habits determine the consumption of food and are of great importance in the characterization of the indigenous food security. They, were studied by age and vulnerability group (i.e., children under 5-y and pregnant women), and included the timing of food along the day, preferences, dislikes, dietary restrictions managing, daily feeding preparations and menus to celebrate special events and community meals. This 
research took distance of reductionism and finalism of medicine and nutrition when studying to food habits and food practices. According to Fischler (1995), somewhere food habits have been described between mechanical and unconscious behaviors or "superstitions" deserving to be removed once the feeding facts would be clarified by nutritional science.

The system prescriptions and dietary prohibitions come to be intelligible by ethnography when food is analyzed in the context of become man and develop the Embera identity. In this sense, we must address the eating habits linked to child-rearing practices and cultural practices that shape the individual status through the life cycle. The analysis of the interviews to the women who were responsible to prepare meals was also an important instrument of representing Embera food system. Visits to households and tambos (wooden houses raised over the ground by posts) were complemented by semi-structured interviews with 40 key informants. To select key informants it is necessary to keep in mind the range of informants and approach them incidentally. Before, semi-structured interviews and before talking to the key informant, it is important to ask the permission of the interviewed to record the interview or to write down notes in order to make him feel confident and comfortable. Interviews were about different themes: dietary habits, production and access to food in households, children care and daily physical activity. Interview guides were prepared by each ethnographer depending on the themes or concepts that he had to ask. It can be captured: What does it means "eating well" for Embera people?, by means of indepth interviews (in French literature it is sometimes reported as lengthy interviews, Crenn et al., 2010). About the dietary ideal, what is the best to eat according to the natives includes always wild meat, fish, rainforest fruits, banana/plantain and maize in various preparations. However, the present alteration of primary rainforest ecology, mainly by reduction of hunting, fragmentation of the forest and the changes introduced by the colonizing species revealed the unsustainability of the food system together with the poor nutrition status observed from anthropometry.

Meals for Oibida from Atausí usually consist of a provision of plantains boiled with salt, served in a bowl from which anyone in the household can take to consume a portion. So long as there is banana or plantain, there is food, stressing its status as axial feed. Main preparations are categorized in Figure 2 depending on the community (Atausí or both Nusidó/Atausí) and the procedure (cooked, roasted or fried). Among usual preparations with banana/plantain four of them were associated exclusively to the rainforest communities from Atausí (Sango, Chucula, Bilinguí or Biringuí and Valderrama). However preparations of maize and plantains found in Frontino are present in other Embera communities from the north (Gálvez, 1993) and belong to common Embera food habits. Meanwhile, the recent changes in eating patterns have reduced maize preparations in the western regions and among the Eyabida from Nusidó; now the axial feed in Nusidó is rice rather than banana/plantain and maize.

Interviewers identified somehow the social and cultural pressures that influenced their behavior change: the need for wages or income for household expenses was an encouragement to seek work, the ecological constraints with shortages of the vernacular food, the proximity to food culture of the rural region of Antioquia and the acceptance of food assistance programs have encouraged the consumption of food items that were not previously present in their tastes and ways of food. Seeking for wages is a concern for 


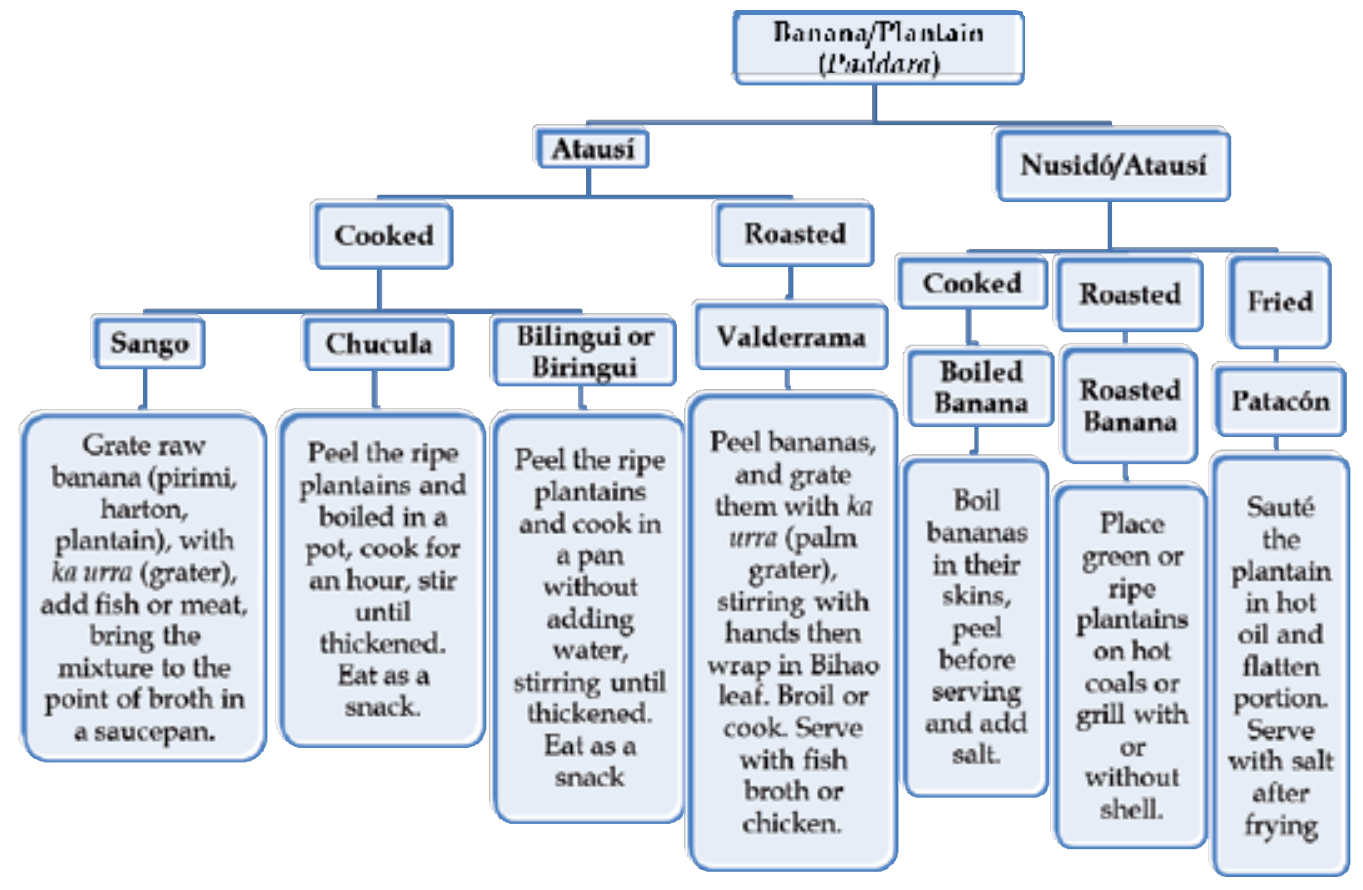

Fig. 2. Hierarchical classification of the preparations based on banana/plantain among Embera from Frontino in the rainforest community from Atausí and the Eyabida from Nusidó.

Indigenous from Nusidó. The speaker recalls lunchtime, and he reminded feeling ashamed of eating plantains, while other laborers coming from the neighboring village ate rice. The cultural pressures were also expressed by identity dilemmas like the experience of "learning to buy food". Thus, the fact of earning money entails the purchase of food, as an indicator of participation as consumers in society, unlike the self-sufficiency that has characterized the natives of the rainforest.

\subsection{Adding surveys and constructing mixed-methods}

This section will show how ethnography was integrated in specific steps during the application of the quantitative methods. Surveys, often called measuring instruments for fieldwork collection data, are sets of structured inquiries based on quantitative methods and often need previous validation to prove they are measuring what intend to measure (precision) with enough repeatability of results. Three surveys were done in each household: a) the food security survey based on demography, housing conditions and economy (income and expenditure) of the household b) the food intake survey based on a 24-hours recall questionnaire and c) the anthropometric survey to determine nutritional status based on indicators of public health (weight for height and height for age). Measuring instruments 
(surveys) used in fieldwork were built in the early stages of the research by means of an intercultural approach.

\subsubsection{The food security survey}

The study of the impact of different forms of food and food production in the biology of populations is an ecological objective of anthropology. The adaptation enables sustainable development when the means and ways of life are facing crises and tensions linked to food production without compromising natural resources. Determining the degree of food security and nutrition in communities that share social, economic and cultural factors has a huge interest in the study of sustainable development. The food and nutritional security (FNS) is a state in which all people enjoy all the time an on-going access to food, in quantity and quality, needed for an adequate intake and biological utilization of nutrients, that guarantee a nutrition status that contributes to the achievement of their health and general welfare (Sociedad Latinoamericana de Nutrición, 1997). Food security refers to the ability to ensure food availability, whether the family produces or buys food in order to meet the needs of all members (FAO, 2006). Food security affects the nutritional status, health and family welfare, child school performance, production capacity, and the preservation of the environment (Rosique et. al., 2004).

Food and nutrition have a decisive influence, along with other factors, on morbidity and mortality of populations and their adaptation to the environment. Nutritional studies are relevant to identifying risk factors for planning food strategies and regional development, based on the needs of the population and desirable goals. Planning food and nutrition security can neutralize the possible misadaptation and promote strategies for sustainability. The study of food security is central to the collective welfare, when considers the assessment of nutritional status, since the breach in the balance between nutrient requirements and intake, is often present in Latin America, involving a cost in health (Alcaraz et. al., 1997, Rosique et. al., 2004). The axes that make up the FNS are (Tables 1 and 2): a) food availability b) physical and economic access to food, c) food consumption, d) biological utilization, and e) food safety (CONPES, 2008). Colombian studies based on food security surveys have been developed from other studies done in other Latin American nearby countries (Lareo et al, 1990) to measure availability and access to food. Surveys finally were validated for rural and urban Colombian populations (Álvarez et al., 2005). However, in the present study of Embera indigenous, researchers adjusted the survey by means of eliminating the scale of food security based on a scale of hunger (Álvarez et al., 2006) because the concept and also the application have problems of bias due to translation and intercultural perception. Moreover, the 24-hours recall questionnaire was in the place of the food availability section to substitute frequency of consumption of the standard survey. Ethnography, in field-notes, intended to get the representation of hunger.

\subsubsection{Variables to characterize food security}

The methodology for characterizing household food security, is based on the interview to the person responsible for preparing food, including questions about the food available at home (stored or just acquired in) to feed the family during the week preceding the survey. The responses are recorded in a layout that contains the name of the food, how it was acquired (purchased, grown, hunted, fished, received in donation or exchange, and so forth) 
the amount (grams, litres), the number of people in the family, age and sex, and if there are pregnant or nursing mothers. In this type of food security surveys, the average energy and nutrients available in the home is compared to the recommended energy and nutrients for each family, finally it is calculated the adequacy or the deficit of energy and nutrients (Álvarez and L.F. Restrepo, 2003; Álvarez et al., 2004; Bernal y Lorenzana, 2001; Programa Mundial de Alimentos, 2006; Reyes et al., 2007). Moreover, variables in the study were more complex than in other studies because the research mixed qualitative and quantitative variables with ethnography (Tables 1 and 2).

\begin{tabular}{|c|l|l|}
\hline Axis & \multicolumn{1}{|c|}{ Variables recorded } & \multicolumn{1}{c|}{ Main activities } \\
\hline \multirow{4}{*}{$\begin{array}{c}\text { Food } \\
\text { availability }\end{array}$} & $\begin{array}{l}\text { Food (amount and quality), Production } \\
\text { in the gardens (tajos), bought in } \\
\text { markets, hunting, fishing, gathering } \\
\text { wild fruits, bartering, or by gifs and aid } \\
\text { programs. Domestic animals (to be sold } \\
\text { or to be consumed). Food for bait fish or } \\
\text { bait traps to hunt. }\end{array}$ & $\begin{array}{l}\text { - Talking with housewifes. } \\
\text { - Survey on food security } \\
\text { Visiting gardens around and } \\
\text { behind households (tambos) } \\
\text { Walking with children for } \\
\text { fishing }\end{array}$ \\
\hline \multirow{3}{*}{ Access to } \\
food & $\begin{array}{l}\text { Economic capacity (balance of income } \\
\text { and expenditures), when indigenous are } \\
\text { involved in human labor. Educational } \\
\text { level. Employment (wages). }\end{array}$ & $\begin{array}{l}\text { Size and composition of households } \\
\text { (pregnant, nursing mothers, } \\
\text { dependents: children under 5-y, and } \\
\text { elderly). }\end{array}$ \\
\hline
\end{tabular}

Table 1. Variables and activities developed to study availability and access to food.

The main constraint of the survey is, it shows only the average apparent availability of food (not actual intake) and it is dependent on the memory of the subject on the days before, moreover do not provide accurate information on the production of native traditional and foreign food, or of wild foods achieved and eaten, in situ. In contrast, this research on Embera used 24-hours recall questionnaire to measure food intake. Several researches in Latin America have been targeted at the perception on food security by the head of household or housewife, by means of a scale consisting of items related to the availability to buy food, the decrease of in-home meals due to lack of money and the experience of hunger in children or adults (Lorenzana y Sanjur, 2000; Álvarez et al., 2006). Perception of food security is described as categorical and does not include all axis of food and nutrition security. The application of scales to indigenous groups is difficult because the concepts of hunger and money economy have problems due to translation and intercultural consciousness. Hence in the present study were of limited interest and their goals were fulfilled by the ethnography of hunger.

\subsubsection{The 24-hours recall questionnaire}

In previous studies, to assess the intake of energy and nutrients in Colombia, by collecting information on indigenous, different methods of fieldwork have being used: the direct 


\begin{tabular}{|c|c|c|}
\hline Axis & Variables recorded & Main activities \\
\hline $\begin{array}{c}\text { Consumption } \\
\text { of food }\end{array}$ & $\begin{array}{l}\text { - Food habits: selection of foods, } \\
\text { menu, pattern of food consumption. } \\
\text { - Food intake (quantitative). } \\
\text { - Physical activity (daily activities to } \\
\text { go to fetch food, firewood and } \\
\text { water). } \\
\text { - Beliefs on foods and special foods in } \\
\text { the crucial moments of the cycle of } \\
\text { live. Cultural preferences and food } \\
\text { rejection. } \\
\text { The use of food aids. Feelings and } \\
\text { approaches on food aid. }\end{array}$ & 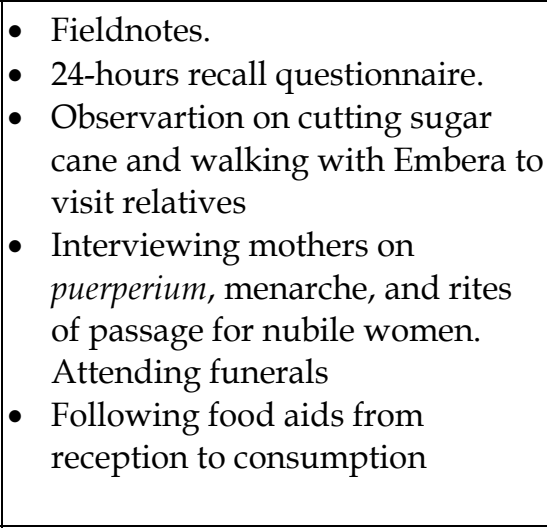 \\
\hline $\begin{array}{l}\text { Biological } \\
\text { utilization }\end{array}$ & $\begin{array}{l}\text { - } \text { Nutritional status. } \\
\text { Information on parasitism and } \\
\text { respiratory illness or diarrhea. } \\
\text { Data on common diseases to fight } \\
\text { against and their treatment by } \\
\text { western medicine, or witchdoctors } \\
\text { and shamans. } \\
\text { - Data on physical, economic and } \\
\text { cultural access to health services. }\end{array}$ & $\begin{array}{l}\text { - Anthropometry and indicators. } \\
\text { - Visiting hospital. } \\
\text { Interviews in day-homes for } \\
\text { children, center for nutrition } \\
\text { recovery and hospital. Fieldnotes } \\
\text { on skin, clinic signs, and children } \\
\text { behaviour } \\
\text { - Talking with leaders }\end{array}$ \\
\hline Food safety & $\begin{array}{l}\text { Data on features or procedures } \\
\text { displayed to detect unfit food for } \\
\text { human consumption. } \\
\text { - Description of food chain from } \\
\text { production to use. Handling and } \\
\text { preparation, storage, utensils, } \\
\text { quality of water for washing hands } \\
\text { and home use. } \\
\text { - Housing conditions and sanitation. } \\
\text { Disposal of excretes and rubbish. } \\
\text { Animal proximity. }\end{array}$ & $\begin{array}{l}\text { - } \text { Interviews. } \\
\text { - Fieldnotes on houses. } \\
\text { - } \text { store maize and foods } \\
\text { - Fieldnotes on housing conditions }\end{array}$ \\
\hline
\end{tabular}

Table 2. Variables and activities developed to study food consumption, biological utilization and food safety

weighing of food with an electronic balance (Alcaraz et al., 1988), direct observation of household food consumption (Duque et al., 1997) and recording the frequency of food consumption in a week (Huamán \& Valladares, 2006). But now there are new techniques that help to approach to the quantification of the amounts in food intake and thus the risk of nutritional deficiency (Nusser et al. 1996). The present study used for the first time in the country, the 24-hour recall in an ethnic minority: the Embera people. In 2005 it was conducted the National Survey on nutritional status in Colombia (ICBF et al., 2006), it included the 24-hour recall questionnaire according to the criteria used in other wide national studies in countries like USA, Canada, Mexico, Spain and South and Central 
American countries, because it was considered a very flexible method to provide a wide range of results: the data can be analyzed as food groups (Figure 3), per capita consumption of food, consumption patterns and nutrient adequacy (Buzzard, 1998).

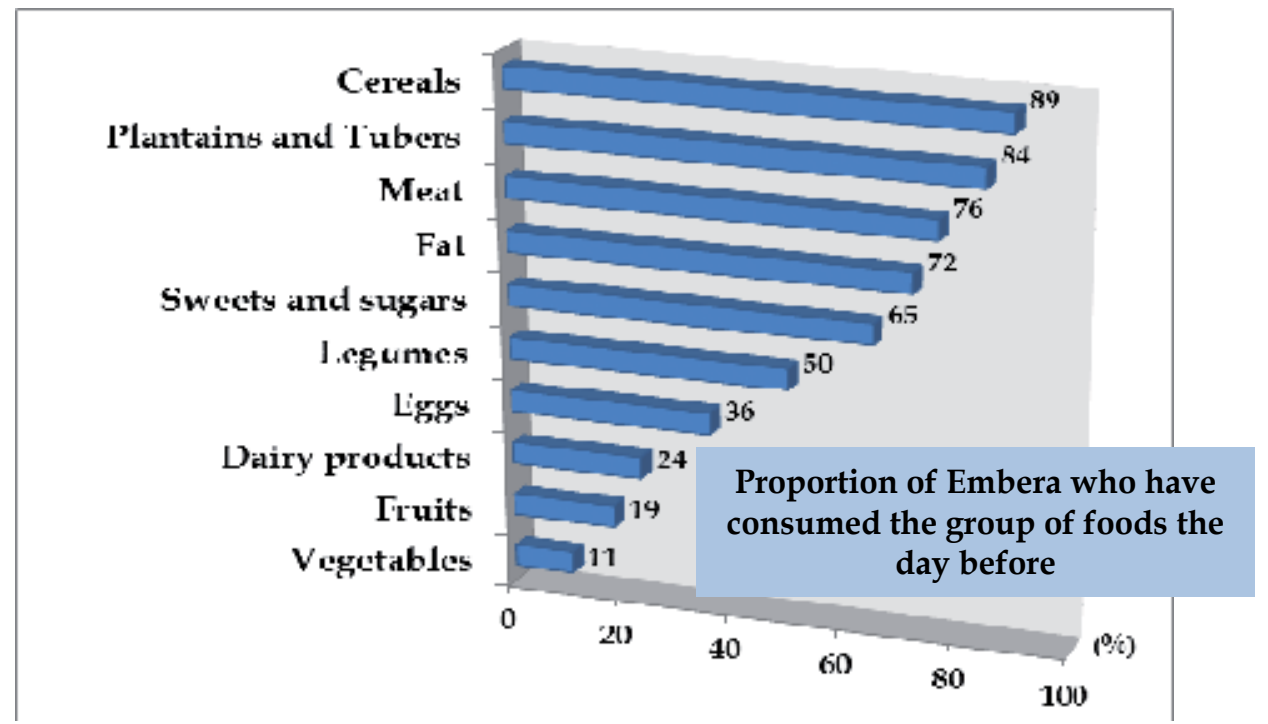

Fig. 3. Intake distribution by ten types of food grouping (following the recomendations for food analysis in Colombia) showing that Embera consumed less often eggs, dairy products, fuits and vegetables than cereals (as rice, and maize), plantains and tubers, meat, fat, sweets and sugars and legumes (as beans). However daily energy consumption was below the recommendation for $73.4 \%$ of the subjects of the comunities.

The national study of Colombia did excluded indigenous people to measure food intake, because the poor specificity for ethnic minorities, the lack of trained translators and moreover the awareness that methods were not adjusted to indigenous peoples. The present study adjusted the technique of 24-hour recall in cooperation with indigenous assistants. This facilitated data collection and quantification of nutritional risk (Carmona-Fonseca et al., 2005; Rosique et al., 2010) allowing comparable information between Embera and the national study. The most important drawbacks needing for adjustments were: data collection is not always carried out by standardized nutritionists in procedures and error handling, because for the indigenous population, professionals do not have the knowledge of the language used in each community, and indigenous people are wary of strangers and hesitate to explain the consumption of certain foods such as birds, monkeys and snakes, among others; the communities live scattered and professionals need to travel across very faraway inhospitable areas, for what most of them are unprepared. To solve those drawbacks, two different strategy types can be used:

Strategy type 1: indigenous interviewers training (Figure 4). It is the strategy developed with indigenous from Chocó. During two weeks they frequented a theoretical-practical course for interviewers selected by indigenous leaders, with the following criteria: easy communication in both languages, writing skills in Spanish, enough recognition and community acceptance, willingness to collect food consumption data and getting permission from the Cabildo. 


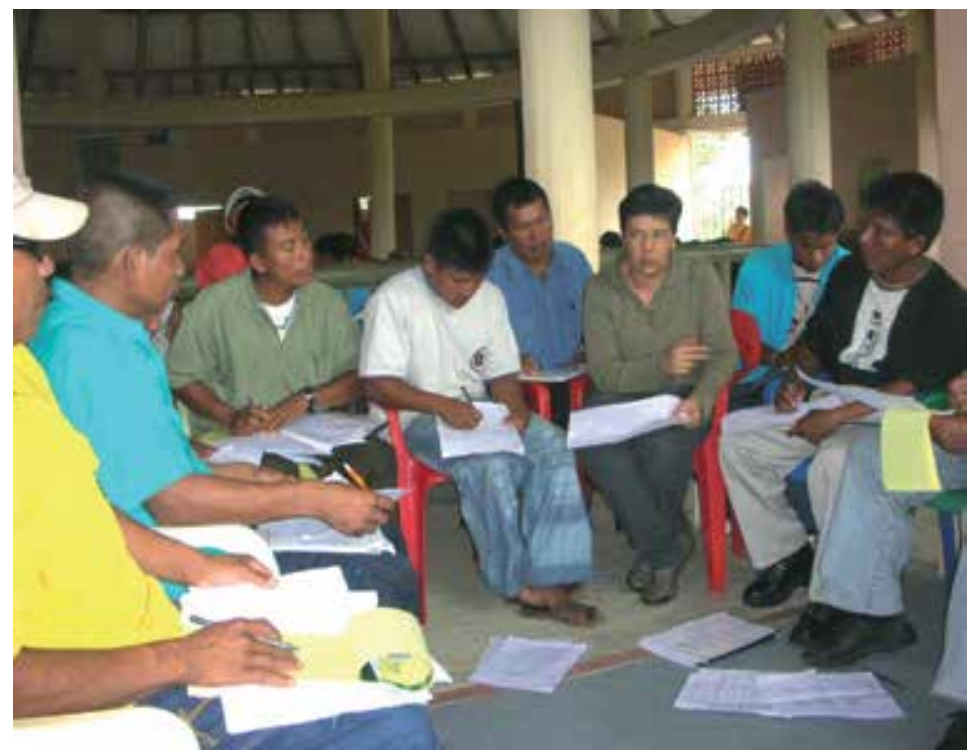

Fig. 4. Indigenous assistants in a session course on recording food consumption during the fieldwork done in the department of Chocó, with the help of Professor Luz Mariela Manjarrés (photo: Manjarrés, L.M.).

This requires full-training, like in the project developed in Chocó, and do not required other professionals to help in the interviews. Advantages of the strategy: interviewers can cover a wider range of communities, sparing time. Disadvantages: training required more effort to standardize all assistants to the same skills.

Strategy type 2: training both anthropologists and indigenous translators. It is the strategy developed with Embera from Frontino. During a fortnight professionals were trained in the technique of registering the 24-hours recall questionnaire. These professionals had a great capacity to adapt to the indigenous communities. The limitation is that they should always be accompanied by trained translators who ultimately capture the information to be passing to the anthropologist in order to be registered, in spite that some anthropologist know words and handle much information in Embera language. This kind of design required more trained people than the former. Advantages: more easily participation of the nutritionist and higher involvement in this strategy of fieldwork with the anthropologists. Disadvantages: households received more researchers and feel sometimes the pressure of the length of time consumed due to the need of translation.

In both strategies, a nutritionist with experience in the application of this technique is the trainer or surveyor of the process; he should use simple language, be friendly and be able to listen to comments and suggestions from the indigenous to make efficient changes to the explanations without affecting the quality of the information. During the training it should be taking into account the dynamics of learning of indigenous people, rather different from the capunia (non indigenous people). For this reason, the teaching methodology should be adjusted with some characteristics of the ethno-education to facilitate learning and achieve goals, such as the use of role playing, participatory meetings with short readings and the use of screenings. The nutritionist should share with indigenous students a procedures manual 
which will detail, in a simple way, each of the steps to be taken into account to fill out the 24hour recall questionnaire form, which is read and practiced. The training continues collecting interviews among peers and later among other Indians. The surveys filled must be reviewed by the surveyor and the same colleagues who verify the implementation of all manual criteria, afterwards the remaining doubts are discussed in group. This methodology helps to identify both successes and failures in collecting data.

The person in charge of food preparation helped to obtain information from other household members and answered duplicated surveys in two different days. This method is a standard one developed by nutritionists. The ethnographer helped to clarify the specific items consumed or the preparations by means of proper questions. He should ask on the items consumed on breakfast, lunch, dinner and inter-meals. Food supplementation or complements should be inquired on, during the survey. Among Embera, supplements were not frequently, but complements are almost always present due to food aids. After survey administration is finished the nutritionist check the answers with the help of the ethnographer to correct registering errors in the presence of the surveyed. The pattern of food intake is categorical and tends to summarize the most usual food items consumed by meal. The survey on food intake was completed by 353 subjects (198 in Nusidó and 155 in Atausí) in the first recall, and was completed by the $52.1 \%$ of the participants $(n=184)$ in the second recall, in non-consecutive days. Food quantities were estimated in the presence of those who prepared them, using models and geometric figures of defined weights, adjusted to food and usual weights previously listed for Colombia (Figure 5).

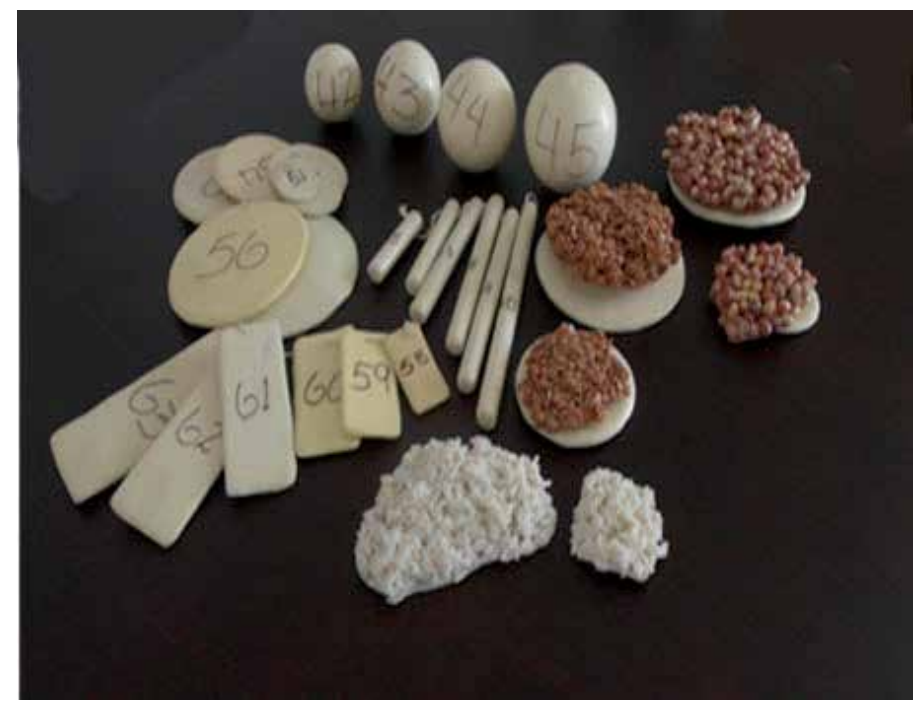

Fig. 5. Geometric models coded by weight, on the left side. Realistic models of basic staples on the right side, based on different types of beans and boiled rice (photo: García, D.)

To use those tridimensional models of food during the surveys, the interviewer ask always to choose the most similar form to that consumed the day before and writes down the code number of the form that is related to its standardized weight (Figure 6). For measuring liquids, a 500 cc measuring cup was used, due to the diversity of glasses and cups or other containers of liquids to drink or prepare meals. 


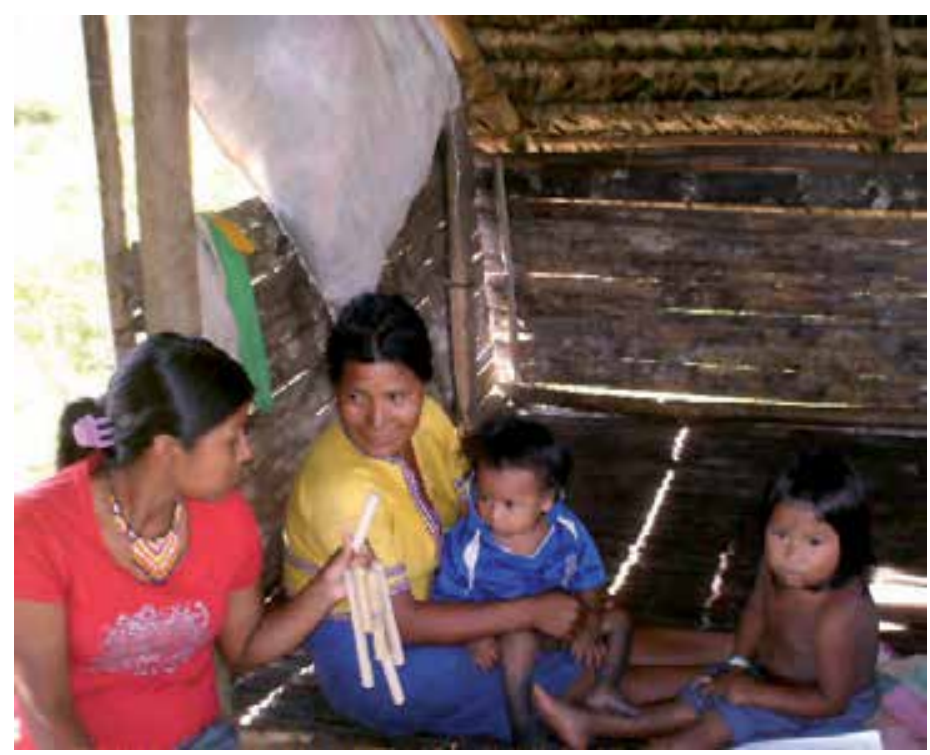

Fig. 6. A moment of the interview done to complete the 24-hours recall questionnaire to choose the length of the plantains consumed the day before (photo: Valencia, E.)

The products with unknown weight were weighed on electronic scale. The record of quantities for each food was written in the recording sheets during fieldwork. The food intake data were entered into the Assessment Dietary Intake Software for the School of Nutrition at the University of Antioquia (Manjarrés \& J. Correa, 2006) that gathers the information on food composition tables of Colombia (ICBF, 1988 ), Latin foods (FAO, 2002) and Hand Book 8 (Food and Nutrition Board, 2004). The software yields the net amount of nutrients for each 24-hour recall questionnaire and food consumption data by each subject. The nutrient data were transferred to be processed in PC-SIDE ver. 1.0 (Software for Intake Distribution Estimates, for Personal Computer) of June 2004, issued by the Statistical Laboratory of the Department of Statistics of the Iowa State University, Ames IA, U.S., to make the statistical adjustments to normalize the distribution of nutrients. The normalization is needed because of the variability of the intake, to generate the total energy and nutrients intake by day. Results are discussed in section 3.4.

\subsubsection{The anthropometric survey}

Anthropometry of height and weight needs a phase of preparation in Laboratory for training anthropometrists in order to learn measurement protocols (M.T. Restrepo et al., 2006), develop a good control of errors and keep the whole test within a reasonable time length. The obtained TEM (Technical Error of Measurement), during the measurement of the same proving subjects during two days, were $0.35 \mathrm{~cm}$ for height and $0.20 \mathrm{~kg}$ for weight. As these values represent the intra-measurer error they were considered acceptable while inter-observer error was less than $1 \%$ and measurer kept steady errors during fieldwork. Those requisites of error control were maintained when measurements were taken at the tambos, by taking into account a rule of tolerances between two repeated measures in order to discard the outermost second measure to ensure the quality of the data (maximum tolerance was $0.5 \mathrm{~cm}$ for height and $0.20 \mathrm{~kg}$ for weight). 
For the weight of children under-four a hanging scale was used, with a capacity of 30 kilograms and accuracy of $50 \mathrm{~g}$; for above four and for adults, weight was recorded using a portable digital scale (TANYTA) of $50 \mathrm{~g}$ of accuracy. The length of under-two was measured with a portable infantometer and the height of above two years and adults was measured by means of a Siber-Hegner anthropometer, all measures taken up to the nearest millimeter. To ensure reliability of data, research supervisors were used to conduct visits to monitor the quality of measurements and to validate the survey sheets during fieldwork. Nutritional indicators were height for age, weight for age, and weight for height for under 10-year children and BMI (Body Mass Index) for adults and adolescents. The construction, use and meaning of indicators was described in Rosique et al. (2010). A small group of subjects from both communities (Nusidó and Atausí) showed reluctance against taking anthropometric measurements, because when the measurer was female, some Embera males were reluctant to permit to take measures on the body. This was also recently observed in fieldwork during an anthropometric survey in Wayuú people located in the northeast of Colombia (La Guajira) during a survey on occupational health and safety promoted by a coal mine enterprise (Rosique, 2010). There is a gender perspective in relation to indigenous body culture. Only few shy under-twelve refused body measurements, in spite of the candies offered by the anthropometrist and the jokes. Some Embera taboos appeared also in elderly people, since they consider the process of measuring with the measuring tape presages death, because this procedure simulates the measurements made by those who select the suits size and the coffin for burials.

\subsection{Considering triangulation}

Although triangulation is at the ending steps of the study, and it is involved in the data analysis, the application it is only possible when some common unit of analysis is defined by each discipline. The same unit of study to analyse dietary patterns was considered by the researchers whatever the method of data collection employed (qualitative or quantitative): the household, it was defined by the set of individuals belonging to a nuclear family, an extended family or a group living under the same roof, which produces and also achieves food, which shares by regular time lapses, in the same fire, the preparations resulting from the joint effort. In ethnography, defining a unit of analysis is not enough because the household has always its network of relationships and, furthermore, because there are other settings of food availability: the commercial establishments, food assistance programs offered by the Government in the school, domestic areas and other food assistance events.

Triangulation can be applied to study economic pressures on food acquisition, food intake and nutritional status. The need of basic feeding is a pressure for Embera families when seeking to emigrate during the year looking for a job. Migration of men was not found as a result of hunting, because it happens to find job. High fecundity is also a pressure to search more food for households because $53.9 \%$ in Atausí and $49.3 \%$ in Nusidó, were under 15 years of age, dependant elderly (> 65 years) were not as much as children and young (less than $2.7 \%$ in both communities). However, preferred jobs are manuals and take place in farming (sugarcane cutters) or mining (gold extraction) because illiteracy is $69.4 \%$ in Oibida from Atausí and 51.1\% in Eyabida from Nusidó (being these differences significant, $\chi^{2}=$ 12.27, 1d.f., $\mathrm{p}<0.001$ ). Median household income in Oibida was almost three times lower than in Eyabida. In both communities the majority of weekly expenses were for food. 
Food production is low in Embera grounds. In both communities grow some foods such as banana/plantain, maize, cassava (sweet) and sugarcane (only in Nusidó) and raise small animals for consumption or sale (mainly pigs). However, the animal protein availability hang often on hunting (individually or collectively depending on the wild animal), this activity is highly respected even if the animals have declined by deforestation. Fishing is favored by the proximity of water courses, despite the reduction in number and catch size.

In Oibida from Atausí, housing is tambo (Figure 7A), it is made of palm leaves (hut of conical roof, no walls, and few divisions) raised over logs about 1.6 to $2.0 \mathrm{~m}$ above ground. While in Eyabida of Nusidó, house is mostly made of bahareque (walls based on cane, sticks and mud), or brick and mortar in deteriorating conditions and humidity. Few homes have latrines and there are no toilets, even if it had there were not used because they are alien to the Indian habits. In both communities there is overcrowding in the home and live with animals. The space for pigs and poultry is under the house or very near it. There is not available drinking water and human excreta deposition is in the courses of water. The wastes are dumped into the peripheral area.
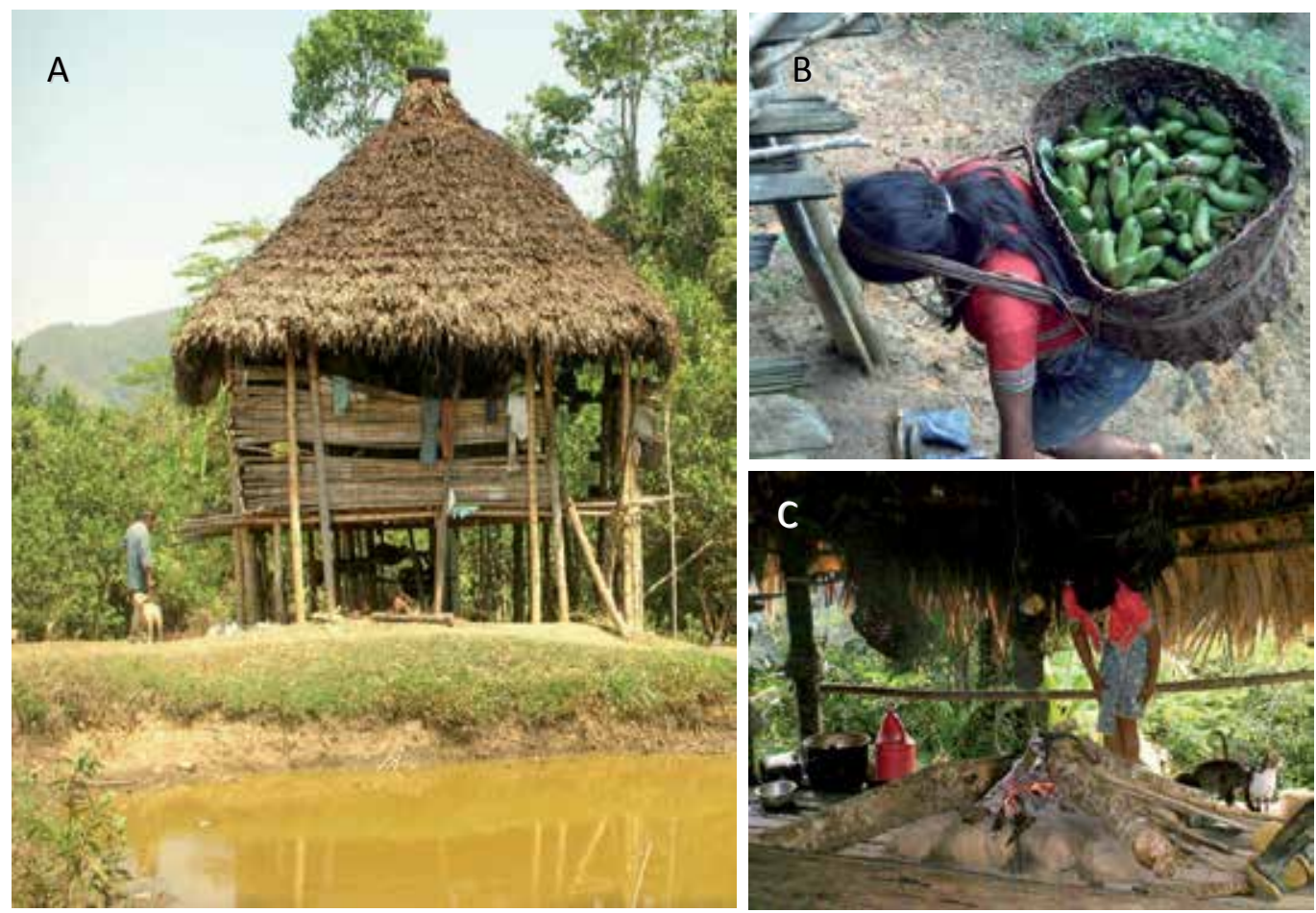

Fig. 7. (A) Tambo in Atausí made of palm leaves, canes and wood, with conical roof, no walls, and raised over logs (photo: Valencia, E.). (B) Woman carrying a basket of green plantains held by his forehead (photo: Higuita, J.C.). (C) Preparing the fire in the upper floor for cooking (photo: Valencia, E.).

The dietary ideal of the Embera people relies on wild animals, cooked green plantains, ripe plantains roasted (in units or in a sweetened beverage), fish, beans and preparations of maize. In practice meat preparations are not always available for the reduction of hunting 
and fishing. The ethnography of indigenous cuisine revealed common staples such as arepa (maize cake flat moulded by hand and baked), mazamorra (dense liquid prepared from cooked grains of maize from a kind of porridge) and varieties of chicha (a drink with different levels of maize or sugarcane-based fermentation) used in shamanic ceremonies and provisions for travel. Intercultural contact has introduced rice, tinned sardines, sparkling soft drinks, and bakery products, now indispensable in the diet and witnesses that food habits have changed and provide higher costs.

Commonly consumed foods, present in the Embera dietary pattern, were (in order of frequency of consumption in one week) vegetable oil, panela a variety brown sugar, banana/plantain, rice, maize, beans, fish, eggs, potatoes and chocolate. Food aids make available some complements (milk, biscuits and other foods provided by governmental institutions). The low intake of fruits and vegetables observed (Figure 3) was more acute in Oibida. However, they consumed more frequently plantain than Eyabida and had a lower percentage of individuals consuming legumes, sweets, fat and eggs. For Embera energy intakes come mainly from cereals and tubers. The average intake of total energy was $1578.6 \mathrm{kcal} /$ person/day, but $50 \%$ of the community did not reach that average. The impaired percentage of population below the recommendation for Colombia in energy intake was $73.4 \%$. The Oibida from the rainforest presented greater impairment $(84.5 \%)$ than Eyabida (65.2\%) and women had more cases of deficiency $(<90 \%$ of the recommendation) than men. Daily physical activity and energy needs for women can be high due to long walks and work for food supply. Women often carry baskets of bananas or plantains held with a piece of cloth by his forehead (Figure 7B). They raise the basket up to the upper floor of the tambo and prepare the fire to cook the load (Figure 7C). Deficiency of energy intake increased with age from 0 to 18 and decreased after that time. The prevalence of the risk of protein deficiency affected a third of the sample with no significant differences by sex and a greater impairment in Oibida. There was a lower risk up to 8 years and an increase from 9 onwards. This increase happens at the same age when studying the prevalence of risk deficiency in the usual intakes of vitamins and minerals except for calcium deficiency which was at the same level in all ages (Rosique et al., 2010).

The prevalence of chronic undernutrition in boys and girls under 10 years, was $68.9 \%$, increasing with age from 2 to 9 years, it was higher than in the Oibida community of the rainforest than in Eyabida $\left(\chi^{2}=7.681,1\right.$ d.f., $\left.p<0.01\right)$ and in boys than in girls $\left(\chi^{2}=5.562\right.$, $1 d$.f., $p=0.018)$. There was no wasting in weight for height in under 10-years children because the Nutrition Recovery Centre can succour extreme cases of Frontino or they died in the months previous to this study. However in under 10-years children there was a prevalence of $33.3 \%$ overweight. In young people aged 10 to 19 years low height prevalence was $77.1 \%$. Overweight was higher in young women than men $(\chi 2=7.13,1$ d.f., $p<0.01)$ and obesity was only present in Eyabida community $(7.8 \%)$ and absent in Oibida. In adults (> 19 years) had $54.1 \%$ normal weight, there were no obese subjects and overweight was more frequent in females $\left(\chi^{2}=10.66,1\right.$ d.f., $\left.p=0.001\right)$.

Nutritional health of the Embera from Frontino has similar problems of under-nutrition as in other Embera communities (Arias et al., 1988; B.N. Restrepo et al., 2006), other ethnic groups of Colombia (Carmona-Fonseca et al., 2005) and Latin America (Huamán \& Valladares, 2006) where high nutritional vulnerability is present. However the prevalence 
of under-nutrition in Embera is high with respect to other similar Latin American studies (Rosique et al., 2010) and obesity is not present in adults. The vicious cycle of inequality and poverty has deeper consequences for Embera health. Nutritional findings were of great concern to various stakeholders groups, including the community, because food insecurity has been present for a long time. Deficiency in dietary intakes of energy, protein and micronutrients along with the demand of energy expenditure, show the nutrition stress due to starvation, linked to a growing acculturation. The analysis of ethnographic data show that Embera feel a distance from the culturally desired food system, they persist in pending the ideal diet upon hunting, gathering and harvesting in their gardens, despite the profound changes in the ecosystem, the depletion of wildlife and land scarcity.

The reception of food aids from Government and international cooperation, it is common only in some more accessible communities, like Nusidó. Although the political discourse of Embera leaders emphasizes the autonomy and food sovereignty, many communities depend on food aid donations to survive. Yet aid has a biological demonstrable effect on nutrition status, as well as the functioning of Nutritional Recovery Center (NRC) established by the local Government. However, food restriction in Embera people is not finished, it is of long-term and has a multi-causal nature: in some communities it results from poverty, lack of opportunities for education and health, poor infrastructure, environmental degradation, low production of food, and in other cases, results from their location near the areas where there is the long-lasting Colombian armed conflict, or inside remote and inaccessible regions that maintain the status of protected natural areas.

Since 1991, Government implemented in Nusidó a program based in home-days for children aged 2-5 years, daily food-assisted by a trained woman in charge. They call her the communitary-mama. Recipients at communitary homes spend much of their time to guarantee four meals a day, and leisure and school activities each week for nearly 10 months a year. The menu provided to the beneficiary population is a standard type for Colombian culture. However in indigenous people it encourages the increase of western food consumption, like rice, sweetened beverages, fruit juices, milk and salads. This could affect the early accession of children to a contrasting food repertoire with regard to their own household cultural practices, within which the substitution of banana/plantain and maize by commercial rice is considered irreversible for ethnographers. Indigenous raised in communitary homes will develop a food culture more similar to the rural Colombian culture.

\section{Conclusions and new perspectives}

Researches addressed on pluralism, interdisciplinary and intercultural approaches need initial steps on steering at common goals and a clear interacting methodology, based on mixed-methods. Recent development on methodology argued that quantitative and qualitative tradition should not have a separate-but-equal status, and should instead interact (Olsen, 2004). The information and findings of the desk study integrated with primary data collection analysis help to triangulation and to depict a more comprehensive study. During project design, emphasis should be done in the selection and training of researchers and indigenous assistants for fieldwork. However, desk study is needed to define theoretical 
frame, sampling, mixed-methodologies and how to use ethnography. Many steps of the quantitative research interact with ethnography mainly during the application of instruments of data collection.

Nowadays there is a need for pluralism in research to construct a different reading of the Embera food insecurity. New perspectives are needed in the context of biological and psychosocial stress being experienced by the community. In this context, in the last decade, suicide has increased among young Embera, of both genders, it is difficult to face such a dramatic event in populations of small scale like this. The team was hit hard when one of the five indigenous helpers hanged himself days after leaving fieldwork. There is no enough attention to suicide, in terms of its biological and social potential triggering causes. It is alarming the diminishing average age of the suicide cases in the Embera people. The emergence of potential nutritional constraints associated with delirio da fome (madness of hunger), or similar syndromes, should be studied in the short term in Embera population. There are few studies on this topic in Latin America, nevertheless it is remarkable the study of Scheper-Hughes (2001) in Brazilian populations of the Northeast.

Studies on food security and nutrition in Embera communities are scarce, perhaps because the difficulties of the language and because they often are located in remote parts with lack of infrastructure. However nutritional health and food security in Embera are far from optimal. Food insecurity arises from a set of causalities, traditional food habits are no longer sufficient for adequate subsistence. The ethnography of food has the power to suggest that the food ideal of hunting and fishing is unsustainable and outdated compared to the current food system. Thus, the communities have been forced to reduce the amount of food in the diet and include exogenous feeding products higher in energy and lower in protein, vitamins and minerals, as a result of an increasingly food acculturation. The cumulative chronic under-nutrition during the growth period in Embera children may also show the adverse food environment that accompanies the indigenous life.

Investment in food assistance programs have not had the expected impact in Frontino but have alleviated some nutritional problems in under-10 year children from Nusidó and were absent in the community of rainforest from Atausí. Although food aids afford limited food complements they had a certain impact on Eyabida because the prevalence of deficiency of energy and nutrients increased from 9 years onwards, when children receive almost no food aid. The challenge is to review food aid programs, and circumstantial supports, in order to make them consistent with the conception of "the Embera good living".

\section{Acknowledgement}

This project was supported by the Institutional Agreement CI 567-2006 of the Government of Antioquia (Mana Program), the Research Group on Environment and Society (Medio Ambiente $y$ Sociedad) enrolled in the CISH (University of Antioquia), and the Indigenous Organization of Antioquia (OIA), with partial support from the European Union (EU) and finally by the Research Group on Food and Human Nutrition (University of Antioquia). Furthermore, the research participated in the 2011-2012 Sustainability Program of the Vice-rector Council of Research at the University of Antioquia, designed for supporting groups of research. The authors are also strongly grateful to the assistants who helped in 
the fieldwork Germán Ariel Marin, Laidy Diana Arias, Juan Camilo Higuita and Johanna Santa, as well as to translators and indigenous helpers Luz Amparo Domicó, Nelson Majoré (†), Lino Domicó, Euclides Carupia and Silvia Domicó.

\section{References}

Alcaraz, G. \& Correa, A. (2006). La ética en la investigación: el caso con los tule (kunas) de Urabá, Colombia. Colombia Biomédica, Vol.26, No.1, pp. 9-21, ISSN: 0120-4157

Alcaraz, G.; Arias, M.M. \& Gálvez, A. (1988). Situación de Salud Materno-infantil en Asentamientos Embera. Dabeiba, Antioquia 1985-1986, Un-published research report, Colciencias, Universidad de Antioquia, Medellín, Colombia

Alcaraz, G.; Bernal, C.; González, G. \& Arias, M.M. (1997). Oral rehydration with a plantainfluor based solution in children dehydrated by acute diarrhoea: A clinical trial. Escocia Acta Paediatrica, Vol.,86, pp. 1047-1051, ISSN: 0803-5253

Álvarez, M.C. \& Restrepo, L.F. (2003). La variedad de alimentos disponibles en el hogar. Metodología para identificar vulnerabilidad a la inseguridad alimentaria y nutricional en hogares campesinos. Revista de Salud Pública y Nutrición Respyn, Vol.4, No.4, ISSN 1870-0160

Álvarez, M.C.; Benjumea, M.V.; Roldán, P.; Maya, M. \& Montoya, E.C. (2005). Perfil alimentario y nutricional de los hogares de la región del Urabá antioqueño. Gobernación de Antioquia, Dirección Seccional de Salud, Programa de Mejoramiento Alimentario y Nutricional de Antioquia, Universidad de Antioquia, Escuela de Nutrición y Dietética, ISBN , 958-9772-04-8, Medellín, Colombia

Álvarez, M.C.; Estrada, A.; Montoya, E.C. \& Melgar-Quiñónez, H. (2006). Validación de escala de la seguridad alimentaria doméstica en Antioquia, Colombia. Salud Pública de México, Vol.48, No.6, ISSN 1606-7916

Álvarez, M.C.; Rosique, J. \& Restrepo, M.T. (2004). Seguridad alimentaria en los hogares de Acandi: La disponibilidad de los alimentos como indicador de suficiencia alimentaria. Revista Chilena de Nutrición, Vol.31, No.3, pp. 318-329, ISSN 0716-1549

Arango, J.U. \& Zuluaga, G.P. (2007). Seguridad alimentaria desde una perspectiva de Gestión Ambiental en territorios de comunidades embera del Atrato Medio Antioqueño. Medellín: Organización Indígena de Antioquia, Fondo Indígena

Arias, M.M.; Alcaraz, G. \& Gálvez, A. (1988). Situación de salud materno-infantil en asentamientos embera Dabeiba- Antioquia 1985-1986. Investigación y Educación en Enfermería, Vol.6, No.2, pp.13-33, ISSN 0120; -5307

Bernal, J. \& Lorenzana, P. (2001). Características socioeconómicas y alimentarias en hogares de niños y madres cuidadoras de guarderías de una zona de bajos recursos en Caracas Venezuela. In: INCI Vol.22, No.12, 23/08/2011, Available from: http:/ / www.scielo.org.ve/ scielo.php?pid=S0378...script=sci

Buzzard, M. (1998). 24-hour dietary recall and food record methods. In: Nutritional epidemiology, W. Willet (Ed.), pp. 50 -73, Oxford University Press, ISBN 0-19-5122176, Oxford

Carmona-Fonseca, J.; Correa, A. \& Alcaraz, G. (2005). Población, alimentación y estado nutricional entre los tules (kunas) del resguardo Caimán Nuevo (Turbo y Necoclí; 
Antioquia, Colombia), 2003-2004. IATREIA, Vol.18, No.3, pp. 258 - 278, ISSN 01210793

CONPES (2008). Consejo Nacional de Política Económica Social. República de Colombia, Departamento Nacional de Planeación. In: Documento CONPES Social 113, 23/08/2011, Available from: http:/ / www.minproteccionsocial.gov.co

Contreras, J. \& Gracia, M. (2005). Alimentación y cultura. Perspectivas antropológicas, Ariel editores, ISBN 84-344-2223-9, Barcelona

Correa, F. (Comp.) (1988) Atención integral a la familia indígena. Documento Marco. Instituto Colombiano de Bienestar Familiar, Unpublished document, Bogotá

Crenn, C.; Delavigne, A.E. \& Téchoueyres , I. (2010). Migrants' food habits when returning home (in Bamako, Mali, and Dakar, Senegal). In: Anthropology of food, 16.06.2011, Available from: http://aof.revues.org/index6629.html

de Garine, I. \& Harrison, G.A. (Eds.) (1988). Coping with uncertainty in food supply, Clarendon, ISBN 978-189-9825-35-6, Oxford

de Garine, I. (1980). Une anthropologie alimentaire des français? Ethnologie Française, Vol.X, No.3, pp. 227-238

de Garine, I. (1988). Antropología de la alimentación y pluridisciplinariedad. América Indígena, Vol.XLVII, No.3

de Suremain, C.E. \& Katz, E. (2009). Introducción: Modelos alimentarios y recomposiciones sociales en América Latina. Anthropology of food, 16.06.2011, Available from: http://aof.revues.org/index6432.html

Duque, M.; Espinosa, I.; Gálvez, A.; Herrera, D. \& Turbay, S. (1997). Chajeradó, el río de la caña flecha partida: impacto sociocultural de la explotación de madera sobre un grupo embera del Atrato medio antioqueño, Colombia, Ed. Concultura, ISBN 958-6122-80-8, Bogotá

Emerson, R.; Fretz, R. \& Shaw, L. (1995). Writing ethnographic fieldnotes, The University of Chicago Press, Chicago, USA

FAO (2002). Latin foods, 15.03.2004, Available from: http://www.rlc.fao.org/bases/alimento/default.htm

FAO (2006). Cumbre Mundial sobre la Alimentación, 1996. Informe de políticas. Junio, No.2, 2.12.2007, Available from: http://www.fao.org/index_es.htm

Fischler, C. (1995) El (h)omnívoro. El gusto, la cocina y el cuerpo, Editorial Anagrama, ISBN 97884-339-1398-2, Barcelona, Spain

Food and Nutrition Board (2004). USDA. Hand Book 8, 10.02.2004, Available from: http://www.hoptechno.com/nightcrew/sante4me/usda19datashape.cfm

Gálvez, A. (1993). La herencia del pájaro cuéndola: la alimentación de los indígenas eyabida del noroeste antioqueño. Mémoire de maîtrise, Departement D'Anthropologie, Faculté des Arts et des Sciences, Université de Montréal

Gálvez, A.; Alcaraz, G.; Arias, M.M.; Gutiérrez, S.Y. \& López, A.D. (2002). El mañana que ya entró: La fecundidad en los pueblos indígenas de Antioquia. Editorial Universidad de Antioquia, ISBN 958-655-544-5, Medellín, Colombia

García, C. (2002). El vegetarianismo. ¿Dieta prudente o estilo de vida? In: Somos lo que comemos: estudios de alimentación y cultura en España, M. Gracia (Ed.), pp. 249276, Editorial Ariel, ISBN 978-84-344-2218-6, Barcelona 
Goloubinoff, M. (1996). Coca et sauterelles grillées. Les aliments modernes face aux saveurs du terroir dans une campagne mexicaine. In: M.C. Bataille-Benguigui \& F. Cousin (Eds.), Cuisines. Reflets des sociétés. Sépia-Musée de l’Homme, pp. 199215, Paris

Huamán, L. \& Valladares, C. (2006). Estado nutricional y características del consumo alimentario de la población aguaruna. Amazonas, Perú 2004. Rev Peru Med Exp Salud Pública, Vol.23, No.1, pp. 12-21, ISSN 1726-4634

ICBF (1988). Tabla de composición de alimentos colombianos. Talleres de sesión de Publicaciones. Instituto Colombiano de Bienestar Familiar, Bogotá

ICBF (2006). Ingesta Dietética. Encuesta nacional de la situación nutricional en Colombia, 2005., pp. 229-261, Instituto Colombiano de Bienestar Familiar, ISBN 978-958-623087-2, Bogotá

Kaberry, P. M. (1957). Myth and ritual: some recent theories. Bulletin of the Institute of Classical Studies, Vol.4, pp. 42-54, ISSN 2041-5370

Kuhnlein, H. V. (2007). Indigenous Peoples' Food Diversity and Food Security. FASEB Journal, Vol.21, No.5, pp. A672-A673, ISSN 0892-6638.

Lareo, L.; Gracia, B.; Fajardo, L.; Romero-Acciarri, L.H.; Pradilla, G.; Maldonado, A.; Redd, C. \& Daza, C. (1990). From food basket to food security the food factor nutritional surveillance. Archivos Latinoamericanos de Nutrición, Vol.XL, pp. 22-29, ISSN 00040622

Le Breton, D. (2004). Antropología del cuerpo y modernidad, Nueva Visión, ISBN 950-6023-33-6, Argentina

López, J. (2003) Algunas consideraciones metodológicas en los trabajos de campo en antropología de la alimentación. Experiencia con mayas ch'orti' del oriente de Guatemala. Revista de Antropología Social, Vol.12, pp. 223-241, ISSN 1131-558X

Lorenzana, P. \& Sanjur D. (2000). La adaptación y validación de una escala de seguridad alimentaria en una comunidad de Caracas, Venezuela. Archivos Latinoamericanos de Nutrición, Vol.50, No.4, pp. 334-340, ISSN 0004-0622

Manjarrés, L.M. \& Correa, J. (2006). Programa de Evaluación de Ingesta Dietética. Software. Escuela de Nutrición y Dietética. Universidad de Antioquia, Medellín, Colombia.

Messer, E. (1995). Un estado de la cuestión: Perspectivas antropológicas sobre la dieta. In: Alimentación y Cultura, J. Contreras (comp.), Editorial Universitat de Barcelona, ISBN 84-475-1103-0, Barcelona

Mintz, S.W. \& Du Bois, C.M. (2002). Anthropology of food and Eating. Annual Review of Anthropology, Vol.31, pp. 99-119, ISSN 0084-6570

Muchnik, J. (2004). Identidad territorial de los alimentos: alimentar el cuerpo humano y el cuerpo social. In: Territorios y sistemas agroalimentarios locales, A. Machado \& M. Pinzón (Eds.), pp. 17-32, Universidad Nacional de Colombia, ISBN 958-701-415-4, Bogotá, Colombia

Murcott, A. (1988). Sociological and Social Anthropologic approaches to food and eating. In: World Review of Nutrition and Dietetics, Vol.55, G.H. Bourne (Ed.), pp. 1-40, Karger, ISBN 3-8055-4703-X, Basel

Nusser, S.M.; Carriquiry, A.L.; Dodd, K.W. \& Fuller, W.A. (1996). A Semiparametric Transformation Approach to Estimating Usual Daily Intake Distributions. Journal 
of the American Statistical Association, Vol.91, No.436, pp. 1440-1449, ISSN 01621459

Olsen, W. (2004). Triangulation in social research: Qualitative and Quantitative methods can really be mixed. In: Devolopments in Sociology, M. Holborn (Ed.), Causeway Press, ISBN 978-1-902796-82-6, Ormskirk, Lancashire

Pineda, R. \& Gutiérrez de Pineda, V. (1999). Criaturas de Caragabí. Indios chocoes: Emberaes, Catios, Chamíes y Noanamaes. Editorial Universidad de Antioquia, Departamento de Publicaciones, ISBN 958-655-33-33, Medellín, Colombia

PNUD (2011). Colombia rural. Razones para la esperanza. Informe Nacional de Desarrollo Humano 2011. Indh, Programa de las Naciones Unidas para el Desarrollo, Pnud, septiembre, ISBN 978-958-8447-63-6, Bogotá

Programa Mundial de Alimentos de las Naciones Unidas. (2006). Diagnóstico de la Seguridad Alimentaria y Nutricional en el Chaco Boliviano. In: Focalización, Monitoreo y Evaluación, October Series, 23.08.2011, Available from: http:/ / www.pma.org.bo

Restrepo, B.N.; Restrepo, M.T., Beltrán, J.C.; Rodríguez, M. \& Ramírez, R.E. (2006). Estado nutricional de niños y niñas indígenas de hasta seis años de edad en el resguardo embera-katío de Tierralta (Córdoba). Biomédica, Vol.26, No.4, ISSN 0120-4157

Restrepo, E. (Ed.) (1996). Renacientes del Guandal. "Grupos negros" de los ríos Satinga y Sanquianga. Proyecto Biopacífico, Universidad Nacional de Colombia, ISBN 978958-9593-61-5, Bogotá, Colombia

Restrepo, M.T.; Quintero, D.; Martínez, M.M.; \& Gómez, A.M. (2006). Técnicas para la toma de medidas antropométricas. Centro de Atención Nutricional, ISBN 978-958-44-0038-3, Medellín, Colombia

Reyes, I.; Nazar, A.; Estrada, E. \& Mundo, V. (2007). Alimentación y suficiencia energética en indígenas migrantes de los Altos de Chiapas, México. Archivos Latinoaméricanos de Nutrición, Vol.57, No.2, ISSN 0004-0622

Rosique, J. (2010). Field diary 2010 may-jun. Estudio antropométrico de comunidades indígenas del Área de influencia de Cerrejón, Personal manuscript, Medellín.

Rosique, J.; Álvarez, M.C.; Restrepo, M.T.; Pérez, F.C.; Rebato, E., Susanne, C. (2004). Seguridad Alimentaria y Nutricional en el municipio de Acandí. Universidad de Antioquia, CODI, Unpublished research report, Medellín, Colombia

Rosique, J.; Restrepo, M.T.; Manjarrés, L.M.; Gálvez, A. \& Santa, J. (2010). Estado nutricional y hábitos alimentarios en indígenas embera de Colombia. Revista Chilena de Nutrición, Vol.37, No.3, pp. 270-280, ISSN 0717-7518.

Scheper-Hughes, N. (2001). La muerte sin llanto. Violencia y vida cotidiana en Brasil. Editorial Ariel S.A., ISBN 978-84-344-7463-5, Barcelona

Sociedad Latinoamericana de Nutrición. (1997). Promoviendo la seguridad alimentaria y nutricional en América Latina. Proceedings of the XI Congreso de la Sociedad Latinoamericana de Nutrición, INCAP and SLAN, Guatemala

Vizcarra, I. (2002). Entre el taco mazahua y el mundo. La comida de las relaciones de poder. Universidad Autónoma del Estado de México, ISBN 968-835-755-3, México 


\title{
From Gambits to Case Data
}

\author{
Keith V. Bletzer \\ Arizona State University \\ USA
}

\section{Introduction}

Ethnography is based on "writing" (graphy) about a group of "people" (ethno) who differ from the reader. In introductory anthropology classes we learned that ethnography can refer to "field" or "text," or both. "Field" was defined as intensive, extended-time fieldwork among the people of a particular society, whereas the "text" was stylistic presentation of research findings on these people. Although these findings are often holistic, that is, allencompassing on many facets of local culture, the place typically was a single community within one area of a town or city, if the research setting was not circumscribed as rural. We were further taught that ethnography is not the same as anthropology. As a professional endeavor, anthropology is a domain of knowledge grounded within a mission, whereas ethnography is a set of techniques that take place "in the field" and in "the text" after and even while fieldwork is occurring. The conventions that characterize the practice of ethnography are utilized by practitioners from other fields of endeavor. Some of the classic monographs were in fact written by practitioners trained outside the field of anthropology. Because they illustrated the practice of ethnography so well, they were included in the classes taught by full-fledged anthropologists. Effective ethnography is unlimited and has no disciplinary boundaries or theoretical orientations.

Publications and conference presentations ground the development of ethnographic theory. This can occur across a body of ethnographic literature, as authors or teams of authors develop and build theory within individual texts or across texts in relation to knowledge gained from research among similar people. Constructing theory is based on related issues but not always the same guiding questions. To explore in greater depth what this means for ethnographic practice, again for "field" and "text," I take the case of field research on illicit drug use among agricultural workers. I first examine 'gambits' that researchers have used in handling the issue of drug use among farm workers, before outlining basic ideas on field samples and data analysis. Gambits appear among the first approaches to a forbidden topic such as drug use, versus investigations at later stages, by which time more researchers have entered the discussion and saturation begins to occur in text-data-theory.

As I write this essay on the practice of ethnography, it has been several years since the study of illicit drug use among agricultural workers has been liberated from prior silence. We owe much to these early glimpses that the behavior existed in farm labor, although no one had an idea how extensive it was, what forms it took, how it fit within the general pattern of cultural practices experienced by farm workers, or what personal and community 
consequences there might have been for those who used and those who were affected by its presence. The topic was one of interest, whose conceptual development was taking place amidst shifting methodological strategies.

\section{Gambits}

Ethnographers approached with caution the subject of illicit drug use among agricultural workers. This is true of early references and those who later became involved in full-scale research on farm workers and drug use. Not wishing to accuse or criticize or taint or slander the people of their research, ethnographers were careful in how they presented field data and through presentation, how they represented their study people. The literature that refers to drug and alcohol use among agricultural workers has been circumspect, considering the historic association of migrant workers with marijuana in public imagination, following the "marijuana scare" of the 1930s (Musto, 1999). No doubt there were other reasons for caution in the way that fieldworkers elected to raise the issue of drug use in agricultural areas where farm labor was concentrated. I first examine gambits that were utilized by these early writers who chose to reveal the presence of drugs within farm worker settings, before presenting examples of cases as sources of ethnographic theory.

\subsection{Resort to ubiquity}

A "resort to ubiquity" is a statement without elaboration to indicate that "drugs are everywhere," hence drug use can be expected with Community O, People K, Village A or Population Y. Author recourse to ubiquity generally lacks information on frequency of occurrence or specificity of use. Analysis is generalized and real-world cases often are lacking. One example of "resort to ubiquity" occurs in the study of perishable crop agriculture by Monica Heppel and Sandra Amendola (1992). They identified a behavioral attitude in the northwestern United States reportedly occurring among farm workers in one intensified agricultural county: "Growers complained about a new 'cocky' and 'disrespectful' attitude that they felt workers were beginning to exhibit." In the same paragraph, they characterized this county as an area where farm workers use drugs, before they link the attitude to drug distribution: "The overall workforce is becoming increasingly difficult - a purported increase in drug trafficking and other criminal activities" (p. 66). The authors imply that drugs in this area are expected among agricultural workers, owing to a "purported increase in drug trafficking" in this farming county. Thus, the implication is: If drugs were available, because distribution has increased and their presence was increasing, then "drugs are everywhere." We are never told how much drug use and/or distribution occurs among farm workers in the Northwest, and nothing is said to link these local behaviors (distribution and use) to farm workers elsewhere in the Northwest. The reasoning is circuitous.

\subsection{Singleton}

This gambit gives a single glance at the phenomenon and its consequences. A comment describes a single instance in no more than a sentence amidst thick description of the author's thesis. More information is avoided to obscure a negative impression of the study community. This gambit works well with case analysis. One example of "singleton" appears in Juan Vincent Palerm's (1992) illustration of a typical farm labor season, using the case of 
Pedro, to provide a glimpse at pill dispensing to workers. Born in central Mexico, and coming to the United States at age 19, Pedro worked in two states in strawberries, asparagus, oranges, berries, celery, construction and day labor. Regarding celery work performed by Pedro, Palerm writes:

The foreman drove the crew hard and hardly gave the workers time to rest... When the workers began to show fatigue and become irritable, the foreman dispensed small triangular pills that he call "pinkos" which he claimed would re-energize the worker. (I suspect that he was administering amphetamines.) One afternoon Pedro cut his hand just above the thumb. (p. 363)

Alliterative expressions "hard" and "hardly" foreshadow "amphetamines" in parentheses to translate the term, 'pinkos'. Palerm does not suggest how extensive pill-dispensing might be or if it occurs elsewhere in the country or only in California. The author narrows his comment to a parenthetical remark, rather than expand this aspect of Pedro's experience to suggest how often he took pills in or outside celery work. It is not clear how much pilldispensing occurred among the crew where Pedro worked. That the crew leader dispensed pills to more workers than Pedro is evident in the passage. If Pedro's case was meant to typify "workers," then we suspect that pill-dispensing was common among other celery workers. Significance of the practice is suggested by linking pill-taking (in parentheses) to Pedro's thumb injury. It is obvious Palerm intends to remove any hint of blame on Pedro, or other workers, for taking the pills, as we note the phrase, "the foreman dispensed..."

\subsection{Serial nesting}

"Serial nesting" is inserting a disparate characteristic or behavior in a series of traits. Generally the series goes beyond the three items customarily found in English texts. Attributes are listed to describe a vulnerable community, such as immigrants. The listing truncates activities that co-exist with variable frequency, among which is one that typically would be disvalued, such as drug use or drug selling, or smuggling. Hence, the negative or disvalued trait is sanitized by nesting its inclusion among a number of activities greater than the typical short list that the reader expects. In ethnography, identifying a few among many plays down the conceptual weight of the phenomenon and it avoids "blaming others" of unsavory activities. This gambit owes it effectiveness to revealing a full picture in a single sentence that shows good and bad; thus, the bad loses its taint. In ethnography, we read examples of valiant people and commendable acts, among which the author includes one or two that refer to unsavory activities. To strengthen the softening, the unsavory might have taken place in the past.

One example of this gambit appears in a study of immigrant women by Pierrette Hondagneu-Sotelo (1994), where one case among her sample of forty is that of a woman asked by her aunt to transport drugs across the U.S./Mexico border (p. 90). Another example is a collection of narratives by persons with agricultural experience in With These Hands (Rothenburg 1998), which includes the cases of two men who used crack-cocaine (pp. 155-159, 177-181) among a selection of seventy vignettes on aspects of farm labor including recruitment, labor practices, family life, housing, schooling, and so on.

A variation on this gambit can be accomplished in case analysis. To illustrate life on the U.S./Mexico border, three cases are presented by Carlos Vélez-Ibáñez in Border Visions 
(1997), beginning with Larry Acosta (pp. 151-154). This case describes a cycle of early settlement, where one was prone to regretted choices. Although Mr. Acosta used drugs during time he moved about while working in mining in the southwestern United States, the case ends on a positive note. He received treatment for addiction and found work as a treatment counselor. Positioning drug use before recovery as a part of his past is unusual and cancels out the relative weight of having one user among a small number of cases. Cases of drug use in the literature are frozen in the ethnographic present rather than nestled into a life trajectory. Vélez-Ibáñez startles the reader with the immediacy of drug use in the first case, rather than one of the later cases. We receive the surprise before deepening description that broadens our understanding of difficulties workers faced and the means by which they persevered and overcame adversity.

\subsection{Acknowledgment}

"Acknowledgment" of drug use or distribution among farm workers occurs when neither one is the analytic focus. A limited number of statements in the text demonstrate the presence of some kind of drug-related activity. An acknowledgment seeks to appraise the community setting with minimal details that avoid a blame-the-victim attitude. Reference to drugs or drug traffic might occur more than once, as a single statement that requires no further elaboration.

One of the earliest references to illicit drugs in the ethnographic literature on farm labor is Linda Whiteford's (1980) study of gender relations in an agricultural area on the MexicoTexas border. Completed as dissertation fieldwork (Whiteford, 1979), her research acknowledged that some residents were smuggling drugs across the international border from Mexico into the United States. It was smuggling and availability of more jobs with federal and state programs that provided an impetus for changes in gender relations, which is the focus of her monograph. She mentions the full cause before describing how changes in gender relations affected the local community. Whiteford (1980) is aware of the dilemma. Through a variant of resort to ubiquity she reports the involvement of local people: "Smuggling of drugs and guns is a delicate topic... smuggling is not relegated to a small group of "lower-class" hoodlums. People who smuggle, or at least peripherally involved in smuggling, are to be found at every level of the social system" (p. 107). She softens disclosure by recognizing the "delicate" difficulty of a practice ("smuggling") that might be considered unsavory. At the same time she reveals local knowledge of the practice, before documenting how common was the practice through a 1977 grand jury investigation that found that one-third of the town was engaged in smuggling (p. 107). She continues by depicting local awareness that smuggling brought greater profits with less work (pp. 4, 108) and provides examples of commodity consumption that illustrates sudden wealth for those who once were poor (p. 110). Finally, she examines changes in local society, whose basis she attributes to money derived "directly or indirectly" from smuggling and the presence of more jobs that were subsidized through government programs (p. 111).

A short distance from the fictitious town, Frontera, studied by Whiteford, a small border town was home-base for journalist Isabel Valle (1994), who lived with a migrant family (parents/children) with whom she traveled to apple and potato harvests in Washington, Oregon and Idaho. She reports on drug dealing across the border and illicit transportation of drugs from South Texas to the Northwest as interrelated and common. She does not 
mention local attitudes and provides no appraisal of effects these activities have on local people. Having learned of their occurrence in her one-year sojourn, she reports their existence, which we take to be valid, because she was living as an insider. Much like an ethnographer might plan and conduct a study of migrant life, Valle chose to study the situation by living and traveling with people from the community.

\subsection{Exemplification}

"Exemplification" is a gambit that celebrates the awareness of local people who recognize that a disvalued activity is taking place in their community. This approach relies on insider viewpoints. Rather than emphasize detriments of these practices, textual references to the activity remain silent on consequences. Presented evocatively in the reported words of practitioners and those directly affected by the practice, the style of exemplification is "hard and direct."

Contractor-as-outlaw and city-as-cause are among several themes that appear in what might be the first published narratives in the literature that describe someone who performed farm work and used hard drugs. Four cases are documented in three ethnographies. Similar to the three cases in Border Visions, all four men "once" used drugs, and each of the four by one means or another fled the labor camp where he worked. Excerpts from narratives imply that each man, who previously used drugs, was coerced to continue using by labor contractors. In one case (Fred Sampson), these individuals formed a family where a few members were later convicted of violations of the Migrant and Seasonal Agricultural Worker Protection Act (Rothenburg, 1998:159).

Two narratives appear in Daniel Rothenburg's With These Hands (1998), an exposition of seventy narratives from a sample of more than one-hundred interviews with men and women across the United States (namely, Southwest, Southeast, Midwest) and Guatemala and Mexico. Most were persons in labor-intensive activities. The monograph includes two men paid by labor contractors in "wine and drugs," which exemplifies addition of illicit drugs to the practice of advances ("loans") from farm contractors to workers, which, according to Rothenberg in his introduction (p. xiv), already included licit commodities of food, cigarettes, alcohol (see Jankowski \& Bradburd, 2003). Two stories in Rothenburg's (1998) monograph, those of Fred Sampson (pp. 155-159) and Calvin Douglas (pp. 177-181), emphasize urban-based drug use and perpetuate an image of 'the city' as an influence that generates drug use. Each man is recruited to farm labor from a city with promise of good money and drugs. After losing a construction job, Sampson was recruited in a large city in Georgia, for example, and after business experience in Tennessee, Douglas was recruited in a city in Florida, within two years of his move to that state.

A third case appears in a collection of essays on the homeless, compiled by Steven Vander Staay (1992). A fourth case appears in a collection of essays on life trajectories of five gay men, prepared by Leon Pettiway (1996). Neither monograph focused on agricultural labor. But each includes one person with prior experience in farm labor. Albert was recruited from a homeless shelter in a city located along the west coast of Florida to work in the Carolinas and Maine, before he left the crew (Vander Staay, 1992:51-52). He took advances in drugs or alcohol, before paying back from his earnings what he had used. At one point, he owed money. His case is upbeat: at the time of interview he was organizing a march against 
homelessness. 'Keisha' (street name) was raised and traveled with a migrant family, when younger. In the context of Pettiway's five-case study of sexual orientation, his background as that of a migrant who performed farm work in the South; four other cases were urbanbased. Keisha makes the transition to drug use while leaving behind his family and farm work and on the street becomes more heavily involved in drug use.

Although the case of Keisha suggests that rural origins are likely to lead to drug involvement, the theme of city-as-cause in the other examples of exemplification (Fred Sampson, Calvin Douglas, Albert) ignore rural origins as "causes" of drug use. All four narratives are silent on distribution of drugs by not only contractors but also farm workers (Bletzer, 2004).

\subsection{Elaborated inclusion}

Generally occurring as a series of references scattered throughout a monograph (rather than nested in one place in the text), "elaborated inclusion" demonstrates an author's sensitivity to the unsavory within a community. The contexts in which drug using/selling might occur suggest variability. Similar to acknowledgment where the unsavory is not the analytic focus, elaborated inclusion is more nuanced. In Mexican Voices, American Dreams, for example, Marilyn Davis (1990) demonstrates awareness of "drinking" as an accepted, expected male activity in Mexico to alcohol consumption across the border, where it becomes a problem that requires intervention. Her first reference to alcohol occurs with the story of Don Benjamin Real, depicted "nursing a beer" in a tavern he purchased with funds from work in the states (pp. 45-46), and her final reference is the case of a disc jockey with a drinking problem that required treatment in the United States (pp. 389-395). Between comments on cultural differences, Davis occasionally refers to marijuana (one man assisted smuggling; one woman smoked), youth exposed to drugs in cities but do not use, greater susceptibility to robbery when one is intoxicated, and the lucrative business of drug sales. These mentions are generalized; no fictive names are given and extensive details are lacking. The author includes one case of a man in rural Oregon suspected of drug involvement, when he stopped communicating with his family. When his wife and mother visit him, he rejected them. This statement of female intervention on behalf of a loved one provides an unusual glimpse of what life is like for a migrant, where many forms of adversity present challenges.

A second example of elaborated inclusion is José Limón's Dancing with the Devil (1994), where he includes casual references to drug use after stating in his introduction that his monograph is a study of border relations in South Texas. He suggests the community he studied, which implicitly comprises an agricultural population, holds variable views of drug use. References to drugs range from a "soft substance" (marijuana) to a "hard drug" (heroin); examples of those involved and/or affected by drugs range from a mother who prays before a saint that her child be delivered from drugs to the author's contact with an implied heroin smuggler at a religious shrine, where he provided transportation to/from the site for his mother. Rare among ethnographic disclosures, Limón discloses his own anxiety toward drugs, when it occurred to him that informants, riding in his car, might have marijuana that would place him at risk of arrest. Attitudes attributed to local people in the community fit the notions of drug use that one would expect to find along the border. That is, some people favor drugs (pro), some are against them (con), and a few are involved in distribution and/or use. Going further than narratives about drug use among agricultural 
workers or other forms of field research on farm labor, Limón provides the reader a glimpse of rural life through individualized close-ups, which are divergent in attitude on what it means to be a member of a border community.

\section{News reporting}

Newspaper articles provide an interesting counter-part to the ethnography of farm labor and drug use. It was the printed news that reported the discovery of crack-cocaine in farm labor settings. Although there is no disclosed intent to make the text ethnographic, news reporting shares one basic element with fieldwork, which is that of an experience-near report of a real-world event or person or situation or issue. Both journalism and ethnography rely on 'textual realism' in their message.

Anthropologists purportedly write for professionals and/or for students taking classes in anthropology, whereas journalists write for a public readership determined by a newspaper's distribution. Journalists seek hot issues. Anthropologists warm to the task of telling an audience what life is like among people with whom readers most likely will never interact (Appadurai, 1991). Journalists write in short word-bytes. Anthropologists take more space to elaborate ideas systematically into article segments or monograph chapters. Both journalists and anthropologists interview and observe, and each professes to utilize conventions to bring the reader closer to another world of experience. Each seeks engagement beyond vague evocation. Although the impression is that ethnographers spend more time in the field than journalists, each might spend an extended time getting to know the situation or the people under investigation.

Ethnographers in the study of farm workers were reluctant, until the past decade, to confront the issue of illicit drug use and drug sales among men and women who perform farm labor. In effect they were sidestepping inside knowledge within agricultural communities rarely articulated in public. Willing to write on farm workers and drugs, journalists in contrast sought to evoke a response to isolated realities (realism), whether they sought to generate a quick-fix or more extensive reform to illicit drugs that form one part of farm labor with its many organizational problems. Both groups were committing errors of representation. Ethnographers generally ignored the issue in publications and journalists sometimes over-reacted.

To extend my discussion, I explore news articles that refer to farm work and drugs from areas of the southern United States. While conducting fieldwork in several eastern states, I took time to review back issues of local newspapers in three locales around the time that crack-cocaine had appeared in the eastern United States. That is, the time period for this review was early to late 1980s. First, I describe the context in which news reporting covered introduction of crack-cocaine in the 1980s, which was followed shortly thereafter by news reports of crack use and distribution among farm labor crews.

\subsection{First news on crack-cocaine}

The New York Times is credited with first disclosure of "crack" in a front-page article, November 29, 1985 (Goss, 1985), which covered the appearance of crack-cocaine sales in New York City. A four-part series on drugs, "The New Addicts," eighteen months earlier (Raab, 1984), made no mention of "crack," despite a careful description of a rising incidence 
of middle-class users of cocaine and heroin. The tacit assumption is that crack first appeared on the east coast is challenged by a report of earlier discovery by a "basement chemist" on the west coast, someplace in Los Angeles, California (Erickson et al., 1994:23-24, citing James A. Inciardi at a technical meeting sponsored by National Institute on Drug Abuse; see also Rattner, 1993). "Crack" appears in the New York Times Index for the 1985 article, but is not mentioned for the 1984 four-part series on changes in new recruits among middle-class users. Possibly, the contacts generated for this series by Times reporters were used to explore "crack-cocaine," apart from information already collected on new habitués. Similar to ethnographers, reporters build on information from previous research which often leads them into new areas.

\subsection{Crack-cocaine among farm workers}

The first reports on the elusive practice of commodity advances by labor contractors to farm workers appeared in local and national newspapers. Four years after the article on crack on New York City streets, another article in the New York Times (Kilborn, 1989) became the definitive source on infiltration of illicit drugs into agricultural labor. The article names a farming community in the Middle South [not named for confidentiality]. To this time, alcohol was most known for distribution by labor contractors. The Times article was cited by various professionals, for example, within opening remarks by Vander Staay (1992:53) that introduce a narrative from a man who once worked on a labor camp where drugs were distributed. Four days after the Times article, the local newspaper in this farming area reported on the same incident. Written by two local reporters, this article provides an alternative view of the arrest of a contractor for drug trafficking. His crew originated from the edge of the citrus belt in the Lower South. The county where the arrest took place was one of three later called "Cocaine Triangle" by the local newspaper, owing to drug trials that were becoming common in the district court.

Both articles focus on forms of peonage between management and farm labor, and each centers their story on discovery of an accounting ledger that allegedly contained itemized re-sales of food, cigarettes, alcohol and, possibly, crack-cocaine. Whereas the Times article begins with discovery of the ledger on a sweet potato farm, the local newspaper begins with an overview of labor recruitment by contractors, hired by growers to supply workers, a practice that varies throughout the United States. That is, the 'contractor' typically has supervisory contact with workers hired, unless he (or she) delegates supervision to one or more crew leaders. Making monetary advances to a worker is common, reported on east coast (Heppel, 1982), west coast (Zabin et al., 1993) and both coasts (Rothenberg, 1998). Commodities sold to workers in camps are over-priced. A worker is docked for what can become all his wages. When arrests for crack distribution took place in the 1980s, the grower and labor contractor were liable for overcharges in commodity re-sale. Sympathizing with farm owners, the local newspaper noted that government restrictions had forced some growers in the Middle South to leave farming. Sympathizing with farm labor, the Times article noted, "Drugs or no drugs, just about every transaction in the book [ledger] is illegal" (Kilborn, 1989:D23). The local news states that crack first entered the county with contractors, whereas the Times reporters refrained from attributing origins.

Discovery of the ledger in 1989 was preceded by an acceleration of drug seizures chronicled in the local newspaper, which started in 1985, the year the national media 'broke the story' 
of crack-cocaine. Seven months after the New York Times article, the local newspaper published its first story on local distribution of crack. This report originated with a talk at a luncheon by the state bureau of investigation director that led to the first local article on crack, June 19, 1986. The first cited "crack" arrest reported in the local newspaper seven weeks later (July 30) described two out-of-state men from New York and Maryland with 56 "crack" vials in their car. That same article credits a March 1986 arrest at a national airport some distance from the farming county as the state's first "crack" arrest, when 239 vials of crack were seized. The next day (July 31) the article on the camp raid appeared. Editors thought it more newsworthy to have a full story with a photo of the arrested contractor from the Lower South than earlier arrests of men from the North caught with large amounts of crack. The raid that led to the arrest utilized an experience-near approach: "The cars continued down the dusty, rough road to the camp... The sun beat down as the officers approached the trailer. A group of officers entered the [crew leader's] home... Thirty workers were sitting around three trailers that faced the crew leader's trailer, the only trailer searched...." [1986]. Curiously, workers seated outside and those returning to camp in the crew bus were not subject to search, which was delayed an hour while sheriff's deputies waited for a search warrant. The crew leader's wife also made the news, as it was reported she was cooking her husband's supper. This was the second drug bust for crack reported in the local paper. Whereas this one was a "raid" (July 1986), the first was a "bust" (March 1986). Local articles after 1986 to time of the ledger discovery reported nationally in the Times in 1989 continued to link crew leaders to crack-cocaine.

Weekly newspapers from adjacent farm towns in the Lower South share features of daily reporting from the Middle South, but they avoided associating labor contractors or farm workers with drug arrests. For these two communities, farm workers were not viewed as intrusive. Each county relied on winter agriculture. Some residents who live year-round in these rural towns are also farm workers. They migrate to areas outside the county and the state to work in agriculture. Farm counties in the Middle South are one area where farm workers are viewed as non-residents who arrive/leave. Four articles appeared in 1986 in the weekly newspaper in the first county of the Lower South: arrest of three for prostitution and intent to sell or deliver a controlled substance (crack) on April 20; crack arrest for possession on August 6 ("rock" = "highly purified form of freebase cocaine"); and crack arrests on November 19 and December 10. Amounts were specified but not the paraphernalia. Charges and prior arrests were identified; law enforcement units rather than officers were credited with arrests; names of arrestees were accompanied by a local address, a few of which were migrant living sites in town; and the place of arrest was not listed, if it would jeopardize an ongoing sting ("set-up").

Although the first article that mentioned "crack," August 20, 1986, appeared after a talk by a state senator at a local Lions Club in the second county of the Lower South (similar to the Middle South), no public appearance led local reporters to investigate crack among farm workers in the second county. The reporter from the first county in the Lower South referred to "street corner delivery" and compared the cost of a crack "smoke" at $\$ 5$ to $\$ 10$ to "the cost of a movie or a box of popcorn." The analogy is surprising: this farming community never had a movie theater. The next issue for the second farm town one week later provided information on "rock" [crack] in the local area. This report was unconcerned about revealing techniques: details appear on modes of administration (laced cigarettes, 
home-made pipes, flattened soda cans) and local price (\$20). The reporter obviously "checked around" to secure information. Two weeks after first mentioning crack, the paper published its first article on a "crack sweep" that resulted in eleven arrests for sale, delivery and manufacture of "rock" (September 3). In another article, the same reporter named a local drug area ("A quick drive in the 'Quarters'") and added to a list of paraphernalia the use of aluminum foil with a piece of automobile antenna. Her report that crack users "scrape the pipe bowl for residue and re-light it" is testimony to her perseverance to get a story and provides early-in-the-history documentation that rural crack users had learned how to generate additional "hits" through remnants and residues, a phenomenon reported in urban drug research, similar to users that collected 'roaches' from discarded marijuana 'joints' (remaining stub) or injector-discarded 'cottons' initially used to strain impurities from a heroin solution.

All three newspapers (one daily and two weekly) from these Middle South and Lower South farm communities utilized a style of writing called "con-use" (Fan \& Holway, 1994) which stresses negative drug effects. In their analyses, this was crack. Whereas one weekly newspaper reported details of local arrests, interweaving then-known "facts" about crack during the first year of its local reporting, the other two newspapers (one weekly, one daily) used an investigative slant to portray the practice of crack use as unsavory (Hartman \& Golub, 1999), which often provoked unintended interpretations that could be construed as "pro-use" (Fan \& Holway, 1994). One of the two rural newspapers, for example, identified local 'copping areas' and described 'paraphernalia' used to smoke crack, whereas the other clearly presented pro-grower sentiments. Moreover, the two latter papers were inclined to identify the atypical in their news stories. Black labor contractors were stigmatized for introducing crack to rural areas of the Middle South, for example. The third newspaper, more known for its con-use style, minimized valorization, focusing on "arrest facts" in police reports, occasionally mixed with then-known "facts" of crack. Interestingly, this newspaper followed a style of generalized reporting: reporters neither accompanied law enforcement nor sought out users and dealers to interview. I had the opportunity to interview two successive editors of this newspaper, each of whom emphasized the need to avoid the "magnification of evil." They instructed reporters "to not alarm the community." Newspapers in various areas of the country have sometimes, often unintentionally, attributed greater involvement than was the case (see Musto, 1999:221, quotation from a report from the Federal Bureau of Narcotics presented to the U.S. Congress).

\section{Sampling in ethnography}

If we believe that a sufficient number of workers use illicit drugs, then we must select a reasonable means of sampling to investigate one or more aspects of use patterns. Case intensification best fits situations where we need to find the individuals who share a characteristic or engage in a practice that is generally limited, such as drug use or drug sales (Figure 1). Once we have collected sufficient field data, we can reliably analyze typical and atypical characteristics of the entire sample or select one or more individuals to illustrate what is common and not so common (Figure 2). 'Typical' and 'atypical' refer to "cases," that is, individuals who engaged in a practice or its characteristics, such as paraphernalia, frequency of use, user preferences for one or more drugs, and other facets of using drugs that might emerge as the field data are being collected. 

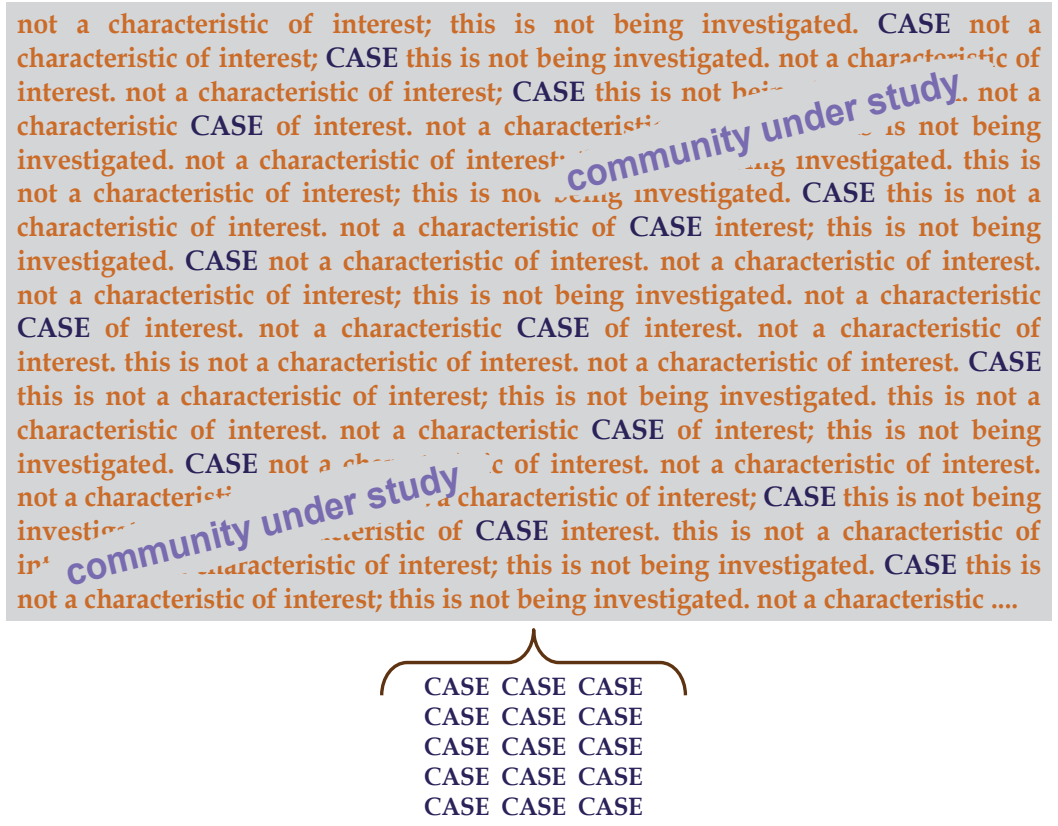

Fig. 1. Intensification in the "field" where unusual and/or hard-to-find cases are sampled

Because agricultural workers who use drugs are not that common, the means of sampling that I most often utilized was intensification of workers in agricultural areas where I was conducting ethnographic fieldwork. I traveled among various states but three in the southern United States were where I collected most my field data from six primary sites and fourteen secondary sites. There were a number of casual sites where I spent time, rarely more than a single visit, but each produced usable field data. A few casual sites became secondary sites, which I continued to visit on a regular basis.

\section{Typical}

rare- unusual- occasional- com mon-occasional- unusual- rare

Atypical

Atypical

rare- unusual- occasional- common- occasional- unusual-rare

Typical and Atypical

can refer to "cases" or "characteristics"

Fig. 2. Incorporation of atypical and/or typical cases into ethnographic "text" 
Given the population of interest is agricultural workers, another issue appears. Farm workers are not stationary in residence. They move around. Some follow crops for short periods of time or longer, which means they leave communities of residence, and some perform local work. Thus, sampling "in the field" must consider farm labor mobility. For a community that exists more or less permanently in one locale, as occurs in the classic ethnographic monographs, an ethnographer can return later and find many of the same people. That might not be possible with farm workers, if an encounter site was seasonal. Instead, we might choose the locale to which farm workers return when not on-the-season. Sampling decisions might require both types of sites, seasonal and home-base, and, if so, how many of each.

Which cases to present in "text" is the next choice an ethnographer must make. For this essay, I chose to randomize selection. Why random cases? Random sampling is not usually used by ethnographers, even at the time they initiate research. It takes place with a few kinds of social science research. Ethnographers rely on emergent sampling, where a sample develops over time ("field"), and emergent discovery, where field data are examined through case analysis ("text"). That is, knowledgeable people are identified over the first weeks or any time during fieldwork on farm workers, where men and women are coming and going, and often leaving for extended periods, whether on the east coast (Tolney, 1999) or west coast (Du Brys, 2007).

Ethnographic findings come from field data collected and analyzed over time, rather than specific pre-planned data. At least this is the path that I chose for this study. When I began with the Migrant Worker Risk Study, a team-based epidemiological investigation (I was hired as on-site project director), I was constrained to exploratory fieldwork in high-risk agricultural settings. The initial data led to ideas I wanted to explore through narratives. So, I secured funding to continue fieldwork as a "single investigator." My home-base for both studies was Agton, a rural town with an intensive agricultural economic base.

When reporting research findings, ethnographers develop materials for presentation, based on cases they select as the most representative for what they wish to illustrate. Cases emerge in organizing and analyzing data through emergent discovery, which crystallizes steps that precede data selection for presentation in publications. Randomization "in the text" is not common in ethnography. Field data typically are derived from community immersion and consistent inter-personal engagement over time, or by pre-arranged contacts, rather than secured and sorted from pre-existing data bases.

For me this style of research became unwieldy. I was immersing myself in settings where actors regularly changed over time. I collected data over multiple sites in several states, but spent most my time in one home-base community. My fieldwork style duplicated the multisited lifestyle that migrant workers experience: move / return home / move again / followed by more returning / moving. Usually, the time to go/return was fixed. People whom I met shifted in time-space. Some left and returned one-two-three-four years later. Some left, never to be seen again. Others replaced them. As I built the emergent sample of people to whom I am indebted, I wondered how I might best illustrate, fairly and accurately, aspects of their lives. Exploring these lives, I wanted to tell the story of the people in my field data. I needed an equitable way to select stories. So I randomized cases for "text." I selected twenty-four transcribed interviews to construct a picture of farm labor drug use. For this essay I include ten of these cases that illustrate three migrant family 
themes: father as primary figure, mother as primary caretaker and wage earner, where her children might continue farm labor into adulthood or shift to non-agricultural work.

\subsection{The sample of narrators}

Most the 127 Narrative Life Story interviews that form the basis of fieldwork were conducted in English with 82 men and women born in the United States, usually in the South and elsewhere in the United States. Forty-five individuals of the 127 were born outside the United States, most of whom spoke Spanish (90 percent preferred their interview in Spanish). Six men born in Latin America or the Caribbean spoke languages other than English, Spanish or French, including nine non-European languages (three Creole-based; six indigenous), and home country language (mostly Spanish, also French). Several came with family members to the states their first time; some were the only members of family to ever travel or live in states.

One similarity in the sample was means of transportation. More men and women rode a bicycle or walked than owned and/or drove an automobile during their lifetime. This is not surprising. The National Agricultural Workers Survey (NAWS) consistently found vehicle owners in less than half of their sampled workers; percentages range from high 40s to low 40 s, or fell below, but never above (Department of Labor, 2000). In my study, more than 85 percent of 127 men and women relied on walking or rode a bicycle, used public transportation or solicited rides within and between local towns. Most rode in harvesting buses or vans and trucks to the fields, orchards, groves, nurseries, packing houses, and distribution warehouses where they worked. A second similarity was incarceration. Fourfifths of the men and more than one-fifth of the women among 127 sampled persons were incarcerated at some point in their lifetime. This is not surprising; estimates from the Border Patrol suggest that ten to fifteen percent of the undocumented they detain have prior arrest records (Banks, 2008). At the high end in my study, 15 men and women served a total of almost sixty years in state prison, mostly for street-level drug sales and auto theft. Another 48 spent time "in and out" of jail, mostly for disorderliness and public drunkenness; robbery and burglary; and parole violation. Twelve women and men spent a few days in jail, once or twice in their lifetime.

Apart from similarities of minimized mobility in transportation and maximized immobility through incarceration, and the criteria of drug/alcohol use and agricultural labor that determined eligibility for the field research, men and women who became narrators of the Narrative Life Stories told a variety of good and bad experiences. Some were sought, some were not. Some were horrendous, but many were not unlike experiences that one might hear in a life story narrated by someone from mainstream society. Humor was embedded in the narrative style of those interviewed (Bletzer, 2010; also Gamburd, 2008).

Important first times are remembered. Many of us, perhaps, can recall the first time we took a bus, jitney, taxi, tram, subway train, or street car. Most all cities have public transportation of some kind, and many rural areas have inter-county bus or shuttle services, so this experience is likely remembered. Many of us also can remember the first time we drove a motor vehicle. Probably it was an automobile, if we lived in a city or the suburbs, or truck or lawn mower or tractor, if one lived in a rural area. These experiences are close to many of us. For other societies, important "firsts" differ from those we emphasize. Can we remember our first community ritual, or the first time we were taken by parents into the forest to harvest yams or fetch firewood, or taken to sea to fish, or the forest to hunt, or the first time we saw costumed 
dancers for a religious festival? For many of us, experiences such as these might not seem to be a big event or one that was important when it took place. To people in communities that hold traditional ideas of what the world is about, these events are crucial steps to adulthood.

Some 'firsts' take people into other worlds of experience. These "worlds" are associated with experimentation while growing up. Do you remember the first time you smoked or drank? Possibly there never was a first time for smoking or drinking. Or, you might be among less than ten percent of the United States population that report they have used an illicit drug at some point in their lifetime. For men and women I met through my research, these events they recalled, such as first drug ever used, each drug used thereafter for the first time, the last time a new drug was initiated, or the point where some "ceased using" and gained sobriety from alcohol and/or drugs. Each instance of drug use onset was significant and personal (Adams, 2008).

\section{Use history}

Seventy percent of the 127 narrators who told Narrative Life Stories were active in farm labor at the time of interview. Each one had current or recent experience in agriculture and all were currently using or had used one/more drugs or alcohol in the recent past. Ten percent received disability or were recovering from injury; twenty percent were inactive in agriculture. Fifty-five percent of the 127 were active users at the time of interview. Mostly they smoked crack and/or drank alcohol. The other forty-five percent were in recovery or in treatment. All together, participants had experienced 12 different classes of drugs, and reported a total 525 onset events that ranged from (a) oral intake by sipping, guzzling, chewing, or swallowing, (b) vapor inhalation through the mouth by heating a drug to melting point, using paraphernalia, (c) smoke created by burning a semi-flammable substance, inhaled through mouth or nose, and (d) injection, by needle and syringe, into the blood stream through a vein or under the skin. These various drugs ranged from commercial beverage alcohol, to illicit street dope, to those that were derived from natural plants.

Three-fourths the first drugs ever used by these 127 men and women were initiated in their "hometown" (72.4\%). Because many initiated more than one drug in their lifetime, onset for one-half $(50.8 \%)$ of the 525 drugs/alcohol initiated occurred in a place of birth, if the individual had remained in their hometown into late adolescence (Figure 3). This was common, although most the men and women whom I interviewed had traveled often and/or moved about and lived in multiple places and locales. What was surprising was to find that a small percentage of drug use onset actually occurred in a place of sojourn, whether it was first ever or later, when these places of temporary short-term abode comprised a large proportion of time experienced, both as a younger person, usually during adolescence, and later in life as a young adult and even later.

First Onset is first use of any drug or alcohol, whereas Later Onset is initiating another drug/alcohol after first drug onset. Later events might pull someone into continuing experiences or they begin a process of gradual or sudden cessation.

\subsection{Ten vignettes}

Ten vignettes were derived from 24 randomized cases of the full sample of 127 men and women interviewed for Narrative Life Stories. Vignettes summarize life trajectories, 


\section{Place-Bonding and Drug Use Onset}

\section{Trans-Migrant and US-Born Agricultural Workers}

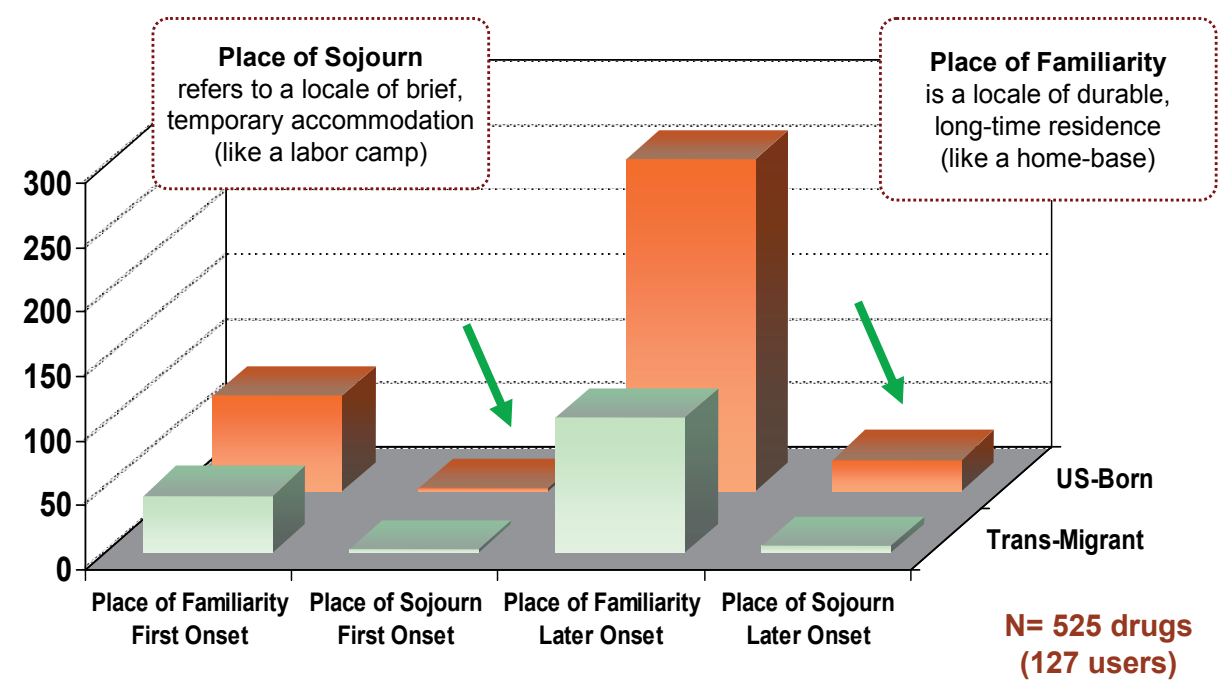

Fig. 3. Variation in first and later onset between place of familiarity and place of sojourn

describe drugs each narrator had used or was using when interviewed, and highlight the social world best known to them. After presenting a mini-summary that identifies onset specifics, I include an illustrative story from each that describes an aspect of use or an incident that was unusual or redemptive or humorous, as a self-reflexive view of life by someone that had developed a consuming passion for drugs. Number of drugs among these 24 cases ranges from two men who drank alcohol, to two men at the high end with fourteen and twelve. Random sample of the 24 is similar to the sample of 127: mean onset age 13.21 (13.64 for entire sample), mean number of drugs used at 4.35 (4.10 for sample) and mean age for last drug initiated 24.58 years (25.61 for sample). Mean age of 36.88 years was younger than 38.57 years for the entire sample, and the mean time in farm labor at 11.00 years was less than 12.73 years for the entire sample.

We start with the case of Arnie, whom I met in the Middle South. To follow the convention of ethnographic texts, I use only fictive names for men and women in case vignettes, and for any individual or place that is named. Arnie's situation was unusual. When he first came to the states, he had never drunk alcohol or used a drug. He spent his youth in a rural area of Mexico, where he went to school, before he left to assist his mother's brother in the local markets, selling perishable produce. Arnie was the oldest child. His father left for the states when Arnie was ten, and for six years neither his wife nor children heard from him. At age 16, Arnie crossed the border without papers (legal age is 18), in search of his father, who worked in agriculture, when he last communicated with his family. This search for the "Prodigal Father" led Arnie to drink.

Assisted by a paternal uncle, Arnie made an undocumented border crossing. To avoid capture they slept by day and walked at night in isolated areas. Arnie remembers carrying 
water. Once they arrived in the states, they spent seven days at the edges of two cities, hiding in trees, bathing in irrigation canals, and eating fruit from nearby fields. He and his uncle joined eight men to be taken by a coyote to the Northwest. Upon arrival the van driver left with a backpack and never returned.

In the morning, the uncle suggested that each one go their own way (cada quien). Arnie stayed with his uncle, who called a local contact. Forty-five minutes later the man arrived and transported Arnie and his uncle to a farm. It was the sugar beet season and time for the harvest. Most the other men went to a dairy farm. When the season ended, Arnie left the Northwest for the Lower South. This part of his story is vague. He was young, spoke no English, carried money he saved from the beet harvest, knew little about the West (three states) or agricultural labor (one crop), and knew nothing about the United States. He arrived with someone he met en route (not his uncle). Nothing about departure or the crosscountry trip he mentions, which otherwise would have been a momentous experience. His story starts at the moment that he reunites with his father. Importantly for our consideration, the locator "there" (ahi) in his story communicates non-movement.

There $(a h \hat{\imath})$ he was; there (ahi) I found him. When I arrived at--he didn't know me. ((inhale)) ((surprised voice)) He didn't know me. Later I told him that they told me when I asked, "Do you know where a man called Urbano lives?" His name is Urbano Sanchez. They told me, "Yes, in that trailer. They chased out the rest. That man is still there, alone." I ask, "But is he Urbano?" "Yes," they told me. "He's short?" they asked. "Yes," I told them. I didn't know he was there. I went--it was good fortune to arrive there.

Surprise in his voice, Arnie says, "He didn't know me," before he takes a breath, and repeats the phrase. Later in the narrative he will repeat the same phrase for himself, after he explains how he found the trailer, by asking several men standing outside, which is a common sight in places where migrants leave early for work. For the listener's benefit, he gives his father's full name. A first name, Urbano, was sufficient to ask the men. To confirm identification, the men give a defining trait, "He is short." Arnie confirms that he is. Arnie minimizes the good fortune he had in locating his father. He continues:

I didn't know him, well I knew him. It's just that, ((motions circle around imaginary bed)) it had a pile of bottles like this on one side of his bed and he was asleep ((head to one side)). I believe he had just gone to sleep. It was like seven o'clock. Others outside were there (allá) to leave for work. ((pause)) ((sadness)) It gave me great sadness, right, to see him there $(a h \hat{\imath})$, as if cast aside, encircled by the booze bottles.

Here Arnie relies on imagery from Mexican popular music, where someone forlorn is surrounded or encircled by bottles. According to Tim Mitchell (2004:141), this scenario alludes to a man that drinks, when saddened by a woman. In this case, it was Arnie who is saddened, which did not come from an experience with a woman, but his own father.

I felt sad. I was by myself. I came with a friend that I met in the truck. Well, if something were to happen to me here (aqui), may the Lord not will it, who would give the message to others? Who'd know where I am? There (alli) I saw my dad, I said to him, I just asked him, 'You're Urbano?' 'Yes' he told me, 'Who are you?' ((pause)) 'Well, I came looking for a man called Urbano, I believe he is my dad' I said. He just stared at 
me. 'Who are you?' he asked, 'What's your name?' 'My name is Arnie. I'm Arnie Sanchez'. ((inhale)) 'My mom is named Ursula' I told him, 'My mom Ursula and I are from Roldano' I told him. My town where we live, it's called Roldano. 'I am from Roldano, I came to find a man called Urbano'. He got up, sleepy-like, drunk-like, and, so, he hugs me, now that he's seen me and starts to cry. 'Don' $t^{\prime}$ I tell him, 'Don't cry' I tell him, 'Here I am' I tell him, 'I came to find you'.

Arnie identifies his given name (Arnulfo) plus nickname (Arnie) with surname (Sanchez), his mother's name and town name where they live. His style is formal. Location phrases that are part of his narrative of encounter, "there" (ahi, alli) and "here" (aqui), are associated with non-movement, whereas the men ready for work, outside, are associated with movement through an alternative phrase "there" (allá). Arnie's tone in the final part of the story resembles an adult who is comforting a child. Except in this instance, it was the child comforting a prodigal parent who had spent many years apart from his family. The imagery of unexpectedness is palpable, no doubt from an image of this personally significant event that was interpreted within cultural practices he learned as a youth (Cravey, 2005; Gamburd, 2008; Limón, 1994), which Arnie carried with him.

For seven months Arnie stayed in the trailer with his dad. He describes the times that he went looking for his father in bars. Because he was underage (state law prohibited a minor to enter bars), he would ask the manager "to bring that man" to him. "Let's go," he'd tell his dad. "Well, let's go," his dad would reply, "What time is it?" "It's twelve, or ten, or eleven." Arnie would take his father home and prepare a meal, "I wanted him to eat, so the beer would not harm him." Sometimes he made him drink coffee, "without sugar, very bitter." Even when his dad returned after 5:30 AM, he was expecting to go to work. Arnie described the toll this took on him, slowing his speech in the process: 'Later it made me want to, begin drinking. At first I didn't drink. I would say, "No." Then I drank one beer. Later, it was two, then three. Buddies would invite me, "Let's go to a dance," "No, I can't, they won't let me." What could I do? Everybody was older. I was the youngest.' He chuckled. Unlike men and women in the first ever sample of 127, and most every instance in the remaining 398 onset events, where various stories delineated the time and place of first use or consumption, Arnie was imprecise on when he first drank. Instead, he tells how his departure from usual behavior set him on a new path, which was the onset of drinking alcohol.

Six weeks later, Arnie had a confrontation with his dad. He had been with friends and came home on a day that his father had been at work in the fields. When his dad asked, "“What's wrong?," Arnie told him, "Nothing." But his father knew enough from his own experience to decipher Arnie's demeanor, "You're drunk, aren't you?" "Yes," Arnie told him, before he went to his small room in the trailer to sleep. Later they argued:

I told him, "It's okay for you to drink, but you want me not to. Do you think I don't feel anything, when you're drunk?" Talking to him like this, I felt bad, but I had to. In the morning he came to tell me he wanted me to stop my drinking, and I told him, "If you stop drinking, I'll stop drinking!"

Arnie eventually talked his father into returning to Mexico to visit his family who had not seen him in several years. He returned while Arnie remained in the states. From that visit by 
his father to Mexico, Arnie's mother gave birth to a daughter; she already had two other children. Arnie continued working in places that he knew along the East Coast, but by the time the daughter was four-years-old, he went back to Mexico. Arnie took her places within the community and he generally assumed a role of responsibility for her overall well-being and safety. He explained that parenting was not a role his father took with him. Like his father who again left his family, shortly after the daughter was born, Arnie too returned to the states. Neither of them, however, ever convinced the other that he should stop drinking.

By the time he was 21 Arnie had lived with cousins in a crack-house (never tried crack) in another county of the same state and performed farm labor in four additional southern states and one western state. Once when he returned to the Northwest, he said people he earlier met for the beet harvest told him that he had changed, meaning he seemed "distraught." Among his experiences: lost his driver's license in the Lower South and forfeited a car he was driving for Drinking-While-Intoxicated; spent forty days in jail for intoxication and later was beaten while drinking in another locale; spent thirty days in jail for intoxication in a Western state; and was robbed returning home drunk in the Middle South. After a binge episode that left him in a coma, he was taken to a detoxification unit. From there he was transferred to the residential treatment program, where we conducted the first of two interviews. In the evening I spent time with him and other men formerly in treatment, currently in Alcoholics Anonymous. One evening while several of us attended a church event to which they were invited, when the night air turned cold, I gave Arnie my flannel over-shirt. He was wearing a T-shirt and visibly shaking.

\subsubsection{Father figures in farm labor}

For the next three vignettes, we follow this theme of father's presence among those in farm labor. For these three individuals, most their early farm labor experiences involved a strong father figure. Each narrator was raised in a family unit in the Lower South that performed migrant farm labor. Father was the primary individual. The adult male in the first case was a stepfather, who lived and worked with his step-son on a year-round camp. The second father arranged work for his family each summer in a northeastern state. In the third, the adoptive father was a labor contractor, who monitored crew leaders in the home-base and regularly took his family on-the-season each summer. Each narrator had reflected to some extent on their drug use, like all those who provided a Narrative Life Story. Through the interview they had an opportunity to express ideas on migratory experiences. At this point I begin each with a fictive name for the randomized case that was selected.

Jay: Born and raised in the Lower South, Jay spent his youth in a small town with no more than 5,000 people the entire time he lived there. After he graduated, he went to live with his sister in a small city in an adjacent state. A year later he moved to a year-round labor camp owned by a large agricultural business in the same state, where he and his step-father lived and worked in citrus for fifteen years. Most summers he migrated to work the lands owned by the agricultural business in other states, or worked for an outside contractor, in crops such as apples and pears in the Upper South, tobacco in the Middle South, and watermelon, cabbage and cauliflower in the Lower South. When his step-father retired, Jay moved to Agton. At the time of his interview at age 40 he had been living there for three years. He had not visited any members of his family for fifteen years, even though all but two siblings were living in the Lower South, two to eight hours by automobile or bus. 
Alcohol (age 17) and Marijuana (age 17): First drank with high school friends at his graduation party with beer purchased by his mother, and first smoked a few days later with buddies from his hometown. Next time he smoked was one month later, with new friends he met in an adjoining state, where he had moved to live with his sister.

Crack-Cocaine (age 22): First smoked crack at a crack house, when he returned from a season of watermelon work in the Upper South to the city where his sister was living. Jay went with six co-workers to a crack-house, where he was told they would buy reefer. Instead, they stayed inside two hours and used crack multiple times, "For about an hour, it was steady using... I tried it and I gave it up." Jay stays in contact with the men. Some still use, but a few have died from drugs or AIDS.

Once is Enough: Jay tried crack but once. After that he returned to marijuana. It might seem unlikely given the myth that crack is consistently addictive. Because I would ask how many people were present the first time one used, the answer from Jay of 'several hundred' surprised me. To that interview (Jay was among the first 25), everyone using crack first tried it in small groups of two or three. When I told him, 'It couldn't have been hundreds,' he explained, 'It was a dope house... This guy was standing at the door. You go in, hit your stuff. You buy it right there... But you got to spend money. If you aren't spending, you got to go.' Jay told me he spent nearly all the money he saved on-the-season, 'I had a thousand dollars. Before I left, I was down to twenty-five dollars.' To my next question, Jay said the other guys spent most their money. The place to buy marijuana was next to the crack-house. When Jay told them, 'I got to get my weed, they say, "Come one, let's try this",' so they went to the crack-house. Jay said the high 'felt pretty good... Yeah, this is all right.' They stayed two hours with an hour of 'steady using.' Having tried and ceased crack in two hours, Jay echoed other sampled African Americans: 'You got to have your mind to get on it. You can have a strong mind to get off it.'

Quentin: Born on his grandfather's farm in the Lower South, which later was sold, Quentin was a pre-teen when he moved with his family to a farm town within the same state at the center of an agricultural breadbasket [farming area where local economy depends on one or more agricultural crops]. From this town, he and his family migrated to the Northeast each summer, where his father arranged for the family and a few local men to return to the same farm. As a young man, Quentin later lived year-round on a labor camp owned by a large agro-producer (where Jay had lived with his step-father), and from there he moved to Agton. Quentin was at the high end of drugs initiated. All together by age 42, he had initiated twelve different drugs over a span of twelve years from age 15 to 27 . Unusual within my sample, most were initiated on-the-season.

Alcohol (age 15) and Marijuana (age 16): First drank alcohol with an age-mate at a sock-hop, several years after his family had moved to the farming town. Next time was a few weeks later. He recalls going from 'town to town' in the agricultural breadbasket to attend teen dances. He said he did not like the taste of beer, but continued with it, to which he added liquor and wine as he grew older. First smoked marijuana on a rainy day, when he and an older guy stayed dry in a car, 'I likèd the high. I got real high, ((inhale)) then I kind of leveled off.' He was close to high school graduation. Next time was that same evening. He said he never liked the smell, but later he smoked with his wife in their hometown; much later, they separated. 
Acid (age 17); Pills (age 18); THC (age 19); Mescaline (age 20): Angel Dust (age 21): Quentin tried a new drug each summer, when his family worked for a grower in the Northeast. Each drug of these five he obtained mostly from rural White youth.

Powder Cocaine (age 22); Free-Base (age 24); Heroin (age 25); Crack-Cocaine (age 27): First tried hard drugs, while working summers with his family. He and a buddy from the surrounding community would use in a nearby city. Crack was one drug Quentin continued, when he returned to home-base. He describes the crack high as 'automatic, explosive, devastating... It stuns you... Once you inhale that smoke, you are already high... The smoke, it has a sweet taste.'

Summer Time: Quentin was experienced with multiple drugs: 'Most drugs I just experimented. I didn't cling to them... I wouldn't mess with anything that made me do weird stuff or act strange... Some you just don't like the high... I liked drugs I could basically control.' It was a sense of control that gave Quentin an "edge-up." He wasn't irritable or frantic. Most his onset was limited to the summer. For acid, for example, he first took it Friday evening, because no one worked the weekend. Its twelve-hour high would have interfered. Next time was the following weekend and two times en route to Lower South. He took 'many kinds of pills,' especially Darvon. For THC (marijuana derivative), 'I likèd it.' Mescaline and angel dust were easy, given prior experience. He snorted powder cocaine with his girlfriend's brother off-season, after the season ended. Next time was a few days later; he used a few times, but stopped, because he did not like the "high." Despite having a wife in his home-base, his girlfriend (her family knew he was married) was one reason he chose to stay one summer off-season. After that stint in the Northeast, Quentin in later summers initiated three more drugs: smoked free-base on a pipe; snorted heroin but never injected or smoked it; shifted from freebase to crack. Because the girlfriend held a good job, the most she used was smoking reefer with her brother and Quentin.

Glow: Born in a nearby isolated community, Glow was adopted at age 9 by a family in Agton where she remained all her life. Raised with four sisters (two adopted), her adoptive father owned property, worked for the county, leased a grocery store, and built a boarding house where Glow lived when she was older. He was a licensed labor contractor. Glow avoided 'robbery gangs' and 'drug gangs,' she says, growing up. Once she was caught as a juvenile with a stolen car, having stayed on the scene, when two teens fled. Grounded for two months, she was restricted from the graduation dance. She worked in local packing plants, grading tomatoes and cucumbers. She never worked local fields, but spent summer with her family, when her father took crews to the Upper South. At age 24 she adopted a four-year-old boy and raised him with her two children.

Alcohol (age 14) and Powder Cocaine (age 15): First drank alcohol with a close friend. Glow and her friend broke into the liquor cabinet in her dad's home. They used a nail file to pick the lock, drank from a bottle (Canadian Club), replaced missing liquor with food coloring and water, and returned the bottle to the cabinet. A couple days later, her father went to give a drink to a visitor. Becoming curious, he poured from the bottle, smelled it and called his daughter. She told him she wasn't alone. This was the first time he spanked her. The next time she drank was ten years later. She first injected cocaine with the same friend. Taking cocaine by mouth she remembers the taste. She says she heard bells ringing. She tried 'shooting it' but stopped when her arm developed an abscess requiring a clinic visit, 'They 
had to dig down in there ' $n$ ' clean it out.' Her friend told her father they were using cocaine. He spoke to his daughter, telling her drugs were 'bad' and must never be a reason to abuse 'God's Cherubs.' He began giving her \$100 a month for expenses to keep from having to perform sex work or steal, which was common for those with drug habits in Agton. Glow never used marijuana, 'I don't like the smell of it....'

Crack-Cocaine (age 28): First smoked after she stopped traveling on-the-season. By this time she was the manager of the boarding house her family owned and her father was giving her an allowance. She was with a friend downtown at a store, when the friend mentioned "The Rock." They went back to the boarding house. The friend retrieved her drug pipe, 'I'm going to try it,' and Glow told her, "I'm scared of it." Her friend placed ashes atop a piece of aluminum foil, tied the foil around the pipe bowl with a rubber band. When finished, she offered Glow the pipe, 'You try it,' and she did, 'I pulled that smoke...I was scared what it was going to do to us, because my heart was beating real fast. I was thinking that I was going to die... I was seeing things... So I got scared... Awhile later I tried it again by myself. ((softly)) That's when I really started.'

God's Cherubs: One element that kept Glow from continuing drugs was her interest in children. She took care in raising her children and those living in the boarding house. Most the tenants, she says, were 'good people.' She fondly remembers Chalo, his wife and two children: 'I just lovèded her.' Sometimes she unknowingly rented to someone that sold drugs. One guy, 'He selling wide open... He had women up ' $n$ ' down the hallway. That's not good for children.' She put a lock on his door. Police came to say she couldn't do that. She removed the lock and later he left. To my question, she told me she couldn't tell the police what he was doing because 'I would get into trouble' (she herself was using, but secured from someone else). Not having 'a man' with her, she did not know what the tenant of the locked apartment might do. Most every story she told of drugs, she mentioned a mistake she had made or she brought "children" into the narrative... Once she was inside a local restaurant: 'I was seven months pregnant... A guy come in there with a shotgun, stood up in the door ' $n$ ' went to pumping ' $n$ ' shooting... I got to the back door ' $n$ ' fell down the steps... My baby survived.' (Shooter intended "to scare" people I later learned: No one was killed or injured) Another time she was walking with her child to the shower at the back of the boarding house, when a man accosted her, 'This guy threw this gun in my face ((mimics gun pointing straight ahead))... I told him, "Listen, if you going to kill me, do that, but not in front of my baby. Take my baby in there." ((inhale)) Then we recognized each other: he had been "talking" to a drug dealer behind the house. He say "I know you. We went to school together. I won't do anything if you take the baby ' $n$ ' go into the house." Again, the dilemma was resolved and no one got hurt. Her children remained safe.

\subsubsection{Mother figures in farm labor}

The next group of three persons performed farm labor with family in separate breadbaskets of the same state in the Middle South, as children and teenagers. None of these three ever migrated on-the-season. All their experience in agriculture came from mostly summer work that was locally available in the surrounding counties, which generally included perishable crops such as watermelon, tomatoes, cabbage and tobacco, among other crops. For all three 
individuals, their respective mother was the main person who assumed responsibility for both caretaking and raising her children, and for securing family work to earn a living. Mostly the work was farm labor. Although other family members lived in nearby towns or counties, each of the three family households was self-sufficient. In each instance, it was the mother who carefully instilled in her children an ethic for work, where the willingness to perform hard labor was expected to bring in sufficient money to survive.

Blake: Born and raised in the Middle South, Blake spent his early childhood on his maternal grandfather's farm, where he performed farm labor with other family members. Most the rest of his childhood he lived and worked in a large town near the farm. Family narrative tells how his grandfather and his brother "jumped a train" from a large farm in an adjoining state, and set-up a new homestead in the low-terrain at the edge of town. Blake left school in tenth grade, as he was caught for a home burglary, but later was sentenced for intent to sell marijuana at school. He spent 18 months in three youth camps. As an adult, Blake returned to local farm labor, and three months each in a grain factory and textile factory, in the local area, after working five years in tree trimming, two years in a hog plant (cutting the inner shank), nearly five years "drinking and drugging," which led to four years in prison for deadly assault, with two additional years on work release. He was working a year as jetoperator in a textile factory, before his interview in a treatment program where I met and spent time with him.

Alcohol (age 12): First drank with buddies with whom he regularly played pick-up basketball in the projects. From this first experience, he says, 'I been drinking every since.' He described his overall progression into drug use as, 'one drug was hand to hand with the next.' He continued to drink as an adult.

Acid (age 17-18): First and only time he used acid was at a youth skating ranch. His first use at a locale of sojourn was rare among men and women in my sample. He recalls the experience, 'Weird things I saw... People kept coming toward me.'

Marijuana (age 14); Powder Cocaine (age 20); and Crack-Cocaine (age 22): First smoked a joint with his cousins. Next time was with the same cousins two to three weeks later. After this, he generally smoked every weekend. First snorted cocaine with cousins, in The Bottom (name used in the South to refer to "lowlands"). Next time and only time thereafter that he used was one year later. First smoked crack with his cousins in 'a house full of people,' a month after he first had tried powder cocaine. He continued using crack for awhile, until he entered a residential drug treatment program in the Middle South.

Learning to Use: His favorite cousin told him, "'Man, try this, man, try this'." At the time Blake knew nothing of drugs, although where he lived they were common. 'I say, "What is that?" He say "Man." He lookéd all high 'n' wild.' He paused, 'See that's the thing about crack. I was curious, what it did, so I wanted to see what it would do ((chuckle)) so I did it.' Like frequent reports in the literature, Blake had to learn to use. 'I told him, "It ain't doing nothing for me." So he showed me-told me how to do it. He instructed me the first time. Because I blew it out. He say, "Man, that's not it".' Blake was having difficulty. 'I say "This ain't doing it for me." He said, "Cause you ain't doing it right." Then he showed me how to pull it through a pipe. It was different. It was like my, my head was ((pause)) like a little buzzing sound, like zzzzzzz. I was high. ((pause)) I felt-I don't know, like, ((pause)) I can't explain it. I never felt that way and I 
never felt that way again.' Next time he used crack was one week later with the same cousins. As he began to use regularly, he would buy crack on credit. He says that his family was too poor to loan money, even if he had asked his mother for the twenty dollars. He was working most the time, and generally used what he earned to pay for crack. Once, when he couldn't pay the seller, he left home to avoid getting his family into trouble.

Blake was close to most drug activity in his rural area. He had reflected on what it entailed, its effects on men and women, and difference between intra-personal violence from alcohol and inter-personal degradation from exchanging sexual services for crack. He reported that some crack house managers allowed one to buy and smoke inside, but for some who permitted "buys," one had to leave to smoke. He noticed over time that a prostitution house was less apt to get 'busted' than a crack house.

Pioneer: Born and raised in the Middle South, Pioneer spent his childhood in rural areas as the third child of seven siblings ( 5 boys, 2 girls). He was the only half-sibling. His mother had an affair. When his step-father found out he agreed to care for Pioneer. His family worked tobacco farms in the local area, and sometimes 'left at night' to another farm to leave debts they had accumulated. Their strategy was spend-again-owe-again: 'I out-ran my school records ((chuckle)). Before I get settled in, we moving to another place.' As an adult, he worked fifteen years as a school custodian, and later he started a company with a buddy, which they closed for lack of business. Living a mile from his mother's house, he and his wife built a small house with scrap lumber and later put a trailer on the property. Recently they built a larger house on the same property. He and his wife have two sons in their 20s, and he has a third son with another woman. Pioneer is among the few in my sample that demonstrate substantial evidence for social mobility through "settling-in" by establishing a household and supporting their family outside agriculture. He was among the unusual cases in that his wife visited him a couple of times while he was in treatment, where I interviewed him. I had the opportunity to meet and talk with her briefly (he introduced me).

Alcohol (age 16) and Alternatives to Alcohol (age 44): First drank beer with four classmates. They came to class "smelling like beer," so other students would know. Beer escalated to wine. He remembers his parents drank and fought. As an adult, Pioneer tried alcohol alternatives, 'Dominance by alcohol... It dominated me, real bad.' He once he drank his wife's cologne, and another time rubbing alcohol, for which he was taken to the hospital: 'I went into, uh, a dark hallway ((pause)) I could see a light. I could hear people screaming. I woke up; I heard somebody say, "We got a pulse".' He named drinking buddies: 'Andrew "Joe" Dover, overdose. Charles Bell, alcoholic, has seizures. Randall Watkins, got clean. And me, I'm an alcoholic.'

Marijuana (age 20): First time he smoked marijuana was with his cousin Yo-Yo in a barn: 'We sitting on a sack, just smoking dope. I felt so foolish, just watching airplanes go by ((chuckle) I'll never forget it.' They initially used on weekends but later he escalated to daily use when he was working as an apprentice brick layer. He last smoked marijuana three years ago.

MDA (age 26): First and only time he used MDA he had hooked-up one night with a young woman. He took Spanish-fly so that he could "perform like a regular super-stud." As a reward she gave him some MDA, which he used that one time. 
Crack-Cocaine (age 36): First smoked crack with a sex worker, at the time he lost his custodial job: 'I got a little hooked on crack--I met this girl... in Rhubarb, at a place called Sam's. This little-old ugly knotty-head girl kept walking by me, walking by me, she said, "First time I looked at you, 'Uh-Uh' ((Black approval)) I got to have you." I didn't know she was a crack-head 'n' she had to have it. One time she say, "Why don't you try it?" So I tried it. I got to looking forward to a hit. I made 300-something dollars a week. We get paid in cash. ((inhale)) I got to asking for 20 dollars when I get off work. That 20 dollars grew ' $n$ ' and grew ' $n$ ' grew. One day, I owed twelve dollars. So, I told my wife check machine broke down, I didn't get paid. Next week, I told her I got robbed. I'm really out there... Next week my wife told me plain, she said, "This week I need money in this house. Check machine did not break down ' $n$ ' if you try to get robbed, you better be a fast running son of a, ((chuckle)) bring money." So I, I held on pretty tight.' First equipment he used was a car antenna with Brillo in it, and tape around it. He later would borrow a glass pipe from a buddy. He stopped two years later, after a near-death experience.

Resilience through Birth: Main theme of interview was I was hated because I was Black, from the day I was born. 'My mama left my-my stepfather, ((inhale)) for my father [CR]. She left him for a few months. Then she-they got back together. So, before I was ((voice strained)) even born, I was hated. My mama told my step-daddy, she said, "I'm pregnant with [CR] baby." My step-dad, he a man, ((tap table)) he did the same thing with his niece. He got a child by her. He said "To-tomorrow morning, I'll go see [CR]." He said, "Listen, I understand you got my wife in trouble." I wasn't born. He said, "We'll take care of the child." ((tap table)) Said he'd take care of' me. [CR] said "Yeah." That [CR] he left the same day, ((chuckle)) moved to the East Coast. 'I seen my father three times ((voice strained)) in my life. First time he gave me a pint of liquor. Second time he gave me a fifth. Third time I saw him, we went to look at a tract of land; he said he'd get me some money from that. Only thing he wanted me to do was drive for him. He called me, ((pause)) maybe, six, seven years ago. Said something to me that I got so mad I could have, bit a dog in two. He said, 'I'm in a bind." "What kind of bind you in?" He said, "I need somewhere to stay." I said, "What?" He said, "I'd like to stay with you for a few months." I said, "He-ll-ll NO. You left me to starve." \{You talked to your mom about this?\} She was dominated by my step-dad ((pause)) She always tried to show a little love. ((inhale)) \{She recognized it?\} Yeah. Sunday dinner she'd give me the biggest piece of chicken. She recognized hurt inside me. She came to me many days: "I'm so sorry" ((pause) "I'm so sorry he's not your father." I was hated since the day I was born, cause of my skin color ((tap on table)) Rest my brothers and sisters looked like that door ((points - light tan)) maybe darker. Then God popped a red baby' ((chuckle)) That's me!

Cal: Born in the Middle South, Cal spent his entire life, all 49 years, in his home state. One of four siblings ( 3 boys, one girl), his activities fluctuated between a small home community and the state capital. As children, guided by their mother, he and his siblings performed farm labor: 'That's how we got school clothes... They wouldn't give Momma child support.' Starting his senior year in high school Cal worked eight jobs (school custodian, farmer's market, fast food server, and cologne factory, among others), before he returned to tobacco work. His first two drugs he initiated in his hometown, the third in the capital.

Alcohol (age 16): First drank alcohol at a club, next time was two weeks later at the same club: 'I didn't like it at first. That hangover it was just something else.' He drank to bolster 
courage: 'With it I could talk; I could be more myself. Otherwise I was sitting over in the corner, half-way scared to talk...' For awhile he would drink heavily for two to three days and stop two to three days, before he slowed down and drank less often.

Marijuana (age 17): First smoked reefer in a hang-out at the edge of town called The Den. Cal says, 'It was a trip the first one I had. My eyes were red and laser-looking.' Unable to hide the appetite he suddenly acquired, when he arrived home, his mother scolded him ((shifts register)), "Boy, you better quit smoking that damn stuff, causing you eat up everything." He explained with affection in his regular voice, 'My momma, she down to earth.' At The Den he was taught to draw on a joint: 'It burned my lungs. Then you do that coughing. I don't inhale it that long... They want you to hold it in awhile.'

Crack-Cocaine (age 22): First smoked crack while living in a cooperative house in the state capital. Initially he was the only one among its occupants who did not use but one day he tried it. Next time was the next day.

Not Asked, He Told: Despite a small drug repertoire (three), Cal initiated each drug with a distinct group of people: strangers in a public setting at local clubs (alcohol); cousins, public to family, private to outside world (marijuana); and housemates in a private setting (crack). His growing awareness that alcohol gave him courage became useful in one club when he reached age 21: 'It built up -- I'm sure they figured that I WAS. But--they would ask me this ' $n$ ' that. I'd play it off, "No-o, I ain't like that." Or I might go over to talk to a girl, just to try throw them off. But, deep down inside, I wanted to come out ((pause)) I finally did: I got drunk ((chuckle)) of course you say things you wouldn't say sober. So I had to deal with what I had said the nights before about, "No, not me" ((pause)) But it felt so-o-o good, telling it drunk. It did. I-I can remember, it was real ((pause)) It felt good because, they were not expecting me to say that I was gay.'

\subsubsection{Farm workers who left farm labor}

Next group of three persons had experience in farm labor as children and teens, but to a lesser extent as adults. After a father left, each respective mother was a key person in arranging local farm work from a breadbasket of the Lower South. Most the migratory work that each of the three had performed while younger, they arranged themselves while still an adolescent. Each of the three cases is unusual owing to circumstances that two individuals currently are on disability, and the third was injured, but never qualified for disability. Each left farm labor but not drugs or alcohol, as they moved into adulthood.

Lebat: Born in the Lower South, Lebat was youngest of four siblings (2 girls, 2 boys). He spent his youth in a boarding house run by his mother in a medium-sized city in one state, older adolescence in a small city in a second state, and adult years in Agton. For a brief time he and three older siblings lived with his mother's sister, when his mother moved to the county adjacent to Agton, where she worked in farm labor. As a pre-teen, Lebat migrated with his mother "on-the-season." By age 14, he was migrating as an emancipated teen on his own but returning each winter to stay with family. He migrated summers and regularly shuttled (commuted) back and forth between Agton and his home-base during winter. He migrated on-the-season until age 26 (total of fifteen years) and continued to travel by work bus as a seasonal agricultural worker to Agton, until age 37, when he settled in Agton. All 
told, he worked a total 23 years in agriculture. In Agton he later worked in packing plants and, later, as a warehouse watchman. Recently he was approved for diabetes disability. $\mathrm{He}$ used his one-time allowance to pay several debts and to purchase a bicycle for himself; the farm town is permissive on bicycles around the town, especially for those who cannot afford a motor vehicle or those who no longer have a driver's license.

Moonshine (age 10): First drank 'corn liquor' with his older brother in the boarding house operated by his mother. He called it a 'bootleg house' because his mother sold moonshine. He and his brother continued 'sneaking ' $n$ ' drinking' after that first time. More than once their mother spent time in jail. Then 'the law fell' where they were living and she fled that state to her hometown in the adjoining state, where she stayed with her brother. She left her children with her sister. She later re-married and moved to a third state. She settled in Tangelo, in the county next to Agton, and sent for her children. As a child, Lebat remembers returning from the season with his mother, and going to the town jail to bail-out his stepfather, who drank while his wife and her son worked on-the-season. Lebat says he was sentenced to two days in jail only once for public intoxication.

Marijuana (age 21): First smoked with a co-worker when offered a reefer, working in Agton, after several years of commuting from/to his home-base. He described the practice of smoking reefer: 'Buy a bag, load it up ' $n$ ' hit it. Might get some beer, some wine, drink that ' $n$ ' get high... Look like you float.' He smoked three years after that first time, but later decreased his use to emphasize alcoholic beverages.

Reefer Sadness: Lebat lived in his mother's home-base in a county adjacent to Agton where he regularly worked in the fields. He came on a work bus, 'People use to come o'er here all the time on those busses.' Lebat never came, except to work. He explained how during the day time, two Black policemen, the first in Agton, kept people from the streets, 'You had to be out there, doing a job, picking cucumbers or whatever.' One time, he came with his older brother, five years before he tried marijuana. Lebat was sixteen. His older brother drove Lebat and two others. They were sitting in a car on a side street: 'Local cop rolled-up on us, "You-all boys must have had fun" ((chuckle)) "No," we told him, "We're from Tangelo." “Well, y'all can't be sitting around here. Better get back to Tangelo." \{This was Derek Bonner?\} I remember it was Sam Horace, "Get your butts outta here." Years back we couldn't walk the street.' His brother liked the first state, where the family had lived, and he returned home after one month. He never came back to visit his family in the third state. As he grew older, Lebat sometimes stayed overnight in Agton and came home late the next day, having worked two days in the field. After seven years of commuting between Agton and his home-base, one day he was offered a reefer cigarette after work, which he accepted, 'I was drunk... A guy gave me my first hit on that stuff. I said "Man, oh man, that's good".' He was one of the few individuals in my sample to choose something new, while on the effects of another drug ('drunk'). Most everyone, even those at the high end of use, tried a new drug, while in a normative state. Only when someone had already been using, they would poly-use two already-familiar drugs (Bletzer, 2009).

Kevin: Born and raised in the Lower South, Kevin was the second youngest of five boys and two girls. He and two sisters were raised by his grandmother in a town less than a thousand residents, except for a year he lived with his mother's sister in a nearby city. After 
completing high school, he moved to Agton, where his older brother and mother had been living and performing farm labor. He spent ten years in the fields (cucumbers, tomatoes and peppers) but mostly he worked in packing plants. Age 27 he severed hand ligaments the first week he was on a new job. When he went for compensation, they denied his claim, giving the reason he had not worked long enough for the company. After that, he was limited to odd jobs through the labor pool. At the time of interview, he was working occasional jobs and staying in boarding houses.

Crack-Cocaine (age 24): First smoked crack with three people; he remembers his 'heart pump fast.' Next time was four days later with four individuals behind a dance club in downtown Agton: 'The stem you put it to your mouth 'n' ((draws breath))' he mimicked with his right index finger and thumb close to his mouth, as he held an imaginary mouth piece. 'You just smoke it; smoke it like that 'n the smoke come, let it get you high ' $n$ ' just blow the smoke back out. It was a real high ... My heart pumped. You ready to go. You be on the move.' He began using most every day, once or twice, with people he knew.

Marijuana (age 26) and Alcohol (age 27): First smoked marijuana by himself, having bought a small bag of reefer $(\$ 10)$ and cigarette papers $(\$ 1.50)$. He rolled it the way he had watched others do and he smoked it behind Sam's Tavern [where I often conducted observations several years later]: 'I knew about how you roll it up ' $n$ ' start smoking, like you would smoke a cigarette. I had seen other people do it.' Shortly after marijuana, he stole a pint of wine from a store, which he drank alone: 'I used to see the people drinking Budweiser ' $n$ ' Miller in a bottle. I just thought I would start drinking Thunderbolt Wine.'

Sheltered: Raised by a single mother who did farm labor, Kevin's childhood was similar to many African American men in my sample. Mothers often did local farm labor with their children, but they left children, sometimes, with relatives and migrated. At age 18 Kevin moved to Agton, where his mother had been living. Age 21, he visited his father in the Northeast. For one year he lived with a woman in another town. On these two events, Kevin says, 'That's all the traveling I done.' After several years in Agton, crack was the first drug he ever used. Like most everyone in the sample, onset occurred once he had lived some time in his new home-base. Unlike the others, his first drug was crack, which he followed with marijuana and alcohol, age 25. He used these two drugs in Agton after leaving a woman with whom he had lived in another city. To my question, he said he would use one or all three drugs between two in the afternoon to midnight, outdoors, with a group of a few individuals behind a building, downtown. Kevin recognized his lifestyle had changed once he came to Agton. He told me that when he was growing up, 'I never did nothing like that.'

Wesley: Born and raised in the Lower South, Wesley was the oldest of five siblings (2 girls, 2 step-sisters, himself). He and his sisters spent summers with their mother performing farm labor within the local breadbasket. At age three, his father left to return to a home community, leaving his mother with three children. Age seven, he learned to harvest cotton and hang tobacco in curing barns; age 12 he learned to crop tobacco. At age 15 he learned "to bump" watermelon (load onto trucks). Age 16 he worked at a local sawmill until he graduated. He attended a segregated grammar school and middle school, and played basketball at an integrated high school. One summer he and his sister, one year younger, visited a maternal aunt in Agton. When Wesley graduated, he moved to town to marry the women he was dating; his sister married her cousin. He helped his aunt with her juke-joint 
and went to local clubs, before his brother-in-law found him a county job that he held for more than a decade, which was unusual for anyone in my sample. Nine years before his interview, he was fired.

Alcohol (age 15) and Marijuana (age 16): Wesley first drank with classmates from high school. He never drank much in his hometown or in Agton. He first smoked reefer with teammates from the basketball team, 'We was riding in a car; just seem like it were hot ' $n$ ' sweaty ' $n$ ' it felt different, made you laugh, mellow like.' Next time was a few days later, with teammates.

Crack-Cocaine (age 34): First smoked crack with two co-workers from the county job; both were previous users. 'I got a rush the first time... That first hit you feel it. Later you spend $\$ 20$ or $\$ 30$, you don't feel it. It's a waste of money. You want more ' $n$ ' more ' $n$ ' more.' Next time was three years later, when his son died. He likens 'craving for crack' to 'craving a cigarette.'

Turnaround: After Wesley married, he and his wife earned good money. Each owned a car and drove to work. Later they had a son that died at age 3: 'He wasn't sick. Went to the ice cream truck; when he came back he fell down. It turned my life around.' That same week, Wesley began to deal marijuana. After buying a pound, he smoked a little and re-sold the rest. He partnered with a man who 'knew about selling' and wanted to take-over. Shortly Wesley tried to get out. He was 'scared of police' and 'smoking up the product.' To my question, he estimated (based on a full-time county job) that it would take three or four weeks to sell six ounces. When things got difficult with the loss of his son, Wesley went to a spiritual healer and was told his drug partner was doing 'root magic' against him. Shortly, he lost his job (reprimands for late lunches) and his car, and was jailed for driving without a license. While in jail, his wife divorced him and moved to her home county. Wesley had developed contacts for marijuana and the spiritual healer, because he traveled on his job. He had a rare opportunity to build a resource network, unlike men in farm labor living in Agton who traveled seasonally. These men mostly spent time with other workers. His turn to crack followed his son's death, 'I thought it would help, but it didn't.' He credits his family for insistence that he stop using. Primarily, it was his mother: 'Who else?' he says. At the time of his two interviews, four months apart, he was on medication. We first met, six years earlier when I first came to Agton for the team research project. Shortly thereafter he further reduced his use through counseling with a community program, which since then had to close its doors, owing to reduced funding.

\section{Seasonal drug use in farm labor}

Farm workers take pride in their work. They gain prestige among peers for physical prowess and stamina, as workers, and a sense of self-respect for earnings (however low or infrequent) by which they live independently. Much like migrant workers who take the view that hard work is the means to assure a sufficient income for at least the basic necessities (Cravey, 2005; Gomberg-Muñoz, 2010), even agricultural workers who use drugs and alcohol communicate in self-disclosures a sense of pride in living independently. They recognize the hardships they have faced and most likely will continue to face as laborers, whether they work in agriculture or secure other employment. They can recite details from events in their lives that led to where they are at 
present, occasions when life was going smoothly and there were fewer worries, and those periods when nothing seemed to fall into place or fit how they felt about life, owing to escalated use that took them from meaningful social relationships (Adams, 2008). Specifically, attitudes toward work are reflected in decreasing drug use for summer labor and increased use for winter labor, which for most workers takes place in their home-base where drugs and alcohol are found more easily (Figure 4).

\section{Drug Use and Farm Labor Days Used Past Month, by Season}

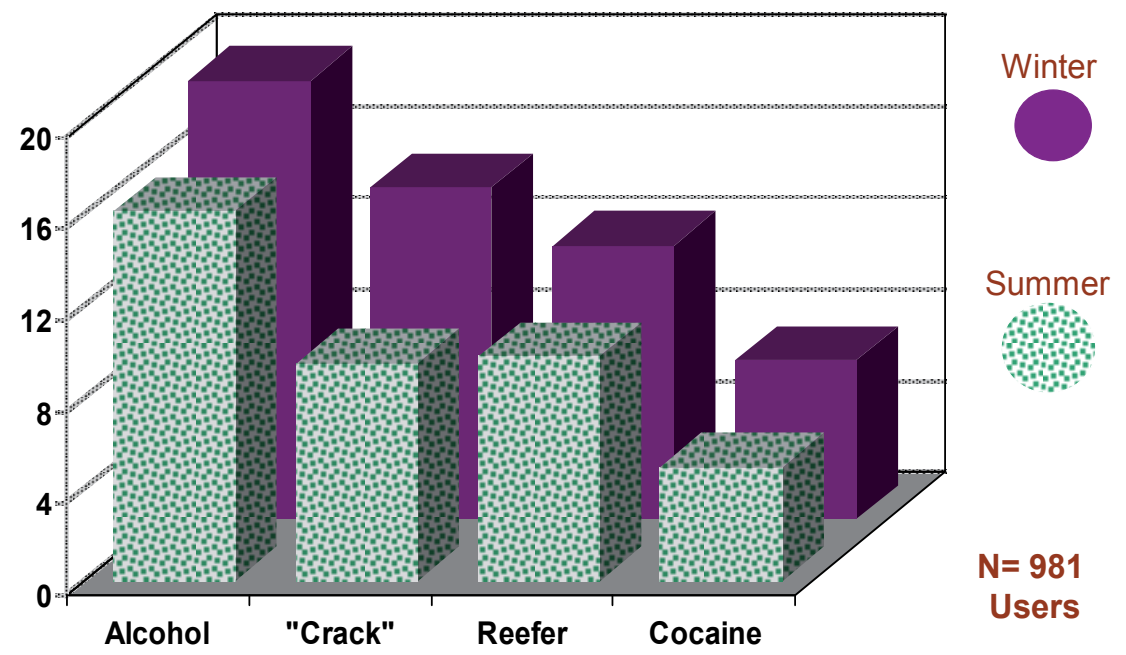

Fig. 4. Comparison of four prevalent drugs according to winter or summer seasons

\section{Conclusion}

Ethnography over the first decade of the 21st Century allows for collection of field data from groups of people increasingly more divergent than decades past. If the interest is drug-using agricultural workers, as indicated in this essay, ethnography provides the methodology to conduct field research to better understand their lives and the difficulties they experience that might not be possible through other methods. Ethnography provides a unique methodology to secure personal narratives that describe the implications of generalized research findings. The basic requirements of ethnography are listed in Figure 5 (below).

Drug use continues to be a concern for people of all backgrounds (Marez, 2004). Farm workers can provide new insights into drug and alcohol use, where traditional assumptions about use, recovery and relapse are based on individuals typically fixed-in-space. That is, these study populations live in the same communities over many years. Some might move from city to city, but not as frequently as the mobility experienced by farm workers. Field data from farm labor portray a different side of drug and alcohol use that takes place as a time-filler when individuals are not working, a means of physical restoration through analgesic applications, and relief from work-demand stresses they face in performing farm labor (Bletzer, 2009). 


\section{Essentials of Ethnography}

Ethnography requires

that people under study give their informed consent

ongoing contact, inter-personal relations with key people in the field

flexibility for unforeseen events within a local area

workable role identity that fits local understanding of why the fieldworker is present

readiness for the collection of singleevent in one locale as well as multisited data across several sites
Ethnography can

generate both qualitative and quantitative data

vary in time periods needed to collect essential field data

incorporate clinical procedures and/or surveys

include multiple investigators working on one project and/or indude multiple sites or studies

take place in one's own society, with one's own people or community, using one's own language

Fig. 5. Parameters that fieldwork should have to be ethnography

\section{References}

Adams, P. J. (2008). Fragmented Intimacy: Addiction in a Social World. New York, NY: Springer Science \& Business Media.

Appadurai, A. (1991). Global ethnoscapes: Notes and queries for a transnational anthropology. In: Recapturing Anthropology: Working in the Present. R. G. Fox (Ed.), pp. 191-210. Santa Fe, NM: School of American Research Press.

Banks, L. W. (2008). The Chiricahua Corridor. Tucson Weekly, Vol. 25, Issue 29, pp. 20, 22, 2425 (September 11-17).

Bletzer, K. V. (2004). Open towns and manipulated indebtedness among agricultural workers in the New South. American Ethnologist, Vol. 31, No. 4, pp. 530-551.

Bletzer, K. V. (2009). Modulation of drug use in southern farming communities: Social origins of poly-use. Human Organization, Vol. 68, No. 3, pp. 340-349.

Bletzer, K. V. (2010). Modification of social identity in experience-toughened trans-migrant agricultural workers. Open Anthropology Journal, Vol. 3, pp 114-123.

Chavez, L. R. (1992). Shadowed Lives: Undocumented Immigrants in American Society. New York, NY: Holt, Rinehard \& Winston.

Conover, T. (1987). Coyotes: A Journey Through the Secret World of America's Illegal Aliens. New York, NY: Vintage Press.

Cravey, A. J. (2005). Desire, work and trans-national identity. Ethnography, Vol. 6, No. 3, pp. 357-383.

Davis, M. P. (1990). Mexican Voices, American Dreams: An Oral History of Mexican Immigrants to the United States. New York, NY: Henry Holt and Company.

Department of Labor. (2000). National Agricultural Worker Survey (online). Washington, DC.

Du Bry, T. (2007). Immigrants, Settlers, and Laborers: The Socioeconomic Transformation of a Farming Community. New York, NY: LFB Scholarly Publishing LLC. 
Fan, D. P., \& Holway, W. B. (1994). Media coverage of cocaine and its impact on usage patterns. International Journal of Public Opinion Research, Vol. 6, pp. 139-162.

Fleisher, M. S. (1995). Beggars and Thieves: Lives of Urban Street Criminals. Madison, WI: University of Wisconsin Press.

Gamburd, M. R. (2008). Breaking the Ashes: The Culture of Illicit Liquor in Sri Lanka. Ithaca, NY: Cornell University Press.

Gomberg-Muñoz, R. (2010). Willing to work: Agency and vulnerability in an undocumented immigrant network. American Anthropologist, Vol. 112, No. 2, pp. 295-307.

Goss, J. (1985). A new, purified form of cocaine causes alarm as abuse increases. New York Times, Vol. 135, No. 46608, pp. A1, B6 (November 29).

Griffith, D., \& Kissam, E. (1995). Working Poor: Farm workers in the United States. Philadelphia, PA: Temple University Press.

Heppel, M. L. (1982). Harvesting the Crops of Others: Migrant Farm Labor on the Eastern Shore of Virginia. Unpublished doctoral dissertation, American University, Washington DC.

Heppel, M. L., \& Amendola, S. L. (1992). Immigration Reform and Perishable Crop Agriculture. New York, NY: University Press.

Hondagneu-Sotelo, P. (1994). Gendered Transitions: Mexican Experiences of Immigration. Berkeley, CA: University of California Press.

Jankowiak, W., \& Bradburd, D., (Eds.). (2003). Drugs, Labor, and Colonial Expansion. Tucson, AZ: University of Arizona Press.

Kilborn, P. T. (1989). Drugs and debt: Shackles of migrant workers. New York Times (October 31), pp. A1, D23.

Limón, J. E. (1994). Dancing with the Devil: Society and Cultural Poetics in Mexican and American South Texas. Madison, WI: University of Wisconsin Press.

Marez, C. (2004). Drug Wars: The Political Economy of Narcotics. Minneapolis, MN: University of Minnesota Press.

Martínez, O. J. (2006). Troublesome Border. Revised Edition. Tucson, AZ: University of Arizona Press.

Mitchell, T. (2004). Intoxicated Identities: Alcohol's Power in Mexican History and Culture. New York, NY: Routledge.

Musto, D. F. (1999). The American Disease: Origins of Narcotic Control. Third Edition. New York, NY: Oxford University Press. (First published 1973)

Palerm, J. V. (1992). A season in the life of a migrant farm worker. Western Journal of Medicine, Vol. 157, pp. 362-366.

Pettiway, L. E. (1996). Honey, Honey, Miss Thang: Being Black and Gay on the Streets. Philadelphia, PA: Temple University Press.

Raab, S. (1984). The new addicts. New York Times, Vol. 133, Nos. 46,050-46,053 (May 20-23).

Rothenberg, D. (1998). With These Hands: The Hidden World of Migrant Farm Workers Today. New York, NY: Harcourt Brace.

Sutter, A. G. (1966). The world of the righteous dope fiend. Issues in Criminology, Vol. 2, pp. 177-222.

Tolnay, S. E. (1999). The Bottom Rung: African American Family Life on Southern Farms. Urbana, IL: University of Illinois Press.

Valle, I. (1994). Fields of Toil: A Migrant Family's Journey. Pullman, WA: Washington State University Press. 
Vander Staay, S. (1992). Street Lives: An Oral History of Homeless Americans. Philadelphia, PA: New Society Publishers.

Vélez-Ibáñez, C. G. (1997). Border Visions: Mexican Cultures of the Southwest United States. Tucson, AZ: University of Arizona Press.

Whiteford, L. M. (1980). Mexican American women as innovators. In: Twice a Minority: Mexican American Women. M. B. Melville, Ed. pp. 109-126. St Louis, MO: C. V. Mosby Company.

Whiteford, L. M. (1979). Family relations in Seco County, a case study of social change. Unpublished doctoral dissertation, University of Wisconsin-Milwaukee, Milwaukee, WI.

Zabin, C., Kearney, M., Garcia, A., Runsten, D., \& Nagengast, C. (1993). Mixtec migrants in California agriculture: A new cycle of poverty. Davis, CA: California Institute for Rural Studies. 


\title{
Syntax Development: The Relevance of Realistic Methods
}

\author{
Maria Luisa Silva \\ Centro Interdisciplinario de Investigación en \\ Psicología y Matemática Experimental - CONICET \\ Argentina
}

\section{Introduction}

Usually syntax developmental studies explore how far (or near) child's linguistic structures are from adults' grammatical forms or which are the differences between child's and adult's comprehension of some grammatical usages. Almost all of these studies share the same underlying (and very strong) assumption: adult grammar is a kind of formal system with different and clear cutting categories and these forms have univocal and not context dependent relationships with their meanings.

Although this perspective has provided our present knowledge about how children acquire their language and the syntactic development processes involved, it was undersupplied for explaining particular trends of syntactic development (i.e. on non -western languages, on poor communities, etc.). Nowadays we believe that is needed to reach a new horizon developing a new, richer and more complex, interdisciplinary approach to the development of syntactic processes.

In that sense we have to take into account that children lives always in a cultural world: they participate in daily communities activities, share different customs and meanings with adults and peers and in these contexts children negotiate with them, and sometimes introduce, through using symbolic system, their own cultural perspective about events and people. So, they are not only learners on social groups but they are also active participants of their groups. Sometimes very young children, at 2 or 3 years old have a fine grained knowledge about how some behaviors are appropriate and relevant (or not) to different activities. Also, because they are group members that could participate from very young in, at least, the life of two social environment routines (i.e. community and schooling settings) they have take into account the differences between them on language performance demands and their relationship with the context of use and role demands. So they, from the beginning, are not only language users they are also community members that, in some sense, can think about how their language uses could change if the context or other constraints require that usage changes. In that sense syntactic resources are a set of specific procedures which allow language changes.

So, if we try to understand how children instantiate and develop a particular set of features of a symbolic system, i. e. syntactic procedures, when they are becoming an adult member of a 
social group, we could realize that the results of traditional syntactic studies have some limitations. As it has been noticed by some other scholars before, some of these limitations are:

1. Understanding child's grammar as a system that may be explained according to a subsidiary relationship with one more stable and autonomous stage: adult's grammar. On this assumption underlies a "maturity" perspective, so child grammar is considered always as an incomplete (or deficient) system (i.e Chomsky, 1975; Correa, 1982; Solana, 1997).

2. Describing grammar forms by emphasizing the relevance of syntactic/formal aspect, taking for granted how symbolization and syntax, as a part of symbolization process, are been affected by interactional, situational or historical parameters (i.e Echeverria, $1976 ; 1978)$.

3. Establishing child grammar stages based on the presence (or to the absence) of some linguistics structures or features (i.e Gili Gaya, 1972; Alarcos Llorach, 1976; Solana, 1997; Mugica \& Solana, 1999).

4. Considering grammar usages as a set of fixed and inalterable forms (i.e Gili Gaya, 1972; Alarcos Llorach, 1976; Solana, 1997; Mugica \& Solana, 1999).

Syntax developmental studies conclude (or suppose) that child usages are, in some instance, deficient usages compared with adults' ones; and, due to this perspective, researchers can't understand the broad amount of grammatical resources that children have and could use, according to the different situations.

Although these arguments have been noticed before (Lust, Lynn \& Foley, 1996; Nelson, 1996) questioning the "formal" view is a work far-reaching yet.

In this chapter we will analyze how the tighten relationship between the "formal emphasis" and experimental methods have conformed our nowadays particular view of syntactic developmental processes. Then we will mention how a different theoretical and empirical perspective, Cognitive-Functional paradigm, can contribute to expand this comprehension. In fact Cognitive Linguistics (Langacker, 1987; Lakoff, 1987) Grammaticalization Theory (Hopper, 1998) and Language Usage Model (Tomasello, 2001; 2003) trough criticizing the traditional notion of grammar model which allows to reach a more deep comprehension of different human symbolic usages, language uses between them.

This new research paradigm studies language considering language uses as epiphenomena of conceptualization, so grammar is always seen as an unstable system, in constant movement and tension. Even when grammar is always unstable, speakers and hearers prefers language over other symbolic systems because the frequent use of some forms make them as conventional uses; in fact a great amount of our everyday language uses are "sedimentation" ones and, by this fact, language allows that speakers and hearers reach mutual understanding in most economical way. In contrast with the chomskyan assumption considering grammar as an a-priori formal system, for Cognitive- Functional Perspective grammar is an "emergent structure": signs are provisional, context-bounding or bounding to other usages shared (or evoked or presupposed) by speaker and hearer (Hopper, 1998).

From this perspective when we study syntactic development processes, we start looking for and describing all the forms that could have same functional features, in a second instance we have to explain their formal structure and/or the meaning differences and, then, we postulate 
different routines, grammaticalization processes (Hopper, 1998; Wierzbicka, 1988), that instantiate psychological or social motivations that could explain why we found these differences. In that sense, Cognitive- Functional Perspective assumes that there is a tighten relationship between descriptive and explanatory phases because both explain human behaviors and, when we study human phenomena, we try to "discover" how interact human cognitive constraints with the particular individual, social, cultural, environmental circumstances and experiences (Rosch, 1978; Rosch, Thompson \& Varela, 1993; Nelson, 1996).

Cognitive Functional Perspective requires a coherent methodological approach, one of these requirements is considering and describing in a fine grained way functional language uses. But, to this end, it is necessary to have representative corpora of natural linguistics uses, obtained from spontaneous speaking or produced at so called "real" communicative exchanges. This kind of data allows us to preserve many aspects that form the complex dimension of behavior phenomena (Diver, 1995; Haiman, 1994).

Ethnographic studies have provided clear and rigorous methodological set of criteria considering setting features, context and human performance relationship (Auer \& Luzio, 1997; Silverstein, 1976). In this sense a lot of developmental studies have used Conversational Analysis tools and made a relevant contribution to reach a deep comprehension of child development (i.e. Gardner \& Forrester, 2010). Nevertheless this analytical perspective was taken for granted in syntactic developmental researches, because, although with this tool we can comprehend how a same child manage different syntactic resources - a "lower" and an " upper " syntactic developmental form - according to the context demands, these studies are considered only as "analysis of cases" and don't respond to traditional requirements of syntactic developmental studies (i.e. reliability, opportunity to replication, etc.).

In contrast, results obtained in recent Spanish syntactic developmental researches (Silva, 2002; 2008; 2010a) demonstrate that it's possible to obtain a new more dynamical view about syntactic language development not only following Cognitive Functional Perspective theoretical assumptions but also obtaining data by a new methodological tool that includes contributions from Etnomethodology perspective: Semi Structured Interview. This methodological tool is a data eliciting technique that allows to obtain relevant child syntactical performance data preserving most of the conditions that regulate real conversational exchanges.

After introducing Semi Structured Interview methodological guidelines, we will present our own researches' results that compare and analyze syntactic developmental processes in Spanish speaking children between 4 and 7 years old. In these studies we have considered linguistic, discursive, cognitive and interactional processes observed when children use Relative Clauses (Rcs.).

We find that different forms of Rcs. coexist at a same age and that they have different contexts of usage and discursive functions. These results have very few points of coincidence with results obtained previously in experimental studies (Gili Gaya, 1972; Solana, 1996; 1997; Múgica \& Solana, 1999; Jacubowicz, 1986; 1996). We believe that the particular eliciting technique allowed us to identify better the tighten interrelationship between child syntactic forms uses and other discursive competence factors, such as Media Length Utterance, or Discursive Contexts of appearance, so we could appreciate in a more fine grained view the relationship between syntax development and language demands posed by some cultural, social or contextual circumstances. 


\section{Syntactic development studies: A constant tension between theoretical assumptions, methodological resources and child discourse uses}

Traditional methodology on child syntactic development studies consists on comparing child syntactic uses with its more likely similar adult form. Syntactic development researchers use to pick up and analyze some child usages considering that, in some way, these unstable forms are "deviant" and/or "corrupted" and that grammatical/ adult forms are "hidden" - in them and, by a maturation process, child would access to a static/ grammatical adult form.

In few words child usages are, by definition, deficit usages and adult uses are complete and stable ones; it is the perspective that has been called "Maturation Perspective" (Borer \& Wexler, 1987). In this sense Solana (1997), analyzing differences observed within child oral and written Relative Clauses (Rcs.), minimizes them by falling back to Maturation Hypothesis "cuando investigamos el conocimiento del lenguaje infantil,[...] no solo el conocimiento específico de las relativas sino también de los principios y parámetros que se ponen en juego, la distinción oralidad/ escritura entra en la determinación del objeto como la variable fundamental, pero no puede decirse que haya dos sistemas completamente distintos [...] sino diferencias respecto de la frecuencia de aparición, de la elección de encabezador, de la complejidad de la construcción sintáctica en particular. [...] pareciera ser más lógico encontrar la explicación del orden de adquisición de estructuras dentro de la hipótesis de la maduración, los niños adquieren unas estructuras después de otras (en este caso unas relativas después de otras) no porque los datos se den asi escalonados sino porque maduran ciertas habilidades lingüísticas" 1 (Solana, 1997: 314)

In this kind of analysis researchers isolate and "cut", within child discourse, some particular and interesting phenomena. This methodological procedure implies that researchers try to "freeze" child syntactic competence and believe that child syntactic uses are, such other language uses, monolithic and static. But, really, this assumption is only an illusion.

Let's go to observe an example of how traditional analysis cuts, isolates and "freeze" child syntactic competence. Magali is a 4,5 years old Argentinean little girl living in a Media Class home in Buenos Aires city. She has attended at kinder from 2,3 years old and speaks Spanish in her monolingual home.

At 3,8 she used the irregular verb / poner/ (to put on) in different contexts, referring to actions performed by different agents.

At age of 4 she is realizing the different irregularities for this verb in past tense, but for the same grammatical adult target form / puse/, she uses two alternative forms: /pusí/ and /poní/. Magali uses two different forms expressing the same grammatical/ conceptual

${ }^{1}$ When we study child language knowledge, [...] not only particular child Relative Clauses knowledge but also Principles and Parameters Knowledge posed, oral and written differences go into epistemological object characterization as an essential variable, but we cannot believe that there would be two wholly different systems [...]there are differences on frequency of occurrences, about relative header choosing, about syntactic construction complexity[..] so it would seem more logical to look for an explanation about structural order acquisition within Maturation Hypothesis, it is that children acquire some structures after others (in this case some Relative Clauses after others) not because data appear in such way, staged, but because some [different] language skills mature at this time. (The translation is our). 
meaning: $1^{\text {st }}$ person + Simple Past + Punctual Action, but very soon she also uses the adequate, normal and expected adult target grammatical form: / puse/.

\begin{tabular}{|c|c|}
\hline Child utterance & Adult-like form \\
\hline /Pono esto aí?/ & /Pongo esto ai?/ \\
\hline Put (Reg.) $1^{\text {st }}$ sg. Pres. this Masc. there Int. & Put. (Irr.) $1^{\text {st }}$ sg. Pres. This Masc. There Int. \\
\hline \multicolumn{2}{|c|}{ Do I put this there? } \\
\hline /Mami, Lupe me puso ete collar! & Mami, Lupe me puso este collar? Te gusta? \\
\hline \multicolumn{2}{|c|}{ Mom, Lupe OD Put (Irr.) 3 3rd. Sg. Past this necklace! } \\
\hline Mom, Li & to me this neckle! \\
\hline
\end{tabular}

Despite the fact that she uses more often "inadequate" forms than the adequate one, the question is: why she uses in some context / poní/ and in other circumstances /pusí/? It is only at chance choice or we can find a pattern?

At first we can appreciate that Magali inadequate forms derive from two different roots of "poner" conjugation forms.

\begin{tabular}{|c|c|}
\hline Poní & Pusí \\
\hline Poner & Puse \\
\hline Pongo & Pusimos \\
\hline Ponemos & Pusiste \\
\hline
\end{tabular}

In fact / Pon-/ is the regular root and /Pus-/ the irregular one (irregular forms are $41 \%$ of all conjugation forms).

Second, we can see that both forms share the same ending stressed vowel /í/. It is possible to think that this ending indicates that the girl is starting with the process of taking out regularities from a set of words (Tomasello, 2001) and she is inferring from this set some grammatical features. In fact, verbs with infinitive ending in "er" or "ir" have final stressed vowel / 1 / expressing 1 st person and punctual action.

Comer: Yo comí (To eat: I ate)

Ver: Yo ví (To see: I saw)

Sentir: Yo sentí (To feel: I felt)

So, we can assume that Magali can identify some aspects of / poner/ verbal conjugation.

But, why does she alternate the use of / pusí/ with / poní/?

The answer of this question comes from analyzing in detail these usages within the context of two interactional exchanges

The girl at 3.8 years old is starting to dress by her own: closes her door room and then she shows her mother the clothes that had pickup to dress. ${ }^{2}$

Mom: ¿Te pusiste e::sO:::?3

${ }^{2}$ The symbols follow Jefferson (2004)

${ }^{3}$ Translation

Mom: Did you put (dress with) this?

Girl: Yes. I put (dressed) cause it is pretty 
Girl: Si::¿Me PUSI: po:que esss BONITO!

In the same day the girl is trying to dress sandals although the day is too cold.

Mom: ¡No-te-pon-gasss! 4

Girl: ¡ Ya me-PO-NI!

In previous examples we can see that Magali's uses seem to obey to a "contextual" pattern: if her mom previously says a verbal form with the root / pus_/, she uses / pusí/ but if her mom uses a verbal form with the root /pon_/ she uses /poní/. We can conclude that the "instability" of Magali uses is not at chance phenomena, but results from some pattern and if we couldn't grasp natural daily exchanges and functional uses of the alternate forms, we couldn't understand why the girl chooses in some instances one form and not the other.

In that sense we believe that a syntactic developmental researcher could be like a cultural researcher, approaching to child language uses focusing on the function (or purpose or goal) that children attempt to do (Rogoff, 2003). So with this attitude it is possible to consider that child uses sometimes have a similar adult pattern, sometimes have a little different adultlike pattern and sometimes exhibit a very different one but always, due to the cognitive constraints that are imposed on its uses, they exhibit a human conceptual organization.

In sum, if we could take into account Magali's irregular forms of / poner/ (/pusi/ vs / poní/ ) only as an intermediate or erroneous or deviant form of the adequate adult like target / puse/ probably we would had a very partial comprehension of Magali's language, grammatical and pragmatic competence. So, we can conclude that traditional child development studies set not only partial and deviate images they reduced the complex dynamic of child discourse and language competence.

Probably the icon of this perspective has been chomskyan model. In fact the chomskyan assumption of autonomous syntax has obligated researchers to control in experimental tasks contextual variables interferences. Experimental tasks were designed to explore child's ability to discriminate meanings only by syntactic cues (syntactic boostrapping) (see revision at Lust, Flynn \& Foley, 1996).

However, some scholars have noticed that this methodological approach has a lot of shortcomings if we want to understand the dynamics of children's syntactic development (Crain, 1992; Bocaz, 1997; Kress \& Fowler, 1983).

As it's been pointed out by some scholars other disciplines have also the same limitation for studying the relationship between language, behavior and human thought. It has been hypothesized, as the source of this limitation, the conception of language symbol as a mere formal entity, an unit detached from its social and psychological uses and constraints (Lakoff, 1987).

On the other hand, Cognitive-Functional Perspective sustains that language development is complex and dynamic process within children incorporate their cultural communal categories.

\footnotetext{
${ }^{4}$ Translation:

Mom: You don't put (dress with) it

Girl: I put (it) yet!
} 
Some social and cognitive abilities allow children to share the symbolic categorization system of their communities (Lakoff, 1987; Hopper, 1998; Langacker, 1993; 2000).

As human beings, children from their birth categorize their world in base of a network of symbolic resources (Tomasello, 2001; 2003). The categorization processes respond to different kind of motivations: psychological, social and/or communicative. CognitiveFunctional Perspective assumes that symbolic usages exhibit "traces" of this fact (Rosch, 1978; Rosch, Thompson \& Varela, 1993; Lakoff 1987; Langacker, 1987, 1993, 2000; Nuyts \& Pederson, 1997). When children learn (or develop) a language, they form abstract routines of surrounding language usages, (Idealized Cognitive Models - ICM-) by a process of neuro-cognitive specialization and by the appropriation of the routines which make language useful for communication together with actions, gestures, pitch differences, etc.. ICM are abstract items formed by children participation on language exchanges and provide the sources by which individuals can create new expressions based on their abstractness degree (Langacker 1987, 1993; 2000; Tomasello 2001). ICM have a high degree of generality, but they are not "universal", they are determined by specific social interaction routines; then, in some cases, it is possible that in different languages a same ICM have very different linguistic expression. In this sense grammar is conceived as an "emergent structure": the signs emerge from discursive contexts and are context bounding, that is they depend on other uses and contexts in which speaker and hearer have participated (Hopper, 1998).

It implies that, when Cognitive Functional scholars describe a linguistic form, they investigate the conditions, constraints, possibilities that speakers updated using this form. To do this it is necessary to have a representative corpus of language uses: spontaneous speech samples or some data provided by natural-like communication exchanges.

In sum, traditional syntactic development research has shown strong explanatory power for understanding child syntactic performance at experimental tasks. But these contributions do not explain usual phenomena in child speech (i. e. the existence of alternative routines, the relationships between forms and contexts/tasks of uses, etc.). In this sense we believe that this limitation is a consequence of the prevalence of experimental paradigm, which does not allow understanding in a deep sense how children manage the variety of symbolic resources that they have.

Children's grammars are not "incomplete", "deviant" or "in developing to a standard adult grammatical system"; they are grammars that express the subtle complexity of language appropriation process (Silva, 2008; 2010a). From a Cognitive Functional Perspective studying syntactic developmental processes implies inquiring about functional characteristics of the forms, and, if we find some differences, trying to find out the psychological or social motivations they cue.

\section{Designing a methodological tool for eliciting child syntactic data: Semi- structured interview}

If we would carry out a syntactic development research in order to explore the tighten relationship between cultural and contextual constraints and child syntactic development, at first, we must take into account the risks of the traditional techniques. 
Because one of the guide assumptions in Language Usage Model framework (Tomasello, 2001; 2003; Silva, 2008; 2010a; 2010b) is considering grammar as a sedimentation of linguistic usages, we would select a methodological tool that could preserve the greater amount of child contextual linguistic usages; but, also this methodological tool would allow us to compare child language performance; in this case, a particular syntactic data.

The previous aims prompted us to design a new technique for eliciting child syntactic data. In fact, when we had decided to study Relative Clauses (Rcs.) development in Spanish, we evaluated different traditional syntactic tasks and concluded that none of them could be useful to our research aims and some of them are even opposite to Cognitive- Functional assumptions.

Thus we had designed a technique according with our theoretical perspective. The task wasn't a simple one: we would design a particular methodological tool and a set of criteria for eliciting different syntactic forms in their most natural and frequent way of appearance, that is in a format of conversational exchanges. But, due to the fact that we would carry out a research about Rcs. child uses, we had not only pay attention to the methodological aspects, although we would consider how eliciting a significant amount of Rcs. functional uses.

At first we considered and pondered different alternatives contexts for recording child language performance: natural exchanges or conversational like exchanges, that is a naturallike exchange. Due to the particular aims of our research, we needed a greater amount of linguistic forms to make a statistic procedure of analysis (at least 100 Rcs.), we choose a reallike (or "realistic") exchange as the better fit option.

In this sense we considered that the interview would be the most adequate option, because it conveyed two important advantages. It allowed us to preserve some particular aspects of spontaneous speech that we wanted to observe (on-line processing, contextual bounding, grounding in some perspective- footing-, etc.) and it could let making a set of ad-hoc guidelines according to our research aims.

In this sense others scholars have appreciated interview methodological values. Interview, compared with other eliciting techniques, and if the interviewer is a good one, is considered as the most "less information filtering" (Avila Baray, 2006; Richaud of Minzi \& Ciuffardi Lemos, 2006) because people interact, after a little touching, in a natural way and people feel free to comment, expand, suggest, compare; in sum speakers talk with their interviewer as if he/she were with an acquaintance (Kress \& Fowler, 1983).

Also it was regarded as an essential tool when we were working with children (Stromswold, 1996) because interview's situation reproduces the conditions that govern everyday conversational interactions (Labov, 1991) and in these exchanges children tend to be more stress-free and comfortable than in experimental situations. In fact interviews have overlappings between speaker and interviewer, a width sample of pitches, shift tones, gestures, etc.; because, as it happens in every day conversations, speakers cannot plan in detail their speech. Sometimes happens that participants include their opinions or other comments not restricted by topics of talk. These aspects were taking for granted when children were interviewed, i.e. in interview's transcriptions these features were "normalized" and disappeared (Rodriguez \& Murillo, 1985). But contributions from Conversationalist Analysis and Ethnomedology studies allowed to understand their 
relevance and realized how could change our syntactic phenomena understanding if we try to preserve them and to give back their contextual meaning (Silverstein, 1976).

In this sense one of the Cognitive Functional Theories, Grammaticalization Theory (Hopper, 1998), assumes that face to face interactions are the main contexts which provide models for the emergence of grammatical categories because in these interactions grammar exhibits two significant characteristics: context bounding and on-line processing dependence (Wierzbicka, 1988).

Also there is evidence that children in interviews with an adult exhibit higher scores of syntactic complexity speech than the scores obtained when they were talking with peers. Wells (1988) found that 5 years old children at home talking with siblings or friends show an 2.8 score of Syntactic Complexity Media, while at school, talking with their teachers, the same children have 3.2 score and at home, speaking to adults, their Syntactic Complexity Media score was 3.1. These results demonstrate that children display more complex syntax when they talk with an adult than when they talk to other child.

In Spanish there are some language development studies based on interviews (Gili Gaya, 1972; Oralia \& Murillo, 1985) but these eliciting data situations were not designed in detail, they usually have been considered as "Free talking" (Plática Libre) and they didn't have a detailed set of criteria by which interviewers would prompt a more natural way of interaction. So children, in these interviews talked about topics that researchers assume are common talk topics for children: how many people did conform their family, what they were doing, what were the games that children use to play, when, and so on. Despite the fact that these interviews provide some relevant linguistic information, they do not provide, in strictu sensu, analogous syntactic data. It is, although we could find that different children use a "same" syntactic form the context in which forms appear and their discourse functions were so dissimilar, so they were not comparables between them (Silva, 2010b).

\subsection{When a topic of talk is a "significant" one at children interviews?}

Considering the problematic characteristics of syntactical data obtained in other interviews with children, we have decided that the eliciting technique to be designed wouldn't be focusing on common topics talking production, because the common topic is not an efficient resource for eliciting a same amount of autonomous talking in different children from different communities. In fact a boy, or a girl, who works with his/ her parents after school has not the same the same opportunities that a Media Socioeconomic Level child to play a lot of time with a width variety of games. Of course his/her comments about toys or games would be scarcer than a typical Media Level child. So if we need to set common topics, we could look for topics that would be part of child life experiences.

Nevertheless we considered that elicitation of common discursive sequences (i.e. narrative sequences appear when someone is retelling a short story, instructional sequences appear when someone gives a description of some trajectory, etc.) could provide us richer syntactical data sources than the elicitation of traditional topics and it would allow to carry out a statistical comparative analysis. So we decided that elicitation technique to be designed would promote children production of some discursive sequences and topics would function as "significant matters" to talk about, as in real conversational exchanges. It implied that first at all we would explore which were "significant matters" in the particular 
children communities in which we would carry out our research. These significant childhood topics could prevent that interviews reproduce experimental circumstances (i.e. children feel self-conscious and evaluated) and would enable children to interact with the interviewer in a most natural and spontaneous way.

How we characterize "significant child topics"? To identify which were significant topics in the communities being studied, two communities of different Socioeconomic Levels, we decided to carry out an exploratory research. The communities were selected due to their Socioeconomic differences, but they were also located in the same geographical area: Buenos Aires city, because this condition could prevent a large dialect fluctuation. So we made interviews in two different urban kindergarten and schools communities: a private and a public one. In a brief social description and depending the area considered, nowadays, at Buenos Aires city, children who attend private kinder and primary school belong to High and Media Socioeconomic Level (i.e. their families have upper incomes, the education of their parents is higher, parents have permanently jobs, etc.); on the contrary the most of the children who attend a public kinder and primary school belong to Media, Low and very poor or marginalized population.

Then, we have to identify the "core" topics that could trigger a good sample of natural-like interaction, a greater amount of child autonomous talk and discursive contexts for the emergence of Rcs.. We named these topics as "Discourse Nuclei" because they pose some interactive and discursive function and topics would be subsidiary to this function. For example if a child relates a quarrel with her sister and with this story argues attempting to persuade interviewer about the need to have certain object for re-establishing "home calm", the topic "a quarrel" will be subsidiary to a pragmatic function: persuading interviewer about the relevance of a child desire. We always had in mind that "Discourse Nuclei" would provide contexts of appearance of specific syntactic data: Rcs. forms, and they would be supporting experiences shared by almost all the children being studied. In an exploratory research we tested some different topics, for narrative discourse: retelling a film, a story that children had read, telling a personal experience (i.e. a little damage or accident in which children were protagonists or observers); for instructional discourse: giving directions about how to prepare their favorite meal, how to repair a toy which was broken very often, how to play their favorite video-game or table/cards-game and for argumentative discourse: explaining why they prefer an object (i.e a particular meal, a game), an activity (i.e. to do swimming or a hobby after school-time) or to do something with somebody (i.e. to play with certain playmates and not with other). Afterwards we had made our exploratory interviews to 20 children of the communities under study, we analyzed them and evaluated data provided. We asked other 2 referee's opinions for deciding which were the topics with a higher score.

We decided that they would be determined by their capacity to elicit a considerable amount of child autonomous talk, so we have considered

1. The significance of the topic within the community being studied (i.e. stories with their pets were important and productive topics for Media Level children but not always for Lower Level children)

2. The topic relevance within a particular life moment of childhood (i.e. birthday parties, vacations, princess or heroes films are significant topics for children between 5 to 7 years old but not for children between 9 to 11 years old). 
3. The possibility that the topics emerge as an interesting matter to talk about during a conversational exchange.

When children talk a lot, emphasize, add comments, include pitch variations, gestures and use the topic to argue, to relate other episode or to include a detailed description, then the topic would be ranked in a high degree. On the contrary, when children participation was scarce or they seemed to be apathetic the topic was considered as non significant (Stromswold, 1996).

After having a list of "Discourse Nuclei" positions, we considered which was the best order of appearance according their "interactional power"; it is the topics that allows "breaking the ice" would be the first to be elicited.

So the "Discourse Nuclei" elicited from the child communities being studied were:

1. Asking about the name and age of children.

2. Asking about child birthday: when it was and asking to relate his/her last birthday party or the most important birthday party that child have remembered.

3. Asking a personal experience in which the child would be the principal character or in which this role could be carried out by a member of his/her family or a mate (a classmate, a playmate, etc.).

4. Asking a retelling of child's favourite cartoon, movie, or stories that he/ she had read if children if children did any reference to some cartoons or movies while children retold their birthdays. Interviewers would paid attention and taken note of these mentions and, asking a retelling of their favorite cartoon, movie, or stories that he/she had read.

In order to have a comparable set of adult-child interactions we made a list of guidelines and suggestions that orient interviewers to take data.

Although we made a detailed set of guidelines orienting interviews, an event happened when we made one of the first interviews changed this protocol. When we were interviewing a girl she mentioned, at her birthday's party retelling, a set of troubles that she had experienced before, and she mentioned the places where each of them had happened. These mentions conveyed a serious communication problem, because the interviewer couldn't understand when and in which order the problems had happened, so, as an ad-hoc solution the interviewer asked the girl to draw the plan of the journey described and to make some crosses to indicate where the problems had occurred. After we had read this transcription we could appreciate that there was a considerable increase of Rcs. uses.

Trough this descriptive sequence the girl built a shared area of knowledge with her conversational counterpart and by using Rcs. the girl was trying to share the reference points with the interviewer (Silva, 2008). So this interview provided a new "Discursive Nuclei": a description to get particular location would include the mention of different reference points to reach the end-point.

As it happened with the girl, when other children were describing the route not only gave detailed route descriptions but also they expressed the need to draw it by taking a notebook and a pen (or pencil) or asking: do you want I draw it? Afterwards they draw rudimentary plans indicating with crosses some reference points to guide the interviewer in this "imaginary" tour. (See Fig.1) 


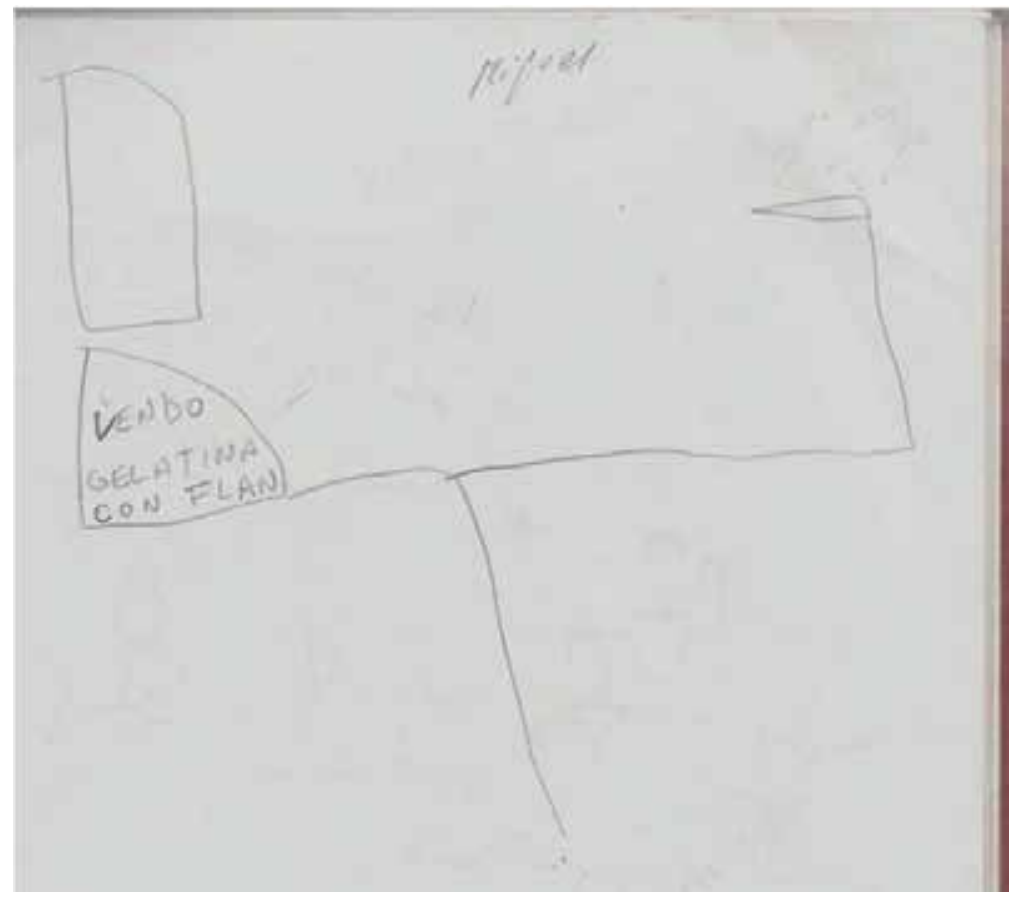

Fig. 1. Plan sketched: The trajectory starts at school and the end-point is the child's house (The boy said: Y ahi en la puertita que tiene un cartel: ven-do gelatina con flan ${ }^{5}$ )

The descriptions elicited were so familiar to children, i.e. answering how to get at child's house from the school, how to get at mate's house from child's house, how to get at child's party saloon from the school. Because the aim of the research was identifying the emergence contexts of Rcs. we attempted that children could explain crosses that they had drawn as reference points for indicating how to get an end- point.

Another "Discourse Nuclei" incorporated was of "shared Rcs." elicitation. This task was included in every context and required that the interviewer, after an ambiguous or unspecific actant/ object mentioned by the child, simulated that he/she couldn't remember the event in which this actant/ object had been mentioned. So interviewer began a phrase using a Rc. but, when he/she would complete the subordinate structure, he/she did as he/she had in the "tip of the tongue" this structure. So the child, that had mentioned it before and had a better knowledge about this referent, completed the utterance with an adequate Rc. form.

\subsection{How to deal with interviewer participation?}

Our revision of previous studies on syntactic development allows us to thinking about on seeming "neutral" position of adult interviewers. On the contrary, Etnomethodology approach contributions showed that studies of social and cultural human relationships and use of symbols depending on scholar's position and his/her community involvement (Rogoff, 2003).

${ }^{5}$ Translation: And there in the little door that has a chart: I sell jelly with caramel 
At first we attempted to clarify in every detail how interviewer's role would be.

One of the choices was deciding which adult would be the best interviewer: if it would be an acquaintance (i.e. children's teacher with a specific training) or if would be a strange people.

The two possibilities showed advantages and disadvantages. If we selected an acquaintance person probably children would omit expressions assuming that referents mentioned were part of adult and children common background. On the contrary, a strange person could intimidate children and could produce shyness or nervous child speech (Rogoff, 2003). So we decided that the best way was a strange person who shared with children their routine activities at kinder or school classes' before making interviews (Rogoff, 2003).

The presence of interviewers at kinder/ schools classes allowed us to obtain sizeable amount of child autonomous speech because interviewers didn't realize so much about child life's and this fact produce "better" child language performance, i. e. if children skip some mentions of events probably interviewers were not able to distinguish referents and they could face off a communication problem and would require a precise use of linguistic resources to resolve it. In that sense there is evidence that children at 4 years old can recognize if their conversational counterpart have a little or a great common background with them, can adequate their speech to this situation (i.e. including more explanations for clarifying) and can resolve communication problems caused by this fact (Mathews, Lieven \& Tomasello, 2007).

Likewise interviewers attempted to be considered by children groups as "Insider/ outsider observer" (Rogoff, 2003), but this position was different due to the particular characteristics of the different groups. For example, posing this dynamic at Media Level 7 years old children group was more difficult than in other groups. On the contrary, at kinder classes it was easier: the interviewer became soon as an "auxiliary" teacher, playing with children at corners, talking with them at circle-time, and so on. The kinder teachers realize very soon the impact of this kind of dynamic for making good interviews. On the contrary 7 years old children of Media Level teacher was reluctant to allow that interviewers attended her classes. Nevertheless in 7 years old group only a boy talked in a scarce way.

An essential issue at those instances was to get for children group's approbation of interviewer's participation. In some occasions actions done for this aim were ad-hoc. In example in the first days of taking interviews interviewers would observe the social dynamic of each group, trying to talk with every child and introducing children to the study (i.e. explaining its aims, showing the technical resources, etc.). At the end of this process, only children selected in order of their age brought to their parents authorizations for participate at the research. However these guidelines didn't guarantee that interviewers could be considered by children as a part of their group. At 6 years old children of Low Socioeconomic Level, the interviewer introduced her to children and was located by the teacher at one corner of the classroom, so far from children. Children twisted their head frequently for look to the interviewer but they did not approach or speak to her. After that, teacher explained an activity in which children would use specific coloured pencils. Some of them did not have these coloured pencils, and they would be allowed to walk through the classroom asking somebody to borrow them. At this circumstance interviewer showed her coloured pencil to a boy who couldn't find anybody who could borrow it. The child 
approached her, took the pencil and came back to his site talking to his mate that the interviewer had a lot of colored pencils required by the activity. After that some other children approached to the interviewer, and asked her if she could borrow pencils, checked with her whether the work was right, showed their drawings or asked her about the research. When the class finished children began to approach freely to the interviewer, holding her hands and relating her some stories (i.e a girl said: do you know that my daddy will bring me a Barbie from his job this night! and other: I haven't a Barbie but I have a lot of dolls! My siblings had a lot and they gave them to me!).

On the other hand interviewers had to overcome different setting limitations, i.e. looking some days for an adequate room to make interviews and recording child speech. For example at Media Level School we had a room in which we installed camcorder and recorders, but this room was originally designated for educational psychologist tasks. This implied that if educational psychologist needed this place we would suspend interviews. Also if educational psychologist entered to the room while we were interviewing children, they changed abruptly their way of speaking: if children before the interruption were talkative, collaborative and expressive, when psychologist was there, they answered with monosyllables or muted.

In sum, these episodes allow us to appreciate the relevance of making "areas of stories safeguarding" when we were getting data from children. With regard to this some children commented daily life episodes at Semi-Structured Interviews, seemingly unimportant but they are crucial to understand children worlds. For example we had collected, at SemiStructured Interviews, stories in which children relate the consequences of living unstable family relationships, poor living conditions, the death of a relative, episodes of discrimination, differences made by parents with their siblings, the loss of a loving toy, and so on. Sometimes, when we had told these stories to teachers, they could realize the relevance of the precautions for getting interviews because only few of them knew episodes that children retold at interviews.

For example, a 4.8 years old Argentinean boy, after mentioned that a mate, a Peruvian boy, had broken one of his toys, explains why he believes that this boy did it: because he is Peruvian and Peruvian people are bad, lie and eat "garbages"

Boy: todo eso comen lo peruano // todo eso animales comen los peruanos // cocinado

Interviewer: ¿una cucaracha cocinada?

Boy: Sí/ la comen ello

Int.: pero jeso no se puede comer!

Boy: lo argentino no pueden comer, pero lo coso sí comen, le ponen ajo, ají y lo comen // [...]

Int.:\{ ¿no comerán pescado o arroz ${ }^{\circ}$ y uno no se dará cuenta? Y parece

Boy: = no // lo argentino comen lo argentino comen // [...] y/ bue:no// eso es lo que cocina// preguntále al Miguel/ y él te va- a-de-cir/claro/ no me dijo Miguel que comían/me dijo que comía flan con chocolate//ÉL MIENTE/poque lo peruano miente// él miente67

${ }^{6}$ Translation 


\section{Child Relative Clauses uses and syntactic development from a new perspective}

Although Rc. development has been considered in a huge amount works from different theoretical perspectives, we studied it because we realize that none of them could explain a seemingly trivial contradiction: children exhibited "deviant" or "later" forms at experimental tasks but when they interact they pose adult-like forms (Gili Gaya, 1975; Alarcos Lloras, 1976; Echeverría, 1978; Hamburger \& Crain, 1982; Solana, 1996; 1997; Dasinger \& Toupin, 1997; Bocaz, 1997; Jisa \& Kern, 1998).

Rcs. developmental studies showed contradictory results (i.e. the order of occurrence of each type of Rc.). We hypothesized that not only theoretical assumptions could be responsible for the differences in results but, also, differences could be attributed to the different methodological perspectives adopted.

If we study Rc. development within Communicative Competence Development and Language Usage Models (Tomasello, 2001; Diesel \& Tomasello, 2001) we consider Rcs. as structures that allow speakers to manage referential function (Matthews, Lieven \& Tomasello, 2007; 2009). Referential function is a cognitive ability by which speakers can provide adequate information to his/her counterpart; by it speaker and hearer could share a same perspective about a referent codified in the message. The development of this skill implies other cognitive skills such as that children could move off from their own point of view to his/ her hearer point of view or the ability to form expectations about the information that could require a conversational counterpart, etc. (Deutsch \& Pechman, 1982; Matthews, Lieven \& Tomasello, 2007; 2009).

For example if we observe a girl of 3,4 walking with her mother and talking with her, we could appreciate real Rc. functional occurrence

Girl (pointing a wall chart in which they see a marinated pork image): Mom, a pi::g!

Mother (looking and pointing wall chart): Yes, as the pig that we saw at Carrefour8.

Child: Aha! The pig we saw.

When the mother is using a Rc. shows the girl that construction headed by "that" allows recalling another previous situation in which were they and the object mentioned. From mom's point of view both objects (the wall-chart pig and the market- pig) are similar, so child could learn, by this, that the object could be the same although they were in different spaces and with them people could do different things: you can see to the wall chart pig but

Boy: all of this Peruvian people eat, all of these animals Peruvian people eat, cooked,

Int.: A cockroach cooked?

Boy: Yes, they eat that

Int.: But, we can't eat it

Boy: Argentinean people cannot, but these guys eat it, they put garlic and chili and they eat that.

Int.: But they won't eat fish or rice and we won't realize that?

Boy: No, Argentinean people eat that, Argentinean people eat/ / And, well, that is that (they) cook, you ask Miguel and he will answer you, of course, he didn't tell me what they ate, he said that they ate caramel with chocolate, he lies, because all Peruvian people lie, he lies.

7 The symbols used in transcription follow Jefferson (2004).

${ }^{8}$ Carrefour is the name of one of the most popular markets in Argentina 
you can take home, cook and eat the market pig. These inferences allow child to conclude that the constructions headed by "that" categorizes two objects in the same class despite the dissimilar events in which them are involved (Silva, 2002).

From this point of view, producing a Rc. implies not only a syntactic development. In fact there is a more complex process, when children use a Rc. they face off a very cognitively complex task: they must realize what shared knowledge is needed, how manage semantic role assignment, how order the lexical items according syntactic/ conventional uses, pick up the appropriate phonemes, etc.. Actually, when we identify different child syntactic forms we could appreciate the complex cognitive task involved (Diesel \& Tomasello, 2001; Silva, 2002).

In this sense Silva $(2008 ; 2010)$ found 5 (five) different Rcs. forms attending Rcs. uses, that Argentinean girls and boys ( 5 and 7 years old belonging to different Socioeconomic Levels) produced at Semi Structured Interviews.

- $\quad$ Rcs. headed by a relative pronoun ${ }^{9}$

Y ACÁ vive mi abuela y::: que está muy lejos (girl 12: 33)10.

Yo me fui de vacaciones y me hicieron fiesta, en la playa y donde jugamos al tesoro del pirata, lo tenía que enterrar en la arena (girl 1: 20)11

- $\quad$ Rcs. headed by an evidential particle (viste) plus relative pronoun

Sí // porque mi hermana se compró $u$, un vestido ¿viste esos que son así, con unas cositas, así? (boy 6:5). 12

- $\quad$ Shared Rcs. headed by a relative pronoun

Girl: Lo tiene en una caja ${ }^{13}$

Interviewer: Pero una caja, que vos

Girl: que yo::, YO NO SÉ DONDE GUARDA ESO, guarda por unas cosas así, al toque, ahí guardamos nuestras cosas pero no sé cuál cajón es de ella (girl 27: 37)

- $\quad$ Rcs. headed by a relative pronoun but children omitted it

Este es el tío y le querían matar a su hijo bebé <al que le va a comer (boy, 5: 56)14

No:: agarran una lata $e_{[s]}$ como que hacen e:: un portalápices con plastilinas, un tubo ${ }_{[a l}$ que] $\mathbf{l e}$ ponen plastilinas, le hacen un muñeco, así (girl 29: 38)15

\footnotetext{
${ }^{9}$ The numbers in brackets correspond to the codification for order of children interviewed and order Rc. occurrence in child's transcription. The bold phrases are Rcs.

${ }^{10}$ Trans.: And here lives my grandmother and that she is so far.

${ }^{11}$ Trans. I went to [was on] holidays and they made a party for me, in the beach, and where we played the pirate's treasure, I had to bury it into the sand.

12 Trans.: Yes, because my sister bought a, a dress, do you see those that they are such as, with a little things, like this?

${ }^{13}$ Transl. Girl: She has it into a drawer

Interviewer: but, a drawer that you

Girl: that I, I don't know where she keeps that, she keeps for some things like this, at the touch, there we keep our things but I don't realize which is her drawer of wardrobe.

${ }^{14}$ Transl.Boy: This is the uncle and they wanted to kill his baby son \{to whom\} he goes to eat.
} 
- Headless Rc.

$Y$ cuando me soltó la señorita, yo estaba pataleando y pataleaba muy fuerte (boy 22: 32) $)^{16}$

Although their syntagmatic differences, all the Rcs. identified share some features; within them: when children structures Reference Point, they discriminate a salient characteristic of previous Conceptual Frame, it is children assign saliency to an element (or part of it) belonging to an activated Conceptual Frame (Fauconnier, 1985). The Conceptual frames are activated by particular exchange needs and/or a mental state that children could anticipate (or suppose) of their conversational partner. It implies that children, as competent speaker, could recognize when and how is needed to increase some actant/ figure cognitive accessibility degree activating relevant information (Langacker, 1987; 1993). In fact, trough a Rc. use, speakers could integrate conceptual information and establish a Reference Point. Reference Point allows to mention and to identify an actant mentioning an event. It's possible that this process could be an expensive and complex conceptual procedure, and, by this, several different Rcs. forms could instantiate this cognitive and sociocultural variation (Sedano \& Bentivoglio, 1997).

Although Silva $(2008 ; 2010)$ found significant correlation between Rcs. frequency and Age, she did not find any correlation with developmental stages (periods of three months). She concluded, in coincidence with other studies, that Rcs. frequency is caused not only by a syntactic developmental factor but it is possible that it could be originated by the interaction of psycholinguistic and discursive developmental factors (i.e, Media Length Utterance, Media Length Clause, total amount of words produced by children during the interview, etc.).

\section{Conclusions}

In contrast with traditional children interviews we stated a set of criteria that allowed us to elicit a sizeable amount of particular syntactic form (Rc.). So we designed a technical tool to elicit considerable amount of child autonomous speech. We named this technique SemiStructured Interview because its format will be "structured" by previous exploratory research. In this exploratory research we could look for some possible functional contexts in which syntactic forms under study would emerge with their natural-like speech function.

In fact exploratory study allowed us to identify that some personal experience narratives, trajectories description, retellings, etc. could be richer "Discursive Nuclei" for eliciting not only sizeable child autonomous speech but also for to create contextual conditions requiring at Rcs. usages. We, following Ethnometodological studies, took a lot of eliciting precautions, within them considering interviewers as classroom community participants and making interview's setting as "safe-guarding stories areas", maintaining child's attention by controlling gaze, body posture and intonation attempting to express interest in the child's talk; so interviews were so similar as "everyday conversations", and children could express freely in them.

These precautions also ensure that children couldn't contextualize or erosionate so much their speech. We consider this technique of great value because with it we could resolve some of the

15 Transl. Girl: No, they catch a can i[s] like that they make e, a pencil holder with modeling clay, a pipe [to whom] they put it modeling clay, they make it a dummy, like this.

16 Transl. Boy: And when teacher lets me go, I was stamping and stamped so fast. 
difficulties involved at studying child syntax development. Among them that the methods for studying adult syntactic competence are not suitable for children (Stromswold, 1996), that there is evidence that child syntactic performance at experimental tests is modified according to test conditions (i.e. when a test administrated has been repeated), and because child syntactic tests exhibit greatest differences with language usage daily demands (Silva, 2008).

Semi- Structured Interviews allowed us to obtain a sizeable and functional amount of syntactic forms. In fact at the "Discursive Nuclei" children use Rcs. when they need to refer and discriminate an object or an actant for some particular exchange needs. Instead syntactic tests we believe that Semi- Structured Interview, carefully designed, provides spontaneous-like conversations, it is an efficient method for producing children comparable samples and allows considering the relevance of factors undermined at experimental tests (i.e how child syntax is influenced by child Media Length Utterance). In fact Semi- structured interview has a peculiar elicitation format of data that reveals features minimized at experimental tests.

In sum, Semi- Structured Interview seems to be a valuable tool to preserve much of child language usage characteristics at context and to understand the complex dynamics of language development and the effective use of language, considering it as social behavior.

\section{Acknowledgments}

I am very grateful to Ana Borzone's corrections and comments because they made this chapter more rigorous and interesting. Also I deeply appreciate her constant encouraging and the support of all members of our research team, at CIIPME, Buenos Aires.

Finally I would dedicate this work to my husband, Leo, and to my daughter, Magali, because they highlight all days of my life.

\section{References}

Alarcos Llorach, E. (1976). La adquisición del lenguaje por el niño, in A.Martinet (Coord.) Tratado de lenguaje. Bs. As.: Nueva Visión (pp. 9-42).

Auer, P. \& Luzio, A. (1997). Introduction, in P. Auer \& A. Luzio (Eds.) The Contextualization of language. Amsterdam: John Benjamins (pp. 1-37).

Avila Baray, L. (2006). Introducción a la metodología de la investigación. México: Eumed.net. URL www.eumed.net/libros/2006c/203.

Bocaz, A. (1997). Las cláusulas relativas y sus funciones en el discurso narrativo infantil, Signo \& Seña, 8, 170- 186.

Borer, H. \& Wexler, K. (1987). The maturation of sintax, in T. Roeper y E. Williams (Eds.) Parameter Setting (pp. 123-172). Dordrecht: Foris.

Chomsky, C. (1975) [1969]. The acquisition of sintax in children from 5 to 10. Cambridge: MIT Press.

Correa, L. (1982). Strategies in the acquisition of relative clauses, in J. Aitchinson \& N. Harvey (Eds.) Working Papers of the London Psycholinguistic Research Group 4. London: Lawrence Erlbaum Associates (pp 37-49).

Crain, S. (1992). Language acquisition in the absence of experience, in H. Bloom, (Ed.) Language Acquisition: the state of Art. Hillsdale: Lawrence Erlbaum (pp. 364-406). 
Dasinger, L. \& Toupin, C. (1997). The development of relative clauses function in narrative, in D. Slobin \& R. Berman (Eds.) Relating events in narrative: a Crosslinguistic developmental study. Hillsdale: Lawrence Erlbaum Associates (pp. 457-514).

Deutsch, W. \& Pechman, T. (1982). Social interaction and the development of definite descriptions, Cognition, 11, 159-184.

Diesel, H. \& Tomasello, M. (2001). The development of relative clauses in spontaneous child speech, Cognitive 11, 131-151.

Diver, W. (1995). Theory, in E. Contini- Morava \& B. Goldberg (Eds.), Meaning as explanation: Advances in linguistic sign theory. Berlin: Mouton de Gruyter (pp. 43-114).

Echeverría, M. (1978). El desarrollo de la comprensión infantil de la sintaxis española. Chile: Univ. de Concepción.

Fauconnier, G. (1985). Mental Spaces: Aspects of Meaning Construction in Natural Language. Cambridge: MIT Press.

Gardner, H. \& Forrester, M. (2010). Analysing interactions in Childhood. West Sussex: WileyBlackwell

Gili Gaya, S. (1972). Estudios de lenguaje infantil. Barcelona: Biblograf.

Haiman, J. (1994). Ritualization and the development of language, in W. Pagliuca, Perspectives on grammaticalization. Amsterdam: John Benjamin (pp. 3-28).

Hamburger, H. \& Crain, S. (1982). Relative clause acquisition, in S. Kuczaj (Ed.) Language Development Vol.I. Hillsdale: Lawrence Erlbaum (pp. 245-274).

Hopper, P. (1998). Emergent Grammar, in M. Tomasello (Ed.), The New Psychology of language Cognitive and Functional Approaches to Language Structure. New Jersey: LEA (pp. 155-175).

Jacubowicz, C. (1986). Mecanismos de cambio cognitivo y lingüístico Substratum N5, 56-86. (1996). La adquisición del lenguaje: hipótesis y datos, Signo \& Seña Nº 8, 61-89.

Jefferson, G. (2004). Glossary of transcript symbols with an introduction, in G. Lerner, (Ed.) Conversation analysis: studies from the first generation. Philadelphia: John Benjamins Publishings (pp. 9-31).

Jisa, H. \& Kern, S. (1998). Relative clauses in French's children's narrative texts, Journal of Child Language, 25, 137-172.

Kress, G. \& Fowler, R. (1983). Entrevistas, in R. Fowler, B. Hodge, G. Kress, \& T. Trew, Lenguaje y control. México: Fondo de Cultura Económica (pp. 89-110).

Labov, W. (1991). Sociolinguistic Patterns. Philadelphia: Univ. of Pennsylvania Press.

Lakoff, G. (1987). Women, fire and dangerous things: What categories reveal about the mind. Chicago: Univ. of Chicago Press.

Langacker R. (1987). Foundations of Cognitive Grammar: Theoretical Prerequisites. Vol I. Standford: Univ. Press. (1993). Reference Point Constructions, Cognitive Linguistics 4, 1-38. (1997). Constituency, dependency and conceptual grouping, Cognitive Linguistics, 8 (1), 1-32. (2000). Estructura de la cláusula en la gramática cognoscitiva, Revista Española de Lingüística Aplicada, 19-63.

Lust, B., Flynn, S. \& Foley, C. (1996). What children know about what they say: elicited imitations as a research method for assessing children's syntax, in D. Mc Daniel, C. McKee \& H. Smith Cairns, Methods for Assesing Children's Syntax. Cambridge: MIT Press (pp. 55- 76).

Matthews, D., Lieven, E. \& Tomasello, M. (2007). How toddlers and preschoolers learn to uniquely identify referents for others: a training study, Child development, 78 (6), 
1744-1759. (2009).The development of reference from two to four years. URL http:/ / pre2009.uvt.nl/pdf/matthews_et_al.pdf.

Múgica, N. \& Solana, Z. (1999). Gramática y léxico: Teoría lingüística y Teoría de adquisición del lenguaje. Buenos Aires: Edicial

Nelson, K. (1996). Language in cognitive development. Cambridge. Cambridge University Press.

Nuyts, E. \& Pederson, J. (1997). Language and Conceptualization. Cambridge: Cambridge University Press.

Rodriguez, O. \& Murillo, G. (1985). Te voy a platicar de mi mundo. Mexico: el Colegio de Mexico, Centro de Estudios Lingüísticos.

Richaud de Minzi, C. \& Lemos de Ciuffardi, V. (2006). Cuaderno de seminario de investigación I. Buenos Aires. CIIPME.

Rogoff, B. (2003). The cultural nature of human development. New York: Oxford Univ. Press.

Rojas Nieto, C. (2008). "Starting small": effects in the acquisition of early relative contructions in Spanish. Proceedings at 12th Rice University Symposium on Language: URL www.ruf.rice.edu/ eivs/sympo/papers/Rojas.pdf.

Rosch, E. (1978). Principles of Categorization, in B.B. Lloyd (Ed.), Cognition and Categorization. New York: Hillsdale (pp. 27-48). (1993) Thompson, E. \& Varela, F. The Embodied Mind. Massachusetts: MIT Press.

Sedano, M. \& Bentivoglio, P. (1997). En torno a una tipología de la variación gramatical. Anuario de Filología Hispánica 1996-1997 Vol. II. Valladolid: Univ. de Valladolid (pp. 997-1011).

Silva, M. L. (2002) Modelo de Punto de Referencia: Uso de Cláusulas Relativas en niños. Actas del IX Congreso de la Sociedad Argentina de Lingüística. Univ. Nac. de Córdoba: Fac. de Lenguas-Centro de Investigaciones Lingüísticas. (2008). Desarrollo y gramaticalización de las cláusulas relativas en el discurso infantil: aportes desde el enfoque cognitivo- prototípico. Unpublished Doctoral Thesis. La Plata: UNLP (2010a). Cláusulas relativas en el discurso infantil: cuestiones pendientes. Bogotá: Academia Colombiana de la Lengua- Ediciones Univ. Central. (2010b). El estudio de la sintaxis infantil a partir del diálogo con niños: Aportes metodológicos, Interdisciplinaria, 27 (2), 277-296.

Silverstein, M. (1976). Shifters, linguistic categories and cultural description, in K. Basso \& H. Selby (Eds.) Meaning in Anthropology. Albuquerque: Univ. New Mexico Press (pp. 11-55).

Solana, Z. (1996). Relativas sin movimiento en la gramática infantil, Signo \& Seña, 8, 101- 113. (1997). El proceso de construcción de relativas en la gramática infantil. Unpublished Doctoral Thesis. Fac. de Filosofía y Letras: Univ. de Bs. As.

Stromswold, K. (1996). Analyzing Children's Spontaneous Speech, in D. Mc Daniel, C. McKee \& H. Smith Cairns, Methods for Assessing Children's Syntax. Cambridge: MIT Press (pp. 24-53).

Tomasello, M. (2001). First steps toward a usage-based theory of language acquisition. Cognitive 11, 61-82. (2003). Constructing a Language. Cambridge, Massachusetts: Harvard Univ. Press

Wells, G. (1988). La experiencia del lenguaje de niños de cinco años en la escuela y en la casa, in J. Cook-Gumperz (Ed.), La construcción social de la alfabetización. Buenos Aires: Paidós (pp.85-108).

Wierzbicka, A. (1988). The Semantics of grammar. Amsterdam: John Benjamins. 


\title{
Informal Learning Amongst Pediatric Rehabilitation Teams - An Ethnography of Tea-Room Talk
}

\author{
Cynthia Hunter ${ }^{1}$ and Adam Scheinberg 2,3,4,5 \\ ${ }^{1}$ Sydney School of Public Health, The University of Sydney \\ ${ }^{2}$ Department of Rehabilitation, The Children's \\ Hospital at Westmead \\ ${ }^{3}$ Victorian Paediatric Rehabilitation Service, \\ Royal Children's Hospital Melbourne \\ ${ }^{4}$ Murdoch Children's Research Institute \\ ${ }^{5}$ Faculty of Medicine, Monash University \\ Australia
}

\section{Introduction}

Chris Baldry writing in his 1999 article 'space - the final frontier' states that for too long the built working environment has been excluded from analysis of work organizations (Baldry, 1999). One of the first things a newcomer to any organization has to learn is how to navigate within their new spatial environment. For example, what are the cues that signal territorial boundaries, and whether such territories are functional or hierarchical? If the question is asked as to how the built environment aids the extraction of surplus value then the work building is far from being a passive container. The building itself is a property and it houses technology. It facilitates managerial control over the labour process in both the co-ordination of production through the division of labour and the construction of systems of surveillance. Furthermore, the building is also said to influence behaviour through the messages it sends - the semiotics and symbolism of the built environment or a form of non-verbal communication. Hall's writings on non-verbal behaviour and proxemics (the use of space in communication) are influential environmental cues (Hall, 1959, 1966). Thus environments provide cues for behaviour and these cues reinforce what is socially appropriate or inappropriate. The above literature, therefore, suggests that environmental cues in the rehabilitation service unit promote certain behaviours around the creation and foundation of a tea-room. This behaviour is linked to Goffman's (Goffman, 1963, 1973) concept of identification and impression management whereby individuals manage the impressions others form of them in order to create and negotiate their presentation of self, in this instance in a public place (hospital service unit) and these by implication are linked to the health of staff members.

Space trends in the current health care design field both in literature and practice is to focus on "patient centred care" and "healing environments" (Mroczek, Mikitarian, Vieira, \& Rotarius, 2005). It is recognized that good health care cannot be administered without health 
care professionals and that burn out and stress may lead to reduced quality of health care A supportive organizational and physical environment are both necessary for health professionals to work effectively and to take care of their personal health (Grandey, 2000). Congress themes of the $4^{\text {th }}$ World Congress on Design and Health (2006 Frankfurt) included 1) design health facilities to allow for change and adaptability and 2) humanize health care environments for patients and staff (Carthey, 2006). There was no specific mention of spaces where teams can informally meet such as tea-rooms. In Australia the Department of Health Guidelines asks for staff rooms for staff respite, but does not dictate where these rooms are located http://www.healthfacilityguidelines.com.au/. In talking to architectural firms (personal communication - Bligh Voller Neild 2007) decisions around tea-rooms in hospitals are dependent on individual client briefs with the overall trend being for communal staff facilities for buildings, which encourages staff interactions and discourages silo-based teams and departments. According to Chastain "It is imperative for clinicians and architects to work hand-in-hand in the design of all healthcare facilities, large or small" (Chastain, 2008, p. 1). Furthermore, Chastain states "The clinicians must be involved in the decisions for their respite areas. Location of break rooms ${ }^{1}$, dining areas, lockers and education spaces must be convenient to their work area" (Chastain, 2008, p. 2).

Informal spaces in hospitals and what is enacted there also has been explored in the literature, as against the formal spaces of the ward, operating theatre, and clinic rooms (Heard, Roberts, Furrows, Kelsey, \& Southgate, 2003; Iedema, Long, Carroll, Stenglin, \& Braithwaite, 2005; Lancashire, Hore, \& Law, 2003; Long, Iedema, \& Lee, 2007). For example, corridors are acknowledged as spaces (public ones) in which consultations between clinicians occur (Heard, et al., 2003, p. 43) and ethical issues have emerged around their 'publicness' (Johnson, Cook, M.Giacomini, \& Willms, 2000).

Clinicians' tea-rooms, or common rooms, differ significantly from corridor spaces because they are not public spaces. Some clinicians' talk might be similar, for example, time management, work flow planning, discussions on equipment costs and purchasing, knowledge and skill exchange, affective talk including social and 'phatic'2 communication, conflict resolution and reflections on attitudes and practices (Long, et al., 2007). The tearoom provides a spatial resource for the enactment and management of the complexity of everyday work practices (Iedema, et al., 2005)

\section{Methods}

\subsection{Study design}

The specific study we describe and analyse was part of a larger ethnographic study of the interactions between clinicians that was conducted in two pediatric hospitals in Australia (C Hunter, Spence, McKenna, \& Iedema, 2008; C Hunter, Spence, \& Scheinberg, 2008; C Hunter \& West, 2010). Data collection occurred over a 12-month period between 2005 and 2006. Ethnography was chosen because it allows detailed 'thick description' (Geertz, 1973) of the everyday workplace practices of clinicians over a period of time cf. (Sinclair, Lingard, \& Mohabeer, 2009).

\footnotetext{
${ }^{1}$ Break rooms is a United States term which is equivalent to tea-rooms in Australia.

${ }^{2}$ Phatic communication $=$ small talk that one hardly notices e.g. hello, have a nice day etc.
} 


\subsection{Participants}

The rehabilitation service is located in a major metropolitan tertiary level pediatric teaching hospital affiliated with a local university. The service consists of an outpatient program of rehabilitation clinics and a small number of inpatient beds on the surgical unit of the hospital. The core rehabilitation team (the "team") consisted of 50 clinicians and six administrative staff. Ethics approval was granted from one university and one hospital ethics committee. Recruitment to the study was voluntary and all rehabilitation staff agreed to participate.

\subsection{Data collection}

Observations, the immersing participation of the ethnographer and detailed descriptive field notes of activities of the rehabilitation staff were collected, based on qualitative methodological literatures such as Denzin (Denzin \& Lincoln, 2005), Pope (Pope, 2005) and (Mays \& Pope, 1995). Observations were conducted during working hours at the workplace. Observations, participant observation and interviews of various lengths occurred in the tearoom over the 12-month period of the study. The ethnographer worked in two other service units simultaneously. This allowed for comparisons between tea-room structures and different meanings for using a tea-room by staff and different dynamics of the teams that congregated there.

An inductive approach to analysis, a hallmark of qualitative research, was used (Janesick 2000). Initially, the task was to extract concepts to make sense of what was going on. Transcribed interview data was analysed using keywords to identify topics and themes. All the data were entered into The ETHNOGRAPH version 5.0 program (Seidel, Friese, \& Leonard, 2006) and this facilitated data organization and retrieval and the identification of keywords, topics, and themes.

\section{Findings}

\subsection{Initiation into the field}

The ethnographer's initiation to the rehabilitation team in 2005 was at a meeting of team clinicians organized by one of the hospital research investigators who was also one of the senior rehabilitation pediatricians. Having been introduced, the first question addressed to me from one of the case managers was: "Do you like cooking?" Puzzled, I answered, "Yes I like cooking." (I was thinking - cripes, where is this going, I am here to do research to observe these people's interactions with each other). [The case manager's reply:] "Oh, good, 'cos we like cakes here" (Phew! So that's it). Nervous now, because of all the things I cook, cakes aren't one of them. Will I have to do a crash course in cake cookery? Is it true that not only am I to enter a new field site but I have to enter with credentials other than those I already had?

In hindsight, the question was a light-hearted one, designed to make me feel at ease, a welcoming gesture. Little did I realize just how important cakes and the tea-room were to become in the project.

\subsection{Tea-room activities}

In the original hospital design planning the current tea-room in the rehabilitation unit was designated a doctor's consultation room (see red circle and box Diagram 1). The original 
design did not have tea-rooms in this section of Level 3 of the hospital. The only areas available for tea or coffee-making are at the other end of the building where there is a kitchen (circled in red on the diagram), and a meeting room (highlighted in yellow) in which hot water is available from a water boiler on the wall. None of the rehabilitation staff, except one, has an office near either of these drink outlets. In fact, the waiting room of the child assessment centre(highlighted in yellow in the diagram) almost divides the two zones 1 and 2 of Level 3. The major consultation activities of the rehabilitation team occur in, and around the series of consultation rooms (boxed in red in the diagram).

The present rehabilitation tea-room is an L-shaped room with a small basin, micro-wave, fridge, low table with lounges along two walls and stackable chairs. There is a variety of wall adornments, a white board, pin board, shelving, some cupboards and a telephone. Mornings and lunchtimes are the busiest and noisiest, while in the afternoons there is less happening in the tea room.

In this tea-room which is used extensively throughout the day there is a diversity of activity from flurry to stillness, from none to one or ten or more persons, from a quiet conversation between one or two to 10 or more, or several conversations happening simultaneously while some participants wash up, make tea and toast, microwave lunch, cut the cakes, store things in the fridge, write on the white board, read a magazine or their mail, answer or make phone calls when responding to a pager, and so on. Sometimes, the door is voluntarily and momentarily closed while something private is disclosed, something that does not, or cannot, be allowed to permeate the public corridor space outside the tea-room.

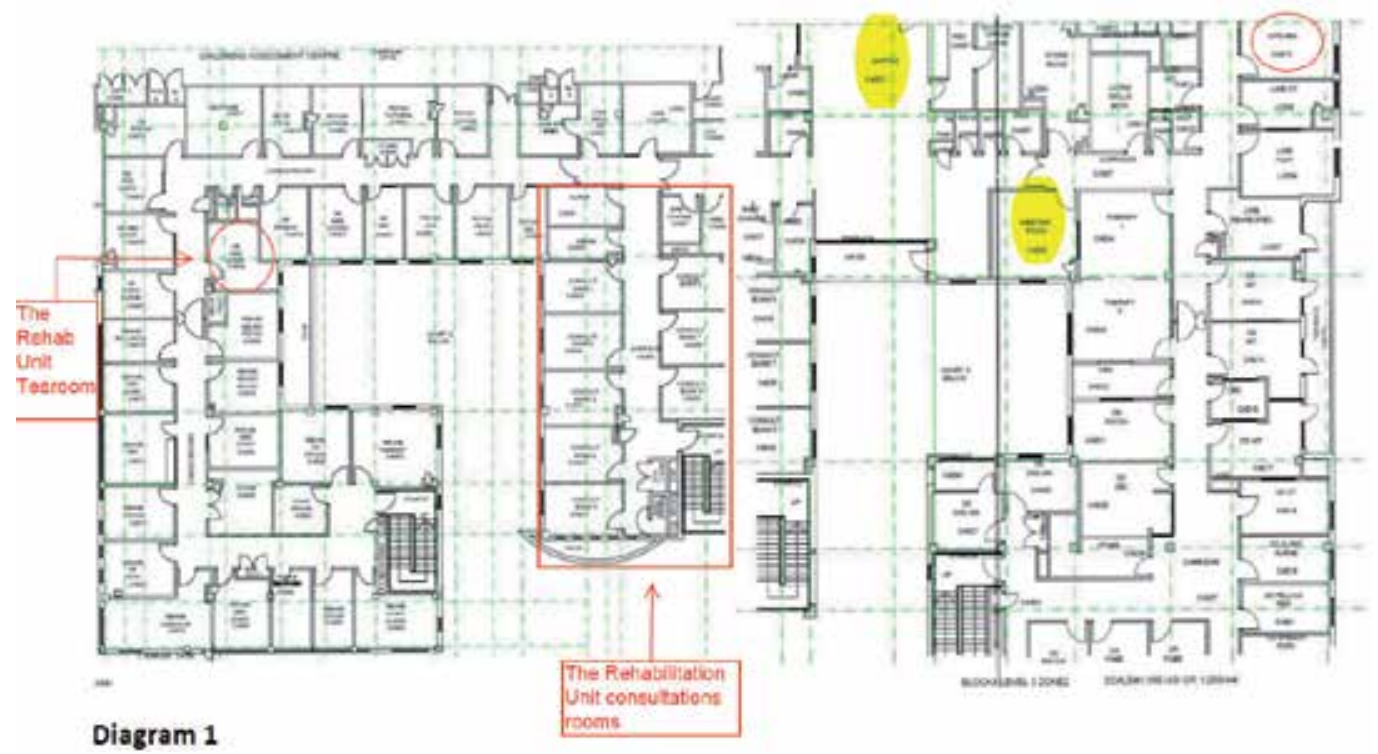

Diagram 1. Diagram of rehabilitation unit level 3 zones 1 and 2

Because individual team clinicians come and go according to their individual needs conversations are said to be heterogeneous, i.e. conversations can move rapidly from one issue to another or from one clinician to another. 
As well as the mundane activities such as addressing the needs of food and sustenance, the tea-room is a space where relationships can be nurtured. Co-workers can attend to and maintain relationships with each other (Sobo, 2009). For example, staff members' birthdays are celebrated with gusto. The birthday person is responsible for bringing a cake or some other delicious food, there is singing and conviviality on these occasions. The light-hearted conviviality and collegiality is reflected in the following:

"Oh look what J's put down for K's birth-weight and medical intervention" (M pointing to the white board where a list of predictions on the birth-weight, sex, name, medical intervention and predicted date of arrival of J's impending confinement) is being drawn up by work colleagues. Tea-room time is 'time out' from the busy formal work schedules. What is discussed there is ever changing.

Of the number of different activities that 'happen' in the tea-room, a great many of them are work related, for example, what happened at the clinic that morning; how are we going to organise a staff replacement. In particular, we will argue that having a space such as a tearoom to debrief, commiserate, relax and vent emotions, leads to better health and positive learning for clinicians. A tea-room or equivalent space precipitates effective interdisciplinary teamwork in this department. Following Long et al. the talk may be clinical, instructive, technological, organizational, affective and reflexive (Long, et al., 2007, p. 43).

Here are some excerpts of conversations taken from transcripts of tea-room conversations over a 12 month period, and analysed for their thematic content.

\subsection{What's in tea-room talk?}

\subsubsection{Excerpt one theme 1}

\section{Appointment planning - administrative staff and rehabilitation paediatrician}

The interaction is between the administrative officer and a staff specialist about the necessity or not of booking an appointment for a patient who required a repeat prescription before his designated follow-up appointment a few months later.

Admin officer: [Name of patient] ... we are not due to see him until October, you don't need to see him to prescribe do you or you do?

SS: Yeah I really do, sorry, ... he's got to have his blood pressure and his weight checked anyway so they could go to the GP for that it's a big palaver I've got to send off documents to the HIC. (pause) ...

You could do it as an half an hour appointment - a quick appointment

\subsubsection{Excerpt two theme 1}

\section{Organizational planning - staffing issues}

In this excerpt planning for a new staff member is being debated.

Senior staff 2: Two days a week.

Senior staff 1: Two half days a week. Maybe we can stretch it to one and a half so it's maybe $\$ 30,000$ it's for half a year so 15 grand, there you are, not a huge amount of dough. 
Senior staff 2: No, that's for sure.

Senior staff 1: I'll pursue that. I'll just check with [Name of another Staff member] Wednesday morning's ok too I think. It's the physical problem of rooms. Monday afternoon is our most flexible day it's good because we have piles of rooms .... .

Work gets done in the tea-room because the complexity and volume of collaborative hospital team-work coerces the team players to have 'opportunistic' interactions with each other. For example, Excerpt One, the interaction between the administrative staff member and the staff specialist could have taken place outside the administrator's office. All the administrative offices have glass panels which open onto the corridor. Excerpt Two could have taken place by phone or in either of the senior staff's offices. However, this tends not to happen because in this spatial context the clinicians' offices are at opposite ends of the unit and the tea-room is midway between them.

\subsubsection{Excerpt three theme 2}

\section{Getting the big picture or extending professional boundaries}

Networking, conferencing and exchanging information are all part of a day's interactions. The following excerpt transpires between the clinical nurse coordinator (CNC), the neuropsychologist, the administrative officer and a rehabilitation staff specialist. The discussion is about an overseas specialist who has come to (Name of pediatric hospital) rehabilitation, and the above staff specialist who had recently returned from a conference in the US.

CNC: ...Surgery, Mexican, and they do really good work; certainly from a spinal point of view they do really good spinal cord injury.

Researcher: So is [name of overseas specialist] attached to one of those hospitals?

CNC: Gillette children's hospital. [Name of hospital 2] is another one.

Staff specialist (SS): so [name of o/s specialist] is a neurosurgeon?

CNC: yes, she does sdr 3 with [name of local neurosurgeon]

Neuropsych: I was at school with a Gillette. She used to get 'the best a man can get' (laughter all round)

[Name of SS] what was the conference?

SS: It was a bit of a [name of hospital 2] type meet. Everybody knew each other. I was like a real outsider. They were all [Name of hospital 2] people

Researcher: Did they know where Australia was?

SS: Just - there was one other Australian a surfie type from Victoria.

The content of this excerpt is both social and humorous while simultaneously work related in two ways. First, the staff specialist is an interdisciplinary team member and the conference attended was for professional development purposes. The other team members

\footnotetext{
${ }^{3}$ selective dorsal rhizotomy, a neurosurgical procedure
} 
are asking questions about a section of the health system in the USA. Gaining information and processing this knowledge for future use is one way of learning about overseas professional practices.

\subsubsection{Excerpt four theme 3}

\section{Reflexivity (the recognition that team members are involved in data production and consciously reflect on its meanings) -}

A debriefing about a specific patient after a Brain Injury clinic; a teenage boy who was attended to by an interdisciplinary team (all work the consultation simultaneously) composed of a case manager, registrar and social worker.

Case manager: Did you notice that a question that you asked him [Name of registrar] and he didn't know and so just immediately goes to Mum and says did I? Like automatically.

Registrar: Yeah.

Social worker: Before the clinic when I saw him by myself there were a couple of things I asked him and he said 'you'll have to ask Mum about that because she knows'. I said 'well, I have spoken to your mum but I want to know what you think.' You can [try to get the patient to answer for him/her], you have to have the time, initially take it slowly, ... in there but doing that in clinic you don't always want to do that. I saw a boy last week with [Name of rehabilitation pediatrician], a teenage boy younger than [Name of patient], with his mum and she spent the first probably ten to fifteen minutes talking about a litany of things he had been doing, rather than the case, and I watched him get really, really teary, nearly into his shirt and [Name of rehabilitation pediatrician] turned to him and said '... do you want to say something about what Mum's said and he was so choked up that the only thing he could have done next was cry so he kind of just sat there immobilized.

This excerpt is rich in work practices reflexivity. The reflection on work practices is through retelling and revisiting the clinical consultation that occurred earlier in the day. These kinds of reflections occur often when interdisciplinary team clinicians eat their lunch or have a quick cup of coffee. It is the backstage dialogue that complements and expands knowledge sharing about the front stage formal clinical consultation. The difference between the backstage and the front stage is that in the latter each clinician has a specific professional role with accompanying tasks to perform in relation to the patient. In the backstage the individual professional identities become less significant as the collegiality of the group emerges in the informal social setting.

\subsubsection{Excerpt five theme 3}

\section{Reflexivity (work flow and time management)}

Registrar: ... I was agonizing at one point because you guys were doing really well and he [the patient] was opening up and lots of things Mum needed to say and I knew I had another patient in the waiting room who'd been out there half an hour

Case manager: That was fine, you just slipped out

This excerpt captures the individual clinician's sensitivity to the consultation process. The registrar is mindful of how well the social worker and case manager were doing in eliciting 
responses from the patient, after a slow start. She is mindful of other patients waiting and how long they have been waiting. She needs to time manage. An unobtrusive departure is negotiated and acknowledged by the case manager 'you just slipped out'. There is little or no disruption to the flow of the consultation at a crucial point where the patient was opening up. The registrar, although not as experienced as the other two clinicians, recognized their expertise in drawing the patient out.

\subsubsection{Excerpt six theme 4}

Affective talk

The outpatient team physiotherapist came to the tea-room in the Rehabilitation Department to report a mother was 'spitting chips' because her daughter had not had the tests and had fasted all day. How the story was retold in the tea-room is described in Fig. 1. $\begin{aligned} \text { Physio : } & \text { (visibly tired and frustrated) and I walked in to ... After I had all the } \\ & \text { seating }{ }^{1} \text { stuff done and ... this is hard work }\end{aligned}$

Staff Specialist : (smiling) just tell us the story, please

Physio : Mum was obviously upset and I said: 'And how are you?' And she said: 'Don't even ask' And she got quite teary because she was quite upset earlier in the morning because [name of child] upset because she hasn't been fed and...2 she just said: 'She hasn't eaten, she hasn't had breakfast, she hasn't had lunch, and we're still waiting for the MRI so now it's just been cancelled has it?'

CNC : (Name of Registrar) got a call when we were on rounds before, saying that ... they couldn't fit her in, the MRI person, they couldn't fit her in, ... they had to cancel it and that she feels bad because they keep on fasting her and then it's cancelled.

Physio : (Name of patient) has fasted all day (pause) all day ...

CNC : ... They physically can't fit them in, but they feel really bad, you know, I'd feel really bad about that but they just can't fit her in. ... Everything's fallen apart.

Physio : this kid's fretting and ticking $a n^{\prime}$... I just don't know in ... (Name of place) ...I've just got to slip back down.

Social worker : So is (Name of social worker) looking after her, (name of social worker)?

CNC : She saw her on Monday afternoon. I don't know what other contact she's had... (Name of Rehabilitation Fellow) and I saw her for about an hour yesterday and um Mum was really quite teary then ...

Physio : and when I went down there before I said: Why don't you just go for a walk, and you've got your phone and if the ward need to call you ...'

1) This child is having a specialized seating system made. The physiotherapist had overseen this earlier. The child was extremely distressed at the seating assessment.

$\left.{ }^{2}\right)$ Having a general anesthetic requires the patient to fast for up to 4 hours before the procedure.

Fig. 1. Affective talk 
This example of affective talk is the result of an incident involving an inpatient. In one sense it is an incident like any other mundane everyday work incident but the emotional labour of frustration it generated for team members was high. The staff involved were enabled to debrief and find sanctuary and solace in the tea-room talk by telling the story. This was particularly poignant for the physiotherapist who felt responsible for the situation that had arisen. By telling her story she expressed her frustration with a system (the hospital) that is stretched to the limit at times. The space allows individual team members the freedom to talk the affective talk. The talk is valued, even if unconsciously because it enables the individual a space to free oneself up from the affect - to disembody it, to take a rest before moving back into the front stage again to become the professional managing damage control with the patient and family.

\section{Discussion}

There are two emerging dominant themes: a service unit tea-room is recognized as a valuable structural space for team communication structures (informal vs. formal), and backstage activities such as debriefing and informal learning are engaged in regularly during heterogeneous interactions (see diagram 1 re physical space of commandeered tearoom).

Space can be viewed as being both a physical site and a social space in which social relations are enacted. In this latter sense a site is ideologically demarcated and separated from other places. Different messages and communications take place there (Kuper, 2003) and values are attached to them. Sites are verbally and spatially identified. The reallocation of social and physical space results in a redistribution of space and the creation of new spatial foci (identity). In our study the reallocation of a demarcated doctor's interview room to become a service unit tea-room by the clinicians themselves identifies certain values and meanings to that space. Over the time the ethnographer worked in the unit, in the internal orientation plans given to new registrars, the name of this space changed. For example:

\section{The space was called:}

\begin{tabular}{|l|l|l|l|}
\hline Original Plan & 2005 & 2006 & 2007 \\
\hline $\begin{array}{l}\text { 3B Med Staff } \\
\text { CAD56 }\end{array}$ & $\begin{array}{l}\text { FAMILY INTERVIEW } \\
\text { ROOM }\end{array}$ & THE TEA-ROOM & THE TEA-ROOM \\
\hline & Aka tea-room & & \\
\hline
\end{tabular}

In social space social relations may include hierarchy, of professionals for example, this means space is also place at the individual or group level (hospitals).

"places come into being through praxis (activity), not just through narratives (spoken word)"

(Rodman, 2003, p. 207).

Having a space to call one's own or territoriality is important for workplace identities (Kuper, 2003). Erving Goffman (Goffman, 1963), in analysing the micro-geographies of organizational life, defined social spaces as either front stage or backstage with each portraying different performances and different selves. For example, for restaurant staff the front stage is in the 
dining area with the guests, the backstage is in the kitchen. A waiter displays different selves in these two adjoining yet different spaces. Backstages are likely to be less inscribed with conduct regulations and institutional prerequisites. Adams (2008) study substantiates this division of space. Her results demonstrate the importance of 'backstage' areas to refer to informal spaces in hospitals and their importance for "informal learning, social support and the unit's cohesion"(Adams, 2008, p. 3). We assert that the rehabilitation service unit tea-room illustrates some of the characteristics of Goffman's backstage. The tea-room as backstage away from the patients' requirements and demands which are front stage, creates space with time to relax physically, mentally and emotionally. Tea-room social interactions exhibit a change of pace to the day's work activities with informal, unstructured and spontaneous exchanges taking place. Finally, this backstage is an opportunistic space that enables clinicians to reenergize for the front stage to follow, i.e. more clinical consultations - thus establishing a healthy balance of everyday workplace activities.

The activities and verbal interactions of the rehabilitation clinicians in their tea-room is significant because there was $100 \%$ consent to the research project and almost all of the 56 rehabilitation clinicians and administration staff spend time there. The verbal interactions include conviviality, organizational planning, reflexivity, affective talk and emotional labour (Grandey, 2000) as with corridor work described in the literature (Heard, et al., 2003; Iedema, et al., 2005; Long, et al., 2007).

The observations of the clinicians' themselves about their tea-room reveal further dimensions of the value of tea-room talk; the size of the tea-room space was thought to be crucial in its encompassing heterogeneity. The space is not big, sometimes it is difficult to find a seat, but people will stand until a seat becomes available rather than depart the tea-room for another space. Clinicians feel that because they created this space for themselves by usurping another clearly designated space on the original hospital plans symbolizes success in the making. As mentioned earlier, there is a designated meeting room with tea and coffee-making facilities on the other side of the patient waiting room area (See diagram 1). However, it is removed from all the clinicians' offices and, as one long term clinician stated,

"Who wants to walk through a crowded waiting room to have a cup of tea and a break when patients are waiting for your services?"

The centrality of tea-room talk and activity is highlighted in the organization of the clinicians' work. Tea-rooms and hospital corridors (Long, et al., 2007) are not the only spaces outside of designated offices or consultation rooms where work gets done. Adams writes of “opportunistic communication and informal learning" (Adams, 2008, p. 12).

Lancashire et al.(Lancashire, et al., 2003, p. 62) state "the doctors' lounge was a source of medical education and social interaction as GPs and specialists met over a morning coffee before rounds." The tea-room is similar - a space where clinicians socially, educationally and professionally interact with each other about patient-centred care or any number of other topics that make up the dynamic unfolding of the day's events. Again, this is iterated in Adams thesis that shifting the focus from frontstage to backstage areas can enlighten our understandings of clinician fatigue, communication and quality of patient care. She specifically mentions "understanding the detail in communication and interaction patterns that occur in break rooms, lounges, cafeterias, enclosed med rooms, kitchens, locker rooms and utility rooms" (Adams, 2008, p. 110). 
The informal and relaxed tea-room is in sharp contrast to the clinic or consultation context, the formal clinical diagnostic consultations or teaching and learning sessions as in lectures or formal structured meetings. It is backstage space that underscores a social focus but other foci occur as well. There is fluidity to the foci - social, professional or unstructured. These heterogeneous interactive sessions are important informal collaborative interactions in informal spaces where multidisciplinary teams congregate.

Contrasts extend to the use of hospital tea-room space in other parts of the hospital. Based on the ethnographer's five years experience of research conducted in hospital settings, the shared, larger tea-room located between the pediatric intensive care unit (PICU) and neonatal intensive care unit (NICU) has an invisible but well-known and acknowledged demarcation line drawn down the middle of the room when it comes to seating (C Hunter, et al., 2008) . The Pediatric ICU nurse clinicians sit on one side and the NICU nurse clinicians sit on the other. The fridges, sink, lunch and snack-making facilities are shared spaces, but to sit down to eat one's lunch, read a magazine or watch TV are not. The administrative and cleaning staff sit at two round tables, occasionally registrars eat their lunch there and spasmodically a staff specialist might stop for a cup of tea. The occupants sit and read, use their mobile phones, watch TV or chat amongst themselves. The structure and this invisible demarcation has an effect on what is enacted there.

In another larger clinicians' tea-room visited once by the ethnographer, the physiotherapists' service unit tea-room, the occupants were all of the same profession or worked in the same department. The dynamics were differently enacted.

\subsection{Informality and workplace learning}

Learning at work constitutes a large part of adult learning (Boud \& Middleton, 2003). The role of workplace learning in the context of patient safety and quality of care has not received the attention it deserves. The patient safety literature emphasizes the role of effective communication and good teamwork, but few compelling accounts are offered of what these phenomena look like (Runciman, Merry, \& Walton, 2007; Vincent, 2006 ). When clinical processes are investigated in ethnographic detail and here we include tea-room talk, it transpires that clinicians engage in mutual, if informal interaction and learning on an ongoing basis (C Hunter, et al., 2008; C Hunter, et al., 2008) .

Informality promotes social intimacy. For example, in Excerpt 4 Theme 3 peers or colleagues share their perspectives about how this particular consultation process unfolded. Others who know the family from previous times join in, or express opinions about past experiences around similar issues. It is about the recognition of work practice skills which encourage the participation of the parent and child to give their viewpoints, when and where and being alert to visible signs of distress or discomfort of the patient, and how to handle that and move on from there. Memory and experiential knowledge of this or other similar patients is provided by other clinicians' accumulated and tacit knowledge.

In Excerpt 5 Theme 3 it is the tea-room dialogue which allows a space for positive learning for the registrar from the more experienced team members. Their affirmation that 'you just slipped out' from the consultation affirms for them her sensibility to the consultation flow, the team's interprofessional collaboration (Sinclair, et al., 2009) and her perception of their expert engagement with the patient. 
These ongoing kinds of learning exceed the structured opportunities for learning defined for clinicians' workplace learning (Colley, Hodkinson, \& Malcom, 2003; Eraut, 2004) as in learning 'on the job' literally in a clinical consultation for example. Our account shows that horizontal or informal learning is crucial for enabling people to do their personal work while ensuring the quality and safety of clinical processes. Clinicians' work practices are becoming increasingly complex at a time when the patient population who need chronic care is increasing (Sobo, 2009).

The literature on organizational learning emphasizes that learning is both product (something learned) or the process that yields such a product (Argyris \& Schön, 1996) - the dialogical ${ }^{4}$ process of tea-room conversations. For example, opportunistic interactions that occur around administrative planning inform and expedite the organizational activities that are part of any large hospital department.

\section{Conclusion}

Spaces such as the tea-room described in this paper have a backstage and informal quality that complements the front stage or formal quality of the rehabilitation team's professional clinical work.

Informal work practices in a designated structural space within a service unit enhance teamwork communication and efficacy of formal work practices.

Clinicians value the informality of the backstage because it provides sanctuary, a rearrangement of the professional and personal relationships and the opportunity for informal learning in the work place.

When clinical processes are investigated in ethnographic detail including tea-room talk, it transpires that clinicians engage in mutual, if informal, interaction and learning on an ongoing basis.

The tea-room backstage space is away from the intensive, complex and different world of the formal tasks and responsibilities carried out in the outpatient clinics, the ward rounds of inpatients and the administrative work each clinician is required to undertake in their everyday practices.

\section{Acknowledgement}

Our thanks to all the staff in the rehabilitation unit who participated in this study. This research was supported by an Australia Research Council Grant awarded to Professor Rick Iedema, the University of Technology, Sydney Australia.

\section{References}

Adams, R. (2008). The Role of of Physical Design and Informal Communication and Learning in Gaining Competency and Reducing Stress among Graduate Nurses. Master of Science, Cornell, Ithaca.

\footnotetext{
${ }^{4}$ Dialogical - characterised by dialogue
} 
Argyris, C., \& Schön, D. (Eds.). (1996). Organizational learning II: theory, method and practice. Reading, Mass:: Addison-Wesley.

Baldry, C. (1999). Space - The Final Frontier. Sociology, 33(3), 535-553.

Boud, D., \& Middleton, H. (2003). Learning from others at work: communities of practice and informal learning. Journal of Workplace Learning, 15(5), 194-202.

Carthey, J. (2006). Humanising the hospital environment. Hospital $\mathcal{E}$ healthcare, December 05 January 06, 18-21.

Chastain, B. (2008). Through the eyes of a clinician (pp. 1-4).

Colley, H., Hodkinson, P., \& Malcom, J. (2003). Informality and formality in learning: a report for the Learning and Skills Research Centre Lifelong Learning Institute (pp. 111). Leeds: University of Leeds.

Denzin, N., \& Lincoln, Y. (Eds.). (2005). The SAGE Handbook of Qualitative Research (2nd ed.). London, Thousand Oaks, New Delhi: Sage Publications.

Eraut, M. (2004). Informal learning in the workplace. Studies in Continuing Education, 26(2), 247-273.

Geertz, C. (1973). The Interpretation of Cultures: Selected Essays. New York: Basic Books.

Goffman, E. (1963). Behaviour in Public Places. New York: The Free Press.

Goffman, E. (1973). The presentation of self in everyday life. Woodstock, N.Y.: Overlook Press.

Grandey, A. (2000). Emotional Regulation in the Workplace: A New Way to Conceptualise Emotional Labour Journal of Occupational Health Psychology, 5(1), 95-100.

Hall, E. (1959). The Silent Language. Greenwich, Connecticut: Fawcett.

Hall, E. (1966). The Hidden Dimension. New York: Doubleday.

Heard, S., Roberts, C., Furrows, S., Kelsey, M., \& Southgate, L. (2003). Corridor Consultations and the Medical Microbiological Record: Is Patient Safety at Risk? Journal of Clinical Pathology, 56(1), 43-47.

Hunter, C., Spence, K., McKenna, K., \& Iedema, R. (2008). Learning How We Learn: An Ethnographic Study In Neonatal ICU. Journal of Advanced Nursing, 62(6), 657-664.

Hunter, C., Spence, K., \& Scheinberg, A. (2008). 'Untangling the web of critical incidents': Ethnography in a paediatric setting. Anthropology \& Medicine 15(2), 91-103.

Hunter, C., \& West, C. (2010). The challenge of positive outcomes for children with complex congenital conditions: Safety and continuity of care Health Sociology Review 19(1), 87-100.

Iedema, R., Long, D., Carroll, K., Stenglin, M., \& Braithwaite, J. (2005). Corridor work: how liminal space becomes a resource for handling complexities of multi-disciplinary health care. Paper presented at the Asia-Pacific Researchers in Organization Studies, Melbourne, Australia.

Johnson, N., Cook, D., M.Giacomini, \& Willms, D. (2000). Towards a "Good" Death: End-oflife Narratives Constructed in an Intensive Care Unit. Culture, Medicine and Psychiatry, 24, 275-295.

Kuper, H. (2003). The Language of Sites in the Politics of Space. In S. Low \& D. LawrenceZúñiga. (Eds.), The anthropology of space and place: locating culture (pp. 248-263). Malden MA: Blackwell Publishing.

Lancashire, W., Hore, C., \& Law, J. (2003). The hospitalist: a US model ripe for importing? Medical Journal of Australia, 179(1), 62. 
Long, D., Iedema, R., \& Lee, B. (2007). Corridor conversations: Clinical Communication in Casual Spaces. In R. Iedema (Ed.), The Discourse of Hospital Communication (pp. 182200). Basingstoke and NY: Palgrave Macmillan.

Mays, N., \& Pope, C. (1995). Qualitative Research: Observational methods in health care settings. BMJ, 311, 182-184.

Mroczek, J., Mikitarian, G., Vieira, K., \& Rotarius, T. (2005). Hospital Design and Staff

Perceptions: An Exploratory Analysis. The Health Care Manager, 24(3), 233-244.

Pope, C. (2005). Conducting ethnography in medical settings Medical Education, 39, 11801187.

Rodman, M. (2003). Empowering Place: Multilocalilty and Multivocality. In S. Low \& D. Lawrence-Zúñiga (Eds.), The anthropology of space and place : locating culture. Malden MA: Blackwell Publishers.

Runciman, B., Merry, A., \& Walton, M. (2007). Safety and Ethics in Healthcare:A Guide to Getting it Right. Burlington: Ashgate.

Seidel, J., Friese, S., \& Leonard, D. C. (2006). The Ethnograph v5.0, from http://www.qualisresearch.com/

Sinclair, L., Lingard, L., \& Mohabeer, R. (2009). What's So Great About Rehabilitation Teams? An Ethnographic Study of Interprofessional Collaboration in a Rehabilitation Unit. Archives of Physical Medicine and Rehabilitation, 90, 1196-1201.

Sobo, E. (2009). Culture E Meaning in Health Services Research. Walnut Creek, California: Left Coast Press.

Vincent, C. (2006 ). Patient Safety. London: Churchill Livingstone. 


\title{
Visual Mapping of Clinical Procedures Using Ethnographic Techniques in Medical Device Design
}

\author{
Mary Beth Privitera, Todd Abruzzo and Andrew Ringer \\ University of Cincinnati
}

USA

\section{Introduction}

Medical device users have a symbiotic relationship with their tools. They are adaptable and highly resourceful when targeted towards reaching their clinical goal. As a result, the ability to make sound decisions regarding the user device interface and subsequent device design requires a fundamental understanding of how device users work, how they are trained, and increasing tacit knowledge as gained through experience. This chapter presents a case study on the design of a novel catheter user interface utilizing ethnographic techniques with emphasis on contextual inquiry to determine and define design opportunity and subsequent design requirements. Integral to the project, a visual mapping of ethnographic information was generated and used to both inform the design team about the context of complex procedures to guide design decisions as well as an alternative use as a training tool for novice device users. This guide demonstrates visual ethnographic information and has been successfully used by both product development teams and in the Mayfield Clinic Endovascular 101 course material. This course targets young inexperienced practitioners and serves as an introduction to a complex type of clinical procedure.

Active use of video ethnography combines a richer sense of understanding and mandates a level of collaboration with all parties involved (Spencer). The priorities between each participating group had to be negotiated and renegotiated throughout the study to determine critical elements and assess which aspects were required to be highlighted. This transparent approach provided a rich foundation for new device design opportunity identification and collaborative mapping. This further elicited data from personal memories and experiences to form a collective intelligence as historical record and advanced training materials. By focusing the research team on answering "so what?" the technical aspects of practice are uncovered and the requirements of device design in this arena were determined.

\section{Visual research, mapping and ethnography}

Visual research methods provide a deeper and subtler exploration of social contexts and relationships are recognized allowing us to see the everyday with new eyes (Spencer). In using photographic techniques in conjunction with ethnography the captured images are used to highlight the truthfulness of appearance and/or the explicitness of performance. In 
medical device design (or product development in general) objects can seem to have a social life of their own and are links to a complex system of production through consumption and exchange. This in turn has value of identity, monetary and social gain (Spencer). The goal of conducting this type of research is to inform a design team about the lifecycle of a device, the devices used in conjunction with a target device and evaluate the relationship the device has with the user as an extension of the user's body. By designing tools as extensions of a user, design teams practice user-centered design and proven human factors principles.

Ethnographic research has been formally conducted for the medical device development industry for the past 10 years (Wilcox). These research techniques are widely used to generate and define opportunity gaps and/or unmet user needs. This method affords a rich experiential understanding of user behaviour that when documented in a usable visual manner can inform design teams in regards to the social interactions and overall flow of user-device-procedure in terms of Whom? Did what? With what? Why? User challenges? Mitigations? As well as identify subsequent design implications. Most interesting to note in using ethnography in medical device design is the discovery that users (surgeons, in general) do not perceive high stress with a negative connotation. In fact, it is this challenge with which they thrive and we as patients benefit. Using the techniques described below, it is possible for a design team to uncover those aspects of a procedure or device design that should be changed based on preferences and those that must be addressed in order for the practice to advance.

\subsection{Methodology: Contextual inquiry}

For clinical procedure background, interventional radiology generally involves the treatment of human disease by therapeutic alteration of internal anatomy and physiology using devices that are deployed and controlled from remote percutaneous access sites with indirect visual feedback provided by trans-corporeal imaging systems that include ultrasound, fluoroscopy, computerized tomography and more recently magnetic resonance imaging. In many interventional radiology procedures, the blood vessels (arteries and veins) are used as conduits for navigation of surgical instruments to the treatment site. Oftentimes the blood vessel itself is the treatment target, and so the vessel serves as the surgical workspace. In interventional neuroradiology practice, endovascular procedures involve maneuvering fine wires and coaxial tubes called catheters, most often from the groin region to the arteries that nourish the brain. To accomplish this, interventional radiologists (users) rely upon image guidance (fluoroscopy) which demands of them numerous mental models, cognitive loads and physical interactions during any given procedure. Specifically, they rely upon their personal dexterity and tactile sensitivity in manipulating the catheters, with very few assistance tools, and must be infinitely familiar with anatomical structures for navigation throughout the body. They rely heavily on tacit knowledge for an expedient procedure. While there are a host of standards applicable to device design in general (AAMI/ANSI HE 75) there are no design standards nor ergonomic recommendations available to improve the interaction of catheters with their operators. This has been identified as a weakness within the industry as is a target research area for the application of ergonomics to device design.

Since physicians have no other choice but to use the devices currently available, the ability to recognize inefficiencies due to poor ergonomic device design is often overlooked. In contrast, all medical devices are subject to challenging requirements vis a vis clinical efficacy and safety. As a result of this dichotomy there is an opinion of acceptance since the clinical 
efficacy and safety is obviously most important. The methodology presented highlights challenge areas as uncovered during this research.

In conjunction with the University Hospital and Department of Neurosurgery (Cincinnati, $\mathrm{OH}), 24$ diagnostic cerebral angiogram cases were observed and documented via the developed multi-channel video system. Todd A. Abruzzo, M.D. and/or Andrew J. Ringer, M.D. served as the attending surgeon for each case, and in some cases provided instruction to one of five fellows with a ranging degree of experience - first year fellowship experience to final year fellowship experience. Prior to collecting data, IRB approval and patient consent was requested and granted. The diagnostic angiogram cases were documented and characterized using a system of careful notetaking, photography and videography units within the surgical theatre (as shown in Figure 1; numerical figures represent data recording locations). Clinicians provided study members with literature review of training manuals prior to beginning the data collection series and were interviewed throughout the study to confirm findings.

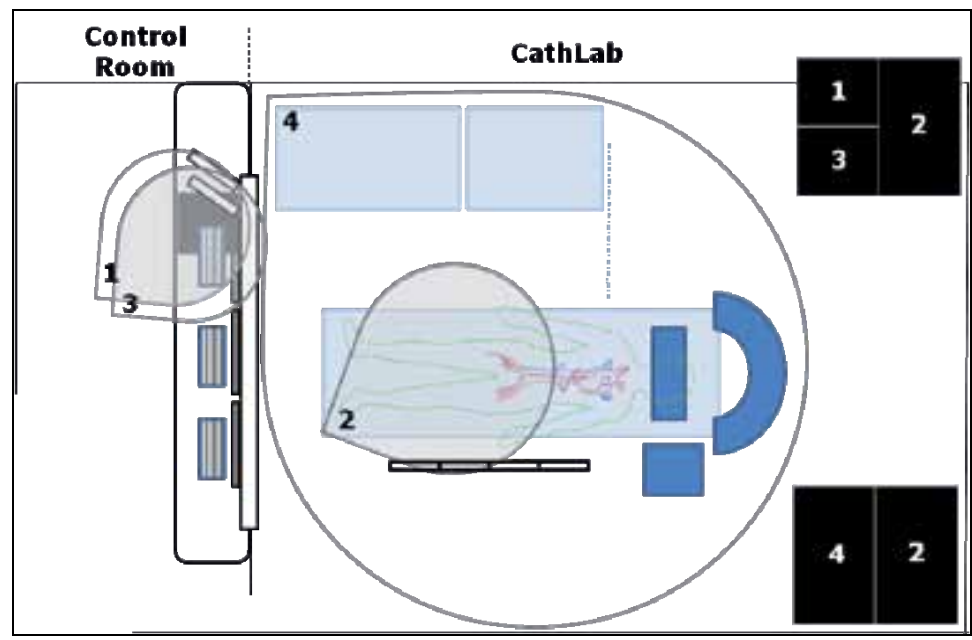

Fig. 1. Surgical Theatre Set-Up

All study participants were observed conducting diagnostic cerebral angiograms and interviewed in-depth. During the interviews participants were asked to describe each step of performing a diagnostic angiogram. In the case of the participants who were currently being trained to accomplish these procedures, they were asked to highlight the differences between the attending physicians. In completing this interview highlighting preferences, a further depth of understanding by the research team was achieved while avoiding any judgement and with the recognition that all techniques represent valid approaches much like the methods and means of "skinning a cat."

An additional technique of using visual metaphors in imagery was used to determine user preferences around a particular step in the procedure. Participants were provided a set of image stickers to which they would adhere the image which best reflects their opinion regarding each step they identified in the procedure. Once all steps had correlating images the research team asked the participant to interpret the selection. This interpretation of visual language can create vivid and authentic personal narratives (Spencer) and in this case determined the emotive context of the procedure. This technique has been adopted and 
practiced within the medical device industry in companies such as Johnson and Johnson and several industrial design consulting offices.

\subsubsection{Data analysis and procedure map development}

Multichannel video was edited into a 4 channel display allowing the research team to capture both the distal working end (internal to the patients body) as well as hand-eye motions of the use (outside the patients body). Video analysis determined ultimate measures and key stages of the clinical procedure. An initial map was developed explaining each step in the procedure with descriptive detail.

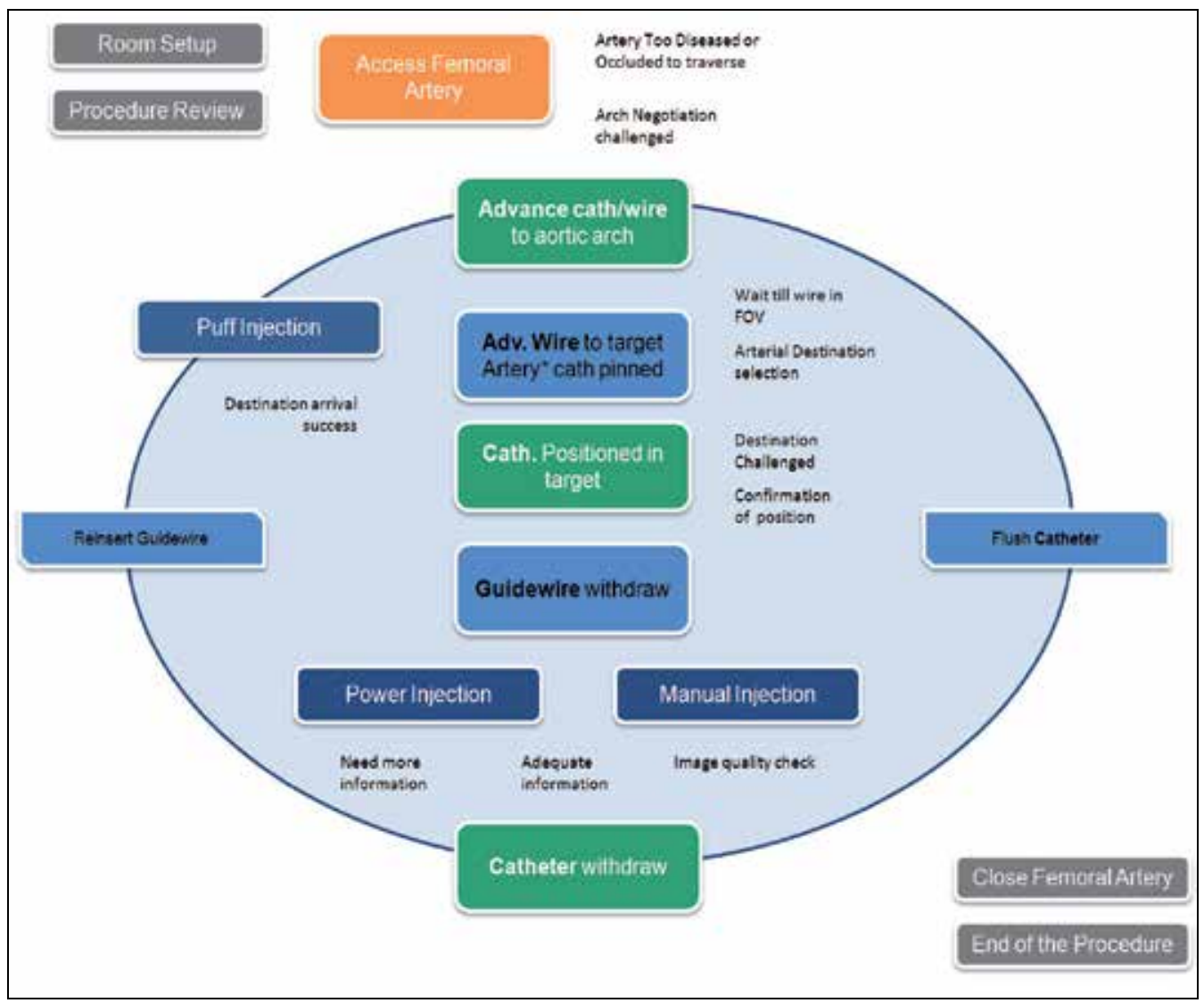

Fig. 2. Basic Procedure Flow (Procedural steps vary somewhat depending on user preference)

\subsubsection{Interpreting results for design}

Many aspects of ethnography determine aspects of a user group which while important in understanding the users behaviours; beliefs and culture do not directly correlate to design directives. For example, the users reliance on visual cues to complete the procedure operate on the most basic level of human perception, yet there is a great deal we do not understand about the complex process of recognition and its attribution of meaning (Spencer). Since we 
are unable to instrument the practicing clinicians this researched solely focused on hand movements specifically to identify which actions of the hand resulted into what behaviors of the catheter at the distal end (farthest most end inserted into the body).

Virtually all catheters are round in cross-section and vary in their durometer (stiffness) throughout their overall length, getting increasingly more flexible towards the distal end and stiffer at the interaction point. The only input a user can have is to either push or pull the catheter and to torque it at a preferred rate to improve the likelihood of directing it to a desired location. As the ethnographic research indicated, a critical component of successful navigation with the catheter technology to the clinical region of interest is efficient and effective guidance of the catheter and guidewire assembly. However, becoming effective and efficient in advancement requires many years of experience. A contributing factor of the difficult learning curve is due to the lack of users awareness in respect to the input torque. The current technology does not provide a haptic or cognitive load that the user can interpret and assess during the advancement phase.

Through root cause analysis these tasks can be simplified in the context of the overall clinical procedure. Emphasis is placed on verifying translation into design criteria with users as design interpretation could be incorrect and negatively impact the design solution. To improve interaction the design team developed the following set of criteris for an improved catheter interface design:

- Stiffness at the proximal end (user interaction point) must be equal to or better than current devices.

- Center lumen of the catheter must remain tubular in order to conform with compatible guidewire for proper advancement

- $\quad$ Feedback of torque between index and thumb must be increased (perceptually) by users with gloved hands

- Manufacturing techniques of extrusion must be considered without significant increase in cost of manufacture

Since the ideal surgical instrument is a contiguous extension of the haptic unit (the hand) that enables an expanded range of effector actions and environmental effects, the design team looked for comparative technologies and/or actions with the same conditions as motivations. For example, in sewing while tying a knot the user simply wraps the thread around their thumb/finger then rotates to achieve an intertwining. In this example, the amount of rotations of the thread work advantageously to tie a better know while the user has little idea exactly how many times the threads are interwoven. In reality, there is an interface between the hand and the surgical instrument creating a barrier that introduce variable levels of interference and impedance between the cognitive process and the intended task. The challenge put forth by the design criteria is to somehow improve knowledge of a condition which is given little thought while maintaining the positive elements of current catheter design.

The proposed design solution is to modify the section of interaction as indicated in figure 3 below. The area of opportunity is approximately 20 inches from the proximal end.

In this area of the catheter there is no tissue interaction per se rather this section is largely for manipulation and has a strengthened inner core which improves device manipulation. In maintaining our design criteria and allowing an open brainstorm session the following cross-sections were determined to be possibilities as shown in figure 4 . 


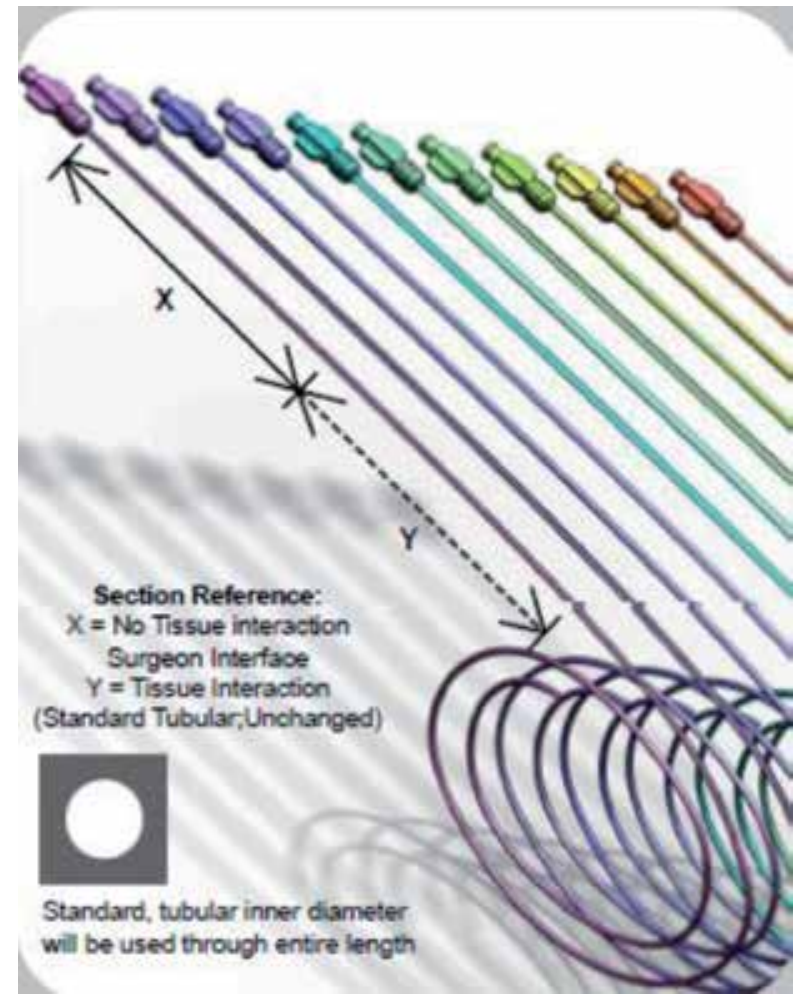

Fig. 3. Catheter Interaction Area 1

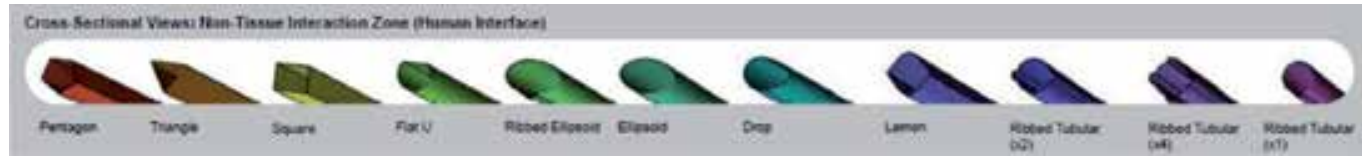

Fig. 4. Variable Interface Geometry 1

While each of these concepts are viable options only a few were modelled for design verification and usability testing. Again, the design team referred back to the original ethnographic results to set up concept verification testing. In using a glass model of the vascular system, users were asked to use the concept catheter as well as the existing catheter to navigate the aortic arch to the innominate artery. The objective of the study was to collect torque, rotation, and time metrics during simulated use to characterize operating profiles for both current state of the art and catheter interface devices. The method used was to instruct users to navigate concept design through simulated vascular model until the catheter distal end-effector has passed a designated line within the right subclavian. Note: the users conduct the test twice per sample. An example of the results from this study are shown in Figures 5 and 6 . Our conclusion is that the revised catheter interface may provide a more controlled and defined work path as shown by decreased change in amplitude oscillation for rotation and torque profiles. 


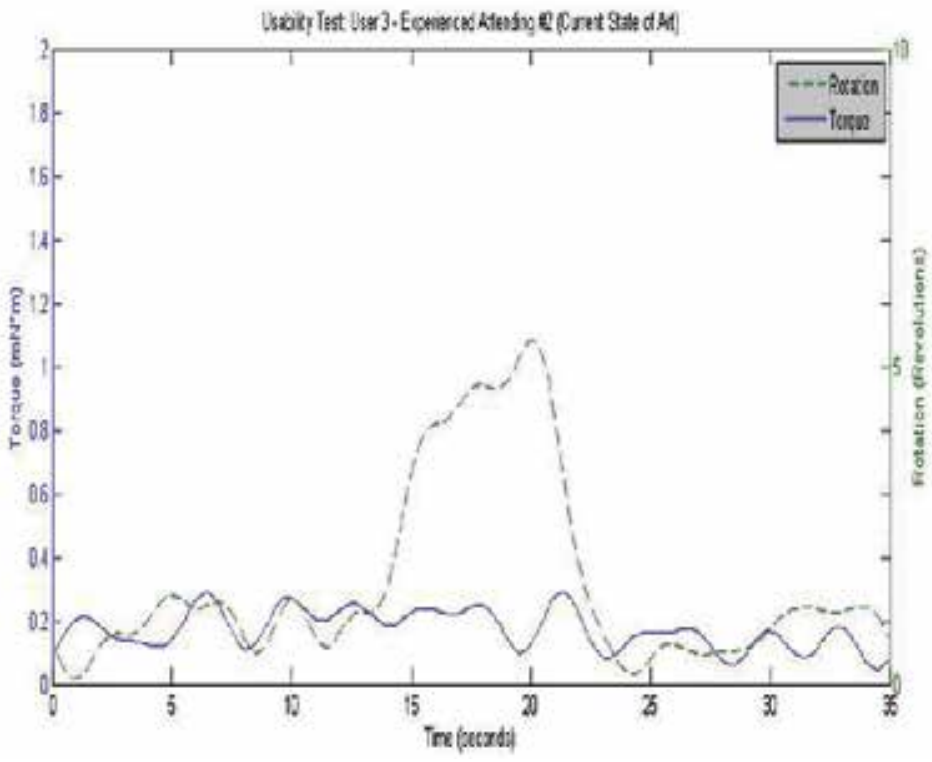

Fig. 5. Current Catheter Design 1

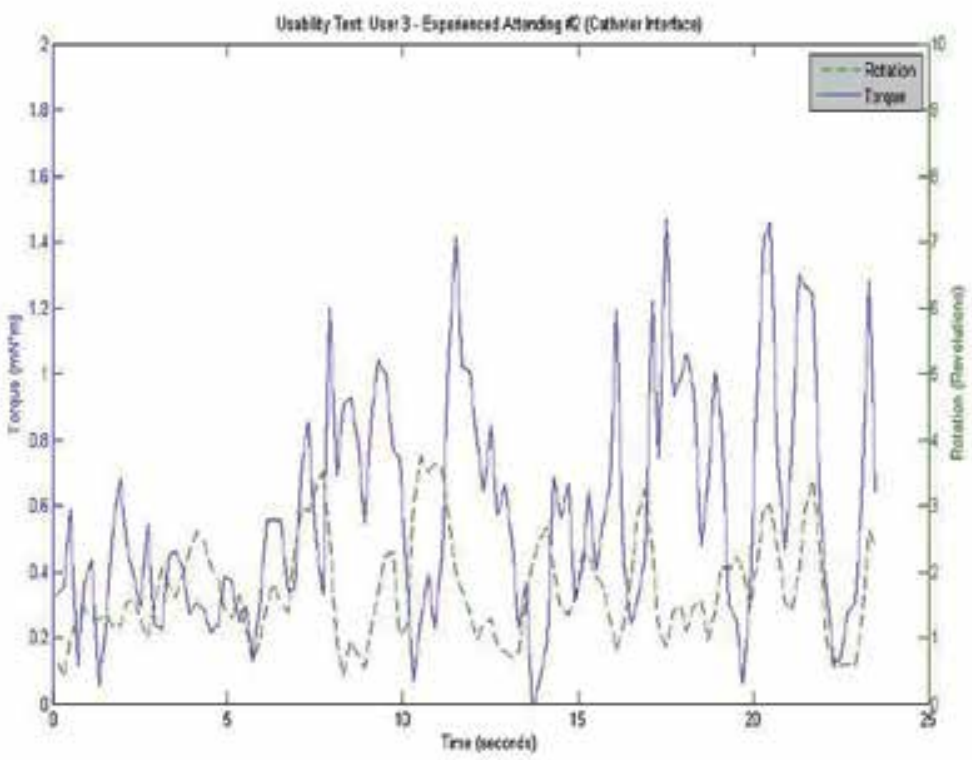

Fig. 6. Conceptual Catheter Design 1

Ethnography provided the foundation of the design proposal and subsequent verification testing. As a result of the collective efforts across various disciplines it was determined that a " $\mathrm{D}$ ' shaped cross-section produced at the proximal interaction length of the catheter is the optimum design configuration to improve haptic feedback of potential energy and prevent redundancy. Figure 7 below depicts the optimum design. 


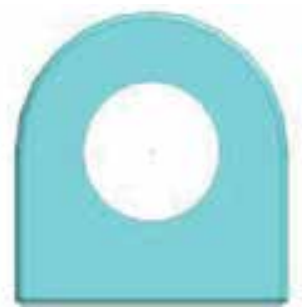

Fig. 7. Ideal Catheter Cross-section 1

\subsubsection{Interpreting results for training}

The procedural map (Fig.8) results of this ethnographic study were re-tooled as guidance to introduce the steps, tools, anticipated challenges-mitigations, and user variances to inform and educate new users who are about to perform diagnostic cerebral angiography.

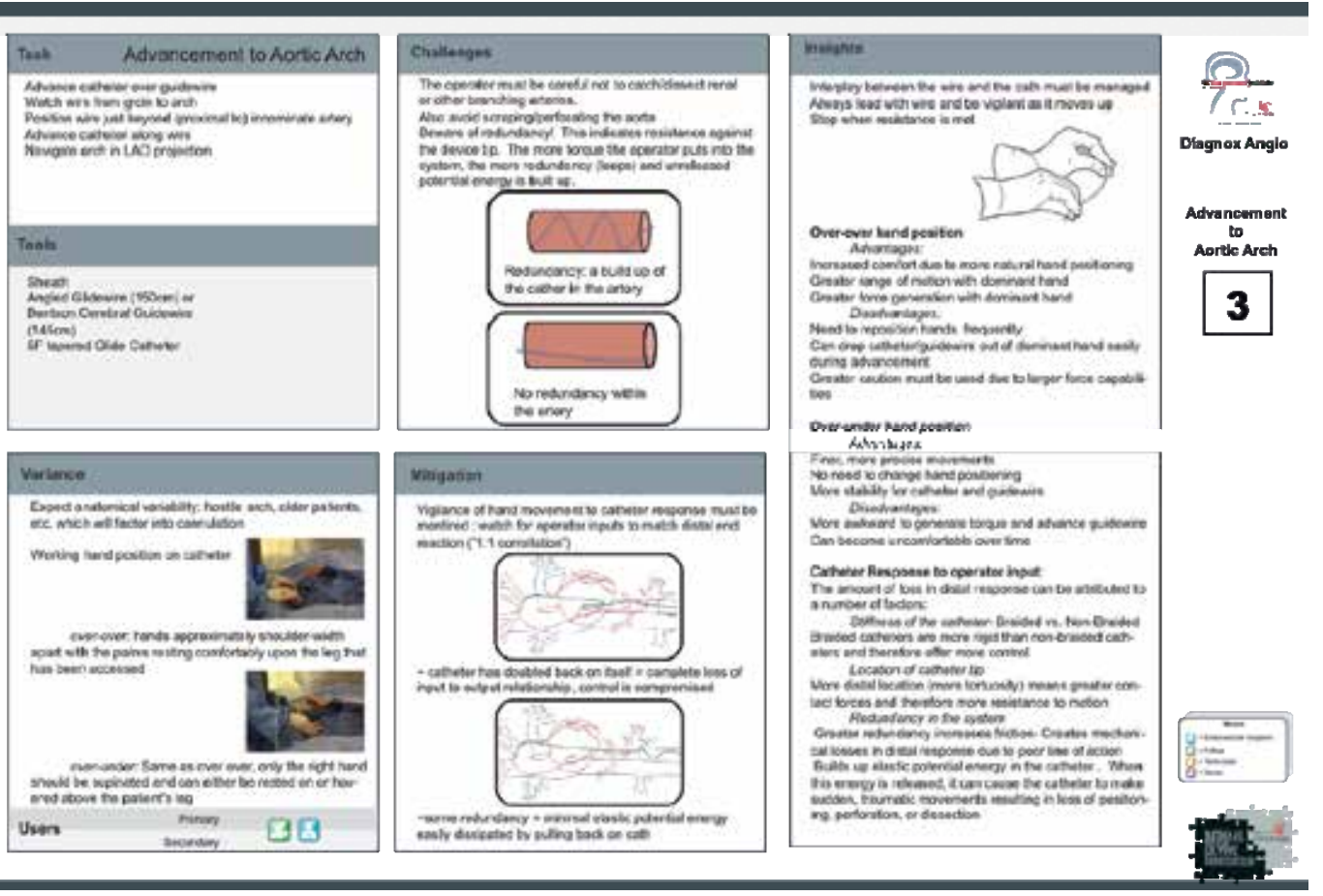

Fig. 8. Training Procedure Map Example

This type of procedural medicine is highly dependent upon technical performance, adherence to accepted protocol may be of paramount importance. The safe and effective performance of medical procedures requires a complete understanding of the technical steps required, mastery of performance of those steps and their performance is the proper sequence. Omitting or altering even a single step may have significant consequences. The two physician authors (AJR, TA) have participated in the performance and teaching of cerebral angiography for many years and direct an introductory course on its performance for trainees from around the country. Cerebral angiography is a common medical procedure with a low tolerance for complications 
$(<1 \%)$ and wide applicability across multiple services and institutions. Standardization of the performance and reporting of the procedure aids in communication across these services and institutions. The procedural diagram has helped in this endeavor in two fundamental ways. First, the careful and complete analysis of each and every step of the procedure allows novice usersto assess and improve the efficiency of each step and to eliminate errors. Review of the diagram helped to identify the most variable and time consuming steps of the procedure and to consider improvements in those steps. Since the goal of the course and training are to produce physicians who are safe and effective performers, identifying the "weak links" is invaluable. Second, the procedure diagram is a visual and interactive teaching tool for our trainees. Following the sequence of steps and the alternatives in a clear and visual diagram makes understanding of each step and the procedure as a whole easier.

As discussed in "Doing Visual research" unlike traditional research methods ethical questions of confidentiality and anonymity were prevalent during this study. Inherent to visual research are the blurring of boundaries between participation and observation. Since this research was conducted in analysis of a complex medical procedure, participation by all levels of clinical leadership were required to attain a depth of understanding.

This study was IRB approved and followed best practices with regard to human subject research. However, due to the visual nature it is impossible to adequately anonymize all of the visual data (DVR). In review and data analysis it is possible to identify performance challenges and best practices based on individual preferences. For example, the design research team noted differences in the number of support personnel required and the subsequent job functions as part of the entire system. Since our results could have the potential negative impact and influence willing participation, this detail was reviewed as superfluous and discarded. Additionally, timed performance to complete the procedure was diligently managed at the onset of the study. This measure proved counter productive as there is an inherent reliance of visual perception by the clinical practitioner to determine what steps are required next based upon the patient's vascular anatomy. Since we 'read' images in front of our eyes through the pictures we have in our heads (DVR), individual interpretations depended on previous knowledge and prior codes developed over time. As a result there is a bias in experience and overall technique.

As discussed earlier, observation and interference gets blurred in visual research anonymity is compromised despite best practices as mandated by IRB protocols. In this research effort this was very true. This affects perceived performance or lack thereof and what the team views as a measure. Another example noted during this study was the variance on amount of interim hand cleaning throughout the procedure. In order to better understand the significance or lack thereof the research team questioned the attending physicians. Once cued into this variability, they in turn became more cognizant. Thus we observed and by highlighting the difference we now unintentionally interfered albeit in a positive direction.

\section{Conclusion}

Surgical or catheter based interventions are complex procedures. The current combination of experience and tools that the physicians have, afford them enough control to turn their intentions into actions. However, there are numerous barriers between the user intentions and how they translate these into actions. These barriers happen simultaneously and are haptic feedback, environmental conditions, and visual discrimination. 
The use of visual mapping techniques of clinical procedures within ethnography can be a powerful tool to determine unmet user needs as well as other areas of improvement in the context of use. In essence by collecting the data and designing the data to meet the needs of multiple stakeholders, in this case a product development design team as well as clinical training, an increased depth of overall understanding is achieved. Mapping assures communication of research findings across various disciplines working in product development and confirms design assumptions with users. Compensatory user strategies are uncovered in the clinical context and a clearer understanding for potential error can be analysed for root cause. The re-purposing of an ethnographic procedural map for training purposes facilitates rapid access to organized procedural flow and serves a reference tool for novice users. The in-depth discussion and use of visualizations affords immediate cautions to ill-advised conditions and subsequent strategies of avoidance.

\section{Acknowledgment}

This research is sponsored by NSF Grant \#IIP-0652208 and industry members of the NSF MIMTeC I/U CRC. We would like to thank the University Hospital, the Mayfield Clinic and the following Medical Device Innovation and Entrepreneurship Students: Mike Wirtz, MS BME, Steve Nelson, BS ID, and Joe Strelnick BS BME, As well as previous Clinical Fellows Drs. Usman Khan and Andrew Grande.

\section{References}

Association for the Advancement of Medical Instrumentation. "Human Factors Engineering: Design of Medical Devices." (April 21, 2009) AAMI/CDV-3 HE 75. Revision of AAMI HE48: 1993.

Bridger, R., Karwowski, Waldemar, Dul, Jan, \& Weerdmeester, Bernard. (2001). Ergonomics for beginners. CRC.

Min-yang Wang, E. (2000, August). What is Ergonomics: international ergonomics association. Retrieved from http://www.iea.cc/browse.php?contID=what_is_ergonomics

Mitchell, C. (2011). Doing Visual Research, Sage Publications, ltd.

Privitera, M. (2009). Applied ergonomics: determining user needs in medical device design. IEEE Engineering Medicine and Biology Society

Spencer, S. (2011), Visual Research Methods in the Social Sciences: Awakening Visions, Routledge, NY, NY

Tannen, R. (2008, July 14 and 2009, April 20). Designing for humans: 5 guidelines for ergonomic observation. Retrieved from

http:/ / www.designingforhumans.com/idsa/2008/07/ five-principles-ofergonomic-observation.html

Thomas MOIX PhD. , PhD Dejan ILIC, , Prof. Hannes Bleuler, , \& PhD Jurjen Zoethout (2006). A Haptic device for guide wire in interventional radiology procedures. Medicine Meets Virtual Reality 14:Accelerating Change in Healthcare, 388-392.

Wilcox, S.B., \& Reese, W.J. (2001, September). Design and development: ethnographic methods for new product development. Design Science, Retrieved from http:/ / www.dscience.com/articles/MDDI2001Ethnogra.pdf

Woolcott, H., (2005) The art of Fieldwork, AltaMira Press

Zenios, S., Yock, P., and Makower, J. (2010) “Biodesign: The Process of Innovating New Medical Technologies. Cambridge University Press. 


\title{
Written Reminiscences and Media Ethnography: Television Creating Worldview
}

\author{
Jukka Kortti \\ Aalto University \\ Finland
}

\section{Introduction}

Collecting written reminiscences, ethnographic writing, has a long tradition in Finnish history and folklore studies, and methodologically they have been categorized as oral history research data. In my study ${ }^{1}$ (Kortti, 2007) on the history of Finnish television I used two collections of written reminiscences about television in Finnish everyday life. In this article I introduce the possibilities, the cons and pros, of this kind of research data in ethnographic research, more precisely in media ethnography. Here, besides the methodological issues, I particularly depict how ordinary Finns have experienced the changing of their world views caused by television.

Written oral history data is rarely used in media ethnographic studies. Belonging to the tradition of cultural studies, media ethnography highlights the importance of social and cultural context. In my study, the importance of context is widened to the history of media experiencing. The framing of television viewing is crucial in the study. Besides the television experiences of individuals, it also relates to the institutional, political and economic history of Finnish television. However, the experiences, in their own words, of ordinary Finns lead the narrative. With the help of narrative texts, the researcher is able to get into the narrator's worldview and mentality. Narrative folklore, oral history, memoirs, life histories, legends, humorous anecdotes and gossip can be put in a dialectic relationship with literature, mass communication and official historical writings.

One of the contextual macro-narratives of the post-Second World War Europe are the different modernization processes. Television as a technological and institutional medium operates within the sphere of these processes of society and culture. The modernization process of the 1960s, when the economic structure of Finland changed and the

\footnotetext{
1 The study concerns the arrival, diffusion, and integration of television and its changing technological and cultural role and impact on the everyday life of the Finns and their worldviews during the period from the mid-1950s to the twenty-first century. Besides the institutional, economic, social, and cultural narrative of the Finnish television, there is also an analytic chapter about the changes in Finnish TV viewing in the study. The objects of research are (1) the role of television as an everyday commodity and the impact of television on the (2) worldviews and (3) social interaction of Finns. The discussion of television in social intercourse is divided into the study of changes in family viewing, gender preferences, and social life outside home. More about the study see also Kortti \& Mähönen, 2009.
} 
characteristics of agrarian society disappeared dramatically, was exceptionally speedy, even relative to the scale of all of Europe. In the late 1950s, however, the majority of Finns still lived in rural communities. Before the 1950s Finland was the least developed country in Scandinavia, ${ }^{2}$ but by the early 1970s it had assumed the typical form of most industrialized societies in the world. The Finnish gross domestic product grew sevenfold between 1956 and 1973, for example.

The role of media, particularly television in this development is unquestionable. As it spread aggressively in the United States in the 1950s and in Europe mainly in the 1960s, television influenced not only communication but also a new social life. ${ }^{3}$ Being at the heart of postwar modernism, it offered models for living and for taking part in an increasingly consumptionoriented lifestyle that was mostly private and revolved around family. Television was 'part of the grain of everyday life' (Silverstone, 1994: 22). And you cannot underestimate the role of television being 'the window of the world', 'both magic carpet ride and university'. When studying TV audiences, television has to be considered as a part of highly complicated national and international changes in economy, politics, and technology. 4

\section{Written reminiscences as media ethnographical data}

"The first television at my home was purchased 23 August 1967 when I was 13 years old. I have carefully written about it in my diary." (Female, born 1954) ${ }^{5}$

In media ethnography, the data are usually collected through interviews and participant observations. Television audience studies have mostly been carried out using surveys, interviews (individual or group, themed or informal) and observational analyses. There are several problems with these methods. For example, in the interview situation the chances of 'remembering wrong' are higher than in independent writing, where you are able to use your own archives, such as personal diaries and photos. In observational research, the privacy of the home and the small number of subjects involved in family research may, for example, make the observer's presence conspicuous (see, for example, Lull, 1990: 178). Written accounts, as Christine Geraghty (1998: 148) states, may offer a greater degree of control for the respondent than the spoken word of the interview. Thus, particular and rehearsed written information can be more appropriate for the researcher than an interview. The use of written ethnographic data has not been employed much in

\footnotetext{
2 Finland's economic growth in the postwar period was extraordinary. The average annual rate of real national product growth by country was 5 percent in Finland in the 1960s and about 3.3 percent in Sweden, Denmark and Norway.

${ }^{3}$ More about the social uses of Finnish television from the late 1950s to the mid-2000, see Kortti 2011.

${ }_{4}$ Like many other European nations, Finland saw strong advocacy for making television a public, noncommercial medium. In the end, however, the compromise arrangement patterned itself after the British system, in which there was both a public and a commercial station. The result was a hybrid system, in which some programming was purely public, while other programming was commercial, much like in the United States. Under the circumstances, Finnish television was diverse, but of high grade in the standards of the time: the balance between educational and entertaining, commercial (i.e. American) programs was good. The Finnish experience differs especially from the other Nordic countries, whose television remained advertising free until the late 1980s.

${ }^{5}$ All the citations in this article are from the research data mentioned and they have been translated from Finnish.
} 
television studies, although the emergence of cultural studies significantly increased the interest on the media use of 'ordinary people' in media studies in the 1980s. There are only a few studies that have used letters (e.g. Ang, 1985) and television diaries (e.g. Gaunlett and Hill, 1999) as source material. On the other hand, the use of online data (fan sites and different Internet platforms, for example) has increased significantly in media studies in recent years.

Still, there are very few studies that have used written recollections in television audience studies. In fact, the use of oral histories is overall quite a rare phenomenon in ethnographic media studies. In Finland, mostly because of The Finnish Literary Society (SKS) and their Folklore Archives, there are remarkable resources and tradition for using these kinds of data. The SKS (est. 1831) has collected oral tradition, personal narratives and memories in a number of different ways since the 19th century. There are also other cultural institutions which organise collection campaigns across the country and also actively maintain their own respondent networks. And, first of all, the variety of people writing for these inquiries is relatively wide; not only 'elite' or older people, but also younger generations participate in the campaigns. Despite the wide range of ethnographic material, the data as resource material is basically the same. Actually, in Finnish, 'oral history' is translated as muistitieto, meaning 'memory data'. Hence, also written data is often categorized under the oral history research data in the Finnish history and folklore studies.

Combining the approach of ethnographic television studies with the oral history tradition could be seen as quite natural. Like oral historians, the cultural studies tradition is interested in everyday life. Actually, the roots of both traditions lie in the 1960s and the 1970s. In the discipline of history, the rise of oral history was a part of the so-called postmodernist turn and 'history from below' trend. Cultural studies also turned to explore how and what common people make of the media messages. It is no coincidence that the oral historian Paul Thompson (2000: 104-5) sees Richard Hoggart's classic The Uses of Literacy (Hoggart, 2009 [1957]), which has been considered a starting point in cultural studies, as an oral history study. The aims of cultural studies are similar, only with minimal interest in the historical context. Oral history research data are closer to the methodologies and theories of folklore studies, but my social historical approach is founded on the ideas and results of ethnographic television audience studies.

As in cultural studies and ethnographic television audience studies, my study looks at the social use of television and television as a commodity shaping everyday life. However, my perspective is different from that of cultural studies in the sense that I am interested in the social historical significance of television in the everyday life of the Finns. You could say that this kind of approach is seminal - not only in Finland, but also internationally. Besides the use of written reminiscences as data, a social historical approach to television viewing is also rare in ethnographic television studies.

Besides the historical approach, one of the main differences in this project, compared to the early ethnographic television studies, is the emphasis on the context affecting and interacting with the television experience. In folklore, the cultural context is considered to be as necessary as source criticism in the study of history. Contextualization must be both cultural and social historical. In particular, the folklorists who refer to the hermeneutics of Paul Ricoeur (see, for example, Ricoeur, 1981) have highlighted the significance of context in the use of oral history. 
Although communication scholars have done media ethnography since the 1960s, the most fruitful studies on Finnish media use have been done by folklorists and sociologists. One of the very few Finnish researchers interested in television audiences, especially from the point of view of cultural studies, is the sociologist Pertti Alasuutari (see Alasuutari, 1999; Alasuutari et al., 1991). National broadcasting company YLE has also published academic anthologies that have included analyses of Finnish television viewing and the role of television in the life of the Finns in the late 1980s. They were influenced by the growing interest in life stories especially prevalent in sociology at that time. Since the early 1990s, the research on Finnish television audiences has been more sporadic and published mainly in the YLE yearbooks. My study (Kortti 2007) was the first historical approach and comprehensive study on Finnish television viewing.

\subsection{The data}

The corpus includes two written reminiscences. The name of the first data set, a written collection, is "Elokuva ennen ja nyt" ("Cinema in the Past and Present"); it was collected by the Finnish National Board of Antiquity in 1996 (6,800 pages, 845 respondents). One part of the memoirs concerns television, and it has not been analyzed previously. The sample of the total data is 246 respondents (65 men, 181 women). About 90 percent of the respondents were born before 1955. To cover the experiences of the younger generations as well, the media memories of students were collected during a course on media history in the University of Helsinki during the autumn of 2005. This data consist of 87 respondents (32 men, 53 women, 2 unknown), mostly born in the early 1980s.

The themes covered in both datasets were: respondent's profession and home location, reasons for buying a television, the first television viewing experiences, choosing television programs, the impact of television on interior decor, television and changes in the way of life, television's impact on hobbies and social intercourse, television and video, etc. In the student data collection, there were also questions about digital television and media convergence.

One problem with the first data was that some of the questions were ambiguous. For example, the conclusion of a question may be the same with both negative and positive answers. It is crucial to set the 'right questions' in written folklore questionnaires as well. As Paul Thompson (2000: 200-29) has emphasized, the reminiscer must be led to relate his or her personal life and experiences. The questions must be straight and simple. In addition, many of the questions prompted the writer in a problematic way. For example, parts of some questions were suggestive and brought forth certain themes. However, this problem was taken care of when collecting the second dataset with the students, as I was able to formulate the questions personally.

Second, it is important to recognize the potential influence of social desirability in the participants' responses. For instance, some writers want to understate the impact of television in their everyday lives, while nevertheless mentioning many examples of such effects. Some forms of watching may thus be culturally more acceptable than others. On the other hand, how people evaluate their television watching is itself a research result. The writers are also giving impressions about their families, professions, genders and neighborhoods through their text, which is problematic for the quantitative results collected 
by the research software (Atlas). The mere number of mentions does not tell what the text is about and whom it concerns. In addition, the student data are problematic in the sense that the narratives are written by very critical, well-educated people, not by ordinary youth (which can be seen as both a challenge and an asset). Therefore, the written accounts have to be analysed as interactive presentations of selves and groups, not necessarily as facts.

Third, the data have some structural deficiencies. As shown earlier, the sex and age distribution is unbalanced. Also, people from the northern parts of Finland are underrepresented. However, the regional and occupational diversity is a clear virtue of the data. In addition, the writings of the students supplement some of the aforementioned deficiencies in the older data, mainly by covering the more recent trends in media consumption. The two datasets also make it possible to study a lengthy time scale: people born before the 1940s also wrote about the television experiences of their parents and grandparents, while the youngest writers are still in their early twenties.

Last but not least, the mere size of the two datasets offers great potential for analysis: it would have been impossible to collect all these media experiences by interview. And many of the writings resemble diaries in their elaborateness and personal tone, making the data possibly more reliable than oral accounts.

\section{Transforming worldviews}

"My grandmother, who died in the age of 85 in 1962, had a cozy armchair in the best spot in front of the television, close enough for her to be able to see, despite her cataract. She used to watch and listen to all the programs, not having the strength to do much else. Television announcers and regular faces became her "friends" whose greetings she would answer to. She was dazzled by the changes in the world, though it was not that long since grandfather had tested her nerves by corroding his trousers' knees when he was building crystal radio receivers. Like old people tend to do, grandmother kept rocking in rhythm so that, in the course of the evening, her chair would travel slowly but surely towards the TV set. When the broadcast ended, grandmother's nose almost touched the screen, and she would stretch her arm to switch off the television, saying "the world has turned again..." (Female, born 1943)

Television has turned global into local in many ways. One outcome of this is the way television unites the world (global village metaphor) and makes it possible to experience global events in real time. In the early days of television this informative dimension was particularly important, because in Finland, for example, television spread rapidly into places where information gathering was still largely tied to the social behavioural patterns and cultural conventions of agrarian communities. Radio had, of course, made similar features available even at an earlier stage, but the visual aspect of television provided much more. Besides news, nature and educational and other informational programs, television entertainment familiarized viewers with the customs of other nationalities, especially the American way of life. It should be kept in mind that television not only provided the model for modern international and consumption-oriented way of life indirectly, it also affected through television commercials directly.

According to media sociologist John B. Thompson (1995: 199, 189), media act as mobility multipliers by enabling people to experience something that would otherwise be out of their 
reach. Furthermore, the media makes this possible so that it is not necessary travel physically. The media also feed people's imagination, in particular because the mediatransmitted experience is indirect. Individuals can more than ever perceive themselves in the position of the other - in a new situation that may be completely different from theirs. Thompson claims that the invention of television emphasized the notion that media gives individuals access to experiences that transcend time and place - experiences that are simultaneous and are not face to face communication.

Thomspson's idea is related to cultural theorist Raymond Williams' notion of mobile privatization, which is the result of broadcasting. Mobile privatization paradoxically combines two different but deeply interlinked tendencies of modern urban industrial life: mobility and increasingly independent family life. Williams (1975: 26) sees broadcasting as part of the triumph of durables in the $20^{\text {th }}$ century. Besides television, the car has also contributed significantly to mobile privatization. Television and car are analogous in the sense that various socio-cultural meanings are attached to both of them (Tichi, 1991: 7). Television used to have a similar status as the car, and both of them can be perceived as leading objects of postmodern society (Silverstone, 1994: 87). In Finland, both spread strongly at the same time in the 1960s:

"The first TV set was purchased into our home in 1965. I recall it, because it happened at the same time as our first car was bought and I got a driving licence - two major events! Perhaps the purchase was influenced by the fact that our neighbours already had a telly, but a more significant reason was the possibility of widening our worldviews - we could sit there like guests." (Female, born 1925)

Television is undoubtedly among the most important technological applications to have changed people's worldview. Upon its arrival, television posed a potential and distracting threat to family life, but it also had potential with regard to education and socialisation (Silverstone, 1994: 101). The ideas of the Enlightenment, which the Finnish philosopher Georg Henrik von Wright (1997: 22) has called scientific worldview, have prevailed in the Western worldview for centuries. They have been associated with a strong technological dimension whose influence has escalated rapidly especially from the $20^{\text {th }}$ century on. To put it simply, worldview can be understood as bodies of scientific knowledge about the world; it can, however, be understood more broadly. The Finnish historian of ideas Juha Manninen (1977) defines worldview as a practice of life: worldview is manifested in people's relationship to their past and future, their possibilities, their personal and societal life, etc. In cultural studies, worldview as a theoretical concept has been understood as a perspective, a viewpoint to culture. Folkloristic worldview analyses consider it crucial that the worldview has a necessary connection to people's experiential reality - that is, to the ways in which the bearers of the worldview express themselves in representations (Knuutila 1989: 172). In investigating these representations, the prolific material is oral history.

In this article, worldview is mainly considered from the perspective of people's relation to culture and society and their history, taking into account how television has influenced on the socio-cultural notions of individuals. An altered perception of foreign countries and their cultures was important especially in the early days of television. In the $21^{\text {st }}$ century, television has lost its position as the leading transformer of worldviews to other electronic media, especially the Internet. However, having a strong foothold in Finland well before television, press has retained its position. 
The importance of television as the transformer of the worldview of the Finns can be presented as follows:

\begin{tabular}{|c|c|c|c|}
\hline & $\begin{array}{l}\text { ERA OF SCARCITY } \\
\text { 1956-1987 }\end{array}$ & $\begin{array}{l}\text { ERA OF AVAILABILITY } \\
\text { 1987-2001 }\end{array}$ & $\begin{array}{l}\text { ERA OF PLENTY } \\
\text { 2001- }\end{array}$ \\
\hline WORLDVIEW & $\begin{array}{l}\text {-TV as 'the window } \\
\text { to the world' } \\
\text {-Modern modes of } \\
\text { consumption } \\
\text {-American way of life } \\
\text {-Collective events }\end{array}$ & $\begin{array}{l}\text {-Satellite and Cable TV } \\
\text {-Local-global } \\
\text {-The flood of news and } \\
\text { information } \\
\text {-Music TV aesthetics }\end{array}$ & $\begin{array}{l}\text {-Internet as the } \\
\text { challenger of TV } \\
\text {-Global-local } \\
\text {-"Information } \\
\text { overload" } \\
\text {-"Anarchistic } \\
\text { aesthetics" and reality } \\
\text { TV aesthetics }\end{array}$ \\
\hline
\end{tabular}

Table 1. Television and worldview

The Finnish television is divided, according to media scholar John Ellis (2000), into three periods. The first period, from the 1950s to the 1980s, was the era of scarcity. This was the phase of the development of public service broadcasting. Television tended to present definitive programming to a mass audience. The second phase, the era of availability, lasted until the millennium, and it meant the explosion of channels and programs through cables, satellites, and videos. Television became an important vehicle for transmitting and creating postmodern culture. Now we are living in the era of plenty, which is linked to the increase of channels, digitalization, (technical and economic) convergence, and effective global media markets. In Finland, this means, roughly speaking, the years 1956 to 1987 (era of scarcity), 1987 to 2001 (era of availability), and 2001 onward (era of plenty).

Next I will introduce the examples from the material on which my research results were based.

\subsection{A window to the world}

"I often wonder how things happen far away and you can see them at once and straight from the scene of events. Technology is certainly amazing." (Female, born 1924)

An apparatus enabling to see life on the other side of the world had been predicted decades before television was invented. For instance, a cartoon by George du Maurier in the Punch magazine in 1879 depicted parents watching their daughter playing tennis in Sri Lanka while talking to her on the telephone at the same. The French artist Albert Robida forecast in his drawing from 1882 that people would one day be able to view distant wars safely from their homes as the images would be projected in people's livingrooms (Wheen 1985: 11-12).

As early as the end of 1880s, with the invention of cinema and telephone, people started envisioning a device through which world events and ceremonies could be followed in real time. Indeed, television ended up being the supreme device for transmitting great world events and spectacles. It was a part creating the society of the spectacle (Debord 1983). Alluding to media philosopher Marshall McLuhan's famous idea that media is the message, the French cultural theorist and philosopher Jean Baudrillard (1998: 127) pointed out in 1970 that what is being transmitted, assimilated and consumed from television - and all of mass 
media - is not so much some given spectacle but rather the potential for all types of spectacles. In this respect, television has defended its position till the $21^{\text {st }}$ century. Even in the age of the Internet, big news and sports events and national rituals are best transmitted via television.

In the early days of television culture, the metaphor "the biggest window in the world" was frequently used in television set commercials. Other slogans were for example: "A looking glass through which the viewer becomes a modern Alice"; "The greatest show in the world"; "All the World's a stage"; "The answer to man's ageless yearning for eyes and ears to pierce the barrier of distance"; "It is both magic carpet ride and university"; "Television cameras will be your eyes and will topple the tower of Babel" (Tichi 1991: 13).

In the early days, Finnish TV set commercials, too, presented television as a device that united the viewers with the world surrounding them in a concrete way. This appeared in two ways: with the help of television, the external world enters the home, or television transfers the viewer to the world outside. The slogan included: "The home is the centre of events... that's where the Philips TV is at"; "You're involved in the focus of both entertainment and news events"; "Each moment the waves of ether bring sound and image from near and far. They also bring the world events to You, to Your home." However, the world at home myth disappeared from TV set commercials after the early years.

In one of the few studies (Helsti 1988) on early Finnish television viewing in which similar oral history data was used as in the present study, nature and cultures of foreign countries, international politics - particularly wars - and sex rose as the most important topic areas. All of these were unpresetended to most Finns, especially in the rural areas. According to a television survey conducted in Lappland, northern part of Filand, in the 1960s (Nordenstreng et al. 1970: 20), most viewers considered it very important that "television brings the rest of the world closer."

To the question when and why their TV was purchased, a respondent replied: "In 1969. We live in the countryside and we don't read the newspapers, so television gives us the news, commentaries and connections to the outside world" (female, born 1928).

On the other hand, the Finnish agrarian historian Juha Kuisma (1990: 34-35) contradicts the view that television would have been "the lens for investigating the world from the couch at home." Instead, this lens merely filtered urban and consumption oriented image to rural households. TV programs and commercials provided housewives in developing areas with instructions for how to make themselves as urban and beautiful as models. To a certain degree this holds true. The truth is not that simple, however, as there were also television commercials targeted to the rural population, such as fertilizer and farming equipment commercials (Kortti, 2003: 303-310). The world-expanding nature of television was attractive throughout Finland.

Television made it possible for an increasing number of urban people to form an opinion of foreign affairs - which used to be sailors' privilege (Helsti 1988: 82-83). "A window to the world," television was considered to have beneficial qualities for the workers in the cities, as the working class was becoming more privatized and family-oriented. The working class, too, considered television a "modern miracle" that provided models for even for new identities especially for working class women (Alasuutari \& Siltari 1983: 66, 
92). Foreign affairs became closer and it was possible, for instance, to attend royal weddings on the couch at home. Television provided access to news ranging from moonwalk to the funeral of the long-standing president of Finland Urho Kekkonen. In the first data set, many respondents emphasized the import of television in widening their worldviews:

"At least to me, television has given a lot of what I wouldn't know otherwise, such as all the nature films. I wouldn't have become acquainted with experiences of other nations, concert, and so on if it wasn't for television." (Female, born 1916)

According to a study conducted in 1968 (Tiihonen, 1969), television was already considered the most important and also the most reliable news media. Those, who used television as their main news media, were often of the lower educational level. Electronic media were the most significant news media among the farmer and worker population in a study (Haapasalo 1976) comparing the Finns' perceptions of the media in 1965 och 1975. Television was a particularly important news source among the rural population. The influence of education was also marked: the more education a person had, the less significance television and radio had as a source of news. In other respects, too, the importance of electronic mass media as a source of information was greater among agrarian and working class population. The same applied to the arts and entertainment functions of the mass media. Research also showed that television's standing had become stable by the mid-1970s - it had ceased to be overrated and criticism towards it had increased. Also, another study (Haapasalo et al. 1977: 67) showed that television had slightly lost its standing as the news media, and radio and newspapers had regained theirs especially as local news media. However, with regard to news from abroad, television was considered by far the most important media.

It is nevertheless slightly surprising that there are relatively few recollections of important international news events that have later gained mythic proportions, such as the murder of president Kennedy in 1963 (8 mentions) and the moonflight in 1969 (5 mentions). To be sure, Kennedy's murder is depicted as a big shock. There are, however, only sporadic mentions of other major news events of the 1960s, such as the Vietnam War, presidential elections, French student riots in 1968, Czeckoslovakian occupation, and the famine in Biafra. Of the news events considered most important in their time in an interview survey (Haapasalo 1974: 12-20), the Vietnam War alone is mentioned in the first data set. The are no mentions of the Chilean coup d'état or the Watergate scandal, for instance. Even if there are few recollections of major international news events in the first data set, the power of television was however noticed:

“Through television, the Vietnam War, May 1968 in France, August 1968 in Czeckoslovakia, the genocide in Biafra, and the moonwalk of American astronauts were instilled in my mind and my worldview." (Male, born 1943)

The students in another data set reflect on their television experiences through significant events as well. One student even recalls one milestone in Finland's recent history from when she was three years old:

"I guess my first television memory is the funeral of President Urho Kekkonen in 1986. I don't remember in detail what went on, but perhaps I remember best that he was such an 
important person in the Finnish society and that my parents were shocked. I don't even remember my parents' opinion of that thought-provoking and controversial person, but I understood enough to get the impression that a particular era had come to an end. During the funeral of President Kekkonen I sat on my usual place on the living room carpet amazed by what had happened. At that time, my grandparents were temporarily living with us, which certainly added to the fuss over the topic at home. For them, President Kekkonen was a more important figure." (Female, born 1983)

By contrast, the death of the Prime Minister of the neighboring country may have had a different effect:

"Another memory dates back to 1986. As I woke up on Sunday morning I went into the living room to watch children's programs. I was alone in the living room while the rest of my family still slept. Just as the children's programs were supposed to begin, an extra news broadcast began instead. Sweden's Prime Minister Olof Palme had been murdered. I thought the broadcast would last just a few minutes and that the children's programs would be on next. But that's not how it went. I was watching the extra news broadcast in my nightgown, waiting for it to end. Eventually, my father woke up, say that probably the children's programs would be canceled for that morning. That Sunday morning was a very bitter disappointment." (Female, born 1977)

Many students remember the year 1986 through big news events (for many it represents the time of first television memories). Perhaps the most important international event from that was mixed with fiction in the mind of one six-year-old boy:

"My first strong memory is related to a situation in which I was alone with my big sister and her friend who were looking after me. The science fiction series The Tripods and the McGyver episode in which a nuclear power plant was on the verge of exploding were on in a row on television. Both of them, but especially the latter, bring back traumatic memories, since this to place in 1986, I think, just after the Chernobyl accident. It could also be concluded that the news on Chernobyl would have had a strong impact, but I don't have any clear recollections of that." (Male, born 1980)

In other words, the writer had experienced an important mediated event in which the "risk society" (Beck 1992) was lifting its head.

The news was not only mentioned as the most important program in the first data set, but they it was also one of the most important motives for acquiring a television in the 1960s. It may have been purchased simply in order to see a specific and expected news event:

"We bought our first television in June 1969 because of the moonwalk." (Female, born 1940)

However, television's weigh as evidence was not necessarily highly regarded:

"Naturally, we watched the moonwalk together, but aunt Amalia (as we were allowed to call the mistress of the house) firmly refused to believe that the men really were on the Moon." (Female, born 1922)

Of all the media, television in particular has a ritual-like tendency to bring people together to participate in the national and global collective events. These kinds of events are usually distant live broadcasts that have been planned in advance. Such events (the Olympic games, 
coronaries, funerals, moonwalk) are always exceptional interruptions to the routine existence, and they allow the general public to participate the public life more perfectly than at other times (McQuail 1997, 90-91).

In addition to the special routines in the home (e.g. when is the TV switched on, or how are the children put to bed), the rituals of television viewing are linked to the ways in which imagined communities, such as a "nation," are being created. The term imagined community was coined by the historian Benedict Anderson (1983), who used it in his research on the origin and spreading of nationalism. It has been discovered that the notion also fits the symbolic function of media consumption. In a way, the media make the concept of nation fictitious and ritualistic.

“The royal wedding had to be seen. Charles and Diana getting married! We didn't have the video yet. I had a job at the lost property office back then. Among all of that stuff, there was a black and white portable TV set someone had left in a taxi, and worked well enough. It was a bit dreary to watch a fairy wedding in black and white. We laid a tablecloth on the coffee table and cleaned the rest of the backroom where we brought the TV set. We bought cakes to go with coffee. The ladies from the archives attended the wedding as well. There were not too many customers. Some of them were amused when they realized we were watching television. The office manager went home to switch on the video recorder. In fact, the manager watched the entire wedding ceremony at home." (Female, born 1935)

According to the media scholars Daniel Dayan and Elihu Katz (1992, ix), these kinds of media events are directed to certain central values or collective memories. Commonly, these spectacles relate an idealized version of society: i.e., where the aspirations of society lie, rather than what the society really is like. Live broadcasts of annual festivities and events, in particular, direct the horizon of expectancy to the future. A typical Finnish example of such media events is the live broadcast from the Independence Day reception: ${ }^{6}$

"We went to the neighbor's to watch television. [Name omitted] was the first to buy a television around here in the late 1950s. I remember it was a spectacular to watch the Independence Day's Reception at the Presidential Palace from TV. But we didn't dress up when went to watch TV at the neighbors. When program ended, the lady of the house served all the guests coffee and buns." (Female, born 1935)

In the early days of television, consideration should also be given to the so-called baby boomers, who were not only large group of young people but also susceptible to the political and cultural impulses of the 1960s. For them, television was an important channel for presenting the new worldviews. Because television had such a great influence on uniting the nation, it gave rise to heated debates especially towards the end of the decade. In the 1960s, television, together with periodicals, created the new public sphere. The mass media provided the baby boomer generation with the means to express their worldview. As the

6 The Independence Day reception at the Presidential Palace on December 6 has dominated the viewer ratings overwhelmingly for decades. The idea of the program is, in short, that the presidential couple receives Finland's political and cultural elite and diplomats from embassies in front of the television cameras, after which they are filmed dancing. In addition, some of the guests are interviewed. The most important issue are, however, the evening dresses and coiffures of the female guests. 
Finnish social historian Jorma Kalela (1988: 43) puts it in his study on the working class way of life and the mass media: "In the 'new' way of life, mass media comes across as a societal institution that generates social cohesion without local ties."

In a very early stage, the news function of television may also have been a way for TV salesmen to get people to purchase a television:

"We were by no means among the first who got a television in this village. I wasn't particularly interested in it, and I didn't care so much for movies, either. They were tried hard to sell us a television. An electrician who was working at our home even gave us a TV set for test use, but we didn't want it. He had diligently tried it many times before the day when President Kekkonen came back from the Note Crisis ${ }^{7}$ negotiations in Novosibirsk in 1962. The electrician in question dropped by and brought us a television, saying 'Now you will see President Kekkonen give a talk. He knew this would work, because dad was a supporter of President Kekkonen and the Note Crisis was a serious incident. At least my parents were afraid that it might even lead to war. And with this excuse the television was allowed to stay in the house for test viewing, but then dad did call the electrician to come and get the television away." (Female, born 1942)

The news flow is currently manyfold compared to previous decades. Indeed, a number of students speak of the abundance of media supply, which may cause 'news and media overload.' As it has been so many times pointed out in the field of media history, new things do not replace the old ones but rather comes on top of it:

"I don't think the Internet use as such has had a very big influence on my television viewing or newspaper reading. I think the net has in a way given me more things to read instead taking away the old ones, like for instance Helsingin Sanomat, ${ }^{8}$ from my reading list. Sometimes I feel that I'm living in a real media overload and that there is no way I can digest and learn all that I think I should." (Female, born 1975)

As a news source and a worldview shaper, television is today used more and more in conjunction with other media. The influence of the Internet, in particular, is strong. While television's arrival seemed to have a decreasing effect on radio listening, radio preserved its position as a news and entertainment media. Many people also used both television and radio, as is the case with television and the Internet today. However, previously television and radio use were much more regulated by the time of day, because there were hardly any television broadcasts, including the news, during daytime.

"We still listened to the radio a lot, though listening had shifted to morning and daytime. In the evenings we used to watch television. Still, we listened to the news and weather forecast on the radio, too, occasionally. It was the same with radio plays and children's programs. It wasn't until the 1980s that our radio listening decreased. Of course, television didn't become the only source of information and worldview shaper, even if it was important. Of the electronic media, the radio remained." (Male, born 1920)

\footnotetext{
7 The Note Crisis (Finnish: Noottikriisi) was a political crisis in Finland. The Soviet Union sent a diplomatic note on October 30, 1961, citing an article of the FCMA treaty (Agreement of Friendship, Cooperation, and Mutual Assistance, also known as the YYA Treaty) referring to the threat of war. The Note was linked to the Berlin Crisis of Cold War.

${ }^{8}$ The biggest newspaper in Finland.
} 
It should be kept in mind that, compared internationally, the press has had, and continues to have, a vital role in the media consumption of the Finns. There are numerous newspapers and magazines published and read in Finland, which suggests that perceiving of the world through media is not limited to the electronic media. However, the Internet has opened new opportunities for counter- and alternative media, which has also entailed international features. This has made the late modern public sphere more fragmented, but it has also enable one to perceive the world past and beyond "official" communications:

"Growing up from a child to a young adult, my attitude to the media changed. As a child my stance toward the media was probably just passive media consumption, for example viewing TV programs without further contemplating the messages or teachings embedded in them. When I watch children's programs today, I notice how they teach children for instance about good and evil, or how they teach a certain worldview. So, my attitude to the media has become more critical over the years. I think I became more critical towards the mainstream media, in particular, during my high school years, when I started finding a lot of information about issues that interested me from the Internet. There are several alternative medias in the Internet, whose reports bring forth issues that mainstream media doesn't necessarily talk about, or who at least view events from a different, and often considerably more humane, perspective. Instead of everything written in the papers or said in television being true, it was just some people's opinions on and views of issues concerned." (Female, born 1984)

Television probably continues to be among the most important news media for many decades. The generations to whom television has been the most important media will remain influential for a long time still, and they will also hold on to their media routines. In any case, television has certain features that are not available in the Internet, especially in terms of live news reports on the events of the world, the most important being communality. Unlike in a virtual group, the events of the world can be experienced in a physical group simultaneously through television, which was discovered in connection with major news events of the 2000s, such as the September 11, 2001 terrorist attacks. On the other hand, the Internet showed its strength during another major disaster, the Asian tsunami, in which the Internet was the most important source of information for the families of the victims of the flood. The social media also played an important part in the Arab Revolutions of spring 2011. From the news function perspective, it seems likely that the mutually reinforcing effect of various media will continue and that different media do not decimate one another or merge into one meta media - at least in the near future.

\subsection{Television as a teacher}

A number of people point out in the data how they have learned to read and speak English with the help of television (in Finland, as well as in other Nordic countries, foreign-language programs are subtitled, with only children's programs being overdubbed):

“Many parents considered children's television viewing harmful, but at least for me the moments spent watching television have been mainly beneficial. Because I was watching a lot of English-language television programs, I learned to speak the language at a very early age. I already knew some English when I went to the first grade. I also learned to read at the age of five, of which I personally give credit mainly to television. My parents didn't have the 
energy to read the subtitles of the foreign-language programs for me, so I had to learn to read myself." (Female, born 1981)

Some of the parents realized the educational function of television, as well as the ability of television to preserve national culture:

"I lived in Cyprus until the age of nine, and what I remember the most of that time is television. My parents made sure that I and brother were sent video tapes from Finland, with Finnish-language programs recorded on them. They considered that our Finnish skills would stay in better shape this way. There was one Finnish TV-series we thought gave us a realistic impression of how it was in Finland, how people speak and behave in Finland, and how Finnish people differ from people in Cyprus." (Female, born 1984)

Television's prospective educational uses were already included in the afore-mentioned visions of Robida from the 1880s. Educational programs were also part of Finnish television repertoire from the early days on. The worldview-broadening effect of television was not, however, particularly important for the educated urban population, because information could also be obtained from elsewhere. Additionally, certain groups of "high cultural capital" shunned television at first, considering it an uncultured and worthless entertainment medium. Contrary to O'Sullivan's (1991: 166-167) survey on British television viewing in the 1950s and 1960s, education of children was not the motive to purchase a television in Finland, which may be indicative of the trust in the Finnish education system.

However, people did find cultivating and educational television programs as well. A Licentiate in Medicine, born in the 1950s, recounts:

"Programs such as language programs, current affairs programs and news were selected on the basis of their usefulness. On the other hand, I also chose lighter television series, but I hardly ever watched Finnish entertainment programs." (Female, born 1954)

Language programs, in particular, are mentioned as important educational television programs:

“One was above all others, namely 'Doprivester', which was the first Russian language course on television. I was completely carried away by the program. I did watch all other course as well, but they were not as good as that first one. In recent years I haven't been able to follow them anymore, because I've become hard of hearing. I used to watch other language courses as well, like Italian, Spanish and English, of which I never learned anything, however. But I had plenty of joy from (and use for) my Russian skills on package holidays. (Female, born 1918)

The utilitarian point of view of educational television programs increased with the arrival of the video. Childen's videos, too, showed educational potential:

"I still remember some of the information I gathered from the program Once Upon a Time... The Americas (Il était une fois... les Amériques). And when we discussed the American history in school, I benefited greatly from having watched the program. Because of the program, I knew something about themes ranging from the South American Indian cultures through the discoveries to the ending of slavery in America." (Female, born 1984)

Besides children's videos, other fictional videos increased the educational utility: 


\begin{abstract}
"As a child, I used to watch videos for hours on end, again and again. One factor affecting good English skills was watching, for example, the Star Wars movies about a million and six hundred times. It was inevitable to learned the dialogue by heart." (Female, born 1984)

In the late modern period, learning from the television is more penetrating than it was for the previous generations. For the 'atomized generation,' appliances have always been present and have always had an important role.
\end{abstract}

"My own television helped me shape my own space which I used - or, rather, where I closed myself in - so that I was able to learn about the world and myself. However, I don't believe I would have learned so much and so critically if I hadn't attended school like a good boy and read books. But it was television that taught me to know myself, which I think has been immensely useful. It also taught things I don't like. It showed models that should be avoided. It introduced me the masses that I definitely didn't want to be a part of. One had to be wiser, more knowledgeable, more unique, etc. Just in recent years have I been able to relate to television and its concepts of man neutrally enough. It is a pity indeed, but I went through my teenage years in front of the television instead of hanging out at the mall or in nice hobbies. (Male, born in the 1980s)

Cultural scholar John Hartley (1999: 38-47) has called television a 'transmodern teacher,' meaning that television combines modern, postmodern and even premodern themes. In other words, even if television teaches in a postmodern way through complex references, it may also act like the Medieval Catholic Church.

On the other hand, with the development of television, the contents of television programs have become more elaborated and challenging. According to Steven Johnson (2006), popular entertainment programs on television demand much more cognitive work from their audiences than they did before, and many of their narrative strategies, for example, would previously have been allowed in avant-garde settings only. An old popular cultural media, the cinema - not to mention computer games or the Internet - is also "making us more intelligent."

In terms of transforming the worldview in the fields of both information and entertainment, the new media have in part taxed the share of television. The Internet, in particular, has partly replaced television and may be causing the above-mentioned information overload:

"For me, the computer may have become an even more essential piece of equipment than television. I listen to music on the computer, even if I bought it as CDs. Sometimes I also watch tv-series and movies on the computer, but the main focus is still on the increased use of the Internet. The endlessly entertaining Internet forums are often enticing, as is chatting with friends in real time. The Journey Planner familiarized me with Helsinki, Wikipedia stores huge amounts of information, and Google has already become dauntingly important. At moment, e-mail is by far the most central element in my life. Sometimes it is scary to open my own e-mail, because it has become such an important tool that it brings with it an

\footnotetext{
9 The concept of atomized generation refers to a nuclear- or mosaic-like generation; the smallest parts move vibrantly and dynamically in the field of cultural phenomena. Atomization can be presented as a large-scale process that cuts through a generation. The freedom and requirement of choice are characteristic of the life of the atomized generation. In Finland, the concept is used by the scholar Mikko Salasuo. See Salasuo (2006, with an English summary).
} 
extra amount of stress and rush. It is also a bit too easy get stuck in the Net; occasionally one tends to get wrapped up in it like it was an addiction." (Male, born in the 1980s)

The student cited above had captioned the theme handling the issue as "Instruments of Coping." The self-reflection of young people seems highly sophisticated, as many of them truly contemplated their relationship with television and television's influence on their worldview. (To be sure, this aspect gets emphasis in the material, because - as mentioned before - most of them are studying the subject.) The television culture of in the era availability and plenty has raised them in a different way than the preceding generations, and they have also been influenced by the growing globalization.

\subsection{The global MTV generation}

As regards the young atomized generation, the metaphor of television as a "window on the world" is linked to the increased internationalization, one part of which is the globalization of the media. Having been one of the most frequently used buzzwords of the 2000s, a great deal has been written about globalization during the past 15 years or so. For television, globalization means, above all, internationalization and convergence of media economics. From the perspectives of television viewing and worldview, globalization is connected to the increase in the number of channels and programs internationally and, in particular, to the tendency of younger generations to travel and live abroad: the atomized generation has a much wider perspective on the media and television than previous generations. From the perspective of their perception of the world, they are - in this respect, too - highly reflexive concerning what and why they view on the television.

In the context of television viewing, globalization is a highly complex concept - especially in view of the relationship of global and local. The threat scenarios of the homogenizing effect of the international media, raised by the postmodernists, have not necessarily been realized, as the media reality has not totally eradicated the social reality. Instead, local cultures tend to reshape the forms and technologies of global mass media. According to television scholar Ien Ang (1996: 159-161), the integrating effects of globalization, of which the media is one sector, should be seen as conditional rather than real.

The definition of the relationship of global and local is much more straightforward now than it was a few decades ago, because today it is way more frequent and natural to get acquainted with other cultures in a concrete manner. Mobilization is a part of globalization, being one of its most coveted values, as sociologist Zygmunt Bauman (1998: 2) points out. He claims that free mobility has rapidly become a stratified factor in the late- and postmodern eras. Several students have indeed spent time abroad and have therefore become acquainted with televisions of other countries:

"It is important for me to keep track of current affairs while I'm living abroad. I have acquainted myself with local media in order to understand the new culture and environment better. Following the media has felt like a natural way get access to a foreign society." (Female, born 1981)

Not only have the students had the opportunity to familiarize themselves with different kinds of television cultures, but television has also provided a means for better understanding of foreign cultures: 
"Italian television is an integral part of my media history. I have already lived more than two years of my life in Italy, where I use media in a completely different way. I like watching television in Italy; even in Finland I prefer watching Italian television (via the Internet) and listen to Radio Italia. Television's role in my knowledge of the Italian culture has been vital. It is easier to take part in conversations and to understand jokes when you know what people talk about. I don't think it is as important in Finland, because it doesn't greatly affect my social relationships if I didn't watch television. I also buy magazines regularly while in Italy, because they cost just one euro and one learns the latest buzzwords from them!" (Female, born 1982)

The purpose of following foreign media is to get a wider picture of the events of the world. Satellite and cable channels, Music Television (MTV) in particular, have been a major influence on the worldviews of those born in the early 1980s (MTV Europe was launched in 1987). The aesthetics of MTV has had a crucial role in creating a medialized culture, a media reality governed by popular culture and a popular public sphere. These have been involved in creating a kind of shared global universe of meanings, through which it has been possible to construct one's own worldview and self-image.

"MTV's music videos have turned out to be the most important television experiences of my youth. When I visited my aunt in Helsinki I was allowed to watch MTV and Sky Channel all night, which was a great independent viewing experience, similar to watching Miami Vice. I was a huge Madonna fan and I could wait till the small hours of the morning to see Madonna's video 'Papa Don't Preach.' I was seventeen and went to evening high school when MTV started showing in our house. When I was alone at home in the mornings I kept the channel on all the time, and in the evenings I was watching it in my room before I went to bed. Our other television, a black and white set, was in my room, and it was fun to watch and wait for Madonna's controversial 'Justify My Love' video that was aired only at nights. These days I watch MTV irregularly and mostly its playing in the background instead of the radio." (Female, born 1975)

A number of respondents were not pleased with the fact that the Music Television that revolutionized their childhood and adolescence had been split into national MTVs (after MTV Europe, MTV Nordic was launched in 1998 and MTV Finland in autumn 2005):

"Nowadays MTV provides the background noise almost everywhere. And it's a big joke to watch the reality shows that they show, like Pimp My Ride and Jessica Simpson's shows. I was really annoyed when MTV became MTV Finland. I think it somehow ruined the whole Music Television, or at least the image I had of it since I was very small." (Female, born 1982)

Music Television's development is indeed interesting from the perspectives of globality and locality. In a sense, the spread of MTV was a kind success story of global media, which had real cultural-imperialistic impact. With the notion of locality, MTV has lost its appeal because, for example, it is not any longer possible to experience a sense of unity with the rest of Europe. In the 1990s, reading a letter sent from Finland was still heard all through southern Europe.

In television history, the relationship of global and local has mainly related to the ways in which different cultures view supranational programs from within their own perspectives and to the ways in which television transforms public into private at home. Television, which has been essentially supranational since the very beginning, has also had an important socio-historical role in shaping national cultures. 


\section{Conclusion}

It has been argued that, in the eras of availability and plenty, television is no longer a collective medium but rather is a part of a segmented post-Fordian market and consumption world in which identities are switched like channels. The student narratives tell another story, however. People seem to like viewing television as members of an imagined community as well as physically in the same space with others, sharing experiences face to face. Indeed, collective viewing seems to dissolve the notion of the fragmentation of television. Certain television programs are increasingly ordered or downloaded-either legally or illegally - to be viewed in a suitable occasion, but it seems unlikely that this would put an end to the need to experience live broadcasts or watching television simultaneously with other people in other ways. Most people want scheduled programs from television to experience "old-fashioned communality" in the digital era, too. To be sure, the television and the computer are by nature different media appliances.

Still, after television has no longer been 'new medium', television has remained as an important news media and educator in the digital age - at least in the countries such as Finland. The overall result of the study is, that television remains a social and cultural medium in the era of availability and plenty. Despite the many technological and cultural changes in television's history, most of the main features of television habits remain. First of all, unlike the visions of 'the postmodern television' forecast in the 1980s and 1990s (see, for example, Ang, 1996: 162-80; McQuail, 1997: 133, 137-8), television has not metamorphosed in the 21st century into an individual, highly segmented medium devoid of common social experiences. As in the era of 'Paleo television' (Eco, 1992), television is still a vehicle for sharing everyday life experiences, it is an object of discussion, and it provides models for living - albeit in different technological and cultural situations. Television is still watched together in the same room at the same time in the age of plenty. In some cases, as with television gossip, the medium's 'oral culture' (see, for example, Fiske, 1987: 77-80), has found its way to online chat formats (multimedia platforms of programmes such as Big Brother) - television is even more social than before. Although the evolution of television technology has changed the 'uses of television' (Hartley, 1999), it is rather surprising, how conservative most people are around the tube.

The above conclusions, which differ from the common assumptions and forecasts of television, show the strength of this kind of ethnographical data. For media ethnography, reminiscences provide longitudinal research material. Unlike ethnographic media studies in general, with these kinds of data one can see the development of media use across the span of media evolution. The material provides excellent information that would not have been collected otherwise. Oral evidence makes for a history that is richer, more vivid, heartrending and true, as oral history classic Paul Thompson (2000: 117-265) puts it. Oral evidence can add something more pervasive and more fundamental to history. It has a triple potential: to explore and develop new interpretations, to establish or confirm an interpretation of past patterns or change, and - last but not least - to express just what it felt like.

The results also serve the decision-makers and visionaries who wish to sketch the future of television in the years to come. In a nutshell, to explore these kinds of phenomena in the history of media, oral history as a source material and methodology has proved a fruitful approach, allowing the reader to peep into the Finnish living room across the decades of television. As oral historian Alessandro Portelli (1997: 6-8) has stated, the goal of oral history is to make both the private life and everyday routines of people and their relations to public life and historical time visible. 
Although there are some problems with the data (ambiguous questions, influence of social desirability, structural deficiencies), the television reminiscences of Finns provide a fascinating journey into the Finnish everyday (not only the weekday, but also celebrations and other occasional events) way of living in the postwar modernization/ postmodernization process. In the 1960s especially, when the spread of television was so unexpectedly fast, Finnish society experienced rapid structural changes in terms of urbanization, migration to Sweden and the formation of the Scandinavian welfare society. The world view of a Finn was on the move. Television played an important role in all of this.

\section{References}

Alasuutari, P \&Siltari, J. (1983) Työväestö ja televisio. Tampereen yliopiston tiedotusopin laitoksen julkaisuja, sarja A 48, ISSN 0358-4585, Tampere

Alasuutari, P. (ed.) (1999) Rethinking the Media Audience: The New Agenda Sage, ISBN-13:9780761950714, London

Alasuutari, P.; Armstrong K.; J. Kytömäki (1991) Reality and Fiction in Finnish Television, Research Reports 3/1991, Yleisradio, ISSN 0789-8444, Helsinki

Anderson, B. (1983) Imagined Communities: Reflections on the Origin and Spread of Nationalism. Verso, ISBN, 0805271783, London

Ang, I. (1985) Watching Dallas: Soap Opera and the Melodramatic Imagination Routledge, ISBN 0-415-04598-3, London

Ang, I. (1996) Living Room Wars: Rethinking Media Audiences for a Postmodern World Routledge, ISBN 0761950710. London

Baudrillard, J (1998) The Consumer Society, Sage, ISBN, 0761956921 London Thousand Oaks, New Delhi

Baumann, Z. (1998) Globalization. The Human Consequences Polity Press, ISBN 023111429X Cambridge

Dayan, D. \& Katz, E. (1992) Media Events. The Live Broadcasting of History Harvard University, ISBN 0674559568, Cambridge

Debord, Guy (1983) Society of Spectacle Black \& Red, ISBN 0 946061122, Detroit

Eco, U. (1992) A Guide to the Neo-Television of the 1980s, In Culture, and Conflict in Postwar Italy, In Z. Baranski and R. Lumley (Eds), pp. 245-55, Macmillan, IASBN 0333458044 London.

Fiske, J. (1987) Television Culture, Routledge, ISBN 0415039347, London

Gaunlett, D. \& Hill, A. (1999) TV Living: Television, Culture and Everyday Life. British Film Institute/Routledge, ISBN 0-415-18486-X, London and New York

Geraghty, C. (1998) Audiences and "Ethnography": Questions of Practice, InThe Television Studies Book, C. Geraghty\& D. Lusted (Eds.), pp. 141-57, Arnold, ISBN 034066231 $\mathrm{X}$, London

Haapasalo, J. \& Lehmuskallio, K: \&Sinkko, R. (1977) Radio- ja televisio-ohjelmien seuraamisen muutokset vuosina 1965-1975. Series B 10/1977, PTS-toiminta, Oy Yleisradio Ab, ISSN 0355-5216, Helsinki

Haapasalo, J. (1974) Suomalaiset joukkotiedotuksen käyttäjinä Series B 11/1974. PTS-elin, OyYleisradio AB, Helsinki

Haapasalo, J. (1976) Suomalaisten käsityksiä tiedotusvälineistä vuosina 1965 ja 1975 Sarja B 20/1976, PTS-elin, Oy Yleisradio Ab, ISSN 0355-5216, Helsinki

Hartley, J. (1999) Uses of televisionRoutledge, ISBN 0415085098, London

Helsti, (1988) Kulttuurin muutos ja televisio. Television ensimmäiset vuosikymmenet suomalaisten kokemina Sarja B 9/1988, Oy Yleisradio Ab, ISSN 0357-5179, Helsinki 
Hoggart, R. (2009) The Uses of Literacy: Aspects of Working-Class Life (Orig. pub. 1957) Penguin Books, ISBN 978-0141191584, London

Johnson, S. (2006) Everything Bad Is Good for You: How Popular Culture Is Making Us Smarter, 2nd Edition, Penquin Books, ISBN 0141018682, New York

Kalela, J. (1988) Työväen perinteisen elämäntavan mureneminen ja joukkoviestintä.Series B 7/1988, Oy Yleisradio Ab, ISSN 0357-5179, Helsinki

Kortti, J (2011) Multidimensional Social History of Television. Social Uses of Finnish Television from the 1950s to the 2000s.Television \& New Media Vol.12, No.4, (July 2011), pp. 299-313, IAAN: 1527-4764 Kuisma, J. (1990) Maaseudun elämäntavan muutos ja sen suhde joukkoviestintäänSunnittelu- ja tutkimusosasto. Series B/1989, OyYleisradioAb, Helsinki

Kortti, J. \& Mähönen, T.A. (2009). Reminiscing Television: Media Ethnography, Oral History and Finnish Third Generation Media History. European Journal of Communication Vol.24,No.1, (March 2009), pp. 49-67, ISSN 10.1177/0267323108098946

Kortti, J. ( 2007). Näköradiosta digiboksiin. Suomalaisen television sosiokulttuurinen historia, Gaudeamus, ISBN 978-495-031-2, Helsinki

Kortti, J. (2003) Modernisaatiomurroksen kaupalliset merkit. 60-luvun suomalainen televisiomainonta SKS, ISBN 951-746-523-8, Helsinki

Lull, J. (1990) Inside Family Viewing: Ethnographic Research on Television's Audiences Routledge, ISBN-10: 0415049970, London

Manninen Juha (1977) Maailmankuvat maailman ja sen muutoksen heijastajina, In: Maailmankuvan muutos tutkimuskohteena M. Kuusi \& R. Alapuro \& Matti Klinge (Eds.), pp.13-48, IABN 9511044249,Otava, Helsinki

McQuail, D. (1997) Audience Analysis Sage, ISBN 0761910018, Thousand Oaks

Nordenstreng, K. \& A. M. Nurminen \& E. Olkinuora (1970) Lapin televisiotutkimus. Tutkimuksen taustaa ja haastatteluaineisto. PTS-tutkimuksia 8/1979. PTS-elin. Helsinki: OyYleisradio $A b$.

O'Sullivan, T. (1991) Television Memories and Cultures of Viewing 1950-65, In: Popular Television in Britain: Studies in CulturalHistory, J. Corner (Ed.), pp. 159-81, British Film Institute, ISBN 0851702708, London

Portelli, A. (1997) The Battle of Valle Giulia: Oral History and the Art of Dialogue The University of Wisconsin Press, ISBN, 0299153703, Madison

Ricoeur, P. (1981) Hermeneutics and the Human Sciences: Essays on Language, Action and Interpretation. Cambridge University Press, ISBN-13:978-0521280020 Cambridge

Silverstone, R. (1994) Television and Everyday LifeRoutledge, ISBN 0-415-01647-9, London

Thompson, J. B. (1995) The media and modernity: A social theory of the media. Stanford University Press, ISBN 0-8047-2679-5, Standford

Thompson, P. (2000) The Voice of the Past: Oral History (3rd edition, orig. pub. 1978), Oxford University Press, ISBN-10:0192893173, Oxford

Tichi, Cecelia (1991) Electronic Hearth: Creating an American Television Culture Oxford University Press, ISBN: 0195079140, New York

Tiihonen, P (1969) Uutiskäyttö ja uutisarvostukset, In Joukkotiedotus ja yleisö K. Nordenstreng (Ed.), Prisma-tietokirjasto 14, pp. 62-73, Weilin+Göös, Espoo

Wheen, H (1985) Television.Century Publishing, ISBN 071260929 6, London

Williams, R. (1975) Television. Technology and Cultural FormShocken Books, ISBN0415314569, New York

Wright, Georg Henrik von (1997) Maailmankuvan käsitteestä, In: Maailmankuvaa etsimässä, J. Rydman (Ed.), WSOY, ISBN 9510216593, Helsinki 


\title{
Digital Auratic Reproducibility: Ubiquitous Ethnographies and Communicational Metropolis
}

\author{
Massimo Canevacci \\ ${ }^{1}$ University of Rome "La Sapienza" \\ 2University of Florianopolis (UFSC-Brazil) \\ Italy \\ ${ }^{2}$ Brazil
}

\section{Introduction}

Ethnography as method has been changing in recent years for many reasons and in different cultural contexts. Bororo, Xavante or Kayapò - if I focus exclusively Brazilian cultures with whom I've been doing research in a "native" fieldwork - are increasingly involved on presenting their rituals by themselves through digital technologies; the same is occurring inside urban youth cultures and their self-production on music, street art, style or expanded design and so on, whose languages are understandable only through their autonomous visions and reflections; transurbanism is their ethnographic fluid context (Mudler: 2002). This accelerated trans-cultural process is spreading out new kinds of subjectivities as well as diasporic citizenship through digital communication.

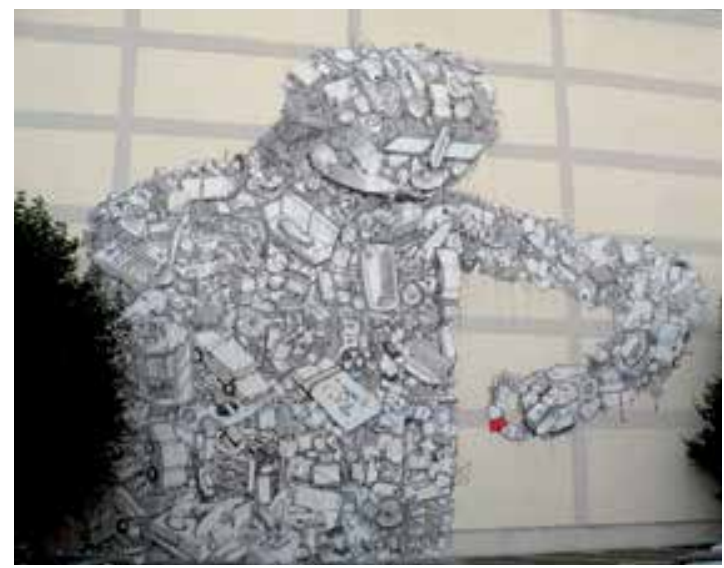

Fig. 1. Bluewallberlin (Blu: 2011)

The fundamental concept of differentiated and positioned self-representation is emerging, regarding a growing number of (native-migrant-urban-digital) subjects: a mutant scenario is producing the most radical challenge for our discipline (Turner:1978, Canevacci:2008). Thus, 
pluralized ethnographies and disseminated self-representations are the keywords I shall initially discuss.

The classical space-and-time concepts were radically changing at the end of XX century ever since the diffusion of "glocal" cultures (see Robertson:1995, Bryan S.Turner: 2010, Appadurai: 1986); now, an expanded digital interconnectivity is upholding ubiquity as an emerging concept which produces an accelerated and horizontal floating process concerning space-time; a fragmented flux of segmented spaces/times is connected, crossed and assembled within innovative and disturbing references on identity, genre, labor, roots, territory.

It becomes possible to connect the diffusion of such a different kind of digital ubiquity to a historical concept in the Marx's theory: the division of labor. This concept, together with the commodities fetishisms, was a basic political concept in his research on capitalist production and cultural alienation of the working class. These are two Marxian concepts I'll use adapting them in a transformed meaning considering contemporary communicational context. Perhaps now, due to digital cultures diffusion, the traditional social division of labor has become the contemporary communicational division of labor. We've been watching growing contradictions in each and every local person's desire, capacity and involvement while using digital cultures in a creative way.

Self-representation is a key-word to understand such a process, in which nobody wants to delegate to another professional the right to represent him/herself. Each person has the narrative power and not only the one of being narrated, but as well a desire to frame a story and not to be framed into a story. Between the one who has the power of communicate and the one who has the impotence of being communicated there is a conflict, a political conflict, a communicational conflict, increased on the visible digital technologies diffusion. In this conflict, there are growing political contrasts, aporias and contradictions between the horizontalisation of multividual performative practices and the verticalization of dominant economic global power. Everybody wants to create his/her own narrative stories; consequently, an emerging political conflict embodies the transformative visions and practices on communication: a dualistic opposition between who frames and who is framed, who communicate and who is communicated, who represents and who is represented is now more problematic and conflictive due to the general interconnectivity diffusions based on trans-urban and trans-ethnical multividuals creative attitude. So, the problematic modern concept of "mass" is melting in the pixel-air.

Contemporary politics is communicational politics. The communicational division of labor is becoming politically conflictual and has been extended in many fragmented subjectivities and cultures. Even classical concepts, such as the Marxian differences between work and labor, are inadequate. If the first one is alienated, repetitive and oppressive, the second one is free and self-determined but still work-oriented; so, I prefer a reformulation of the Latin word opus bringing a creative open-ended composition, mixing consumer production, aesthetics cultures, performative communication which are expressed inside/outside the structural system of production.

Ubiquity is a de-centered liberation of spaces and times. Spacetimes.

Another concept I'd like to stress is the one of composition. Composition as a simultaneous trans-narrative and trans-sensorial mix-media expression which would represent research in 
its manifestation and process.The hegemonic form of representation through writing is not adequate to contemporary digital challenge. Composition is a process of writing (essay, ethno-poetic, fiction), visual (ad, ideogram, design, photos, movie etc.), sonic (music, silence, noise), through a philosophical and ethnographical elaboration of another classic concept: the montage.

Now, let me stress montage as a performing method - not only external - internal to any frame (see, Mann: 2003, Benjamin: 1982, Bateson: 1958). In a symphony, different instruments are playing all together (or partially separated). One can appreciate the melodic individuality of a single violin, the separated orchestra as a group and the music as a contrastive whole. It is possible to apply an ethnographic composition through different narratives, fictions or essays fluxes: an ethnographic composition of separated and connected instruments, which proposes a divergent symmetry between performative composition and research experiences. This polyphonic and ubiquitous composition is emerging from the context and the method, crossing communicational metropolis and digital cultures.

This ethnographic research may be connected and composed through visual or performative arts, urban or "native" visions and behaviors, transurban movements, elaborating a processual montage of mutant opus emerging from the meta-fetishistic and metamorphic panoramas of body-corpse. The shifting border between human being and things, subjects and objects, bodies or commodities - live and dead. Facticity - in the Adorno's sense - is a transit between objects, things, commodities ... and pixel (Canevacci:2007).

Following Thomas Mann as an innovative anthropologist: "Talking about myself, my desire to clarify is the method of montage (...). It is strange: my relations with music are quiet famous, I always know how to make of literature a sort of musical composition, I feel myself as a half-musician, I had transferred inside romance the musical textual technique" (2003:1315). And so it will be for ethnography composition, stressing the internal montage as important as the external one and the ubiquity as a material/immaterial simultaneity. D.A.R

\section{Simultaneity, chronotopos, ubiquity}

I would like to reanalyze the concept of simultaneity elaborated by Italian Futurists at the beginning of the $\mathrm{XX}$ century and its connection with a disturbing vision of transurban performance. This vanguard was involved with perturbative sensorialities determined by the metropolitan context. Futurists fell in love with these uncanny techno-sensorialities beyond any nostalgia for the past. From such a chaotic traffic, the Marinetti's concept of simultaneity (1921) was emerging and unifying artistic or popular differences on styles and behavior. A car, a human being or a dog were in the same time in different spaces; a Painter, an Architect, a Poet or a Musician had to approach perturbative dissonance through simultaneity in order to transform it in Art. At the beginning of that century, a historical subject was emerging together with the changing patterns of transurban experiences: a subject-performer inspired and fascinated by the disorienting fluxes of bodies, communication, and technology along those fragmented metropolitan contexts.

The Futurists were theorizing simultaneity and applying it on Visual Arts (painting, sculpture, architecture) and on the Performing Arts, in which poetry, music, stories were presented just simultaneously at public events. Concerning these conceptual choices, futurists 
were the first vanguard that loved metropolis as opposed to the countryside nostalgia and to the moon glow tedium: on the contrary, simultaneities were emerging from urban landscape dissonance, multiple images co-presence, desires for bodyscape extensions, passions for mechanical noise. The metropolitan experience were mixing machines and bodies. In my point of view, simultaneity represents only the ubiquity "material side". Its pervasive behavior in the everyday life is influenced by the rising cinema, in which the montage was a radical visual innovation while expressed through an optical contiguity among autonomous narrative segments. For the futurists, simultaneity is an aesthetic experience of fragmented codes floating between metropolis and technology; it is the expressive pulse towards assembled images or liberated words (Marinetti's parolibere, phrases without any consecutio) being possible thanks to a simultaneous subject: the futuristic subjectivity. Those artists were trained to look at the space extended flexibility into the mobile time observed along multi-sensorial urban panoramas. Such training is a poetical initiation towards a future simultaneous to the present while being indifferent to the past. Iconic/sonic movements are emerging on the road, crossing the atelier window and then located on the painter canvas or on a musician score. Simultaneously...

There are contiguities and differences between simultaneity and ubiquity. The last concept has a long symbolic history as well as a theological meaning when touching an "ubiquitous God". Yet I would like to stress how digital culture has been empirically modifying such kind of notion from an ethnographic point of view - an ethnography applied to digital cultures has to modify concepts, paradigms, fieldworks, methodologies and writing. Ubiquity is a diasporic concept beyond any mono-discipline and any self-oriented division of knowledge (university, department, faculty). Ubiquity is a sensorial concept applied to expanded individual experiences along digital cultures, artistic styles, expressive behaviors. If the web experiences are ubiquitous, then communicational ubiquities are characterizing the internet space-time relationship and the performative "everyday life" as a metacommunicational context: the context of the context.

One other difference between simultaneity and ubiquity is connected to territory. The sensorial experience of simultaneity is related to the specific territory of the urban space as a chaotic and creative context. The sensorial experiences of ubiquity are contemporaneously material and immaterial; in my compositive project, they are material-immaterial as digital cultures are blowing through the symbolic hyphen.

Ubiquity is beyond any dualism of space and time male and female, material and immaterial, nature and culture, labor and work, body and soul. Ubiquity is the ontology of the sacred spreading out in the air of pixel.

In my interpretation, ubiquity is connected with visual fetishisms (a different version of traditional fetishism which comes beyond religions, reifications, and perversions). Metafetishism is the immanence of the sacred and the uncanny in a subject and object mix, thing and body, commodity and corpse, skin and screen. Ubiquity is an ungovernable body-corpse, a constant transition between living body and dead corpse; in Adorno's sense, ubiquity is incomprehensible: it cannot be "comprehended" - i.e., grasped, cached, fixed - into the identity principle of logics. Ubiquity is imagination mixed to technology: an ubiquitous doll embodied by Rilke's ding-seele (thing-soul in his poem (1999). Ubiquities are connecting the transurban experiences with the multi-sensorialities of digital cultures: from its mutant interiorities, the odd concept of multividual is spreading out. It is worth noting that "individual" is a Latin 
translation of the Greek term for atomon, the indivisible; now the in- prefix may be replaced by multi- in order to express the multitude of egos ("eus" or "ii") inside the same subject.

From an ethnography oriented in these floating-and-fragmented digital panoramic cultures, the ubiquitous multividual self-representation is mixing observer and observed, emic and etic, researcher and researched. In the expression process of my research and from such metamorphic fetishisms emerges the concept Digital Auratic Reproducibility (DAR). The as friendly as hardly contrast between Adorno and Benjamin - on technologies, revolution, reification, aesthetics - shall be faced by the following empirical and theoretical statement: performing arts, expanded design, digital communication or decentralized subjects are morphing the aura into reproducibility and vice versa. Meta-fetishisms and meta-morphing are doing the immanent body-corpse connection through synth-ethic biology in the bio-art perspectives (Hauser: 2005).

DAR: This concept of ubiquity - connecting digital fieldwork and diasporic ethnography has been moving between different disciplines aiming in elaborating contextual methodologies of research and innovative styles of composition. It seems to me that the immanent concept of ubiquity - unrest even in front of itself - is disseminating in a web modus operandis as it has been experiencing expanded design. The web is ubiquitous and ubiquity is going to portray multividual subjectivities at the same time that it mixes internet space-time relationships and, obviously, social network.

There are affinities and differences between the Michail Bakhtin concept of chronotopos (an original physical word treating a space-time mix) and ubiquity. If polyphony manifests different instruments or voices simultaneous presence, regulated in western culture by harmony, Bakhtin transformed the polyphony-chronotopos relationship in a methodological interpretation upon nineteenth-century romance. Polyphony had approached a form of writing in which spacetime presents a connective dynamic (chronotopos), and where the hero was not only the center of the novel, but also the projective personality of the author, while all the other characters were linguistic and psychological peripheries (monologism). Following Bakhtin, only with Dostojewski the hero becomes no longer a monological projection of the author, but each character develops its own linguistic and psychological autonomy. Dostojewski brought decentralized styles for each person - everyone with discursive and psychological autonomy; so, "the hero and the author" were presenting a polyphonic narrative pattern, by Dostojewski, created in order to multiply characters and styles of representation (1988).

If chronotopos and polyphony are the prerequisite for the decentralized development of literature, in which any subjectivity have his/her psycho-linguistic autonomy within their irreducible individualities, the same methodological perspective should be applied in the anthropological research. For this reason, Bakhtin's polyphonic chronotopos has influenced a significant part of Anthropologists researchers. For me, it is possible to say the same about Pessoa's concept of heteronomy, whose vision should have an even more significant ethnographic perspective, as it decentralizes not only the "heroes" narrative identities, but also the unquiet subjectivity of the author (desassossego), who assumes different names and styles for writing and feeling.

Now, I would like to connect Marinetti's simultaneity, Bakhtin's polyphony, Pessoa's heteronomy to the meaning of digital ubiquity moving beyond the futuristic materiality, the 
plurality of Dostojewski characters or of the writer identity. Perhaps the philosophical or theological version for ubiquity derives from its traditional meaning the one that refers to the abstract concept or invisible being. Ubiquity is the ontology of the sacred. It is a tension beyond any dualistic distinction on human logics and also beyond the institution of religion - both interested in the orthodox control of theory and behavior.

Ubiquity is not the result of an empirical experience along urban life as simultaneity or literary writing as chronotopos or heteronomy; on the contrary, it belongs to a visionary perception that come to affirm the transitory condition of human beings as constantly observable from the divine glance, from which it is nowhere impossible to escape, as this ubiquitous divinity reaches everyone everywhere. Ubiquity is material/immaterial in his sensorial and logic immanence. It is one of the first concepts that expresses tension beyond dualism, as well as beyond human condition. It is simplified by binary oppositions, whose undoubted practical function is still the domain of traditional alliance between ratio and realism. Ubiquity is incomprehensible, uncontrollable, undetermined. It is outside of political control, mono-logical rationality, linear space-temporal determination, fixed identity.

Ubiquity is the potential imagination linked to sensorial technology.

Recently, a new vision of ethnography has been developed showing affinity to what precedes. Cultural exchanges between different cultures, which in the past have been seen as dissolution of "native" tristes tropical cultures, has been constantly growing according to the continuous remixing by syncretisms more than homologation by "entropic" dissolution. The ethnographer is not only a trained anthropologist who applies some established procedures. Having said that, the field has been expanded into diasporic simultaneity, digital polyphony, multividual heteronomy, a field always further connected to the material/immaterial ubiquity. The ubiquitous ethnography requires to be penetrated and specified. My researcher identity do not remain identical to myself while in different contexts, but it performs simultaneously diagonal relations and methodologies within different glocal areas - less geographically characterized and more subjectively involved. Identities are more flexible and mutant, plural and unstable, relating in the same frame to different entities or contexts: ubiquitous identities. The eye is now trained to decode discordant or differentiated coexisting symbols (written, visual, musical, mixed codes) and to interact according to different modalities. The ethnographer glance is practiced - more than participant observation - as an observing observation into the screen, through his/her eyesfull body.

Space-time coordinates tend to become superfluous or better in a continuous movement. A subjective multividuality based on the ubiquitous experience is expanding. Even researchers are placed under ubiquity, immersed in their personal experience in relation with the others. Yet, these others are ubiquitous, in the sense that they are living where and once their digital system is activated. This experience doesn't mean a dematerialization of interpersonal relationships; it attests a complex network (or geophilia) of optical connections and body-corpse imaginations which moves the immobility of any subject. The psychological implications are obvious, it would require a specific research and, initially, also a self-search by the subjectethnographer who experiences this accelerated uneasiness. The multividual concept manifests him/herself in those ubiquitous connections. Ethnography is a pattern which connects fragments of space/time without a specified identification or, better, multiplying temporary identities. The multividual is the subjective experience of an ubiquitous ethnography. 
An internal montage shows this condition. While the traditional external montage joined fragments of stories logically or spatially separated, the internal one - helped by digital morphing and anticipated by analogical collage - multiplies the coexisting images for each frame. Internal montage expands the optical perception of simultaneity, the narrative polyphonies of chronotopos, and the heteronomy experience of ubiquity. The internal montage incorporates the ubiquity along the pixel air atmosphere and towards a multi-sequential composition beyond the monological ethnographic writing.

The Anglo-Iraqi Architect Zaha Hadid is an ubiquitous philosopher who invents present/future scenarios. It is necessary to interrogate her works, to observe them and to dialogue with every detail expressed by her post-Euclidian forms, to read her interviews or statements about a different rationality and optical sensitivity emerging from her works. I take as an example her project "Performing Arts Center on Saadiyat Island"' (Abu Dhabi): the structure becomes a flexible theatre mutant as a performance, an archi-performatica: «an emerging sculptural form from the linear intersection of pedestrian paths within the cultural district, gradually developing into a growing organism that sprouts to subsequent network of branches" (www. Performing Arts Center Abu Dhabi).

Human routes are producing an emotional design by imaginary walking transfigurated into organic network intersections, in a body-corpse mixing alive and dead, bodies and things, organic and inorganic: "As it winds through the site, the architecture increases in complexity, building up height and depth and achieving multiple summits in the body housing performance spaces, which spring from the structure like fruits on a vine and face westward, toward the water". The space becomes performative, the wind which crosses the site attracts similar looks, an eyesfull body is listening to the multiplicity of sounds. "The concert hall is above the lower four theatres, allowing daylight into its interior and dramatic views of the sea and city skyline from the huge window behind the stage. Local lobbies for each theatre are orientated towards the sea to give each visitor a constant visual contact with their surroundings". I suggest to read again the unforgettable notes described by Nietzsche evocating the architectural philosophy of a Greek theater, in which the subject who assists the tragedy feels every sensoriality expanded towards the astonishing cosmic landscape around. An ubiquitous ethnographer should direct a sensitive attention for this woman who is a constructivist philosopher; her architectural visionary glances are anticipating the processes of displaced transurban sensorialities. She is a contemporary philosopher who reveals the present-future, before and better the classical academic authors usually quoted. Philosophy is outside philosophy; as well as anthropology is outside contemporary anthropology. That's why ubiquity - crossing and mixing disciplines, knowledges, spaces/times - is an ethnographic experience.

\section{Auratic serialities: Benjamin/Adorno and Warhol}

Here I'll provoke an ubiquitous encounter between Bateson's cybernetic anticipations and Benjamin's reproducible reflections on these polyphonic scenarios. The incomparable cities storyteller developed a methodological affinity with the ecology of mind maestro.

As known, Benjamin elaborates a famous essay on technical reproducibility in dialectical conflict with the "aura", so political art by popular classes is a challenge against the aristocratic-bourgeois class structure as well as fascist communication aesthetisation. As technology is a constitutive part of arts, cinema, photography and the emerging visual arts - 
by becoming reproducible - it can inspire a revolutionary turning point in the diffusion of their products.

Subsequently, and with an entirely independent itinerary, the art of Andy Warhol addresses seriality in a way akin to Benjamin's reproducibility and different from Adorno's massification. There was political and theoretical tensions between these two Frankfurt School friends: Adorno responded to Benjamin's essay laying on art reproducibility with a book about the reification of listening. He presentes a scenario in which massificated technologies - rather than liberation under the banner of reproducibility - would increase mass reification and authoritarian personality. These divergent point of views regarding technology and culture could never be resolved between the two of them and perhaps will never be by none of their followers. My hypothesis is that the ubiquitous digital communication may face and transform their opposition - based on the Hegel-Marx dialectics - through another vision of thought beyond synthesis, dichotomies, and also beyond any dialectics.

Ignoring that method, Warhol operates not in synthesizing, but in syncretizing the two friends in pop seriality. Doing so, he dissolves the dialectic contradiction on reproducible or massification. His art expresses a sensual fetishism through a commodification of mass icons and through the dissemination of their empty symbolisms inside impure signs. Assimilating Mao, Marilyn and Campbell, he ambiguously excites and intoxicates their political, sexualized, commercialized global power. After him, the dialectics between auratic or massified arts have no sense. Pop art penetrates the serial body of goods, selects the most diffuse mass media icons, dislocates empty commodities and symbol through the expansion of serial-reproducible-massificated icons. Paradoxally, Warhol - as an ironic-erotic-iconic neo-dandy - unifies Adorno and Benjamin. He crosses the XIX century flaneur parisien and XX century newyorker dandy; he creates the analogical reproducibility of auratic serialities.

Reproducibility, massification, and serialization are intertwined, flowing and conflicting together. In the same time, Warhol is conditioned by mass culture from which he depends: pop art does not exist without analogical mass media. The actual scenario is quiet different: digital technology expands communication in a decentred and autonomous potentiality inside the traditional media and even more outside of them. Internet subtracts the initial mass from the traditional media, beyond massified, reproducible or serializable media: the web affirms "a media", one singular-plural media that incorporates a series of operationalities, previously differentiated and now unified in a single instrument. This singular-plural media is helping a multividual subjectivity connecting experiential logics, emotional researches, and compositional results. Perhaps the same concept of media is obsolete.

Going further, the concept of Fake - presenting another meaning in a classic movie - is now emerging from the air of pixels where generalist mass media are dissolving: fake doesn't mean false (not-true) anymore, but rather is exploring meanings beyond the true-false dualist opposition. If art can really escape from this dialectical trap, it will be through digital arts which are multiplying such fake powers. Orson Welles presents this dissolution in one of his last films - F for Fake (1974) - where the prospects of an auratically reproducible fake-being is expanding uncanny cultures as well as and fluid identities beyond the true-false dichotomy 1 . Such a fake-scenario is irresistibly growing from the body-corpse of digital cultures: D.A.R.

\footnotetext{
${ }^{1}$ I tried to applied this concept - Fake-in-China - in contemporary Chinese cultures and communication (Canevacci:2011)
} 
Now, some interweaves of digital arts and visual communication offer inedited perspectives. A transitive generation of artists, designers, architects, musicians and pirates are shaping performative works of arts initially inside the mass media's core (the so called avant pop, see McCaffery, 1995) and now in a very indy way. Therefore, instead of dialectic opposition between aura and reproducibility, the digital articulations mix these perspectives that, instead of dichotomic, became syncretistic, polyphonic, and diasporic. A reproducible auratic communication emerges from digital cultures beyond the dualism of analogical technologies (and philosophies). A musical, a novel or an artistic piece connected to a social network can remain in its "auratic" expressive autonomy as well as can be available for endless mutations and decentralized reproducibility. Instead of collective art, there are connective artists. For this reason, the copyright crisis is becoming a political-economic, cultural-communicational, legal-technological conflict that characterizes the contemporary political condition.

In this sense, the itineraries from cultural industry - discussed with anticipated passion by Benjamin and Adorno - to digital communication will encourage an unsuspected tendency for my hypothesis: the digital culture crosses and mixes auratic aesthetics and technical reproducibility.

Instead of an oppositional dualism between bourgeois aura and working class reproducibility (between reification and identification), the digital syncretizes reproducibility and aura. This reproducible aura - which is an aporia for dialectical thinking expresses liberationist manifestations for a digital communication in which the ethnographical method is challenged by performative compositions. In fact, this decentralized mix of horizontal technologies and diasporic subjectivity makes any visual product consumable anywhere and potentially modifiable by everyone.

\section{Digital communication is irreproducible and reproducible at the same spacetime. DAR is ubiquitous}

This transit dissolves the ties with the social classes structure that Benjamin still identified with objectivity: form one side, bourgeois-aristocratic and worker-proletarian from the other. That aesthetic modern solidification of the concept of aura - the usability of the work of art in a given time and context (the hic et nunc) - is now offered along the digital innovations for the experience of every ubiquitous artist or glocal teenager.

\section{Ubiquitous case studies: Björk, FakePress, Transurbanism}

Now I'll present some case studies emerging from different artistic areas in order to introduce an initial ethnographic research on empirical DAR experiments.

\subsection{Björk}

She creates musical and visual compositions. She is a songwriter, a composer and an artist. "It will be a fantastic century", says Björk - "We are lucky to live at the beginning of a humanistic revolution and unification with nature thanks to technologies". Her last artistic work - Biophilia - more than an album is a space full of experiences In-App. Ten songs via iPhone and iPad, elaborated by an Apple tablet and influenced by experience design, will help any person to create a new version of the trace: this platform allows to explore the physical forces of nature in a tridimensional interconnectivity, from the atom to cosmos. 
Musicians are playing computer and an iPad is checking the sharpsichord, an instrument invented by Björk, half carillon and half harp. The Guardian wrote that Biophilia is equivalent to the Opera or Cinema invention. For me, it is an excellent example of DAR productive application. This opus is an applied philosophy.

\subsection{FakePress}

FakePress is an experimental group that is exploring and introducing Augmented Reality themes, describing the approaches used in the creation of digital layers of information, expression and communication which are seamlessly integrated with the physical world and which allow for independent, free, autonomous representation and enactment of our points of view on reality. They are exploring the multiple definitions which can be given to the concept of Augmented Reality, starting from the more philosophical and ethnographic ones and arriving to the ones which are more oriented to art, business, activism, marketing and communication. The idea of being able to create additional layers of accessible information stratified on top of our ordinary reality, expressing multiple points of view and approaches to the world, became clear and suggested scenarios and ideas.

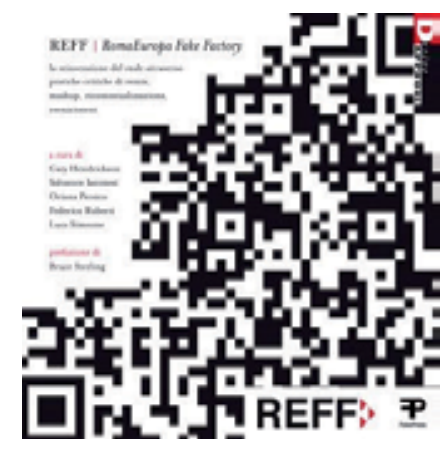

Fig. 2. REFF

They presented a "complete software kit that has been used in the following parts of the workshop, including tools dedicated to the creation of AR applications for mobile devices and the development frameworks that allow for the creation of ubiquitously accessible content. The workshop's objective was to understand the possibilities offered by ubiquitous publishing techniques and methodologies and to produce an end-to-end project that would have been published at the end of the workshop. Thus, we introduced the project to be developed: an Augmented Reality Movie. We introduced the idea of being able to create a new kind of cinematographic experience. Classic Cinema proposes a linear storyline (even in those cases in which directors and screenwriters experiment, as in movies such as Memento or Inception, the experience offered by Cinema is a linear one) which is the product of a single point of view: the movie camera is a single eye onto a time/space using characters, locations and events to propose a single perspective".

Following this connective group, their idea of an Augmented Reality Movie proposes a model which is radically different from this. "In an AR movie the storyline unfolds in non-linear ways, across a series of different points of view, in a time dis-continuum which can include synchronicity, atemporality, and simultaneity". The Augmented Context can be imagined under a variety of forms: 
"People are imagined to use Smartphone, stickers with QRCodes disseminated in the architectural space, urban furniture and signage providing information and instructions on how to access the AR content, stenciled QRCodes, sounds, signs, billboards and anything that can be imagined as placed in the physical space to offer information and awareness about the presence of the augmented content. In the same spacetime and through a MACME platform, realtime information (coming from databases and/or social networks) and instructions on the access and usage of the mobile app needed to access the AR Experience, opportunities for interaction, allowing people to comment and describe their experience and to interconnect with other previous visitors" (FakePress Publishing)

In their work, MACME allows using a WordPress CMS creating cross medial content, including text, video, sounds, and social media, and to automatically generate it in versions which are suitable for printing, attaching, packaging, putting on stickers, $t$-shirts and any objects or location onto which a QRCode can be attached.

In a few words, DAR is a practical experience of copy-left political and aesthetical subjects that are subverting the traditional way to project, realize, communicate, consume. "Multiple subjects provide their own point of view on the story/subject/plot of the AR Movie. To do this they produce content designed to be placed in space using some form of AR Content Management System (CMS)". This scenario opens up an incredible amount of opportunities for ethnographic investigation and discussion. Among these are a multiplicity of points of view is creating a narrative which is not intended for sequential, linear viewing, and which is enacted each time in a different way according to how the viewer traverses space, and so this narrative is involving a no-ending number of points of views. Their fundamental idea is not the reproduction of a linear narrative structure, but a new form of expression involving spatially disseminated elements of expression, knowledge, information and interactivity, they call it "emergent environmental narrative".

Digital is auratically reproducible.

\subsection{Transurbanism}

The transformation of the industrial city into an ubiquitous metropolis is the context within which it is necessary to set the ethnographic gaze. The digital culture experiences applied on web sites, design, architecture, music, fashion, advertising; the end of fixed work and the affirmation of fluid identities; the performative subjectivities on consumption and aesthetics; the diasporic individualities crossing and mixing places, spaces, interstices; the hybridization processes changing glocal fragments; the political acceleration of visual communication: all these qualitative indicators are spreading the melting and dissonant transition toward the ubiquitous metropolis.

This metropolis dissolves society with its dualistic dialectic and the centrality of industrialist work; it crushes culture in its homogeneous sense into syncretistic fluid mixtures; it dilates communication, which meltes "all that is solid" in the pixel air. Instead of using inadequate terminology (post-modern above all), the most interesting explorations between anthropology and architecture identify the ubiquitous context where bodies and spaces are mixed in a transurbanism process (Koohlaas: 2001, Mulder: 2002). This transformation is based on the already perturbative and now normalized body-corpse panoramas along metropolitan areas and on the possibilities for a new subject ("multividual") to transit into 
interstices, producing transitive metropolises and ubiquitous identities. The ubiquitous metropolis is materialimmaterial.

The links between digital technologies and body-corpse styles release diasporic identities, technological syncretisms, dissonant soundscape, visual imaginations, iconic oralities. This pulsing metropolis shuffles public-private, nature-culture, organic-inorganic, familiar-stranger in addition to binary simplifications, philosophic-religious universalisms, anthropologic structuralisms, and interpretative neutralism. In transurban processual practices, the change - the transit - transforms the city into an ubiquitous metropolis. Industrial production is not the economic-political center that frames civil society: the culture-consumption-communication triptych dissolves the traditional concept of society, fluidifies territories, marriages, works, genders, generations, ethnicity.

Trans-urbanism alters the conditions of classical geometrical perspective. Hence the ethnographic glance desires every detail and the body-corpse/location dialogical relationship is the privileged indicator: the polyphonic methodologies is looking for empirical attractors transiting between panoramic bodies and places-spaces-interstices. For an anthropology of metropolis, the empirical research flows beyond Euclidean forms and toward an expanded design, connecting advertising, soundscape, body-corpse, fashion\&styles, street arts, digital skin-screen.

In my hypothesis, the identities are constructed, modified, and pluralized within this connective process, where the links between body and metropolis delineate potential posthuman affinities. Transurban ethnography is a training to observe and be observed, to apply a be-seen method as an eyesfull body 2; it puts focuson attractors, as qualitative indicators of visual codes with a high fetishist value that absorb the attention and fix the gaze in a challenge to decipher the proliferation of mini-symbols, a semi-uncanny charade; it moves the fieldwork from the center/peripheries dialectics to ubiquitous interstices, where nonminority minorities are going to anticipate styles and behaviors that are becoming "temporary majorities" in their respective cultural contexts.

Here I selected a final transurban focus of my empirical research where the keyword is the ubiquity glance. My aim is to connect the architects Herzog\&De Meuron - who are changing the experience for a performative metropolis - to the industrial music group Throbbing Gristle, who anticipated such kind of ubiquitous experiences inside the interstices of the emerging communicational metropolis. So, my excursus selects three locations in London as empirical indicators of the process from disused industrial areas to the pulsing ubiquitous metropolis.

This first image is a dislocated classic factory, which industrial architecture configures the control of the people working there. It frames spaces and humans to determine times and methods, bodies and wages. This flyer anticipated the post-industrial phase and was designed by musicians that felt the times-are-in-a-changing before politicians or social scientists. Since the beginning of the 1980's, a fragment of British punk - Throbbing Gristle selected the dead factory as the compositive space for industrial music. Their dissonant

2 The English translation of my expression "farsi vedere" is difficult: I mean the process of an optical methodology, training an ethnographic way to look transforming the whole body of a person "into a gaze", the making of him/her-self a body-eye, a re-flexive gaze. 
ethnographic soundscape presents a challenge for any fixed identity or discipline - and a creative process for ubiquitous displacements. Work tools and sites are transformed into musical instruments and panoramas. Dissonant acoustic sensorialities were emerging from these Tayloristic experiences with sonic noise for eXtreme subjectivity. Multisensorial soundscapes incorporated atypical spaces and instruments; a pulsing body felt through dissonant beauty of flaky walls, dusty floors, abandoned machines. Industrial work was no longer the political center that gave meaning to everything else and became industrial sound. Performatic instances embodied by restless subjectivities were moving toward an activism that invaded the locations of "working time" transformed in "interstices of desire".

In the second image, the dead factory located in the center of London is gentrified and becomes the Tate Modern, one of the most significant space for contemporary art. Tate Modern leads the metamorphosis from the industrial city to the communicational metropolis, thanks to its opens spaces where works of arts become performances and consumption. The Tate does not have windows like factory or shopping center: all the observations must be addressed within and not ouside. Looking at the photo, it can be noted that the architectural structure is a classical industrialist design, which geometrical perspective was framing the workers inside and the citizens outside. The affinity between architecture and subjectivity is perceivable: the factory requires a fixed, repetitive, homogeneous identity and so it constructs the workers identity.

Tate1 is already insufficient, thus the same architects - Herzog\&De Meuron - have designed the Tate2: an ubiquitous architectural choices attesting the transition from the industrial era to the communicational metropolis.

By observing the project Tate2, the transitive process is activated and the various post (industrial or -modern) become obsolete: an ubiquitous being - a syncretic and polyphonic, meta-morphic and meta-fetishist "building" - expands irregular, diagonal, dissonant facets. Every floor is different from any others both in a horizontal synchrony and in a vertical diachrony, every partial identity is diversified and contiguous, this montage of fragmented and transitive identities configures a musical composition, a score to be listened and expanded in any level. Another geometry is emerging beyond the Euclidean one - and also beyond the industrialist society or the worker identity. Perhaps the concept of opus or opera can designate such a mutant sensitive experience - more than work or labor - as the creation of the artifices / architect subject. Such a "being" is favoring the desire for self-expression in any visitor who is experimenting the extension of diagonal conceptual spacetimes and digital techno-syncretisms. So the subject-visitor identity is challenged toward an astonished multi-faceted identity: a dialogical score between multiple "beings" - architecture and visitor beings - is manifesting an irreducible composition to the classical geometrical politics. Digital is not just technology: it is a logical-expressive potentiality that induces flows of fragmented subjectivity to emerge, disperse, montage in fluxes of pixel air.

Identities centralize the geometrical process toward trans-urbanism as a communicational conflict. The concept of identity was founded on precise and fixed roots: an identity connected for all the life through to a steady job, indissoluble marriage, familiar country, dualistic sexuality, a well-defined generation. Work-love-country-aging define one identity within an unmovable frame. Now all of this is diluted in constant changing identities that is favoring the possibility to live multiplicities of work, sexual, spatial, generational statuses. 
The multividual is a communicational subject that lives together with unquiet montage of egos in conflict with traditional psycho-political schemes.

Tate2 is an auratic-reproducible multividual, similar to the fluctuating identities of transurban subjects: both are producing a compositive metropolis among ubiquitous spaces.

The sequence of these three architectural beings is changing the relationships between politics and party, work and desire, communication and society, writing and languages. The industrialist frontal perspective of the Tate1 is a symptom of a social science locked in an empty factory together with as the Fordist "scientific" methodology developed from its body. Oblique, diagonal, unquiet multi-perspectives are emerging weaving simultaneous assemblies of asymmetric codes. Architectural and human subjectivities are dialoguing through dissonant polyphonies. From these ubiquitous flows, noises and landscapes, aesthetics and styles, performance and design can be experimented in ethnographic compositions based on sensorial concepts.

Tate2 is an ubiquitous being and every floor is a dissonant montage of co-present multilevel identities.
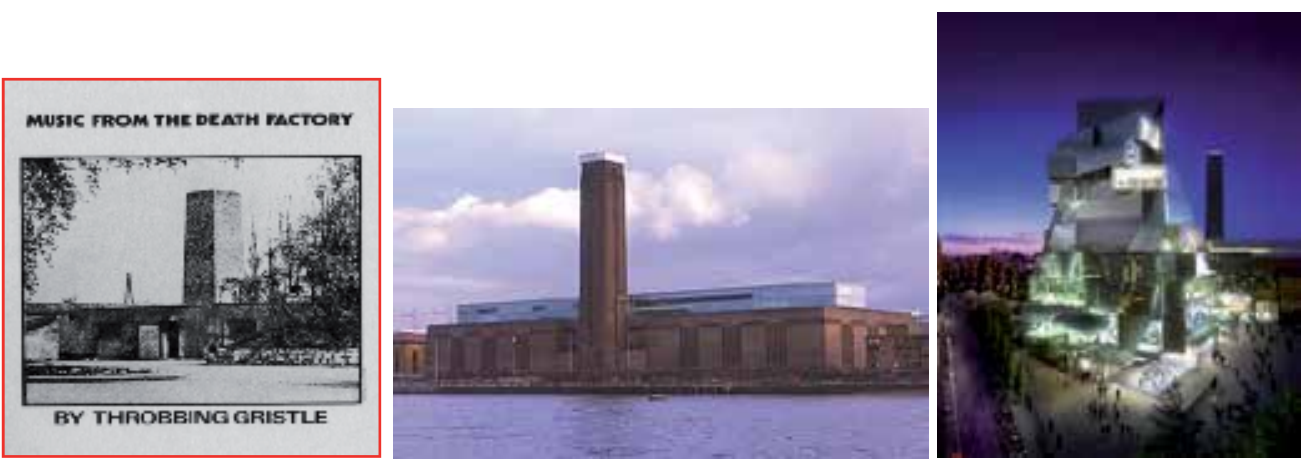

Fig. 3. Flyer - Tate Modern 1 - Tate Modern 2

\section{Digital cultures performs an auratic reproducibility.}

This auratic-reproducible montage is an indicator for interpreting the cultural changes in contemporary arts and styles. It favors a paradigmatic shift with respect to the past. That's why, investigating this process, it is necessary to modify methods and narrative compositions. It delineates a transitive dimension of identities, cultures and subjectivities, where such emerging concepts - as digital syncretisms, visual fetishisms, diasporic selfrepresentation, communicational metropolis - could be applied to such dissonant scenarios. An ubiquitous ethnography applied to sonic landscapes (soundscape), fashion body-corpse, expanded designers or post-Euclidean architects becomes necessary to experiment different compositional logics and multi-sensorial narrative components.

\section{Schismogenesis and feedback: Bateson and Wiener}

The history of digital culture is interwoven with anthropology. The reference is Gregory Bateson: in the interview done by Steward Brand together with Margaret Mead entitled For the love of God, Margaret! (2001), Gregory presents his choice to collaborate with Wiener in 1946, 
extending anthropology to cybernetics since the beginning. So my question is why George Marcus, a Bateson's intense interpreter, did not write about Gregory's relationship with cybernetics, risking to reproduce the dichotomy between the so called two cultures. The reason lies in the indifference for Writing Culture scholars to the emerging digital cultures that were changing everyday experiences, global economies, and communicational languages.

Bateson developed the term schismogenesis in his initial ethnographic research (Naven): during interaction processes, there are self-correction mechanisms inside a culture in order to restrain conflictual relations and even disunions. For this concept, he was involved by Wiener to participate to his research group, because his feedback model (or retroaction that Wiener was developing) presented a complex affinity with schismogenetic self-correction cultural mechanisms. This connection between schismogenesis and feedback represents a challenge for complexity paradigm crossing sciences and cultures: an alliance that becomes even more significant for our hypothesis, as both Bateson and Wiener criticize those cyberneticists that isolate input-output. Says Bateson: "The essence of Wiener's cybernetics was that the science is the science of the whole circuit. (...) And you're not really concerned with an input-output, but with the events within the bigger circuit, and you are part of the bigger circuit. The engineer is outside the box and Wiener is inside the box...I'm inside the box" (2001:135).

For him, epistemic and ethnographic problems were unresolved by informatics who were projecting software and engineering processing outside of the "box". For an anthropological point of view, ethnographers should stay inside this metaphoric box as they are part of a reflective research that surrounds and connects every subject on the fieldwork. This statement introduces the actual reflections on self-representation and focalizes the connections of cyber-communication and web-ethnography as a basic fieldwork. There is an urgent desire and also an epistemic need to connect epistemology and ethnography, involving researchers in the flows of digital communication. An innovative alliance or, better, a reciprocal interpenetration may be produced between current informatics - often living in self-referential worlds like some anthropologists - in order to favor progressive solutions toward web models beyond the binary logic of current software. Another problem is how it is possible to dissolve the strict relation between authoritarian economic power and an horizontal web research, exploring multi-logical and multi-sensorial communicational processes.

Digital communication is crossing and mixing informatics and ethnography.

In this very specific way, von Foerster answers to a suggestion of Margaret Mead: "what we need now is a description of the 'describer'; or, in other words, we need a theory of the observer" (2001:152). That is what should still be put inside the box today: the ethnographic and informatics describers, both producing research with (and not on) all of the subjects involved in the process. The "description-of-the-describer" is an epistemic, communicational and political breakpoint that involves every researcher in an explorative compositional process. The task of changing the Internet arises from infusions between anthropology and cybernetics - between ethnography and the web: the description of the describer.

This initial self-corrective mechanisms of cybernetics is transiting into contemporary digital cultures and web communication; such a self-regulating transmission of informations along the circuits will favor a digital auratic reproducibility, beyond any classical dialectic: D.A.R 
In his afterword of 1958, Bateson explain: "How to string together data is what I mean for interpretations" (1988:264). That's the reason why for George Marcus "Naven is one of the first experiment in modern ethnography (...). His common idea of text construction is to string together a set of separate essays dealing with different themes or interpretations of the same subject" (1988:192). Also for the other co-editor of Writing Culture, James Clifford, Naven is a critical change: "The cuts and sutures of the research process are left visible ; there is no smoothing over or blending of the work's raw data into a homogeneous representation. To write ethnografies on the model of collage would be to avoid the portrayal of cultures as organic wholes or as unified, realistic worlds subject to a continuous explanatory discourse" (1988:146).

I'll try to connect not only Bateson and Wiener, but also Naven and Balinese Character: an attempt to focus on the same ritual with different perspective and a textual montage of writing, filming, photographing. "No one has been photographed at the height of Gregory (...). I have never seen any book that even comes close to Balinese Character" (Mead, 2001:144). That's the point: the method as a montage was experimented before in the Balinese fieldwork and after in New York, where Bateson and Mead did the final composition through a documentary (Trance and Drama in Bali) and a book (Balinese Character) full of sequences of photos for any partial cultural trait. Such influent compositions involved experimental musicians, ethnographers, video-artists, filmmakers. In Bateson, ubiquity is a way of research and living, of writing and visualizing. His neoanimism is determined by a deep expansions between different being; his ecological mind was an expansion of the ego out of the border of a human skin, animal fur, bast of a tree, dust of earth. Bateson's ecology of mind represents an attempt of favor a continuous retroactive transit between human being, a forest of sequoia, a flying butterfly and a participant Leica.

Finally, I'll present another possible "strange connection" between Gregory Bateson, Thomas Mann and Walter Benjamin, based on the montage imperative. An epistemic transit between Bateson's neo-animist ecology, Benjamin's immanent metaphysic and T.Mann's aesthetical literature. In a letter from Pacific Palisade, Thomas Mann wrote to Adorno: "What I'm trying to explicit, commenting myself, is my method as montage, that is crossing all my book (Doctor Faustus, NdA) in a singular and quiet irritant way" (2003:13). It is a deep epistolary exchange between the two exiled men as well as between Benjamin in Paris and Adorno in California. In a note on Passegen-Werk, Benjamin wrote: "The method of this work: literary montage" (1982:595). The method as a montage is a possible philosophical key-word through which disciplines are crossed and become ubiquitous. SimultaneityChronotopos-Ubiquity, Digital-Auratic-Reproducibility, Multividual Transurbanism, Method-asMontage are sensorial concepts through which my ethnographic composition is an attempt of transfigurating our fieldwork and the way of representing our research beyond the "writing culture" attempt.

Bateson scientific formation was totally different from these German authors, anyway his afterword, Mann's letter, Benjamin's note are offering ubiquitous methodologies expressed before, during and after the research: how to assemble data - the method is the montage - literary montage. So a stratified process of knowledge and composition is emerging through divergent points of analysis and expression. An ubiquitous ethnography may create a partial meta-montage and a dissonant interpenetration of Tomas Mann, Benjamin, Adorno, 
Warhol, von Foster, Bateson, Wiener, Mead, Bakhtin, Zaha Hadid...and waiting for Herzog/DeMeuron performative Tate2, where an auratic reproducibility may be transfigurated in a expanded sonic design.

\section{References}

Adorno T.W.( 1958 ) Dissonanzen, Gottingen: Vandenhoek

Appadurai, A. (1986) The Social Life of Things, New York: Cambridge University Press

Bachtin M. (1988) L'autore e l'eroe, Torino: Einaudi

Bateson, G.\&Mead, M. (1942). Balinese Character. A Photographic Analysis. New York: Academy of Sciences

Bateson, G. (1958) (1988) Naven: A Survey of the Problems suggested by a Composite Picture of the Culture of a New Guinea Tribe drawn from Three Points of View. Stanford: Stanford University Press

Betsky, A. \& Adigard E. (2000) Architecture Must Burn, San Francisco: Ginko Press

Benjamin, W. (1955) Das Kunstwerk im Zeitalter seiner technischen Reproduzierarkeit, Frankfurt: Suhrkamp Verlag

Benjamin, W. (1982 ) Das Passagen-Werk, Frankfurt: Suhrkamp Verlag

Brand, S. (ed.) (2001) For the love of God, Margaret! Interview with Gregory Bateson and Margaret Mead, Bologna: "Cultural Studies", n. 1

Bryan S. Turner. (2009) The Routledge International Handbook of Globalization Studies, London: Routledge

Canevacci, M. ( 2004) Sincretismi. Esplorazioni diasporiche sulle ibridazioni culturali, Milano: Costa\&Nolan

Canevacci, M. (2007) Una stupita fatticità, Milano: Costa\&Nolan

Canevacci, M. (2008). La linea di polvere. La cultura Bororo tra mutamento e autorappresentazione, Roma: Meltemi

Canevacci, M. (2011) Fake in China, Maceiò: EdUFAL

Clifford J.(1988) The Predicament of Culture, Cambridge Mass: Harvard University Press

Clifford J. \& Marcus, G. (ed.) (1986) Writing Culture: Poetics and Politics of Ethnography, Berkeley: The Regents of the University of California

Hauser J.( 2005) SYNTH-ETHICS, in catalogue "Hybrid", Linz: Ars Electronica

Hadid, Z., www. Performing Arts Center Abu Dhabi

Koolhaas, R. (ed.). (2001) Project on the City (II), Kohln: Taschen

Mann, T., - Adorno, T.W. (2003) Il metodo è il montaggio. Lettere 1943-45, Firenze: Passigli

Marcus, G. E. (1988) An opportune re-reading of Naven, (in Bateson:1988)

Marinetti, F.T. (1921) Manifesto della letteratura futurista, in "Il Futurismo", n. 11

McCaffery, L. (ed). (1995) The Avant-pop Anthology, London: Penguin Book

Mudler, A. (ed.) (2002) Transurbanism, Rotterdam: V2_Publishing

Rilke, R.M. (1999) Bambole, in "Bambole, giocattoli e marionette", Firenze: Passigli

Robertson, R. (1995. Globalization: Social Theory and Global Culture, London: Theory, Culture\&Society, Sage

Sobchack, V. (ed.) (2000) Meta-morphing, Minneapolis: University of Minnesota Press

Turner, T. (1978) The Kayapo of Central Brazil, In A. Sutherland (ed.) "Face Values", BBC Publications, London. pp. 245-279 


\subsection{Arts, movies, music}

Bateson-Mead, Trance and Drama in Bali, 1952

Björk, Biophilia, 2011

FakePress - cross-media, multiauthor, emotional publishing for bodies, objects, architectures

Welles, O., F for Fake, 1975

Throbbing Gristle, Greatest Hits, 1980 

